\title{
Improving Osmo-convective Dehydration as a Processing Technique to Food Preservation, Quality Enhancement, and New Product Development
}

\author{
Felix Umaizimede Akharume
}

Follow this and additional works at: https://researchrepository.wvu.edu/etd

\author{
Recommended Citation \\ Akharume, Felix Umaizimede, "Improving Osmo-convective Dehydration as a Processing Technique to \\ Food Preservation, Quality Enhancement, and New Product Development" (2017). Graduate Theses, \\ Dissertations, and Problem Reports. 5041. \\ https://researchrepository.wvu.edu/etd/5041
}

This Thesis is protected by copyright and/or related rights. It has been brought to you by the The Research Repository @ WVU with permission from the rights-holder(s). You are free to use this Thesis in any way that is permitted by the copyright and related rights legislation that applies to your use. For other uses you must obtain permission from the rights-holder(s) directly, unless additional rights are indicated by a Creative Commons license in the record and/ or on the work itself. This Thesis has been accepted for inclusion in WVU Graduate Theses, Dissertations, and Problem Reports collection by an authorized administrator of The Research Repository @ WVU. For more information, please contact researchrepository@mail.wvu.edu. 


\title{
Improving Osmo-convective Dehydration as a Processing Technique to Food Preservation, Quality Enhancement, and New Product Development
}

\author{
Felix Umaizimede Akharume \\ Thesis Submitted To \\ Davis College of Agriculture, Natural Resources \& Design \\ West Virginia University \\ In Partial fulfillment of the requirement for the award of the degree of \\ Master of Science in Forestry \\ Kaushlendra Singh, Ph.D., Chair \\ Litha Sivanandan, Ph.D., Co-Advisor \\ Jacek Jaczynski, Ph.D. \\ Mrs. Winifred McGee \\ School of Natural Resources \\ Davis College of Agriculture, Natural Resources and Design \\ West Virginia University.
}

Keywords: Osmotic dehydration, osmo-convective kinetics, microbial analysis, quality assessment, blueberries, apples, apple juice, and liquid smoke.

(C) Felix Akharume 2017

West Virginia University Invention Disclosure \# 2017-039. 


\begin{abstract}
Improving Osmo-convective Dehydration as a Processing Technique to Food Preservation, Quality

Enhancement, and New Product Development
\end{abstract}

\title{
Felix Umaizimede Akharume
}

This thesis is organized into five chapters. Chapter 1 contains a contains background information review of literature on osmo-convective drying of fruits, as well and nutrition, microbiology, and sensory attributes, Chapters 2 through 4 are three journal articles presented in the manuscript style. While chapter 2 is already published chapters 3 and 4 are prepared for submission to scientific journals. The chapter 2 addresses the use of apple juice concentrate as an alternative to the conventionally use of sugar solution in osmotic dehydration(OD) and convective drying of blueberries (fresh and frozen). OD was carried out at $50{ }^{\circ} \mathrm{C}$, atmospheric pressure and $50 \mathrm{rpm}$. Follow up convective drying was set to $70{ }^{\circ} \mathrm{C}$. Sugar gain, water loss, solid gain and OD yield were the parameters measured to compare the effect of these treatments. Additionally, desorption isotherm of fresh and frozen blueberries was measured to ascertain the role of freezing prior to OD and from these data the effective diffusion coefficient was estimated. The key points from the experiments reveal that fresh blueberries are not effective in OD. The use of apple juice experimentally did reflect a gain in solid, water loss and yield and as such can be used as an alternative. However, cost implication is not considered here.

Chapter 3, explored the use of sucrose with or without addition of food grade refined liquid smoke (RLS) in osmotic dehydration of apple cubes. Osmo-dehydration kinetics of solid gain, water loss, dry matter content, solid soluble content as well as effective diffusion coefficient of water loss or solid gain were measured or estimated. The methodology was similar to experiment reported in chapter 2 with slight modification, but detailed in this report. The results showed that sampled osmosed in sucrose solution with $1 \%$ w/w RLS significant recorded a higher solid gain water loss, dry matter, and solid soluble content. Again, average effective diffusion coefficient on water loss was the same for both samples, but 
average effective coefficient on solid gain was higher in samples osmosed in sugar solution without $1 \%$ w/w RLS.

Chapter 4 expanded on the methodology and data from chapter 3. Here dried apple slices were using experimental procedure described in chapter 3. The apple slices were analyzed for microbial growth, texture, and color quality to ascertain the effect of the addition of $1 \% \mathrm{w} / \mathrm{w}$ RLS on these sensory attributes. Results showed that dried apple slices pretreated in pure sugar solution retain the color of fruit better than untreated dried samples, while samples infused with RLS showed a characteristic brown coloration. Additionally, RLS infused dried apples showed the highest textural properties and control showed the lowest. In all samples, significant microbial reduction (below $5 \log \mathrm{CFU} / \mathrm{g}$ ) was recorded throughout storage period. However, RLS infused dried apples showed the highest microbial growth reduction and the control showed the lowest microbial growth reduction in a non-vacuum package.

The last chapter, chapter 5, summarizes the major finding in these studies and recommends area of future expansion. In addition, raw data and statistical analysis of experimental data are presented in the appendix. 


\section{Dedication}

I dedicate this thesis to Almighty God: my help in ages past and my hope for years to come for His infinite love, grace, and mercy throughout the period of this research and beyond.

I also dedicate this work to my parents - Mr \& Mrs Akharume, my wife - Olubunmi Sadibo and my Siblings. 


\section{Acknowledgement}

I want to use this opportunity to express my unreserved gratitude to my amiable and erudite advisor- Dr. Kaushlendra Singh for his immense support, constructive criticism, and professional advice. I equally expressed my indebtedness to my Supervisor and co-advisor Dr. Litha Sivanandan. Words alone cannot express how much I appreciate your support, funding, understanding, professional advices and recommendations. In no small measure, I did appreciate the duo of Dr. Jacek Jaczynski and Ms. Winifred McGee, both of whom are my co-advisors and committee members. I am grateful for your time and talent, support and contributions. I did thank Dr. Jaczynski for the opportunity to use his microbiology laboratory.

More so, I want to appreciate very significantly the following people who have contributed immensely to my success: Susan Slider, Sarah Beamer, Dr. Brett Kenney, Dr. Chen, Li, and Ms. Lacey. I particularly express my gratitude to Susan who was there all the way.

Lastly, I will be an ingrate if I fail to recognize and appreciate my friend and colleague Oluwatosin Oginni, a friend like a brother, Sohrab Rahimi, Oluwasogo Alonge, Oladyoin Abimbola, Damian Oshoba and of course my better half Olubunmi Sadibo. As the saying goes "Always remember to forget the friends that proved untrue. But never forget to remember those that have stuck by you.",

Finally, thank you all, for it has been indeed a wonderful time of self-discovery, learning and professional development. 


\section{Table of Content}

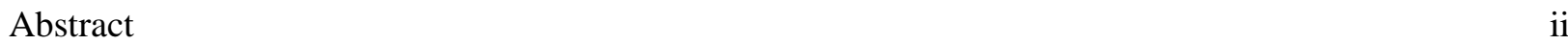

Dedication $\quad$ iv

Acknowledgement $\quad \mathrm{v}$

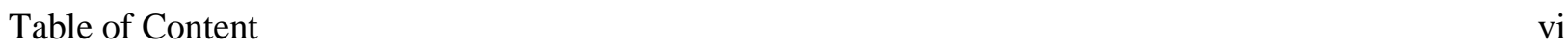

List of Figures

List of Tables $\quad x$

Chapter 1: Introduction and Background Information 11

Production, Nutrient Value, and Uses of Selected Fruits (Blueberries and Apples) 11

Various Fruit Preservation Techniques 16

Current Status of Knowledge About Osmotic Dehydration 17

Current Status of Knowledge About Convective Drying of Fruits 25

Advantages of Osmotic Dehydration Prior to Convective Drying 29

Nutrients, Microbiology, and Quality of Osmo-convective Dried Fruits 31

Latest Research Interest in Osmo-Convective Dehydration 36

$\begin{array}{ll}\text { Liquid Smoke } & 37\end{array}$

Summary of Current Status of Knowledge $\quad 39$

Problem Statement 39

Objectives of the Research $\quad 40$

$\begin{array}{ll}\text { References } & 41\end{array}$

Chapter 2: Influence of Osmotic Solution Type on Osmotic De-hydration and Drying Characteristic of

Fresh and Frozen Blueberries $\quad 54$

$\begin{array}{ll}\text { Introduction } & 55\end{array}$

Materials and methods $\quad 56$

$\begin{array}{ll}\text { Results and discussion } & 63\end{array}$

$\begin{array}{ll}\text { Conclusion } & 75\end{array}$ 
Chapter 3: Effects of Liquid Smoke on the Osmotic Dehydration Kinetics of Fresh Apple Cubes 80

$\begin{array}{ll}\text { Introduction } & 81\end{array}$

$\begin{array}{ll}\text { Materials and methods } & 84\end{array}$

$\begin{array}{ll}\text { Results and discussion } & 89\end{array}$

$\begin{array}{ll}\text { Conclusion } & 96\end{array}$

$\begin{array}{ll}\text { References } & 98\end{array}$

Chapter 4: Influence of Liquid Smoke on Quality and Microbial Shelf Life of Convectively and Osmo-

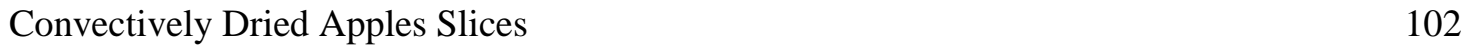

$\begin{array}{ll}\text { Introduction } & 103\end{array}$

$\begin{array}{ll}\text { Materials and methods } & 105\end{array}$

$\begin{array}{ll}\text { Results and discussion } & 108\end{array}$

$\begin{array}{ll}\text { Conclusion } & 121\end{array}$

$\begin{array}{ll}\text { References } & 123\end{array}$

$\begin{array}{ll}\text { Chapter 5: Summary } & 126\end{array}$

$\begin{array}{ll}\text { Recommendation for future research } & 127\end{array}$

$\begin{array}{lr}\text { Appendix } & 129\end{array}$ 
List of Figures

Figure 1: A map of West Virginia showing the areas with commercial apples, peaches, and grape production.

Figure 2: Total production of apples in West Virginia between 2005 - 2014.

Figure 3: Utilized production profile of West Virginia apples for 2005 - 2014.

Figure 4: Value of utilized production profile of West Virginia apples for 2005-2014.

Figure 5: Utilized production profile of West Virginia apples for (a) 5-year average 2009 - 2013. (b) US apple 2014 utilized production profile.

Figure 6: Schematic diagram of osmotic dehydration process.

Figure 7: Schematic diagram of convective drying unit.

Figure 8: Typical drying rate curves for porous materials.

Figure 9: Schematic diagram of a typical blueberry showing the axial dimensions: a (x-axis), b (y-axis), and c (z-axis).

Figure 10: Relative moisture (moisture ratio) over the drying period performed at isothermal temperature of $105{ }^{\circ} \mathrm{C}$ in a thermogravimetric analyzer in dry nitrogen for fresh and IQF (thawed) blueberries.

Figure 11: Relationship between drying rate ( $\mathrm{g}$ of water evaporated per gr of drying fruit per minute) and mean moisture content of fresh and IQF (thawed) blueberries during drying under isothermal temperature of $105^{\circ} \mathrm{C}$ in the thermogravimetric analyzer under dry nitrogen.

Figure 12: Variation of sugar concentrations over time for (a) fresh blueberries and its sugar-based osmotic solution and (b) IQF blueberries and its osmotic solution during osmotic dehydration performed at $50^{\circ} \mathrm{C}$.

Figure 13: Increase in sugar concentrations for fresh and IQF blueberries during their osmotic dehydration with an osmotic solution at $50^{\circ} \mathrm{C}$.

Figure 14: Decrease in water activity and moisture content (MC) during air-drying of osmotically dehydrated fresh and IQF blueberries in a fruit dehydrator at $74{ }^{\circ} \mathrm{C}$.

Figure 15: Variation of sugar concentrations over time for (a) IQF blueberries and its sugar-based osmotic solution and (b) IQF blueberries and its apple juice-based osmotic solution during osmotic dehydration performed at $50^{\circ} \mathrm{C}$.

Figure 16: Sugar gained over immersion time for IQF blueberries in (1) sugar and (2) apple juice concentrate osmotic solution.

Figure 17: Decrease in water activity of osmotically dehydrated IQF blueberries using sugar-based and apple juice-based osmotic solutions in a fruit dehydrator at $74^{\circ} \mathrm{C}$. 
Figure 18: Samples of cut apple cubes before osmotic dehydration (OD).

Figure 19: Variation of moisture content apple cubes during osmotic dehydration for different durations from 5- $240 \mathrm{~min}$ at $50^{\circ} \mathrm{C}$ isothermal temperature.

Figure 20: (a) Soluble solid content and (b) dry matter content in apple cubes during osmotic dehydration for different durations from $5-240 \mathrm{~min}$ at $50^{\circ} \mathrm{C}$ isothermal temperature.

Figure 21: (a) Solid gain and (b) water loss in apple cubes during osmotic dehydration for different durations from 5- $240 \mathrm{~min}$ at $50^{\circ} \mathrm{C}$ isothermal temperature.

Figure 22: (a) Rate of water loss (WL), (b) rate of solid gain (SG) in apple cubes during osmotic dehydration for different durations from $5-240 \mathrm{~min}$ at $50^{\circ} \mathrm{C}$ isothermal temperature.

Figure 23: Scanning electron microscopy (SEM) micrographs of treated and untreated (control) apple samples. (a) control after $1 \mathrm{~h}$; (b)treatment after $1 \mathrm{~h}$; (c) control after $2 \mathrm{~h}$; (d) treatment after 2 $\mathrm{h}$; (e) control after $4 \mathrm{~h}$; and (f) treatment after $4 \mathrm{~h}$ of osmotic dehydration.

Figure 24: Samples of (a) untreated (b) sugar-infused (c) smoke-infused dried apple slices.

Figure 25: Aerobic plate count (APC) in apple slices untreated, sugar- infused, smoke-infused and stored at room temperature in (a) non-vacuum pack (NVP) and (b) vacuum pack (VP).

Figure 26: (a) Total yeast count and (b) total mold count in stored apple slices untreated, sugar- infused, smoke-infused stored at room temperature in non-vacuum pack (NVP) and vacuum pack (VP). 120 


\section{List of Tables}

Table 1: Physical characteristics, mean (standard deviation) of fresh and IQF (thawed) blueberries.

Table 2: Average moisture content, initial and final sugar concentration of fresh and IQF blueberries and solutions, solid gain and water loss from fruit, osmotic duration and yields during osmotic dehydration at $50^{\circ} \mathrm{C}$.

Table 3: Average moisture content, initial and final sugar concentration of IQF blueberries and osmotic solutions (apple juice-based and sugar based), solid gain in fruit and water loss during osmotic dehydration at $50^{\circ} \mathrm{C}$.

Table 4: Characteristics of Refined Liquid Smoke (RLS) used in this research.

Table 5: Physical characteristic of treated and untreated (control) apple samples before and after 240 min. OD duration.

Table 6: Osmotic dehydration kinetics of treated and untreated (control) apple samples before and after 240 min. OD duration.

Table 7: Changes in color parameters of convectively dried apple slices: untreated, treated in pure sugar OS, and treated in sugar OS with $1 \%$ RLS.

Table 8: Texture properties of convectively dried apple slices: untreated, treated in pure sugar OS, and treated in sugar OS with $1 \%$ RLS. 


\section{Chapter 1: Introduction and Background Information}

The fruit industry is one that continually draws the attention of health-conscious consumer. Fruit and vegetable consumption is recommended for food value and by necessity due to the nutritious and nutraceutical benefits and to maintain healthy living. Daily fruit consumption has been extensively linked to reduced risk of cancer, cardiovascular diseases, stroke, Alzheimer diseases, cataracts, and some of the functional declines related to aging through different epidemiological studies (Liu, 2003; Van Duyn \& Pivonka, 2000). Over the past 20 years, the consumption of fresh fruits and vegetables in industrialized countries has increased (Hui et al., 2008). The world fruit production is estimated to be 434.7 million metric tons and vegetables 90.0 million metric tons (Chavan \& Amarowicz, 2012) while in the US about 23.55 million metric tons of fruit were produced in 2016 (USDANASS, 2017). However, fresh fruits generally are highly perishable edible crops due to their high moisture content. Most fruits have wet-basis moisture content as high as $80 \%$ and above (Jangam et al., 2010); 85\% for blueberries (Shi et al., 2008), 85.56\% for apples (USDA 2015b). Consequently, fruits have very short shelf life: 2-3 weeks for blueberries (Shi et al., 2008), 3 days for fresh cut apple (Rocha \& Morais, 2003).

\subsection{Production, Nutrient Value, and Uses of Selected Fruits (Blueberries and Apples)}

\subsubsection{Blueberries}

The highbush blueberry (Vaccinium Corymbosum L.) is one of the predominantly cultivated blueberry species in the United States, in comparison to rabbit eye blueberry (Vaccinium ashei Reade; syn. Vaccinium virgatum Ait) and lowbush or wild blueberry (Vaccinium angustifolium Ait) (Retamales et al., 2012). Highbush cultivars are further separated into northern, southern, or intermediate types depending on their chilling requirements and winter hardiness (Retamales et al., 2012). More than $80 \%$ of the world blueberries are commercially grown in United States and Canada with about $95 \%$ of cultivated blueberries consisting of the northern highbush varieties grown in cooler climates of the northern temperate zone (Hui \& Barta, 2006). The United States is by far the largest producer of blueberries, with a total production of 257 kilotons in 2014 (USDA, 2015a). In terms of production by States, Washington 
(44 kilotons) ranked first, followed by Georgia (42 kilotons), Michigan (42 kilotons), Oregon (39 kilotons), New Jersey (26 kilotons), California (24 kilotons) and North Carolina (22 kilotons) (NASS, 2014).

About $40 \%$ of the blueberries are consumed as fresh produce, and the remaining are consumed in processed products. For example, blueberries are a main additive ingredient in the manufacture of bakery, dairy and other convenience products. More so, dried blueberries are used in jams, jellies, syrup and baby food (Hui \& Barta, 2006). Blueberries are also known for their nutraceutical value. They contain a wide variety of non-nutritive and bioactive compounds such as flavonoids, phenolics, anthocyanins, phenolic acids, stilbenes, and tannins, as well as nutritive compounds such as sugars, essential oils, carotenoids, vitamins, and minerals (Jimenez-Garcia et al., 2013; Nile \& Park, 2014). A typical nutraceutical composition of blueberries includes: total sugar (9.96 g/100 g), fiber (2.4 g/100 g), fructose (4.5 g/100 g), sucrose $(0.11 \mathrm{~g} / 100 \mathrm{~g}),(4.87 \mathrm{~g} / 100 \mathrm{~g})$, total lipid (0.33 g/100 g), protein (0.74 g/100 g) (USDA, 2015b). Blueberries are a rich source of antioxidants, such as anthocyanin, which have been proven beneficial to human health, for memory loss, cancer, heart diseases, diabetes, urinary diseases, vision problems and aging (Martineau et al., 2006; Shi et al., 2008). Very recently, it was reported that extracts from blueberries might be a potential valuable food supplement for individuals exposed to high cadmium levels (or cadmium toxicity) (Oprea et al., 2014).

Prior to processing, fresh berries are either bulk frozen or individually quick frozen (IQF) to preserve their bioactive compounds (Hui \& Barta, 2006; Shi et al., 2008). Blueberries are high water content fruits and the moisture content of fresh blueberries can be as high as $84.21 \mathrm{~g} / 100 \mathrm{~g}$ wet basis, which is reduced to $14.80 \mathrm{~g} / 100 \mathrm{~g}$ wet basis, in dried sweetened blueberries (Hui \& Barta, 2006; USDA, 2015b). Blueberries are dried to remove excess water and lower water activity via direct air drying or osmotic dehydration followed by air-drying. Some commercially dried blueberry products are: air dried blueberries (moisture content 11 to $18 \%$ w.b.), freeze-dried blueberries (moisture content 2 to $3 \%$ w.b.), and drum-dried blueberry powders (moisture content 3 to 5\% w.b.) (Feng et al., 1999). The overall goal 
of the dehydration process is to achieve a water activity of 0.6 or less (Hui \& Barta, 2006; López et al., 2010).

\subsubsection{Apples}

Apples dominate the fruit crops in the market. They are widely grown and among the leading fruit exports of the US. The total apple production in the US for 2014 was 272.2 million bushels $(11,431.2$ million pounds) $10 \%$ higher than 2013 and 13\% higher than the five-year average (2010-2014) (USApple Association, 2015). The US fruit markets have grown in recent times, both in exportation and importation, since the mid-1980s to meet consumer demands all year around. The major commercial apple growers in West Virginia are located in four counties: Berkeley with 27 commercial operations, followed by Hampshire with 18, Jefferson with 8, Mineral with 5 and Morgan with 4 (Fig. 1) (West Virginia Agricultural Statistics , 2004). In West Virginia, total production was 2 million bushels (82 million pounds), with a $14 \%$ decrease from the previous year and a 3\% increase above five-year average, making West Virginia ranked ninth amongst states producing apples. The total utilized production was 82 million pounds with no quantity recorded for un-harvested or not sold (U.S. Department of Agriculture National Agricultural Statistics Service, 2015). Value of utilized production was $\$ 12.4$ million, 4\% less than 2013 and 10\% less than five-year average. Of the total utilized production in 2014, fresh fruit accounted for $21 \%$, remaining the same as the previous year and over five-year period; processed fruits accounted for $79 \%$ over the same period. The processed apple profile in 2013 shows that $2 \%$ of the utilized apples went into processing other than canning and juice making (possibly dried, frozen and others) and remained same for the previous years and five-year average (USApple Association, 2015). Figure 2-5 shows a trend of apple production and utilization analysis, as well as values of obtained in West Virginia for several years prior to 2014.

A typical nutraceutical composition of apples includes: total sugar $(10.39 \mathrm{~g} / 100 \mathrm{~g})$, fiber $(2.4 \mathrm{~g} / 100 \mathrm{~g})$, carbohydrate $(13.81 \mathrm{~g} / 100 \mathrm{~g})$, total lipid $(0.17 \mathrm{~g} / 100 \mathrm{~g})$, protein $(0.26 \mathrm{~g} / 100 \mathrm{~g})$, water $(85.56 \mathrm{~g} / 100 \mathrm{~g})$ (USDA, 2015b). Some commercial apple products include: dried apple pomace (Carson et al., 1994), air 
dried apples (Cruz et al., 2015), osmotic-air dried apples (Sosa et al., 2012) and freeze-dried apples (Cortes R et al., 2009).

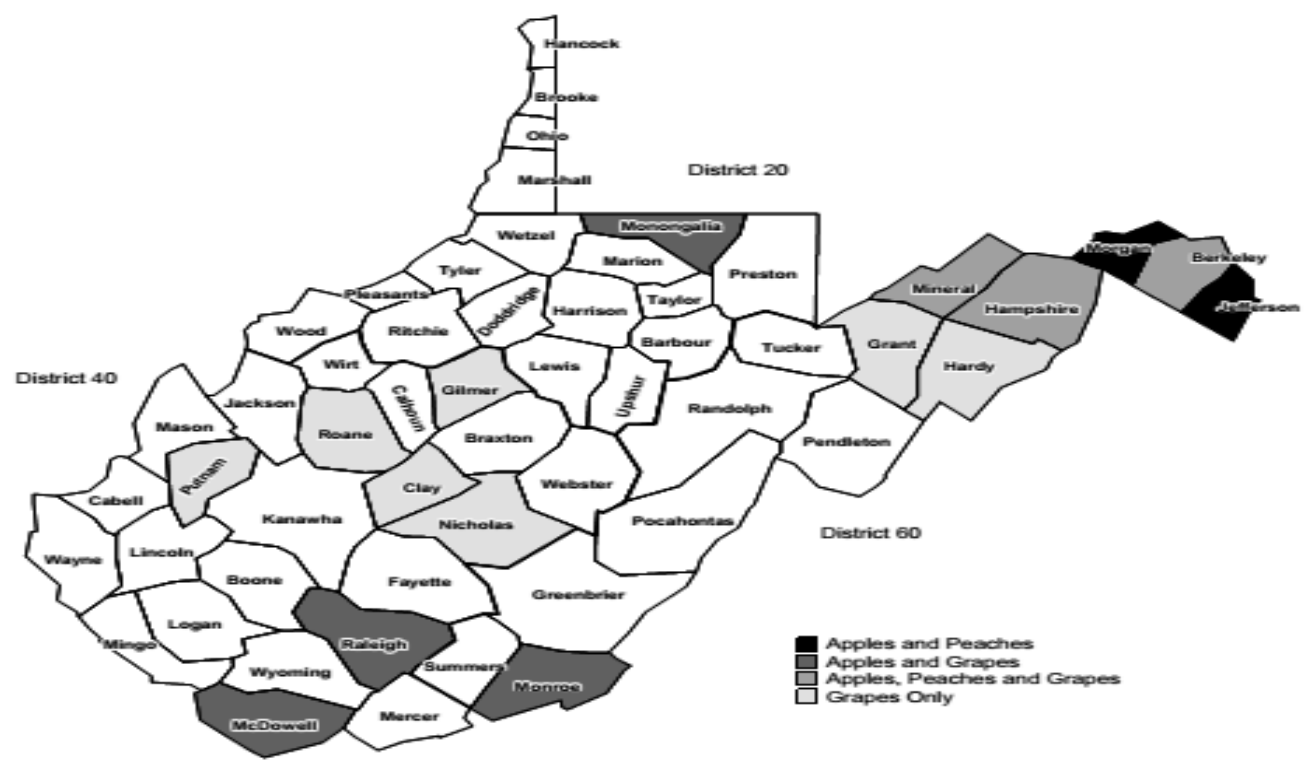

Figure 1. A map of West Virginia showing the areas with commercial apples, peaches, and grape production (West Virginia Agricultural Statistics , 2004).

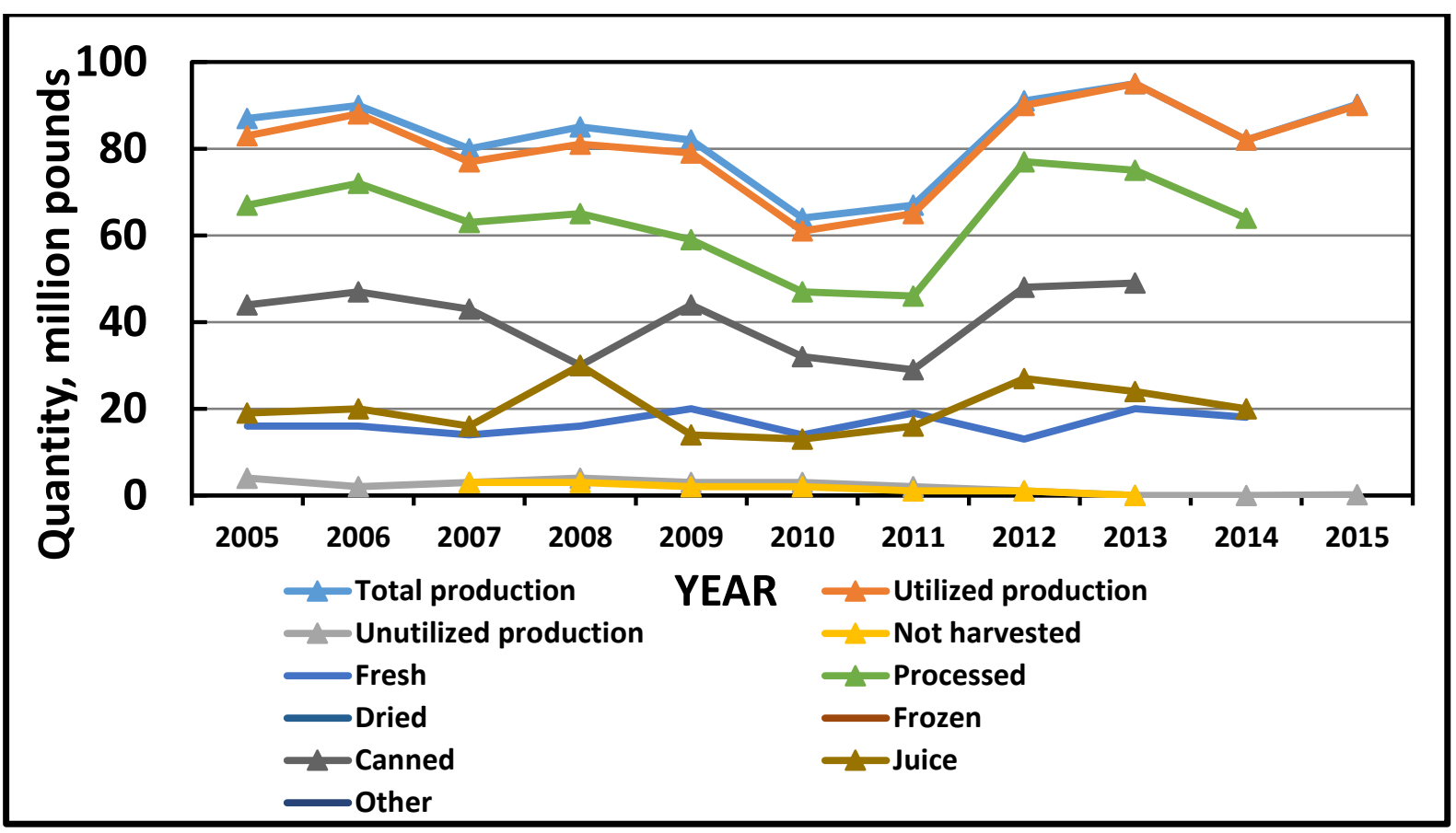


Figure 2. Total production of apples in West Virginia between 2005 - 2014 (USApples Association, 2015).

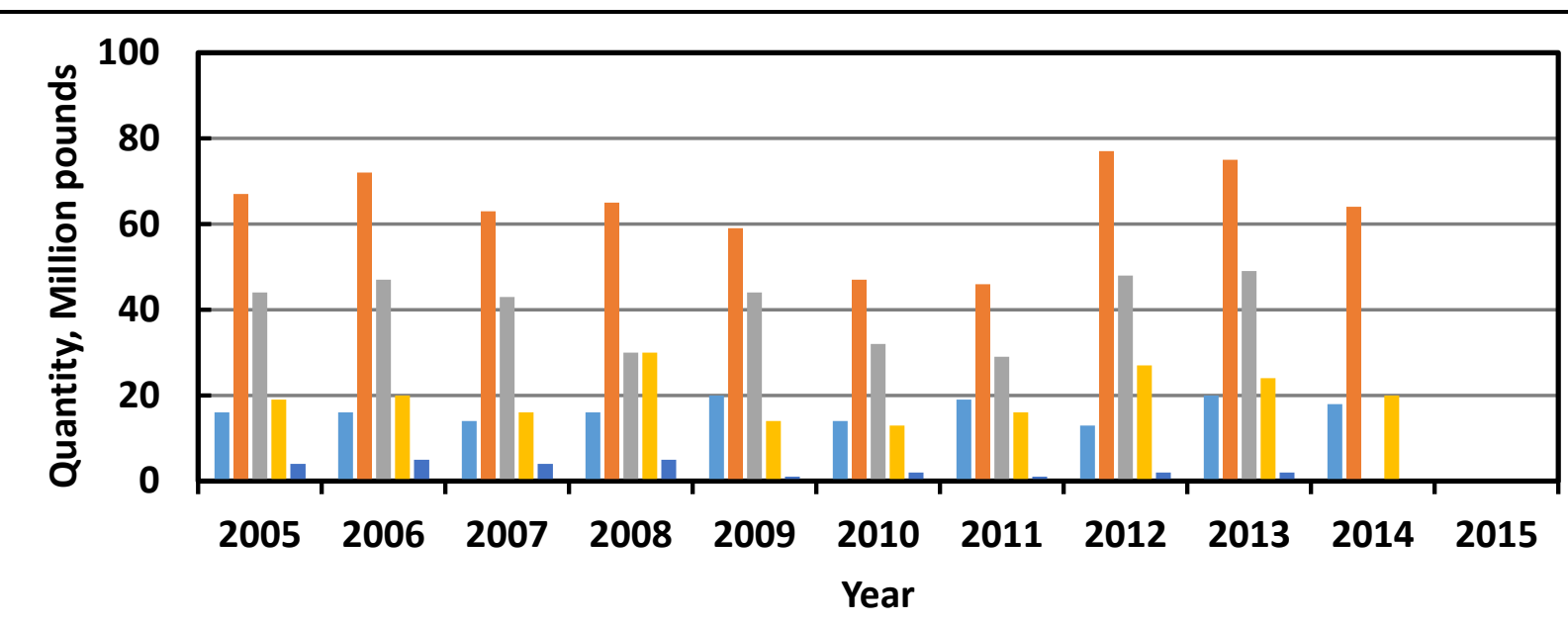

Fresh Processed Canned Juice $\square$ Other

Figure 3. Utilized production profile of West Virginia apples for 2005 - 2014 (USApples Association, 2015).

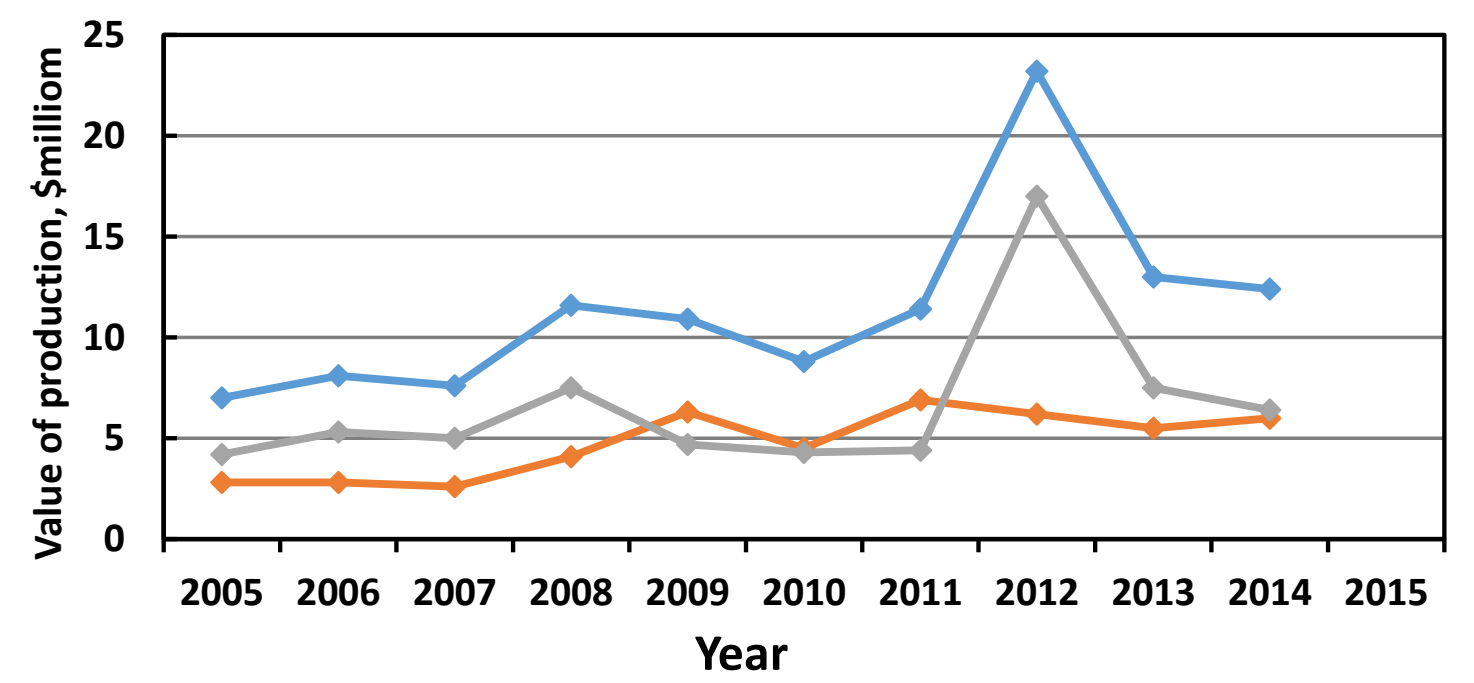

$\leadsto$ Utilized production value $\leadsto$ Fresh $\leadsto$ Processed 
Figure 4. Value of utilized production profile of West Virginia apples for 2005- 2014 (USApples Association, 2015).

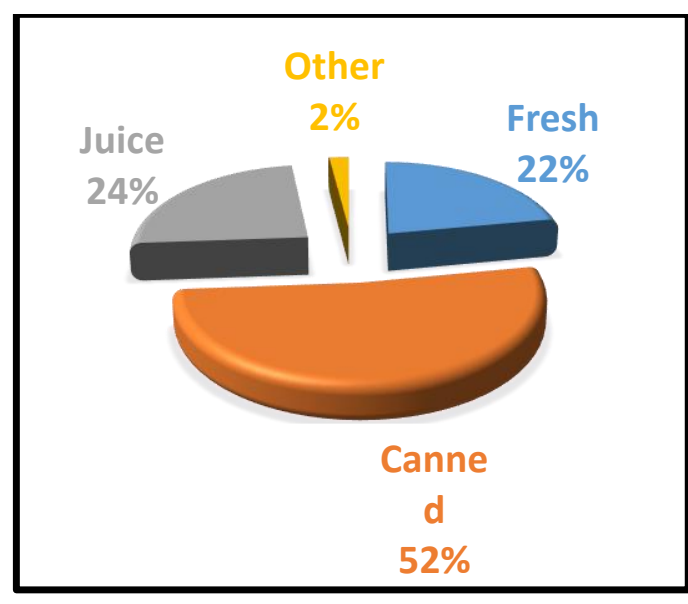

(a)

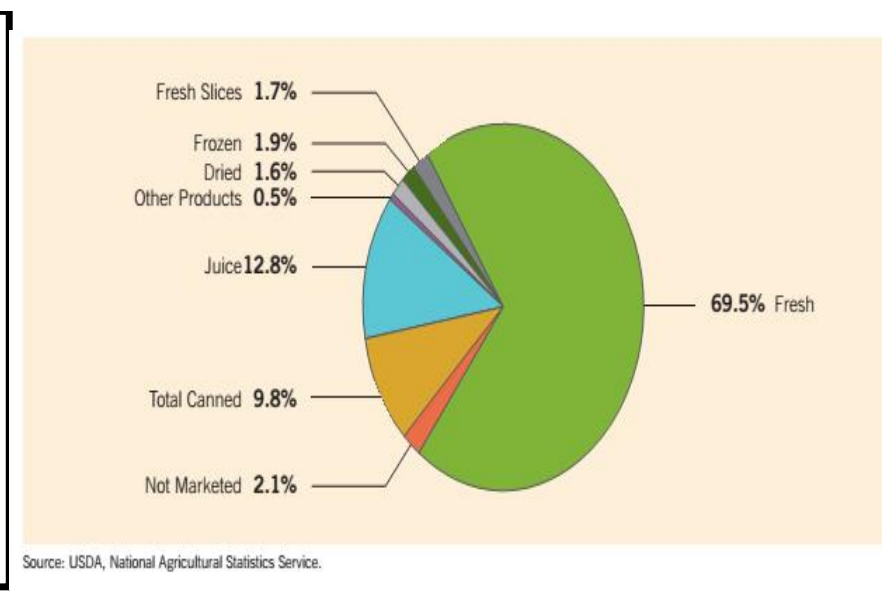

(b)

Figure 5. Utilized production profile of West Virginia apples for (a) 5-year average 2009 - 2013. (b) US apple 2014 utilized production profile (USApples Association, 2015).

\subsection{Various Fruit Preservation Techniques}

Fruit preservation is a necessary technique to minimize fruit deterioration, eradicate waste, ensure availability all year around, and provide safe and nutritive fruits to the consumers. Different preservation techniques exist depending on the desired end-product of the fruit. The use of modified atmosphere package (MAP), edible coating, natural and chemical preservatives (calcium, citric acid, Alginate) or a combination of the fore listed have been applied as post-harvest treatment of fresh fruit to prolong shelf life, producing fresh cut fruits. Mild or Non-thermal treatment of fruit is performed using osmotic dehydration, high pressure processing, irradiation, pulsed electric fields, power ultrasound, ozone and oscillating magnetic fields to produce "minimally processed fruits" with extended shelf life. Thermal treatments, such as hot air drying, osmo-convective drying, ohmic heating, dielectric heating, microwave heating, radio frequency heating have equally been used to produced dried fruit snacks. 
Osmo-convective drying involves two independent processes: 1. Osmotic dehydration and 2. Follow-up convective drying. The term "osmo-convective dehydration" is coined from two words describing two different dehydration techniques: "osmotic dehydration" and "convective drying". The later technique requires the use of hot air, as will be discussed later. Thus, the term is sometimes referred to as osmoticair dehydration in some texts (Tiwari, 2005; Yu, 1998).

\subsection{Current Status of Knowledge About Osmotic Dehydration}

\subsubsection{Osmotic dehydration}

Osmotic dehydration (OD) is a well-known dehydration and preservation technique. It works on the wellestablished principle of lowering water activity by the addition of humectants and removal of water from the food source (Lewicki \& Lenart, 1995). Osmotic dehydration has been well defined by several authors as "a phenomenon that exists, when a solid food material is immersed in a hypertonic solution, usually a solution of edible solute (such as sugar, salt, fructose, high fructose corn syrup (HFCS), maltodextrin, sorbitol, additives, or combination of these). A counter-current flow of water from the food into the solution and solutes from the solution into the solid food through a non-selective semi-permeable membrane occurs with leaching of a negligible amount of solute (sugar, organic acid, vitamins, minerals, salts, fragrances, colorants etc.) from the food into the solution. In Osmotic dehydration of fruits, the fruit cell walls act as the semipermeable membrane allowing the exchange of water and low molecular solute. Because of the low permeability of this membrane, solute impregnation occurs closely to the surface of the fruit and not the core. However, the water molecules are being removed across the fruit matrix by capillary flow and diffusion (Ahmed et al., 2016; Chiralt \& Talens, 2005). The flux of water removal is considerably larger than the flux of solute infusion, hence the reason for dehydration to be added to osmosis. For some fruits with thick skin or cuticle such as blueberries, apples, mango, and so on, the epidermal tissue is peeled off/scarified /frozen to expose the inner vascular tissue that made up the cell wall to facilitate osmosis (Lewicki \& Lenart, 1995). The turgor pressure as a result of osmotic pressure 
difference between the fruit and the ambient solution provides the enabling force through which this mass exchange occurs (Lewicki \& Lenart, 1995).

Ever since the pioneering work of Ponting et al. on the application of osmotic dehydration to foods. (M. R. Khan, 2012; Ponting et al., 1966), there has been a continuous research to explore this technique. More recently, there has been renewed effort to control its application to assure improved product quality, develop products with wide range of formulation and enhanced functionality, and provide a robust industrial application. Osmotic dehydration has so many advantages over drying or other methods of moisture removal from fruit:

(1) Low energy investment owning to the fact that osmotic dehydration occurs without a phase change from liquid water to liquid vapor, even so it can be conducted at low temperature range 20 $-50{ }^{\circ} \mathrm{C}(\mathrm{M}$. R. Khan, 2012)

(2) High product quality with minimal processing, obtaining characteristics of fresh produce with intermediate moisture fruit, if so desired

(3) Relatively inexpensive to operate due to low cost of the ingredients, and equipment, required.

(4) (By controlling chemical composition and formulations), new products such as functional foods are obtainable.

However, Osmotic dehydration is considered a partial water removal technique. Ready to eat minimally processed foods obtained through OD results in product with about 20-30\% moisture reduction (M. R. Khan, 2012; Yadav \& Singh, 2014). Similarly, intermediate moisture foods are obtained from osmotic dehydration carried out at temperature with 30 - 70\% (M. R. Khan, 2012; Yadav \& Singh, 2014) moisture reduction. These OD products are not shelf-stable without deterioration for a long time due to high water activity (0.92 -0.97) (Moreno et al., 2000). Therefore, OD is often followed up by another dehydration /processing technique (such as convective drying, freeze-drying, freezing, or addition to other food formulations) to extend the product's shelf life. 


\subsubsection{Mechanism of osmotic dehydration}

To understand the mechanism of osmotic -air dehydration, it is best to evaluate each part that makes up this technique separately. Osmotic dehydration is based on the principle of osmosis (fig. 6), wherein there is mass transfer through a semi-permeable membrane powered concentration gradient on either side of the membrane. On one side of the fruit cell membrane is the vacuole, which contains a cell sap of certain concentration. The cell sap has its osmotic pressure exerted on the protoplasm and the cell wall making the cell turgid (Lewicki \& Lenart, 1995). On the other side on the membrane is the osmotic solution with a higher concentration and pressure against the cell wall. Owing to this pressure difference, there occurs an exchange of water from the fruit for osmo-active solute from the surrounding osmotic solution. Fruits, like other biological material, are made of heterogeneous tissues with connecting cells and micro-pores; as such, OD processes occurring throughout the fruit matrix and mass exchange during OD are facilitated by both diffusion and capillary flow (M. R. Khan, 2012; Shi et al., 2009). Earlier works on OD often consider the fruit as a macroscopic matrix of homogenous tissue (Le Maguer \& Yao, 1995; Maguer, 1997; Salvatori et al., 1998). It was assumed that diffusion is the only mechanism of mass transport during OD processing and a superficial transport front exists within 2-3 mm depth of the fruit matrix , causing a barrier to subsequent solute impregnation from the OD solution and exodus of soluble solute from the fruit (Marcotte \& Le Maguer, 1992; Raoult-Wack et al., 1991; N. K. Rastogi et al., 2002). As such, the OD process was explained and modelled using Fick's second law of unsteady state diffusion. However, recent works on OD explore the microscopic approach to understanding the mass transfer mechanism. Salvatori and coworkers proposes the concept of "advance disturbance front' (ADF) to explain the mass exchange mechanism during OD, especially at room temperature. The ADF is described as a virtual plane separating layers of fruit with non-significant mass transfer (Salvatori et al., 1998). They submitted that, with a long OD time, it is possible to extend ADF to a depth of $15 \mathrm{~mm}$ from the fruitsolution interface. Rastogi et al. report the same possibility in their research, explaining that the state of cell membrane does not remain constant as earlier assumed, but changes with osmotic stress and could change from semi-permeability to full permeability allowing the dehydrating front to proceed to the 
center of the fruit from the surface. At the beginning of OD, the tissue in contact with the OD solution exudes water through diffusion, ruptures and shrinks. Consequently, this dead cell increases the permeability index of the material. As OD progresses, the dehydrating front moves inward to the core of the material, causing a disintegration of the already dehydrated tissues.

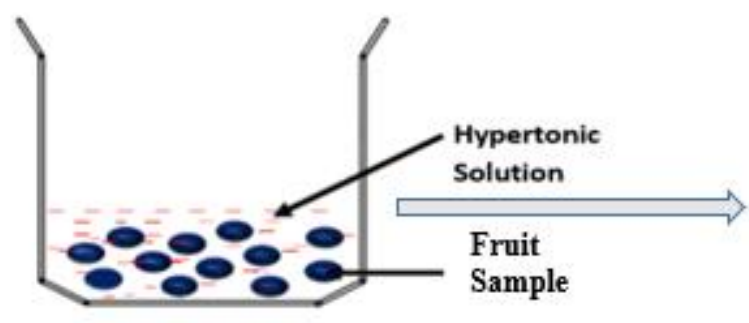

Figure 6. Schematic diagram of osmotic dehydration process.

This makes it possible for water to diffuse through the whole part of the material through diffusion and a capillary flow: water moves from the core to the neighboring layer, then to the surface layer and finally to the osmotic solution until equilibrium is reached (N. Rastogi et al., 2000; N. K. Rastogi et al., 2002). When osmotic dehydration is carried out under vacuum as with vacuum pulsed OD, fruit or vacuum impregnation rehydration, the proposed mass transfer model is Hydrodynamic Mechanism (HDM) (Corrêa et al., 2010; Pedro Fito, 1994; P. Fito \& Pastor, 1994). The HDM results from a combination of pressure gradients and capillary flow imposed on the fruit-solution system (Corrêa et al., 2010; Pedro Fito, 1994; P. Fito \& Pastor, 1994). Fruit as porous material is made up of gas occluded in the intercellular spaces. When vacuum is applied, there is a lower pressure in the fruit-solution system compared to the atmospheric pressure. Thus, the occluded gas expands and escapes from the fruit creating room for the capillary inflow of surrounding solution when pressure is restored, which dewaters and impregnates the fruits simultaneously (Sagar \& Kumar, 2010).

\subsubsection{Effect of process conditions during osmotic dehydration}

Osmotic dehydration, either as a drying pretreatment or as a separate dehydration technique, has the unique advantage over all other dehydration methods. OD provides an opportunity to control, modify or 
create a new formulation depending on the desired quality intended for the final products. This is possible because quite several process parameters can influence OD process such as: type of solution/osmo-active agents; composition and concentration of solution; molecular weight of osmo-active agents, fruit to solution ratio; fruit geometry, size and maturity; temperature; time; ambient pressure (atmosphere or vacuum); degree of agitation; osmotic dehydration method and equipment as well as type of pretreatment if used as a separate dehydration technique. From the onset of its application to food, there have been a continuous stream of publication and patents exploring the permutation of these parameters with the intent of product and process optimization and new product developments. Similarly, convective drying, a counter current heat and mass transfer, is also influenced by certain parameters such as temperature, time of drying, ambient pressure, air velocity and initial moisture of the fruit material. Therefore, in applying osmo-convective dehydration, it is imperative to consider both sets of processing parameters to ensuring quality product and cost-effective processing.

\subsection{3a. Osmotic solution type and concentration}

The nature of the osmotic solution is an important factor in the development of the final products. The type of solution/osmo-active agents; composition and concentration of solution; molecular weight of osmo-active agents strongly influences the osmotic gradient, which is the driving force for the OD process. Consequently, the solution greatly influences the WL/SG index, the water activity, and overall

quality of the fruit. Shi et al. studied effect of different osmotic agents (fructose, dextrose, polydextrose, sucrose, maltodextrin, and corn syrup) on the solid gain in blueberries under dynamic infusion method. The results show that Monosaccharide (fructose, dextrose) caused a higher solid gain than polysaccharides (polydextrose, corn syrup and maltodextrin) for the same concentration and process condition. The explanation for this was that monosaccharides with lower molecular weight have a higher diffusion coefficient than disaccharides (Shi et al., 2009). The fact that the type, nature, concentration, and molecular weight of solution correlates positively with increased mass transfer has been corroborated by several works (Azoubel \& Elizabeth Xidieh Murr, 2004; M. A. Khan et al., 2011; Lazarides et al., 
1995; Nsonzi \& Ramaswamy, 1998; Sacchetti et al., 2001). The concentration of the solution is known to affect the WL/SG index. The higher the concentration, the higher the solid gain and water loss. Giraldo and co. reported an increase in water transfer rate when mango fruit was treated in a sucrose solution with concentration range of $35-65^{\circ} \mathrm{Brix}$ at $30^{\circ} \mathrm{C}$ under atmospheric pressure. However, the increase was only observed from $35-45^{\circ}$ Brix, but not 55 and $65^{\circ}$ Brix (Giraldo et al., 2003). In an experiment with apple, banana, and kiwi fruits osmosed with varying sucrose solution concentrations $(30 \%, 40 \%$, 50\%), solid gain and water loss was observed to increase with the concentration up to 50\% (Panagiotou et al., 1998). Therefore, depending on the type of fruits and process condition, the WL and SG may only increase significantly with concentration up to certain point. For example, there was non-significant water loss or solid gain in pumpkin osmosed with 55\% and 65\% sucrose solution after 4 h of OD (Pan et al., 2003). As such a careful combination of parameters is needed for optimization. While increase in solution concentration correlates positively with increase in solid gain and water loss up to certain point, it however negatively correlates with average diffusion coefficients for water loss and solid gained. In a separate experiment, where apple slices where osmosed with $40,50,60 \%$ sucrose solution at $27^{\circ} \mathrm{C}$, effective diffusion coefficients for water loss were $35.930,13.282,7.603 \times 10^{11} \mathrm{~m}^{2} / \mathrm{s}$, respectively and solid gain were $2.174,0.939,0.264 \times 10^{11} \mathrm{~m}^{2} / \mathrm{s}$, respectively (Rodrigues \& Mauro, 2008).

Another factor worthy of note is the osmotic solution $\mathrm{pH}$. The $\mathrm{pH}$ concentration of the solution influences the mass transfer rate during OD by modifying the fruit cell architecture. In a study on Nitella cells, it was discovered that penetration of $\mathrm{NO}_{3}$ ions into the cell sap was increased by the hydrogen ion concentration in the surrounding solution: Penetration decreases as the solution moves from acidic to alkaline (Hoagland et al., 1923). Furthermore, exosmosis of chlorine from the cell is an indication of injury and altered permeability of the cell (Hoagland et al., 1923). In two separate experiments, Allali et al. and Tappi et al. performed osmotic dehydration of apple fruits using a solution (1) sucrose $+0-2 \%$ citric acid (2) sucrose $+2 \%$ ascorbic acid, respectively. Both research groups recorded increase in water loss and solid gain and affirmed that the increase recoded was due to the presence of this acid ingredients (Allali et 
al., 2010; Mauro et al., 2016). Additionally, both group submitted that modified fruit cellular structure from the action of the organic acids was responsible for the increase of WL/SG index. Similarly, the addition of salt to OD solution has been known to facilitate mass transfer in OD. Singh et al. reported an increase in water loss and solid gain when salt concentration in a $50^{\circ}$ Brix sucrose solution increased from $5 \%$ to $15 \%$ (Singh et al., 2007).The composition and concentration of the OD solution impacts the quality and consumer's choice of the product. Sacchetti et al. reported a negative correlation of OD solution concentration with consumer acceptability when apple was osmosed in a sucrose-salt solution. An addition of $0.5 \% \mathrm{NaCl}$ resulted in a reduction in consumer acceptability as much as $5 \%$ sugar addition (Sacchetti et al., 2001). A mixture of low concentration of sucrose and additive salt is usually recommended from a health point of view (Pan et al., 2003). Shi et al. also report that the use of fructose gives the best quality product (soft and sweet) compared to other osmo-active agents mentioned above. They observed that blueberries infused with sucrose were slightly firmer than fructose-infused products and corn syrup and polydextrose and dextrose-infused blueberries had akin sweetness (Shi et al., 2009). Osmotic dehydration, irrespective of the solution type, has been established to maintain the color and flavor of the fruits, increase chewability, retain volatile compound loss from fruit and increase the shelf life of the resultant dry product due to the solute infusion (Yadav \& Singh, 2014).

\subsection{3b. Fruit characteristic and fruit to solution ratio}

Other parameters such as fruit to solution ratio, fruit geometry, fruit size and maturity as well the degree of agitation of the whole system affect the ratio of SG/WL, diffusion coefficient, and quality of the products. Theoretical evidence, from the various model describing OD process shows that the thickness of the fruits varies inversely to the concentration gradient in fruit $\left(\mathrm{SG} / \mathrm{SG}_{\mathfrak{c}}\right.$ or $\left.\mathrm{WL} / \mathrm{WL}_{\mathfrak{c}}\right)($ Azuara et al., 1992; Crank, 1975; Ochoa-Martinez et al., 2007; Peleg, 1988). This evidence is supported by the works of Panagiotou et al. in which osmotic dehydration of apples, banana and kiwi fruits was carried out at temperature of $40{ }^{\circ} \mathrm{C}$, sucrose concentration of $40 \%$ under atmosphere pressure. Thickness of apples slabs was maintained at 4, 8,12, 16 and $20 \mathrm{~mm}$. The kiwi fruit samples were formed from two half-slab 
samples, and the average diameter for kiwi fruit and banana was $4.5 \mathrm{~cm}$ and $2.2 \mathrm{~cm}$ respectively. Their result shows that the thickness of the fruits negatively correlated to water loss and solid gain (Panagiotou et al., 1998). In the same experiment, they further reported that the rate of agitation correlates positively to rate of with water loss and solid gain. Additionally, they reported that with a faster speed of agitation, the equilibrium time $(6 \mathrm{~h})$ of small sizes apples, banana, and kiwi fruit less than $4 \mathrm{~mm}$ can be reduced. Mathematical models of different fruits geometry used in OD has been extensively researched and compiled (Assis et al., 2016; Crank, 1975; Ochoa-Martinez et al., 2007).Theoretically, it is known that the more surface area of the fruit in contact with the solution, the higher rate of mass transfer facilitated (Panagiotou et al., 1998; van Nieuwenhuijzen et al., 2001). Depending on the objectives of osmotic dehydration (dewatering or impregnation), the fruit to solution ratio influences the rate of water loss and solid gain. Decreasing the "fruit to solution ratio" increases the water loss and solid gain (Singh et al., 2007). However, there was a deviation from this theory with the experiment on OD of carrot (Singh et al., 2008). Singh et al., observed that when carrot cubes were osmosed in sodium chloride solution having concentrations: $5 \%, 10 \%$, and $15 \%(\mathrm{w} / \mathrm{v})$, at solution temperatures of 35,45 , and $55^{\circ} \mathrm{C}$, sample to solution ratios 1:4, 1:5 and 1:6, for $240 \mathrm{~min}$. there was no significant difference $(\mathrm{P}>0.05)$ in the amount of solid gained or water loss due to "fruit-solution ratio". The increases in SG or WL were attributed to temperature effect. (Singh et al., 2008). Fruit to solution ratio range of 1:4 to 1:6 is recommended for a balance of water loss and solid gain (Khan et al., 2011).

The nature of the fruits (fresh or frozen, degree of ripeness, time of storage prior OD) is another factor to be considered. In an experiment conducted by Akharume et al. on osmotic dehydration of fresh and frozen blueberries osmosed in a $42{ }^{\circ}$ Brix solution at $50^{\circ} \mathrm{C}$ for 0 - $10 \mathrm{~h}$, the group recorded three times as much solid gain and four times as much water loss in the frozen blueberries, compared with the fresh ones (Akharume et al., 2016). To influence mass transfer during OD, especially when using fruits with thick epidermal layer (e.g. blueberries, mango, apples, etc.), a host of different research (exploring different pretreatment methods prior to OD) have been published. Examples include:, freezing in osmotic 
dehydration of blueberries to enhance SG and WL (Akharume et al., 2016); using edible coating to reduce solute uptake in mango, apples, and other fruits (Azam et al., 2013; Ferrari et al., 2013; Jalaee et al., 2011), blanching by ohmic heating to damage apple tissue and enhance mass transfer (Allali et al., 2009), enzyme processing in blueberries (Kucner et al., 2013; Yu, 1998), using ultrasound (Deng \& Zhao, 2008; Kucner et al., 2013), and using inorganic chemicals ( $\mathrm{NaOH}$, liquid nitrogen etc.) (Ketata et al., 2013; Kucner et al., 2013).

\subsection{3c. Temperature, time, and pressure}

Effects of temperature, OD process time, ambient pressure (atmosphere or vacuum) are the major process parameters in OD that influence the kinetics of solid gain and water loss. osmotic dehydration method and equipment as well as type of pretreatment equally influences the osmotic kinetics. Nsonzi and Ramaswamy measured the effect of these parameters (time, temperature) under atmospheric pressure in osmotic dehydration of blueberries at varying sucrose concentration ranges ( $\left.47^{\circ} \mathrm{Brix}-70{ }^{\circ} \mathrm{Brix}\right)$. They reported that time and temperature effects were significant on water loss $(\mathrm{P}<0.001)$ and on solid gain at $(\mathrm{P}<0.05)($ Nsonzi \& Ramaswamy, 1998). Lazarides et al. reported similar effects for temperature, an increase in temperature resulted in an increase in water loss and solid gain rates (Lazarides et al., 1995). Wang et al. assayed the effect of vacuum (20kpa) and normal pressure on water loss and solid gain of apples. Irrespective of the other process conditions (concentration, time, temperature), vacuum pressure favored a lower water loss in fruit compared to normal pressure and supported a higher solid gain compared to normal pressure (Wang et al., 2015). In another OD experiment where apple slices were impregnated with $\beta$-carotene, pulsed vacuum osmotic dehydration condition resulted in a higher solid gain of 4.7, 5.5, and $6 \mathrm{mg} \beta$-carotene/g ds, while OD under atmospheric pressure condition yielded 1.5, 3.5, and 4.1mg $\beta$-carotene/g ds for concentration level 30, 40, and $50{ }^{\circ}$ Brix (Santacruz-Vázquez et al., 2008). 


\subsection{Current Status of Knowledge About Convective Drying of Fruits}

\subsubsection{Drying}

Drying is a thermal processing technique in which heat is bought in contact with the surface of the material being dried. (e.g. fruits, vegetables, biological and non-biological materials). The medium of heat transfer is generally used to classify the drying process as: convective drying, conductive drying or radiative drying, although broader classification may consider the heat source, the pressure during drying, the mode in which the material is fed and held in the drying equipment dried (batch or continuous) and the equipment used in the drying process. Convective drying uses fluid in heat transfer, in this case hot air is passed to the surface of the drying material. Different kinds of equipment provide this technique of drying, for example, tray dryers, cabinet dryers (Ramaswamy \& Nsonzi, 1998), tunnel dryers, fluidized bed dryers (Yemmireddy et al., 2013), spray dryers, freeze-dryers (Sosa et al., 2012) etc. In these equipment, there are common features that are peculiar and pertinent to their functionality: a heat source, a fan or blower to circulate and carry heat and a housing to hold the drying materials (Fig. 7). Convective drying has been widely used to dehydrate high and intermediate moisture fruit into dried fruits snacks with moisture content of 5\% (Geankoplis, 1993; Yemmireddy et al., 2013) and water activity usually lower than 0.61, where no bacterial growth is observed (Beuchat, 1981). Convective dehydration is a commonly used method of drying farm produce because of it's a relatively old and simple technique. However, the products from this method is often of low quality: the long drying time and high temperature cause a loss of color, flavor and nutrient of the final dried products. Drying beyond temperatures greater than $80^{\circ} \mathrm{C}$ induced maillard and caramelization reaction at lower moisture content. Traditional hot air-drying produces shrunken and tough dried product with noticeable browning, little rehydration ability and low nutritive value (Koyuncu et al., 2007; Pallas, 2011).

Therefore, the combination of osmotic dehydration and convective air drying, in which the osmotic dehydration process is used as a pretreatment is now been widely adopted and commercialized to solve the inherent challenges associated with the hot air drying. Many articles have been published on this 
subject to address different fruits and food materials. Notably among them include: osmo-convective drying of blueberries (Akharume et al., 2016; Giovanelli et al., 2013; Ramaswamy \& Nsonzi, 1998); osmo-convective dehydration of apples (Aktas et al., 2013; Kowalski \& Mierzwa, 2013; Sosa et al., 2012); osmo-convective dehydration of Papaya (Germer et al., 2014); osmo-convective dehydration of cherries (Rudy et al., 2013).

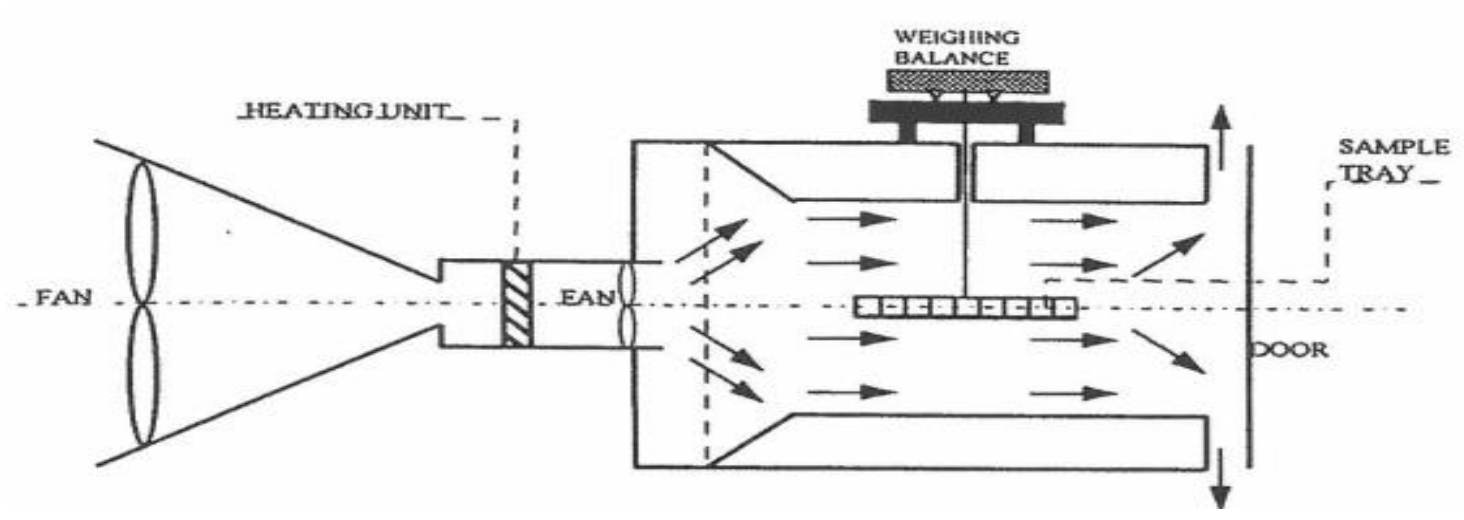

Figure 7. Schematic diagram of convective drying unit (Ramaswamy \& Nsonzi, 1998).

\subsubsection{Mechanism of convective drying}

Convective drying is a common energy intensive method of dehydration in which free water moleculesare removed in the form of vapor by hot air in contact with the food material, from the surface as well as moisture from the interior of solid material (Mehrafarin and Faghihi, 2001). The phenomena underlying this process is a complex problem involving simultaneous mass and energy transport in a hygroscopic, shrinking system (Ratti, 2001). Generally, in drying, a single- or multi-component liquid gradually evaporates and is removed from the complex porous structure via combined heat and mass transfer processes. Convective drying occurs through evaporation of moisture from the exposed surface of a solid. At separate and independent times, moisture removal involves the combination of convective and diffusive flows from the depths of the solid to the surface when there is a concentration difference between the depth of the solid and the surface. Fruit as a biological material contains network of cells, interconnecting pores. and channels of varying pore sizes. Free moisture moves through these capillaries and pores from the depth of the porous solid to the surface through capillarity action and not by diffusion. 
As the water is removed, a point is reached where there is insufficient water left to maintain continuous film across the pores. At this point moisture movement is through diffusion, especially in fine pore solids (Geankoplis 1993).

The output of a drying test is usually presented as a "rate-drying curve" (Fig. 8), which is a graph of drying rate, $\mathrm{h}=-A^{-1} \mathrm{dw} / \mathrm{dt}$ (moisture loss per unit time per unit area of the exposed surface), versus moisture content of the material. This curve varies among porous materials and with different drying conditions. However, two distinct and well-defined regimens, namely, a constant drying-rate period followed by a falling-rate stage, as shown in Fig. 8 are commonly identified (Mehrafarin and Faghihi 2001).

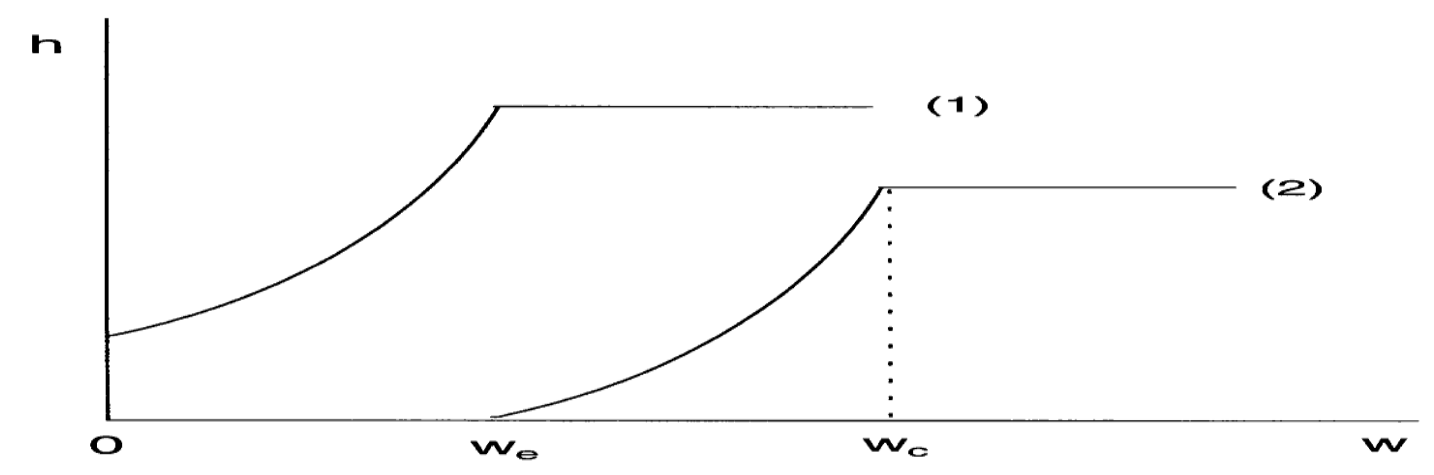

Figure 8. Typical drying rate curves for porous materials (Mehrafarin and Faghihi, 2001)

During the first stage of drying (the constant-rate period), moisture evaporates from a saturated surface of the material. This moisture is unbound and is supplied from the interior of the material by capillarity. The drying of porous media occurs homogenously with a constant drying rate until a critical moisture content is attained (Mehrafarin and Faghihi, 2001; Faiyas et al., 2015). However, at the critical moisture content (falling rate stage), the drying process is no longer continuous and evaporation takes place from within the solid. In this stage, drying is dominated by internal mass transfer (e.g. internal vapor transport) (Faiyas et al., 2015; Mehrafarin and Faghihi, 2001).

\subsubsection{Effect of convective drying process conditions}


Convective drying temperature, time of drying, air velocity, ambient humidity, initial moisture of the fruit, size of the fruit and types of pretreatment material are the major parameters that influence mass transfer during convective drying of fruits' solid material. Like the process condition in OD, an increase in the convective parameters (temperature, time, air velocity) positively correlates with moisture loss, and weight reduction. However, ambient humidity, the size and initial moisture content of the fruits correlates negatively with moisture loss, weight reduction and drying time. Many works have been published, testing the effects of all these parameters. Irrespective of the equipment used in the convective drying, the effect of the process conditions is similar. However, the efficiency of one dryer over another lies in the design of the dryers to effectively incorporate all the drying process conditions (temperature, relative humidity, and air velocity) with optimum energy and exergy utilization. In an experiment, to study the kinetics of convective drying of blueberry variety (O'neil) at three different temperatures $(60,70$, and $80^{\circ} \mathrm{C}$ ) with an air flow of $2.0 \pm 0.2 \mathrm{~m} / \mathrm{s}$, the result obtained showed that drying times depend largely on the air temperature as evidence from the drying characteristic curves. Blueberries dried at $80^{\circ} \mathrm{C}$ showed the lowest drying time, followed by blueberries dried at $70^{\circ} \mathrm{C}$ and next $60^{\circ} \mathrm{C}$. (Vega-Gálvez et al., 2009). Similarly, in another research drying time of rabbit eye blueberries was recorded to be $50 \%$ longer when dried at $85^{\circ} \mathrm{C}(5.20 \mathrm{~h})$ compared to $107^{\circ} \mathrm{C}$ in trio of air-impingement, fluidized bed, and forced air dryer to reach $a_{w}$ of $0.55 \pm 0.05$. Additionally, fluidized bed, air-impingement, and forced air dryers showed increasing drying times in this order. The lamina air flow condition and slow air flow rate $(0.4 \mathrm{~m} / \mathrm{s})$ were identified as the reason for the higher drying time recorded with forced air dryer (Yemmireddy et al., 2013). In a separate experiment on convective drying, freshly harvested cornelian cherries were dried at 50, 60 and $70^{\circ} \mathrm{C}$ temperatures. Selected drying air velocities were $0.3,0.6$ and $0.9 \mathrm{~m} / \mathrm{s}$ for each temperature. Effects of air temperature were reported to change drying time significantly, while air velocity did not affect drying time significantly. However, the air velocity reduced the amount of energy needed for drying. Finally, air velocity of $0.3 \mathrm{~m} / \mathrm{s}$ and temperature of $70^{\circ} \mathrm{C}$ were recommended to dry the cherries to $8 \%$ moisture content dry basis (Koyuncu et al., 2007). However, when drying beyond $80^{\circ} \mathrm{C}$ for 
8-10 h at very low moisture content induces maillard caramelization reaction in fruits (Wilford et al., 1997).

\subsection{Advantages of Osmotic Dehydration Prior to Convective Drying}

The application of osmotic dehydration as a pretreatment to further processing is being widely applied to improve the quality characteristics of dried fruits, such as texture, aroma, color, taste, microbial stability and functionality (Torreggiani \& Bertolo, 2001). Several research projects using osmo-convective dehydration to produce dried fruits snack with better organoleptic properties have been published. Research documents dehydrating several vegetables and fruits (apple, ginger, carrot, and pumpkin) using osmotic agents such as sucrose, and salt as a pretreatment then followed by thermal drying (Pan et al., 2003). This group revealed that osmotic dehydration considerably reduces the drying time of all osmosed samples compared to fresh ones as well as significantly changed the drying characteristics of all osmosed samples. For example, material osmosed in high concentration sucrose was observed to reduce the heating-up period during drying compared to the materials osmosed in low sucrose concentration including fresh ones with no treatment. Additionally, material osmosed with sucrose and salt was observed to significantly reduce drying time compared to pure sucrose. Again, the temperature at which OD was conducted did not have remarkable effect on drying time or drying behavior of the osmosed sample. Thus, it was recommended that OD be carried out at low temperature (Pan et al., 2003).

In a separate, but similar experiment Mandala et al. studied the influence of different osmotic pretreatments on apple air-drying kinetics and physical properties. Apple samples were osmosed in $30 \%$ and $45 \%$ glucose or sucrose for 3,12, and 18h OD time, then osmosed samples were air dried in air oven at $55^{\circ} \mathrm{C}$ air velocity of $2 \mathrm{~m} / \mathrm{s}$. At the end of OD, the moisture content of osmosed samples was within $20-$ $55 \%$ of the untreated sample. During air drying, samples osmosed in glucose at $30 \%$ and $45 \%$ concentrations showed rapid moisture losses in the first $1 \frac{1}{2} \mathrm{~h}$ of drying compared to untreated ones. Samples osmosed in $30 \%$ sucrose showed a similar behavior after 40-50min, though closer to the 
untreated. After this period, all samples recorded a similar decrease in moisture loss. They theorized that the infused sugar molecules interfere with the desorption of moisture during this period and was responsible for the similar characteristic exhibited by all samples. However, osmosed samples in $45 \%$ sucrose, showed a greater mass resistant throughout the drying period due to low initial moisture content and higher sugar gained (Mandala et al., 2005). In another research, Ramaswamy and Nsonsi investigated the effects of osmotic dehydration pretreatment conditions (temperature, concentration, and contact time) on the drying time osmo-treated blueberries. OD was carried out at temperature range 37$53^{\circ} \mathrm{C}$, temperature range $47-63 \mathrm{Brix}^{\circ}$, and $\mathrm{OD}$ contact time $0.5-5.5 \mathrm{~h}$ using a sucrose solution. Then osmosed samples were dried in a cabinet dryer (air velocity $0.64 \pm 0.02 \mathrm{~m} / \mathrm{s}$, relative humidity $14 \pm 1 \%$, temperature $50 \pm 1{ }^{\circ} \mathrm{C}$ ) to final moisture content of $18 \%$ w.b. Results revealed that most of the osmosed samples showed a longer drying time compared to untreated ones. Temperature and sucrose concentration significantly affected drying time, while contact time did not. OD temperature did not show a great effect on drying time at low sucrose concentration $\left(50{ }^{\circ}\right.$ Brix $)$ and low contact time, but did reduce at higher contact time. At higher sucrose concentration $\left(55^{\circ} \mathrm{Brix}\right)$, OD temperature reduces drying time at specific contact time. They submitted that high temperature decreases the viscosity of the sucrose in both OD and air drying, which favors more moisture desorption. However, when the concentration increased to 60 ${ }^{\circ}$ Brix, drying time was higher than sample osmosed in $55^{\circ}$ Brix sucrose solution but lower than samples osmosed $50{ }^{\circ}$ Brix sucrose solution. Additionally, increasing the contact time reduces the drying time of osmosed samples, since the water needed to be removed in drying decreases with contact time (Ramaswamy \& Nsonzi, 1998). In another experiment, OD was reported to reduce the energy inputs for drying cherries by 33-52\% compared to non-OD cherries (Rudy et al., 2013). While it may be difficult to predict the effects of concentration and osmotic agents on drying characteristic and convective drying time of different osmosed samples compared to fresh ones due to the diverse behavior of the different osmotic agents used, it is true that OD temperature and contact time reduces time and the energy requirements needed for drying, compared to fresh samples. 


\subsection{Nutrients, Microbiology, and Quality of Osmo-convective Dried Fruits}

One advantage of osmotic dehydration in fruits processing is that final product's safety, nutrition, and sensory attribute can be controlled to meet consumer's desire. By selective incorporation of the solutes without modifying the fruit integrity, as well as balancing WL/SG index, the properties of osmosed food can be enhanced, even in further processing such as drying, where nutrient loss and quality is a concern (Torreggiani \& Bertolo, 2001). The overall quality of osmo-convectively dehydrated fruit has been well researched by several authors in last decades. More recently the possibility of using osmotic dehydration in functional foods is receiving great attention. Certain quality indicators such as color, taste, nutrients content, aroma, texture, appearance (shrinkage), and microbial shelf life are used to evaluate the overall consumer acceptance of food products, including dried fruit snacks.

\subsubsection{Effects of osmo-convective drying on nutrients of dried fruits}

Convective drying of fruit has been known to produce products with low quality. Dehydration are often associated with physical, chemical and biological changes such as maillard reactions, lipid oxidation, nutrient loses etc. Osmotic dehydration as a pretreatment to convective drying is been constantly explored to improve the quality of products. Though osmotic dehydration is associated with leaching out of negligible amount of nutrient such as polyphenols and vitamin $\mathrm{C}$, the loss can be complemented by careful choice and infusion of edible osmo-active agents that bind and retain these nutrients (such as trehalose). To better understand the loss of vitamin $\mathrm{C}$, apple slices were osmosed in either sucrose or trehalose at concentrations of $20^{\circ}$ Brix and $50^{\circ}$ Brix for $30 \mathrm{~min}$ then dried at 50, 60, and $70{ }^{\circ} \mathrm{C}$. The dried samples were then stored in a plastic bag at room temperature for 12 months. Loss of Vitamin C was the highest in untreated sample compared to osmo-treated ones. Maximum vitamin $\mathrm{C}$ retention was recorded for the trehalose treatment. Again, vitamin C was higher in samples osmosed with $50{ }^{\circ}$ Brix trehalose than that with $20^{\circ}$ Brix. All samples showed great loss of vitamin C during storage, especially first 6 months (Aktas et al., 2013). Effects of additives in retention of vitamin C has been investigated during osmo-air dried papaya (Germer et al., 2014): the treatment includes: CA/CL - $0.1 \mathrm{M}$ citric acid with calcium lactate 
(0.5g/100g syrup); LA/CL - $0.1 \mathrm{M}$ lactic acid with calcium lactate $(0.5 \mathrm{~g} / 100 \mathrm{~g}$ syrup); CA/CC - $0.1 \mathrm{M}$ citric acid with calcium chloride $(0.5 \mathrm{~g} / 100 \mathrm{~g}$ syrup); LA/CC - $0.1 \mathrm{M}$ lactic acid with calcium chloride (0.5g/100g syrup); PME/CC - PME (1mL/kg fruit) with calcium chloride (1 $/ \mathrm{kg}$ fruit); and P - papaya without additives. The results showed a percentage vitamin C retention of 33.1, 33.51, 46.62, 34.05, 62.81, and 56.78 for CA/CL, LA/CL, CA/CC, LA/CC, PME/CC, and P respectively.

Osmotic dehydration also affects polyphenol content. In Aktas et al. study, retention of total phenol content was reported to be higher in osmosed samples than untreated samples $(137.1 \mathrm{mg} / 100 \mathrm{~g}$ dry matter) after drying. However at the end of 12-months' storage a higher phenol content was recorded for untreated samples (Aktas et al., 2013) than osmosed ones. The polyphenols compounds are reported to leach out of apple slices during osmotic dehydration. In an experimental study involving two varieties of apples (Golden delicious and Granny Smith), Kebe et al. demonstrated that the concentration of mannitolbased osmotic solutions $(0,0.2,0.4$, and $0.6 \mathrm{M})$ was positively correlated with the amounts of leaching of polyphenols (Kebe et al., 2014). Likewise, loss of carotene from pumpkin and carrots has been correlated with water loss during osmotic dehydration (Pan et al., 2003). In another study, Giovanelli et al. report effects of osmotic dehydration on the total phenolics, total anthocyanins and antioxidant activity on osmoair drying of blueberries. Osmotic dehydration was carried out in either $60{ }^{\circ}$ Brix sucrose solution or 48.6 ${ }^{\circ}$ Brix glucose/fructose solution (1:1 w/w) and follow-up air drying was performed in a cabinet dryer set at $70{ }^{\circ} \mathrm{C}$, air velocity of $1.5 \mathrm{~m} / \mathrm{s}$. They report a significant decrease in total phenolics, total anthocyanins and antioxidant activity for all treatments, including untreated samples. Polyphenol degradation was the lowest in untreated samples, having a total phenolics, and total anthocyanins loss of 11 and $26 \%$, respectively. Combined loss of $21-25 \%$ total phenolic was recorded for the blueberries osmosed in sucrose or glucose/fructose osmotic solutions. Likewise, losses of anthocyanins were $43 \%$ and $30 \%$, reported respectively, for blueberries osmosed in sucrose and glucose/fructose solutions, (Giovanelli et al., 2013). 


\subsubsection{Effects of osmo-convective drying on microbial stability of dried fruits}

Scientific studies on the effects on osmotic dehydration on the microbial quality of dried fruits are scarce in literature. Dried foods are considered safe from microbial hazard due to low water activity levels. Typically, water activity levels in the dried fruits are within $0.1-0.55$ (Koyuncu et al., 2007; Yemmireddy et al., 2013; Akharume et al., 2016). Generally, no bacterial growth occurs below 0.61 water activity (Beuchat, 1981). However, reducing the water activity inhibits microbial growth but it does not result in a sterile product. Additionally, drying reduces total microbial load but does not totally obliterate the microbes present in or on the food; therefore, food spoilage organism might cause problems upon rehydration of product (Sagar \& Kumar, 2010). In a study, a selected number of commercial commodities sold at retail had indigenous yeast and mold bioburden counts ranging from $10^{2}-10^{3} \mathrm{CFU} / \mathrm{g}$; for example, an average of about 6061, 608, $264 \mathrm{CFU} / \mathrm{g}$ was found in walnuts, dates and raisins (Ic et al., 2007). Shelf life may be increased by osmotic dehydration, for example, the shelf life of fresh cut apple slices increased from 3-4 days to 6 days (Castelló et al., 2009). Similarly, OD has reported to increase the shelf life of strawberries to 7 days, which was further enhanced to 15 and 30 days when steam blanching or microwave treatments, respectively were used before OD (Moreno et al., 2000).

\subsubsection{Effects of osmo-convective drying on quality and sensory attributes of dried fruits}

Color, texture, aroma, and taste are among the physical properties of food that contribute to consumer's judgement, preference and general acceptability of certain foods, fruit inclusive. Dried fruit's color is a function of the chemical, biological and physical reactions that occur during thermal processing. Color correlates well with other physiochemical properties and it has been used as the fastest and the simplest indirect measurement of quality attributes (flavor and other pigments) (Pathare et al., 2013). The primary pigments imparting color quality are the fat-soluble chlorophylls (green) and carotenoids (yellow, orange, and red) and the water-soluble anthocyanins (red, blue), flavonoids (yellow), and betalains (red). In addition, enzymatic and non-enzymatic browning reactions may result in the formation of water soluble brown, gray, and black colored pigments. The enzymes involved in browning reactions include 
polyphenol oxidase, which catalyzes the oxidation of polyphenolic compounds, and phenylalanine ammonia lyase, which catalyzes the synthesis of precursors to phenolic substrates (Barrett et al., 2010). Textural parameters of fruits and vegetables are perceived with the sense of touch, either when the product is picked up by hand or placed in the mouth and chewed (Barrett et al., 2010). Flavor combines the taste and aroma of foods. Taste has been described as being comprised of five primary componentssweet, salty, sour, bitter, and umami (Barrett et al., 2010). Quality attributes of fruits can be measured subjectively, by visual or other sense organs, in most cases by a trained panelist. These attributes could also be measured objectively using instruments (Pathare et al., 2013). In a study on quality attributes of dried apples (untreated, sucrose osmosed and trehalose osmosed) stored over time, the group discovered that there was a high deviation in color parameter just after drying for all samples. Total color change of samples dried at $60^{\circ} \mathrm{C}$ was 24.03 ; lower changes were observed in osmosed samples $(14.24-17.14)$ (Aktas et al., 2013). During storage, degrees of lightness and hue increased with an increase in water activity, especially in the last 6 months. After 12 months, browning was observed in all samples and part of the untreated samples were starting to deteriorate. Samples osmosed in the $50{ }^{\circ}$ Brix sucrose solution retained the color more than those osmosed in $20^{\circ}$ Brix sucrose solution. Additionally, samples osmosed in both 20 and $50^{\circ}$ Brix trehalose solutions showed a better color retention.

The effects of osmotic dehydration on color, textural, and sensory properties of dried apple slices were investigated by Chauhan et al. Prior to drying, apples were osmosed in glucose, fructose, sucrose, maltose, sorbitol, or honey. Their result showed that osmotic agent used had significant effect $(\mathrm{p}<0.05)$ on the color of the fruits. $\mathrm{L}^{*}$ values was highest (87.75) for maltose osmosed samples and lowest (52.45) for honey osmosed samples. It was found that hardness was significantly $(\mathrm{p}<0.05)$ higher $(20.104 \mathrm{~N})$ in sucrose-dipped samples and at a minimum $(4.441 \mathrm{~N})$ in sorbitol-dipped samples. "Fracturability" and adhesiveness were significantly $(\mathrm{p}<0.05)$ higher in sorbitol $(0.911 \mathrm{~N})$ and honey $(4.593 \mathrm{Ns})$-osmosed samples, respectively. Springiness and cohesiveness $(0.177,0.151)$ were found to be a maximum in fructose-treated samples, whereas chewiness $(0.303 \mathrm{~N})$ was shown to be of a high magnitude in sucrose- 
treated samples (Chauhan et al., 2011). Additionally, sensory evaluation of osmo-dried apple slices revealed that sucrose-treated slices had significantly $(\mathrm{p}<0.05)$ more overall acceptability than other samples. Honey-treated samples showed significantly $(\mathrm{p}<0.05)$ lower color and texture values when compared to other samples as they possessed brown color and leathery texture. The samples osmosed with sucrose showed significantly $(\mathrm{p}<0.05)$ higher values for taste. The sorbitol osmosed samples had comparatively lower values for aroma, which was found to be the maximum in the case of fructose- and sucrose-dipped samples. The samples osmosed with maltose, sorbitol, or honey showed lower values for all the sensory parameters (Chauhan et al., 2011).In another experiment, Komopacka, et al. compared sensory characteristics of the sour cherry in several osmotic solutions (concentrated apple juice (AJ), mixture of concentrated apple juice and sour cherry juices (AJ+SCJ), de-acidified concentrated apple juice (DeAAJ) and sucrose solution as control $(\mathrm{S})$ ). They reported that use of concentrated apple juices (AJ, AJ+SCJ) intensified the cherry taste and aroma, adjusting the flavor to consumer preference. The products resulting from $\mathrm{AJ}$, and $\mathrm{AJ}+\mathrm{SCJ}$ osmotic dehydration were perceived to be significantly more acidic but less sweet than those resulting from sucrose $(S)$ or deacidified apple juice (DeAAJ) (Konopacka et al., 2008). Therefore, the choice of osmotic agent and its concentration, temperature of osmotic solution, and fruit-to-solution ratio during osmotic dehydration have large impact on product texture, color, and sensory quality (Pan et al., 2003).

\subsection{Latest Research Interest in Osmo-Convective Dehydration}

The osmotic step in osmo-convective dehydration is a slow process owning to the thick epithelia cells and non-uniform cellular network, which often create an obstruction to the two-way mass transfer of water and solute exchange within the fruit matrix. Efforts are being made to increase the micro pores in the thick epithelia cells to facilitate enhancement of mass transfer rates prior to performing OD. For example, treating fruits with ultra-sound, microwave, pulsed electric field, ohmic heating, centrifugal force or gamma-irradiation to rupture the skin have been tested (Ahmed et al., 2016). In a study, apples exposed to microwave prior to drying were compared with freeze-drying and air drying without 
pretreatment (Azarpazhooh \& Ramaswamy, 2011). Microwave assisted OD created a better texture, softer and chewable product, compared to that produced from other two processes. In contrast, freeze dried product was brittle and air dried was hard (Azarpazhooh \& Ramaswamy, 2011). High pressure assisted OD of apples (George et al., 2016) and ohmic heating assisted OD of apple cubes (Allali et al., 2009) have also been reported.

Additionally, a reduction of consumer preference for sugar-infused fruits due to dietary concerns is opening new selection for the use of alternative osmotic agents instead of conventional use of sugar. Edible coating of fruit to reduce influx of sugar, but permitting the exodus of water and retention of nutrient, is also being embraced. Silva et al. evaluated the influence of two different edible coatings on air drying characteristics of osmotically dehydrated pineapples. The osmotic solution was made up of $50 \%$ of sucrose, $4 \%$ of calcium lactate, and $2 \%$ of ascorbic acid and OD was performed for an hour. Following OD, the osmosed samples were coated with pectin, a mixture of whey protein isolate (WPI) + locust bean + gum $($ LGB $)+$ glycerol, and a control sample was uncoated. Results were that samples with coating retained vitamin $\mathrm{C}$ more than the control. Water diffusion was slightly affected by both coatings (Silva et al., 2015). In other research, gluten-based coating on mango was reported to reduce solute uptake and improve the dehydration index during osmotic dehydration using a sucrose solution (Azam et al., 2013).

The production of probiotic-dried fruits and other functional foods is also another new area that is attracting researchers and consumers. Although there is still ongoing discussion on the microbial safety of probiotic and its application to fruits, Betoret et al. developed a probiotic-enriched apple using osmotic dehydration under vacuum. Apples were impregnated with commercial apple juice containing Saccharomyces cerevisiae, and with whole milk or apple juice containing $10^{7}$ and $10^{8} \mathrm{cfu} / \mathrm{ml}$ of Lactobacillus casei (ssp. rhamnosus). To assure stability and preservation, fruit were further dried to a moisture content of $0.037 \mathrm{~kg}$ water/ $\mathrm{kg}$ dry matter and stored at room temperature for two months. $L$. casie viable cells in dried and stored products was greater than $10^{6} \mathrm{cfu} / \mathrm{g}$ (Betoret et al., 2003). Other functional foods have also been produced, for example, $\beta$-carotene enriched apples (Santacruz-Vazquez et 
al., 2008), zinc enriched whole potato tuber (Erihemu et al., 2015), selenium enriched cabbage (Haizhen et al., 2006), calcium and iron fortified apples (Barrera et al., 2004) etc. Recently, the use of liquid smoke in imparting smoky flavor in brining and osmotic dehydration of meat and fish is another area receiving attention (Alcicek \& Atar, 2010).

\subsection{Liquid Smoke}

Liquid smoke, an alternative for the age long smoking process, is an aqueous condensate of wood smoke produced by smoldering wood chips or sawdust under limited oxygen and controlled conditions (Saloko et al., 2014). The chips or sawdust are commercially fractionated and refined to remove undesirable polycyclic aromatic hydrocarbon (PAH) and to adjust the intensity of the flavor and color. This yields refined liquid smoke oil or dry powder, which has flexible application in food industry and minimizes pollution problems (Saloko et al., 2014; Sofos et al., 1988). Several research projects have explored the potency of commercial liquid smoke as antioxidant and antimicrobial agent in food preservation, and the concomitant organoleptic potential (in terms of flavor and color) in foods, especially for consumers desiring smoky flavor, taste and color.

Van loo et al. investigated the antimicrobial effects of eight commercial liquid smoke products by comparing their minimum inhibitory concentration (MIC) against Salmonella enteritidis, Staphylococcus aureus, and Escherichia coli. The results showed that liquid smoke had an inhibitory effect on the growth of the bacteria with MIC from 0.5 to $6.0 \%$ for E. coli, 0.5 to $8.0 \%$ for S. enteritidis, and 0.38 to $6 \%$ for $S$. aureus (Van Loo et al., 2012). Other researchers have particularly applied liquid smoke to food products to investigate its effect on bacteriostatic and quality profiling. Donnelly et al., made fermented sausage from a combination of lactic starter culture and varying concentrations of liquid smoke. They found an inhibition of bacteria in the liquid smoke treated samples (Donnelly et al., 1982). Similarly, the potency of liquid smoke's anti-listeria effects was corroborated by the work of Susan et al. They found that treating Chum Salmon inoculated with strains of Listeria with a mixture of brine and liquid smoke in a particular concertation 5 s to $15 \mathrm{~min}$ had reduced L. innocua counts to below detectable levels (Vitt et al., 2001). In 
the same study, consumer and sensory attributes of the final products revealed that flavor and desirability scores were significantly lower for 5-min dipped salmon and it had a bitterness and strong after taste. Liquid smoke has also been applied to texture profiling of meat. Martinez et al. investigated the effects of two different liquid smoke types (coded F1and F2) on the textural analysis of meat products (salted pork loin and salted bacon). The smoke flavoring F1, which is low in carbonyl compounds, modified the cohesiveness, springiness and gumminess of the pork loin, and the hardness, fracturability and springiness of the bacon. Smoke flavoring F2, rich in carbonyl compounds, caused changes in the springiness and gumminess of the pork loin, and all the texture parameters of the bacon. Application of liquid smoke flavorings has varied in their bacteriostatic potential and in their sensory impartation to final products. This may be related to their source, composition and the method of extraction and smoke concentration (Montazeri et al., 2013; Van Loo et al., 2012). Liquid smoke has been made from common woods like hickory, white and red oak wood, cherry, chestnut, hard maple, mesquite, aspen, douglas- fir and so on (Maga \& Fapojuwo, 1986). Other researchers have added some aromatic plants to the base wood; Oak and Thymus vulgaris L and Salvia lavandulifolia Vahl (Guillén \& Manzanos, 2005), rice husks (Pino, 2014), and pecan shells (Van Loo et al., 2012).

\subsection{Summary of Current Status of Knowledge}

Osmotic dehydration is an important pretreatment step prior to convective drying without which the convective drying of fruits would have become unpopular. At the same time, the use of osmotic dehydration prior to convective drying has well documented benefits of energy consumption and fast drying times. It has also been well established that use of osmotic dehydration enables retention of the color and pigment of dehydrated fruits and it improves the texture, flavor, and consumer acceptability. However, the loss of heat labile nutrient (vitamin C) and leaching of polyphenol during osmotic dehydration, and follow up drying, are still major concerns. It is not clear whether osmotic dehydration retains these nutrients better than non-osmosed samples. Additionally, the infusion of sugar in fruit is a concern among some consumers but it is cheaper to use sugar than apple juice or any other known 
osmotic agent (Konopacka et al., 2008). It has also been demonstrated that the use of sodium chloride might offset the sucrose flavor but it can only be applied in less amount to avoid loss of consumer acceptability (Pan et al., 2003).

In spite of all this challenge, there is room for continuous process and product improvement in osmoconvective drying. Finally, osmotic dehydration has a great advantage and prospect for modifying formulation and developing new products. The possibility of using it for drug delivery in the gastrointestinal system by pharmaceutical industries is a grey area for exploitation.

\subsection{Problem Statement}

Fruit production is central to the agriculture industry of West Virginia. For example, the state is ranked $9^{\text {th }}$ and $11^{\text {th }}$ in apple and peach production respectively (U.S. Department of Agriculture National Agricultural Statistics Service, 2016). Although production remains relatively stable, there are decline in acreage and some farmers were observed to be divesting from apple production (U.S. Department of Agriculture National Agricultural Statistics Service, 2004). The cause of decline may be attributed partly to the fallout of small farmers from market by competition from big apple players with a consolidated, integrated production and supply chain; and partly to the decline in the consumer taste for the red delicious apple, which is a predominant variety in the US (Brendan, 2010). A solution to the excessive competition in the fresh produce market is to develop novel dried products using osmo-convective dehydration of fruits. The new dried snack products would not only provide an alternate market for the small farmers, and but it would also circumvent the loss that may arise from unsold fresh fruits. While different types of artificial sugar solutions (sucrose, glucose, trehalose etc.) have been widely used in osmotic dehydration of fruits, the use of natural sugars solution such as apple juice is not widely reported in literature. Additionally, liquid smoke, as an additive has only been applied to meat and fish products, no record of its application to fruits and vegetables has been found in literature, to the best of our knowledge. Hence, we propose to test two osmotic agents (apple juice concentrate or liquid smoke) 
during osmotic dehydration to improve quality of fruits dried through osmo-convective drying and to develop a totally new dried smoky product for consumer patronages.

\subsection{Objectives of the Research}

Specific objectives are to evaluate the:

1. Influence of osmotic solution type on osmotic dehydration and drying characteristics of fresh and frozen blueberries.

2. Effects of liquid smoke on the osmotic dehydration kinetics of fresh apple cubes.

3. Influence of liquid smoke on quality and microbial shelf life of convectively and osmoconvectively dried apples slices. 


\section{References}

Ahmed, I., Qazi, I. M., \& Jamal, S. (2016). Developments in osmotic dehydration technique for the preservation of fruits and vegetables. Innovative Food Science \& Emerging Technologies, 34, 29 43.

Akharume, F. U., Singh, K., \& Sivanandan, L. (2016). Characteristics of apple juice and sugar infused fresh and frozen blueberries. LWT - Food Science and Technology, 73, 448-457. doi:http://dx.doi.org/10.1016/j.lwt.2016.06.041

Aktas, T., Ulger, P., Daglioglu, F., \& Hasturk, F. (2013). Changes of nutritional and physical quality characteristics during storage of osmotic pretreated apple before hot air drying and sensory evaluation. Journal of Food Quality, 36(6), 411-425.

Alcicek, Z., \& Atar, H. H. (2010). The effects of salting on chemical quality of vacuum packed liquid smoked and traditional smoked rainbow trout (oncorhyncus mykiss) fillets during chilled storage. Journal of Animal and Veterinary Advances, 9(22), 2778-2783.

Allali, H., Marchal, L., \& Vorobiev, E. (2009). Effect of blanching by ohmic heating on the osmotic dehydration behavior of apple cubes. Drying Technology, 27(6), 739-746.

Allali, H., Marchal, L., \& Vorobiev, E. (2010). Effects of vacuum impregnation and ohmic heating with citric acid on the behaviour of osmotic dehydration and structural changes of apple fruit. Biosystems Engineering, 106(1), 6-13. doi:http://dx.doi.org/10.1016/j.biosystemseng.2009.08.005

Askari, G., Emam-Djomeh, Z., \& Mousavi, S. (2006). Effects of combined coating and microwave assisted hot-air drying on the texture, microstructure and rehydration characteristics of apple slices. Food Science and Technology International, 12(1), 39-46.

Assis, F. R., Morais, R., \& Morais, A. M. (2016). Mathematical modelling of osmotic dehydration kinetics of apple cubes. Journal of Food Processing and Preservation.

Azam, M., Haq, M. A., \& Hasnain, A. (2013). Osmotic dehydration of mango cubes: effect of novel gluten-based coating. Drying Technology, 31(1), 120-127. doi:10.1080/07373937.2012.727055 
Azarpazhooh, E., \& Ramaswamy, H. S. (2011). Optimization of microwave-osmotic pretreatment of apples with subsequent air-drying for preparing high-quality dried product. International Journal of Microwave Science and Technology, 2011.

Azoubel, P. M., \& Elizabeth Xidieh Murr, F. (2004). Mass transfer kinetics of osmotic dehydration of cherry tomato. Journal of Food Engineering, 61(3), 291-295. doi:http://doi.org/10.1016/S0260$\underline{8774(03) 00132-8}$

Azuara, E., Cortés, R., Garcia, H. s., \& Beristain, C. I. (1992). Kinetic model for osmotic dehydration and its relationship with Fick's second law. International Journal of Food Science \& Technology, 27(4), 409-418.

Barrera, C., Betoret, N., \& Fito, P. (2004). Ca2+ and Fe2+ influence on the osmotic dehydration kinetics of apple slices (var. Granny Smith). Journal of Food Engineering, 65(1), 9-14. doi:http://dx.doi.org/10.1016/j.jfoodeng.2003.10.016

Barrett, D. M., Beaulieu, J. C., \& Shewfelt, R. (2010). Color, flavor, texture, and nutritional quality of fresh-cut fruits and vegetables: desirable levels, instrumental and sensory measurement, and the effects of processing. Critical Reviews in Food Science and Nutrition, 50(5), 369-389.

Betoret, N., Puente, L., Díaz, M. J., Pagán, M. J., García, M. J., Gras, M. L., . . . Fito, P. (2003). Development of probiotic-enriched dried fruits by vacuum impregnation. Journal of Food Engineering, 56(2-3), 273-277. doi:http://dx.doi.org/10.1016/S0260-8774(02)00268-6

Beuchat, L. R. (1981). Microbial stability as affected by water activity. Cereal Foods World, 26(7), 345349.

Carson, K., Collins, J., \& Penfield, M. (1994). Unrefined, dried apple pomace as a potential food ingredient. Journal of Food Science, 59(6), 1213-1215.

Castelló, M., Igual, M., Fito, P., \& Chiralt, A. (2009). Influence of osmotic dehydration on texture, respiration and microbial stability of apple slices (Var. Granny Smith). Journal of Food Engineering, 91(1), 1-9. 
Chauhan, O. P., Singh, A., Singh, A., Raju, P. S., \& Bawa, A. S. (2011). Effects of osmotic agents on colour, textural, structural, thermal, and sensory properties of apple slices. International Journal of Food Properties, 14(5), 1037-1048. doi:10.1080/10942910903580884

Chavan, U., \& Amarowicz, R. (2012). Osmotic dehydration process for preservation of fruits and vegetables. Journal of Food Research, 1(2), 202.

Chiralt, A., \& Talens, P. (2005). Physical and chemical changes induced by osmotic dehydration in plant tissues. Journal of Food Engineering, 67(1-2), 167-177. doi:http://doi.org/10.1016/j.jfoodeng.2004.05.055

Chun, H. H., Kim, M. S., Chung, K. S., Won, M., \& Song, K. B. (2012). Dehydration of blueberries using maltodextrin and the physicochemical properties of dried blueberries. Horticulture, Environment, and Biotechnology, 53(6), 565-570.

Corrêa, J. L. G., Pereira, L. M., Vieira, G. S., \& Hubinger, M. D. (2010). Mass transfer kinetics of pulsed vacuum osmotic dehydration of guavas. Journal of Food Engineering, 96(4), 498-504. doi:http://dx.doi.org/10.1016/j.jfoodeng.2009.08.032

Cortes R, M., Chiralt B, A., \& Suarez M, H. (2009). Influence of storage conditions on freeze-dried apple fortified with vitamin E. Vitae, 16(1), 31-41.

Crank, J. (1975). The mathematics of diffusion: Oxford: Clarendon Press.

Cruz, A. C., Guiné, R. P. F., \& Gonçalves, J. C. (2015). Drying kinetics and product quality for convective drying of apples (cvs. golden delicious and granny smith). International Journal of Fruit Science, 15(1), 54-78. doi:10.1080/15538362.2014.931166

Deng, Y., \& Zhao, Y. (2008). Effects of pulsed-vacuum and ultrasound on the osmodehydration kinetics and microstructure of apples (Fuji). Journal of Food Engineering, 85(1), 84-93. doi:http://dx.doi.org/10.1016/j.jfoodeng.2007.07.016

Donnelly, L., Ziegler, G., \& Acton, J. (1982). Effect of liquid smoke on the growth of lactic acid starter cultures used to manufacture fermented sausage. Journal of Food Science, 47(6), 2074-2075. 
Erihemu, Hironaka, K., Koaze, H., Oda, Y., \& Shimada, K. (2015). Zinc enrichment of whole potato tuber by vacuum impregnation. Journal of Food Science and Technology, 52(4), 2352-2358. doi:10.1007/s13197-013-1194-5

Falade, K. O., \& Shogaolu, O. T. (2010). Effect of pretreatments on air-drying pattern and color of dried pumpkin (cucurbita maxima) slices. Journal of Food Process Engineering, 33(6), 1129-1147.

Feng, H., Tang, J., MATTINSON, D. S., \& FELLMAN, J. K. (1999). Microwave and spouted bed drying of frozen blueberries: the effect of dryingand pretreatment methods on physical properties and retention of flavor volatiles. Journal of Food Processing and Preservation, 23(6), 463-479.

Ferrari, C. C., Sarantópoulos, C. I. G. L., Carmello-Guerreiro, S. M., \& Hubinger, M. D. (2013). Effect of osmotic dehydration and pectin edible coatings on quality and shelf life of fresh-cut melon. Food and Bioprocess Technology, 6(1), 80-91. doi:10.1007/s11947-011-0704-6

Fito, P. (1994). Modelling of vacuum osmotic dehydration of food. Journal of Food Engineering, 22(1), 313-328. doi:http://dx.doi.org/10.1016/0260-8774(94)90037-X

Fito, P., \& Pastor, R. (1994). Non-diffusional mechanisms occurring during vacuum osmotic dehydration. Journal of Food Engineering, 21(4), 513-519. doi:http://dx.doi.org/10.1016/0260$\underline{8774(94) 90070-1}$

Geankoplis, C. (1993). Transport Processes and Unit Operations. Prentice-Hall. New Jersey, USA.

George, J. M., Senthamizh Selvan, T., \& Rastogi, N. K. (2016). High-pressure-assisted infusion of bioactive compounds in apple slices. Innovative Food Science \& Emerging Technologies, 33, 100-107. doi:http://dx.doi.org/10.1016/j.ifset.2015.11.010

Germer, S. P. M., Ferrari, C. C., Lancha, J. P., Berbari, S. A. G., Carmello-Guerreiro, S. M., \& Ruffi, C. R. G. (2014). Influence of processing additives on the quality and stability of dried papaya obtained by osmotic dehydration and conventional air drying. Drying Technology, 32(16), 19561969. doi:10.1080/07373937.2014.924963 
Giovanelli, G., Brambilla, A., \& Sinelli, N. (2013). Effects of osmo-air dehydration treatments on chemical, antioxidant and morphological characteristics of blueberries. LWT-Food Science and Technology, 54(2), 577-584.

Giraldo, G., Talens, P., Fito, P., \& Chiralt, A. (2003). Influence of sucrose solution concentration on kinetics and yield during osmotic dehydration of mango. Journal of Food Engineering, 58(1), 3343.

Guillén, M., \& Manzanos, M. (2005). Characteristics of smoke flavourings obtained from mixtures of oak (Quercus sp.) wood and aromatic plants (Thymus vulgaris L. and Salvia lavandulifolia Vahl.). Flavour and fragrance journal, 20(6), 676-685.

Haizhen, M., Min, Z., \& Jincai, S. (2006). Effect of drying process parameters on dehydrated cabbage enriched with selenium. Drying Technology, 24(12), 1657-1663. doi:10.1080/07373930601031497

Hoagland, D. R., Davis, A. R., \& With the Assistance of, J. C. M. (1923). The composition of the cell sap of the plant in relation to the absorption of ions. The Journal of General Physiology, 5(5), 629646.

Hui, Y. H., \& Barta, J. z. (2006). Handbook of fruits and fruit processing (Vol. 1st; 1.). Ames, Iowa: Blackwell Pub.

Hui, Y. H., Cano, M. P., \& Gusek, T. W. (2008). Handbook of Fruits and Fruit Processing (1). Hoboken, US: Wiley-Blackwell.

Ic, E., Kottapalli, B., Maxim, J., \& Pillai, S. D. (2007). Electron beam radiation of dried fruits and nuts to reduce yeast and mold bioburden. Journal of Food Protection ${ }^{\circledR}, 70(4)$, 981-985.

Jalaee, F., Fazeli, A., Fatemian, H., \& Tavakolipour, H. (2011). Mass transfer coefficient and the characteristics of coated apples in osmotic dehydrating. Food and Bioproducts Processing, 89(4), $367-374$.

Jangam, S. V., Law, C. L., \& Mujumdar, A. S. (2010). Drying of foods, vegetables and fruits. ISBN- 978981-08-6759-1, Published in Singapore.(free download-http://serve. me. nus. edu. 
sg/arun/file/Publications/books/Drying\% 20of\% 20Foods\% 20Vegetables\% 20and\% 20Fruits\% 20Volume\% 201.pdf).

Jimenez-Garcia, S. N., Guevara-Gonzalez, R. G., Miranda-Lopez, R., Feregrino-Perez, A. A., TorresPacheco, I., \& Vazquez-Cruz, M. A. (2013). Functional properties and quality characteristics of bioactive compounds in berries: Biochemistry, biotechnology, and genomics. Food Research International, 54(1), 1195-1207. doi:http://dx.doi.org/10.1016/j.foodres.2012.11.004

Kebe, M., Renard, C., Amani, G., \& Maingonnat, J.-F. (2014). Kinetics of apple polyphenol diffusion in solutions with different osmotic strengths. Journal of Agricultural and Food Chemistry, 62(40), 9841-9847.

Ketata, M., Desjardins, Y., \& Ratti, C. (2013). Effect of liquid nitrogen pretreatments on osmotic dehydration of blueberries. Journal of Food Engineering, 116(1), 202-212.

Khan, M. A., Shukla, R., \& Zaidi, S. (2011). Mass transfer during osmotic dehydration of apple using sucrose, fructose and maltodextrin solution. Paper presented at the Published in the Proceedings of 11th International Congress on Engineering and Food-Athens, Greece.

Khan, M. R. (2012). Osmotic dehydration technique for fruits preservation-A review. Pakistan Journal of Food Sciences, 22(2), 71-85.

Konopacka, D., Jesionkowska, K., Mieszczakowska, M., \& Płocharski, W. (2008). The usefulness of natural concentrated fruit juice as osmotic agent for osmo-dehydrated dried fruit production. Journal of Fruit and Ornamental Plant Research, 16, 275-284.

Kowalski, S., \& Mierzwa, D. (2013). Influence of osmotic pretreatment on kinetics of convective drying and quality of apples. Drying Technology, 31(15), 1849-1855.

Koyuncu, T., Tosun, İ., \& Pınar, Y. (2007). Drying characteristics and heat energy requirement of cornelian cherry fruits (Cornus mas L.). Journal of Food Engineering, 78(2), 735-739. doi:http://doi.org/10.1016/j.jfoodeng.2005.09.035

Kucner, A., Klewicki, R., \& Sójka, M. (2013). The influence of selected osmotic dehydration and pretreatment parameters on dry matter and polyphenol content in highbush blueberry (vaccinium 
corymbosum 1.) Fruits. Food and Bioprocess Technology, 6(8), 2031-2047. doi:10.1007/s11947012-0997-0

Lazarides, H. N., Katsanidis, E., \& Nickolaidis, A. (1995). Mass transfer kinetics during osmotic preconcentration aiming at minimal solid uptake. Journal of Food Engineering, 25(2), 151-166.

Le Maguer, M., \& Yao, Z. (1995). Mass transfer during osmotic dehydration at the cellular level. Food Preservation by Moisture Control: Fundamentals and Applications, 325-350.

Lewicki, P. P., \& Lenart, A. (1995). 28 Osmotic Dehydration of Fruits and Vegetables.

Liu, R. H. (2003). Health benefits of fruit and vegetables are from additive and synergistic combinations of phytochemicals. AM J Clin Nutr, 78(3 Suppl), 517S-520S.

López, J., Uribe, E., Vega-Gálvez, A., Miranda, M., Vergara, J., Gonzalez, E., \& Di Scala, K. (2010). Effect of air temperature on drying kinetics, vitamin c, antioxidant activity, total phenolic content, non-enzymatic browning and firmness of blueberries variety óneil. Food and Bioprocess Technology, 3(5), 772-777. doi:10.1007/s11947-009-0306-8

Maga, J. A., \& Fapojuwo, O. O. (1986). Aroma intensities of various wood smoke fractions. Journal of Sensory Studies, 1(1), 9-13.

Maguer, M. L. (1997). Mass transfer modeling in structured foods. Food Engineering 2000, 253-269.

Mandala, I. G., Anagnostaras, E. F., \& Oikonomou, C. K. (2005). Influence of osmotic dehydration conditions on apple air-drying kinetics and their quality characteristics. Journal of Food Engineering, 69(3), 307-316. doi:http://dx.doi.org/10.1016/j.jfoodeng.2004.08.021

Marcotte, M., \& Le Maguer, M. (1992). Mass transfer in cellular tissues. Part II: Computer simulations vs experimental data. Journal of Food Engineering, 17(3), 177-199.

Martineau, L. C., Couture, A., Spoor, D., Benhaddou-Andaloussi, A., Harris, C., Meddah, B., .. . Haddad, P. S. (2006). Anti-diabetic properties of the Canadian lowbush blueberry Vaccinium angustifolium Ait. $\quad$ Phytomedicine, $\quad$ 612-623. doi:http://dx.doi.org/10.1016/j.phymed.2006.08.005 
Mauro, M. A., Dellarosa, N., Tylewicz, U., Tappi, S., Laghi, L., Rocculi, P., \& Rosa, M. D. (2016). Calcium and ascorbic acid affect cellular structure and water mobility in apple tissue during osmotic dehydration in sucrose solutions. Food Chemistry, 195, 19-28. doi:http://dx.doi.org/10.1016/j.foodchem.2015.04.096

Montazeri, N., Himelbloom, B. H., Oliveira, A., Leigh, M. B., \& Crapo, C. A. (2013). Refined liquid smoke: a potential antilisterial additive to cold-smoked sockeye salmon (Oncorhynchus nerka). Journal of Food Protection®, 76(5), 812-819.

Moreno, J., Chiralt, A., Escriche, I., \& Serra, J. A. (2000). Effect of blanching/osmotic dehydration combined methods on quality and stability of minimally processed strawberries. Food Research International, 33(7), 609-616. doi:http://doi.org/10.1016/S0963-9969(00)00097-1

NASS. (2014). $2014 \quad$ Blueberry $\quad$ Statistic. $\quad$ Retrieved from http://www.nass.usda.gov/Statistics by State/New Jersey/Publications/Blueberry Statistics/201 4\%20Blueberry\%20Statistics.pdf

Nile, S. H., \& Park, S. W. (2014). Edible berries: Bioactive components and their effect on human health. Nutrition, 30(2), 134-144. doi:http://dx.doi.org/10.1016/j.nut.2013.04.007

Nsonzi, F., \& Ramaswamy, H. (1998). Osmotic dehydration kinetics of blueberries. Drying Technology, $16(3-5), 725-741$.

Ochoa-Martinez, C. I., Ramaswamy, H. S., \& Ayala-Aponte, A. A. (2007). A Comparison of Some Mathematical Models Used for the Prediction of Mass Transfer Kinetics in Osmotic Dehydration of Fruits. Drying Technology, 25(10), 1613-1620. doi:10.1080/07373930701590665

Oprea, E., Ruta, L. L., Nicolau, I., Popa, C. V., Neagoe, A. D., \& Farcasanu, I. C. (2014). Vaccinium corymbosum L. (blueberry) extracts exhibit protective action against cadmium toxicity in Saccharomyces cerevisiae cells. Food Chemistry, 152, 516-521. doi:http://dx.doi.org/10.1016/j.foodchem.2013.12.020

Pallas, L. (2011). Drying methods and their effects on bioactive compounds and quality of Georgia blueberries. Unpublished doctoral dissertation]. Athens, GA: University of Georgia. 
Pan, Y., Zhao, L., Zhang, Y., Chen, G., \& Mujumdar, A. S. (2003). Osmotic dehydration pretreatment in drying of fruits and vegetables. Drying Technology, 21(6), 1101-1114.

Panagiotou, N. M., Karathanos, V. T., \& Maroulis, Z. B. (1998). Mass transfer modelling of the osmotic dehydration of some fruits. International Journal of Food Science \& Technology, 33(3), 267-284. doi:10.1046/j.1365-2621.1998.00167.x

Pathare, P. B., Opara, U. L., \& Al-Said, F. A.-J. (2013). Colour measurement and analysis in fresh and processed foods: a review. Food and Bioprocess Technology, 6(1), 36-60.

Peleg, M. (1988). An empirical model for the description of moisture sorption curves. Journal of Food Science, 53(4), 1216-1217.

Pino, J. A. (2014). Characterisation of volatile compounds in a smoke flavouring from rice husk. Food Chemistry, 153, 81-86.

Ponting, J., Watters, G., Forrey, R., Jackson, R., \& Stanley, W. (1966). Osmotic dehydration of fruits. Food Technology, 20(10), 1365-\&.

Ramaswamy, H., \& Nsonzi, F. (1998). Convective-air drying kinetics of osmotically pre-treated blueberries. Drying Technology, 16(3-5), 743-759.

Raoult-Wack, A.-L., Guilbert, S., Maguer, M. L., \& Rios, G. (1991). Simultaneous water and solute transport in shrinking media - PART 1. Drying Technology, 9(3), 589-612. doi:10.1080/07373939108916698

Rastogi, N., Angersbach, A., \& Knorr, D. (2000). Evaluation of mass transfer mechanisms during osmotic treatment of plant materials. JOURNAL OF FOOD SCIENCE-CHICAGO-, 65(6), 1016-1021.

Rastogi, N. K., Raghavarao, K. S. M. S., Niranjan, K., \& Knorr, D. (2002). Recent developments in osmotic dehydration: methods to enhance mass transfer. Trends in Food Science \& Technology, 13(2), 48-59. doi:http://dx.doi.org/10.1016/S0924-2244(02)00032-8

Ratti, C. (2001). Hot air and freeze-drying of high-value foods: a review. Journal of Food Engineering, 49(4), 311-319. doi:http://doi.org/10.1016/S0260-8774(00)00228-4 
Retamales, J. B., Hancock, J. F., \& ebrary, I. (2012). Blueberries (Vol. 21;no. 21.;). Cambridge, MA;Wallingford, Oxfordshire, UK;: CABI.

Rocha, A. M. C. N., \& Morais, A. M. M. B. (2003). Shelf life of minimally processed apple (cv. Jonagored) determined by colour changes. Food Control, 14(1), 13-20. doi:http://doi.org/10.1016/S0956-7135(02)00046-4

Rodrigues, A. E., \& Mauro, M. A. (2008). Effective diffusion coefficients behavior in osmotic dehydration of apple slices considering shrinking and local concentration dependence. Journal of Food Process Engineering, 31(2), 207-228.

Rudy, S., Dziki, D., Krzykowski, A., Polak, R., Biernacka, B., \& Kulig, R. (2013). Influence of osmotic dehydration on convective drying process of cherries. Teka Komisji Motoryzacji i Energetyki Rolnictwa, 13(1).

Sacchetti, G., Gianotti, A., \& Dalla Rosa, M. (2001). Sucrose-salt combined effects on mass transfer kinetics and product acceptability. Study on apple osmotic treatments. Journal of Food Engineering, 49(2-3), 163-173. doi:http://doi.org/10.1016/S0260-8774(00)00206-5

Sagar, V., \& Kumar, P. S. (2010). Recent advances in drying and dehydration of fruits and vegetables: a review. Journal of Food Science and Technology, 47(1), 15-26.

Saloko, S., Darmadji, P., Setiaji, B., \& Pranoto, Y. (2014). Antioxidative and antimicrobial activities of liquid smoke nanocapsules using chitosan and maltodextrin and its application on tuna fish preservation. Food Bioscience, 7, 71-79.

Salvatori, D., AndrÉS, A., Albors, A., Chiralt, A., \& Fito, P. (1998). Structural and Compositional Profiles in Osmotically Dehydrated Apple. Journal of Food Science, 63(4), 606-610. doi:10.1111/j.1365-2621.1998.tb15795.x

Santacruz-Vazquez, C., Santacruz-Vazquez, V., Jaramillo-Flores, M. E., Chanona-Perez, J., WeltiChanes, J., \& Gutiérrez-López, G. F. (2008). Application of osmotic dehydration processes to produce apple slices enriched with $\beta$-carotene. Drying Technology, 26(10), 1265-1271. 
Santacruz-Vázquez, C., Santacruz-Vázquez, V., Jaramillo-Flores, M. E., Chanona-Pérez, J., WeltiChanes, J., \& Gutiérrez-López, G. F. (2008). Application of Osmotic Dehydration Processes to Produce Apple Slices Enriched with $\beta$-Carotene. Drying Technology, 26(10), 1265-1271. doi:10.1080/07373930802307266

Shi, J., Pan, Z., McHugh, T. H., \& Hirschberg, E. (2009). Effect of Infusion Method and Parameters on Solid Gain in Blueberries. Food and Bioprocess Technology, 2(3), 271-278. doi:10.1007/s11947008-0116-4

Shi, J., Pan, Z., McHugh, T. H., Wood, D., Hirschberg, E., \& Olson, D. (2008). Drying and quality characteristics of fresh and sugar-infused blueberries dried with infrared radiation heating. $L W T$ $\begin{array}{llll}\text { Food } \quad \text { Science } \quad \text { and } & \text { Technology, }\end{array}$ doi:http://dx.doi.org/10.1016/j.lwt.2008.01.003

Silva, K. S., Garcia, C. C., Amado, L. R., \& Mauro, M. A. (2015). Effects of Edible Coatings on Convective Drying and Characteristics of the Dried Pineapple. Food and Bioprocess Technology, 8(7), 1465-1475. doi:10.1007/s11947-015-1495-y

Singh, B., Kumar, A., \& Gupta, A. K. (2007). Study of mass transfer kinetics and effective diffusivity during osmotic dehydration of carrot cubes. Journal of Food Engineering, 79(2), 471-480. doi:http://dx.doi.org/10.1016/j.jfoodeng.2006.01.074

Singh, B., Panesar, P. S., \& Nanda, V. (2008). Osmotic dehydration kinetics of carrot cubes in sodium chloride solution. International Journal of Food Science \& Technology, 43(8), 1361-1370. doi:10.1111/j.1365-2621.2007.01623.x

Sofos, J., Maga, J., \& Boyle, D. (1988). Effect of ether extracts from condensed wood smokes on the growth of Aeromonas hydrophila and Staphylococcus aureus. Journal of Food Science, 53(6), $1840-1843$.

Sosa, N., Salvatori, D. M., \& Schebor, C. (2012). Physico-Chemical and Mechanical Properties of Apple Disks Subjected to Osmotic Dehydration and Different Drying Methods. Food and Bioprocess Technology, 5(5), 1790-1802. doi:10.1007/s11947-010-0468-4 
Tiwari, R. (2005). Application of osmo-air dehydration for processing of tropical fruits in rural areas. Indian food industry, 24(6), 62-69.

Torreggiani, D., \& Bertolo, G. (2001). Osmotic pre-treatments in fruit processing: chemical, physical and structural effects. Journal of Food Engineering, 49(2), 247-253.

U.S. Department of Agriculture National Agricultural Statistics Service. (2015). West Virginia Annual Bulletin. $\quad$ Retrieved from https://www.nass.usda.gov/Statistics_by_State/West_Virginia/Publications/Annual_Statistical_B ulletin/index.php

USApples Association. (2015). The Production and Utilization Analysis for the 2015 U.S. Apple Association Apple Crop Outlook and Marketing Conference Retrieved from, Vienna, Virginia:

USDA. (2015a). Indiana Fruit Production 2014. (NR-15-06). Lansing MI: USDA Retrieved from http://www.nass.usda.gov/Statistics by State/Indiana/Publications/Current News Release/nr150 6in.pdf.

USDA. (2015b). USDA National Nutrient Database for Standard Reference Release 28. ( 09050, 09054, 09163). The National Agricultural Library: USDA Retrieved from http://ndb.nal.usda.gov/ndb/foods.

USDA. (2017). Outlook for US Agricultural Trade. Retrieved from USDA

USDANASS. (2017). Crop Production (1936-3737). Retrieved from

Van Duyn, M. A. S., \& Pivonka, E. (2000). Overview of the Health Benefits of Fruit and Vegetable Consumption for the Dietetics Professional: Selected Literature. Journal of the American Dietetic Association, 100(12), 1511-1521. doi:http://dx.doi.org/10.1016/S0002-8223(00)00420-X

Van Loo, E. J., Babu, D., Crandall, P. G., \& Ricke, S. C. (2012). Screening of commercial and pecan shell-extracted liquid smoke agents as natural antimicrobials against foodborne pathogens. Journal of Food Protection®, 75(6), 1148-1152. 
van Nieuwenhuijzen, N. H., Zareifard, M. R., \& Ramaswamy, H. S. (2001). Osmotic drying kinetics of cylindrical apple slices of different sizes. Drying Technology, 19(3-4), 525-545. doi:10.1081/DRT-100103932

Vega-Gálvez, A. A., Lemus-Mondaca, R. R., Tello-Ireland, C. C., Miranda, M. M., \& Yagnam, F. F. (2009). Kinetic study of convective drying of blueberry variety O'Neil (Vaccinium corymbosum L.).

Vitt, S. M., Himelbloom, B. H., \& Crapo, C. A. (2001). Inhibition of listeria innocua and L. monocytogenes in a laboratory medium and cold-smoked salmon containing liquid smoke. Journal of food safety, 21(2), 111-125.

Wang, Z., Wei, T., \& Zhang, M. (2015). Effects of vacuum and normal pressure impregnation on water loss and solid gain of apple (Malus Pumila Mill). Journal of Food Processing and Preservation, 39(6), 1045-1050.

West Virginia Agricultural Statistics (2004). West Virginia Orchard and Vineyard Survey, 2004. https://www.nass.usda.gov/Statistics_by_State/West_Virginia/Publications/Annual_Statistical_B ulletin/index.php

Wilford, L. G., Sabarez, H., \& Price, W. E. (1997). Kinetics of carbohydrate change during dehydration of d'Agen prunes. Food Chemistry, 59(1), 149-155. doi:http://dx.doi.org/10.1016/S0308$\underline{8146(96) 00272-5}$

Yadav, A. K., \& Singh, S. V. (2014). Osmotic dehydration of fruits and vegetables: a review. Journal of Food Science and Technology, 51(9), 1654-1673. doi:10.1007/s13197-012-0659-2

Yemmireddy, V. K., Chinnan, M. S., Kerr, W. L., \& Hung, Y.-C. (2013). Effect of drying method on drying time and physico-chemical properties of dried rabbiteye blueberries. LWT-Food Science and Technology, 50(2), 739-745.

Yu, L. (1998). Osmotic-Air Dehydration of Cherries and Blueberries. Msc Thesis. Department of Biosystem Engineering,. University of Manitoba, Winnipeg, Manitoba. Retrived from http://www.collectionscanada.gc.ca/obj/s4/f2/dsk2/tape17/PQDD_0003/MQ32286.pdf 
Chapter 2: Influence of Osmotic Solution Type on Osmotic Dehydration and Drying Characteristics of Fresh and Frozen Blueberries

Abstract

Use of apple juice concentrate as an osmotic solution was compared with a standard sugar-based osmotic solution, at same concertation, during osmotic dehydration (OD) at $50{ }^{\circ} \mathrm{C}$ of and following with air drying at $74{ }^{\circ} \mathrm{C}$ for Individually Quick Frozen (IQF) and fresh blueberries. Additionally, IQF and fresh blueberries were compared for moisture desorption characteristics using a thermo-gravimetric analyzer (TGA) under an isothermal condition $\left(105^{\circ} \mathrm{C}\right)$ to evaluate the influence of pre-freezing on overall liquid diffusion. Results showed that the use of apple juice as an osmotic solution increased IQF blueberry sugar concentration to $30.30{ }^{\circ}$ Brix, which was similar to that obtained from the use of sugar-based osmotic solution (32.90 ${ }^{\circ}$ Brix). Additionally, irrespective of the osmotic solution type, all samples reached the desired safe water activity $\left(a_{w}\right)$ range $(0.40-0.50)$ in the same drying time $(600 \mathrm{~min})$. Results from moisture desorption characteristics experiments showed that fresh blueberries took about $53 \%$ additional drying time compared to that of IQF. However, overall liquid diffusion coefficients for both IQF and fresh blueberries were found to be $8.72 \times 10^{-10} \mathrm{~m}^{2} / \mathrm{s}$ and $9.11 \times 10^{-10} \mathrm{~m}^{2} / \mathrm{s}$, respectively.

Key words: Blueberries, Osmotic Dehydration, Thermogravimetry, Air Drying, Sugar Solution, Apple Juice $^{1}$

\footnotetext{
${ }^{1}$ Published in journal of food science and technology(LWT) - Elsevier. Akharume, F. U., Singh, K., \& Sivanandan, L. (2016). Characteristics of apple juice and sugar infused fresh and frozen blueberries. LWT-Food Science and Technology, 73, 448-457.
} 


\subsection{Introduction}

Blueberries (Vaccinium Corymbosum L.), a high value economic but highly perishable product, are widely consumed fruit, owing to their nutraceutical and nutritive value (Giovanelli et al., 2013; JimenezGarcia et al., 2013; Martineau et al., 2006; Nile \& Park, 2014; Shi et al., 2008a). The United States is by far the largest producer of blueberries, with a total production (wild and cultivated) of 309 kilotons in 2014 (USDA, 2015).

Owning to their short shelf life, blueberries have to be preserved to ensure availability all year round. Direct air-drying, via convection, is one of the most widely used methods for preserving blueberries. However, direct air-drying of blueberries takes prolonged drying time, high energy input and may lead to non-uniform quality of the final product (Liping, 1998; Vega-Gálvez et al., 2012). To improve on the quality, drying time and overall energy cost of dried fruits, direct air-drying is generally preceded by the combination of pre-drying treatments, such as blanching, freezing, osmotic dehydration (OD), enzymes and chemical treatments (Vega-Gálvez et al., 2012). Osmotic dehydration (OD) is being widely applied as a pretreatment because it minimizes energy consumption and improves the quality of fruit by reduced heat damage to the fruit's texture, color and increased retention of volatiles as well as infused the berries with inexpensive sugar (Ketata et al., 2013; Azarpazhooh \& Ramaswamy, 2010; Shi et al., 2008a). During OD process, mass transfer kinetics are facilitated by several factors: size of the fruits (Shi et al., 2008b); pretreatments - liquid nitrogen, $\mathrm{NaOH}$ etc. (ketata et al., 2013; kucner et al., 2013); process conditions - contact time and temperature (Nsonzi \& Ramaswamy, 2008); osmotic agents - fructose, dextrose, polydextrose, sucrose, maltodextrin, and corn syrup (Shi. et al 2009; and many authors).

Traditionally, six-carbon sugars (sucrose or glucose) are widely used for making osmotic solutions; however, it makes dried product sugar-rich, a dietary concern among consumers striving to reduce calorie intake from added sugar. We visualize substituting six-carbon sucrose with 5-carbon sugars present in most fruit-juices, for example, apple juice concentrate. However, not much scientific data is available on 
the use of apple juice as an osmotic solution, either in terms of its effect on the yield of dried blueberries or on osmo-convective kinetics and behavior. Therefore, the following were the objectives for the present research: (1) evaluate the use of fruit (apple) juice concentrate as an osmotic solution during osmotic dehydration; (2) compare the osmo-convective drying behavior of osmotically dehydrated blueberries using fruit juice concentrate, with that using sugar-based solution; (3) compare influence of pre-freezing blueberries on the osmotic dehydration process; and (4) compare the moisture desorption characteristics of IQF and fresh blueberries using Thermogravimetric Analyzer (TGA) under an isothermal condition of $105^{\circ} \mathrm{C}$.

\subsection{Materials and Methods}

\subsubsection{Blueberries and Osmotic Agents}

Fresh blueberries (Bleuets, distributed by Sunbelle Inc. Miami FL. USA) and frozen blueberries (IQF) (Blue Crop and Blue Jay varieties, distributed by Kroger Co. Cincinnati OH. USA) were purchased from a retail store. The fresh blueberries were stored below $4{ }^{\circ} \mathrm{C}$ in a refrigerator and IQF blueberries were stored in a freezer below $-18{ }^{\circ} \mathrm{C}$ prior to use. For the purpose of physical characterization and moisture desorption characterization experiments, the frozen blueberries were thawed at room temperature for $2 \mathrm{~h}$ and blotted with tissue paper to remove excess water before use. However, for the osmotic dehydration treatment, frozen blueberries were used without thawing. Please note IQF and frozen are used interchangeably in this article.

To make the various osmotic solutions, granular sugar (Psst brand, distributed by Kroger Co. Cincinnati OH. USA) and apple juice concentrate (Kroger $100 \%$ juice apple frozen concentrated, distributed by Kroger Co. Cincinnati OH. USA) were purchased from a retail store. The apple juice concentrate had an initial sugar concertation of $42 \pm 2{ }^{\circ}$ Brix. Therefore, osmotic solutions from granular sugar were prepared at the same $42 \pm 2{ }^{\circ}$ Brix concentration. About $252 \mathrm{~g}$ granular table sugar was thoroughly mixed $348 \mathrm{~g}$ of deionized distilled water in a conical flask. For quick solubility of the sugar, the solution was heated to a 
temperature of $100{ }^{\circ} \mathrm{C}$ before it was cooled to room temperature prior to use. A cover of poly-film metallic foil prevented solution loss through evaporation during heating.

\subsubsection{Physical Characterization Measurements}

The three-significant axial dimensions (Fig. 9) of 100 randomly-selected fresh and IQF (thawed) blueberries were measured using an electronic Vernier caliper (least count $0.02 \mathrm{~mm}$ ). Effective diameter $\left(\mathrm{D}_{\mathrm{e}}\right)$, sphericity $(\phi)$, aspect ratio $\left(R_{A}\right)$ and surface area $\left(S_{A}\right)$ were calculated using the axial dimensions according to equations (1, 2, 3 and 4) given below (Jain, 1997; Mohsenin, 1986; Omobuwajo, 1999):

$$
\begin{aligned}
& \mathrm{D}_{\mathrm{e}}=(\mathrm{abc})^{1 / 3} \\
& \phi=\frac{\mathrm{D}_{\mathrm{e}}}{\mathrm{a}} \\
& R_{A}=\frac{b}{\mathrm{a}} \\
& S_{A}=\frac{\pi \mathrm{a}^{2}(\mathrm{bc})^{0.5}}{2 \mathrm{a}-(b c)^{0.5}}
\end{aligned}
$$

Where, $a$ is the major diameter $(\mathrm{mm}), b$ is the intermediate diameter $(\mathrm{mm})$, and $c$ is the minor diameter (mm).

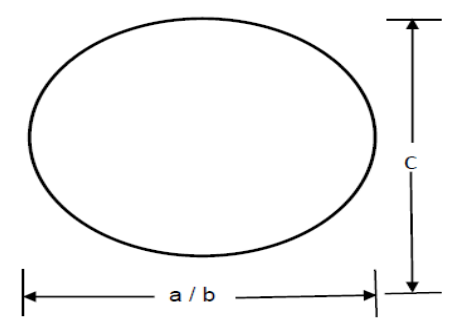

Figure 9. Schematic diagram of a typical blueberry showing the axial dimensions a (x-axis), b (yaxis), and c (z-axis) 
Additionally, the fresh and frozen (thawed) blueberry samples were characterized for moisture content, bulk density, true density, and volumetric moisture compression. The dried samples of fresh and frozen blueberries were also tested for volumetric shrinkage, bulk density and true density. Both fresh and IQF blueberries were assayed for initial moisture content according to the AACC method 44-15A (Moisture Air-Oven Methods) (AACC, 2000). The bulk density of fresh as well as oven-dried blueberries was measured according to ASTM standard (ASTM C29/C29M - 2009). To measure the true density, the actual volume of the samples, excluding pore volume, was measured using a multipycnometer (Model: MVP.6DC, Quantachrome, Boyton Beach, FL. USA). Volumetric shrinkage was calculated using equation 5.

$$
\text { Volumeric Shrinkage }=\frac{V_{\text {Green }}-V_{\text {Oven-dry }}}{V_{\text {Oven-dry }}} \times 100
$$

Additionally, volumetric compression of water present in the blueberries was calculated by following equation 6.

Volumetric Compression of Water $=\frac{\left(m_{\text {Green }}-m_{\text {Oven-dry }}\right) / \rho_{\text {Water }}-\left(V_{\text {Green }}-V_{\text {Oven }- \text { dry }}\right)}{\left(m_{\text {Green }}-m_{\text {Oven }- \text { dry }}\right) / \rho_{\text {Water }}} \times 100(6)$

Where, $m_{\text {Green }}$ is the weight of the fresh sample $(\mathrm{g}), m_{\text {Oven-dry }}$ is the weight of an oven-dried sample

$(\mathrm{g}), \rho_{\text {Water }}$ is the density of water $\left(\mathrm{g} / \mathrm{cm}^{3}\right), \mathrm{V}_{\text {Green }}$ is the volume of the green sample $\left(\mathrm{cm}^{3}\right)$, and $\mathrm{V}_{\text {Oven-dry }}$ is the volume of the oven-dried sample $\left(\mathrm{cm}^{3}\right)$.

\subsubsection{Moisture Desorption (Drying) Characteristics and Overall Liquid Diffusion Coefficient}

To investigate the drying characteristics of the samples, drying of fresh and IQF blueberries samples was carried out in a Thermogravimetric analyzer (TGA) (Model: TGA 701, LECO Corporation, IL) under constant nitrogen flow at the isothermal temperature of $105^{\circ} \mathrm{C}$. About $8 \mathrm{mg}$ of sample, replicated twice, was placed in a TGA crucible. The samples were heated from room temperature to $105^{\circ} \mathrm{C}$ at the rate of 
$16{ }^{\circ} \mathrm{C} /$ min under constant dry nitrogen flow to keep the relative humidity zero following an ASTM standard (ASTM, 2012). During the heating as well as during the isothermal drying, the weight of the sample, duration, and furnace temperature were recorded in a computer connected to the TGA. The weight-time-temperature data were further processed to produce drying characteristics curves (rate of weight loss as a function of time, moisture ratio or mean moisture content) and to calculate overall liquid diffusion coefficients.

The moisture content was calculated on a dry-basis as follows:

$$
M C_{i}=\frac{m_{0}-m_{i}}{m_{i}} \times 100
$$

Where, $M C_{i}$ is the dry-basis moisture content at $i^{\text {th }}$ time $(\%), m_{0}$ is the initial sample weight $(\mathrm{g}), m_{i}$ is the sample weight at $i^{\text {th }}$ time. For further calculations, fractional moisture content and drying rate $(d X / d t)$, were calculated according to equations (8 and 9) according to Geankoplis, (2003).

$$
\begin{gathered}
X_{i}=\frac{M C_{i}}{100} \\
D R=\frac{d X}{d t}=\frac{X_{i-1}-X_{i}}{t_{i-1}-t_{i}}
\end{gathered}
$$

Where, $X_{i}$ is moisture fraction at $i^{\text {th }}$ time, $d X / d t$ is drying rate $\left(\frac{g \text { of water }}{\text { gof dry solids.min }}\right)$ between $(i-1)^{\text {th }}$ and $i^{\text {th }}$ time intervals and at mean moisture fraction of $\left(\frac{X_{i-1}+X_{i}}{2}\right)$.

To compare drying behaviors of samples having different initial moisture contents, the moisture ratio was calculated to normalize moisture content at the $i^{\text {th }}$ interval with initial moisture contents, as given below (Chen et al., 2012)

$$
M R=\frac{M C_{i}-M C_{e}}{M C_{0}-M C_{e}}
$$


Where $M C_{0}$ is initial moisture content, $M C_{i}$ moisture content at $i^{\text {th }}$ time $t$, and $M C_{e}$ is the equilibrium moisture content, which is zero under the current experiments.

Overall liquid diffusion was assessed from the TGA data according to the procedure outlined by Geankoplis, (2003). According the procedure, the drying process of biological materials mostly occurs in the falling rate period. Fick's second law of diffusion (Eqn. 11) has been extensively used to describe the drying process and interpret drying data. The mathematical solution of Fick's second law for diffusion is shown in Equation. (12):

$$
\begin{gathered}
\frac{\partial M R}{\partial t}=\nabla\left[D_{e f f}(\nabla M R)\right] \\
M R=\frac{6}{\pi^{2}} \sum_{n=1}^{\infty} \frac{1}{n^{2}} \exp \left(-\frac{n^{2} \pi^{2} D_{e f f} t}{r^{2}}\right)
\end{gathered}
$$

Where $n$ is a positive integer, $t$ is the drying time(s), $D_{\text {eff }}$ is overall liquid diffusion coefficient $\left(\mathrm{m}^{2} / \mathrm{s}\right)$, and $r$ is the effective radius of the blueberries (m).

When the sample shrinkage is negligible, initial moisture distribution is uniform, and constant moisture diffusivity is assumed, Equation (12) is suitable for determining the $D_{\text {eff }}$. This equation could be further simplified into Equation 13 by taking the first terms of the series solution for long drying times (Ramaswamy \& Nsonzi, 1998; Shi et al., 2008a)

$$
\ln (M R)=\ln \left(\frac{6}{\pi^{2}}\right)-\left(\frac{\pi^{2} D_{e f f}}{r^{2}} t\right)
$$

Effective liquid diffusivities are typically determined by plotting experimental drying data in terms of $\ln (M R)$ vs. time. From equation (13), a plot of $\ln (M R)$ versus drying time, gives a straight line with a slope $\left(K_{o}\right)$

$$
K_{o}=\frac{\pi^{2} D_{e f f}}{r^{2}}
$$




\subsubsection{Osmotic Dehydration Experiments}

Osmotic dehydration was facilitated by soaking a desired fruit sample in an osmotic solution at a constant incubation temperature of $50{ }^{\circ} \mathrm{C}$. The fruit-to-solution weight ratio was targeted at $1: 3$. In a typical osmotic dehydration experiment, about $200 \mathrm{~g}$ of fruit sample was placed in about $600 \mathrm{~g}$ of the hot osmotic solution. The pre-formulated osmotic solution was heated up quickly to a designated temperature (100 $\left.{ }^{\circ} \mathrm{C}\right)$ before the blueberries were immersed. The fruit-solution mixtures were cooled to the target temperature of $50{ }^{\circ} \mathrm{C}$ before transferring to a Lab Line Imperial III incubator (Model: 305, Thermoscientific, IA. USA). Agitation in the incubator was provided by a platform shaker (Model: EXCELLA E2, New Brunswick Scientific Co. NJ. USA) set at $50 \mathrm{rpm}$. Sugar concentrations of the solution and blueberries were measured at intervals of $1 \mathrm{~h}$ by means of a Reichert Digital Refractometer, according to the method of Association of Official Analytics Chemist (AOAC) 990.35(Shi et al., 2009). After the blueberry concentration reached equilibrium with the solution, the blueberries were removed from the solution and rinsed with tap water for $30 \mathrm{~s}$ on a rubber mesh. They were then blotted with tissue paper to remove excess water. The final weight of the sample was recorded. Solid gain ( $S G, \mathrm{~g}$ water/g dry solid), and water loss (WL, g water/g dry solid) were calculated according to (Liping, 1998; Shi et al., 2009) as follows:

$$
\begin{aligned}
& S G=\frac{W *(1-M)}{W_{o} *\left(1-M_{o}\right)}-1 \\
& W L=\frac{W_{o} * M_{o}-W * M}{W_{o} *\left(1-M_{o}\right)}
\end{aligned}
$$

Where, $M$ is the moisture content of the sample after osmotic dehydration on a wet basis $(\%), M_{o}$ is the initial moisture content of the sample on a wet basis (\%), $W$ is the weight of the sample after osmotic dehydration $(\mathrm{g}), \mathrm{W}_{\mathrm{o}}$ is the weight of the sample before dehydration $(\mathrm{g}), S G$ is the solid gain of the sample on an initial dry matter basis ( $g$ solid $/ g$ dry solid), and $W L$ is the water loss of the sample on an initial dry matter basis ( $g$ water/g dry solid) 


\subsubsection{Air-Drying of Osmotically Dehydrated Blueberry Samples}

Osmotically dehydrated fruit samples were placed on tray and further air dried in a fruit dehydrator (Model: 3900T, Excalibur Products, CA. USA) in a climate-controlled room maintained at ambient condition of relative humidity $(43.00 \pm 5.00 \%)$ and temperature $\left(21.10 \pm 2.00{ }^{\circ} \mathrm{C}\right)$. During air-drying, the fruit dehydrator was maintained at $74{ }^{\circ} \mathrm{C}$. Only two of the dehydrator trays were used in the drying for efficient hot air circulation. The trays were placed in the middle of the dehydrator cabinet, directly facing the blower and separated one step from each other. Osmotically dried blueberries were spread uniformly on the tray and the trays were rotated clockwise at every $1 \mathrm{~h}$. Moisture content and water activity were measured at intervals of $1 \mathrm{~h}$. The water activity was measured using a water activity meter (Model: Aqua Lab Water Activity Meter series 3TE, Decagon Devices, Inc. WA. USA.). Additionally, moisture content was measured by recording the weight loss of a "20 g weighted representative sample", taken from the bulk sample, during drying. Air-drying was considered complete when the water activity reached a range of 0.45-0.5. After air-drying was complete, the representative sample was then oven-dried at $105{ }^{\circ} \mathrm{C}$ for $24 \mathrm{~h}$ for moisture measurement. The air-dried samples were then cooled to room temperature and weighed.

\subsubsection{Experimental design}

A completely randomized design was applied for the experiment. To compare osmotic dehydration of fresh and IQF blueberries, two treatments of fruit type (Fresh and IQF blueberries) were considered with three replications $(\mathrm{N}=6)$ for the pre-determined response variables (osmotic dehydration time, solid gain, water loss, and air-drying durations). To compare the influence of osmotic solutions, two treatments of osmotic solution type (sugar-based and apple juice based osmotic solutions) with three replications $(\mathrm{N}=6)$ were considered for the same response variables. Microsoft Excel 2010 was used in summarizing and generating graphs. The $t$-test procedure in SAS statistical software (University Edition) was used in performing a $t$ test (at $95 \%$ confidence interval). 


\subsection{Results and Discussion}

\subsubsection{Physical Characteristics of the Blueberries}

The fresh and frozen blueberry samples were characterized for the following physical characteristics: moisture content, shape characteristics, bulk and true densities. In addition, the same samples were ovendried and volumetric shrinkage, moisture compression, and bulk and true densities under dry conditions were calculated. Results of all physical characteristics are presented in Table 1. The fresh and frozen blueberry samples used in this study had moisture contents of $5.16 \mathrm{~g}$ water/g of dry solids and $5.70 \mathrm{~g}$ water/g of dry solids respectively, and upon thawing the moisture content of frozen berry reduced to 4.30 g water/g of dry solids, a $25 \%$ decrease. Similar values were reported by (Feng et al., 1999; Liping, 1998; Shi et al., 2008). Various shape characteristics results for fresh and frozen blueberries were within the range reported by other authors (Kaleta, 2011). After drying of the fresh blueberries, the true density increased to $1.72 \mathrm{~g} / \mathrm{cm}^{3}$, while the bulk density reduced to $0.20 \mathrm{~g} / \mathrm{cm}^{3}$. Total volumetric shrinkage of $88.10 \%$ took place as result of drying. Moisture content data showed that, on average, $69.51 \mathrm{~cm}^{3}$ of water was present in only $62.75 \mathrm{~cm}^{3}$ space, probably due to compression of water inside the blueberries. Therefore, on average, there was $9.75 \%$ volumetric compression of water. Thus, the density of water inside blueberries was taken to be $1.11 \mathrm{~g} / \mathrm{cm}^{3}$. Similarly, after drying of IQF blueberries, the true and bulk densities decreased to $0.96 \mathrm{~g} / \mathrm{cm}^{3}$ and $0.19 \mathrm{~g} / \mathrm{cm}^{3}$ respectively, the total volumetric shrinkage of $73.52 \%$ and on average $79.76 \mathrm{~cm}^{3}$ water was present in only $59.70 \mathrm{~cm}^{3}$ space. Statistically, the compression of water in the thawed blueberry was similar to that of the fresh ones. Therefore, the density of water inside the thawed IQF blueberries was $1.37 \mathrm{~g} / \mathrm{cm}^{3}$. 
Table1. Physical characteristics, mean (standard deviation) of fresh and IQF (thawed) blueberries.

\begin{tabular}{|c|c|c|c|}
\hline \multirow[b]{2}{*}{ Properties } & Fresh blueberries & $\begin{array}{l}\text { IQF blueberries } \\
\text { (thawed) }\end{array}$ & $\begin{array}{l}\text { Similar data from } \\
\text { literatures }\end{array}$ \\
\hline & Mean (SD) & $\operatorname{Mean}(\mathrm{SD})$ & Mean (SD) \\
\hline \multirow{2}{*}{$\begin{array}{l}\text { Moisture Content (g water/g dry } \\
\text { solid) } \\
\text { Volumetric Shrinkage (\%) }\end{array}$} & $5.16(0.20)$ & $4.30(0.19)$ & $\begin{array}{l}5.30 \text { (Liping 1998) } \\
4.71 \text { (Feng et al. 1999) }\end{array}$ \\
\hline & $88.10(1.28)$ & $73.52(15.07)$ & this work \\
\hline $\begin{array}{l}\text { Blueberry Moisture Compression } \\
(\%)\end{array}$ & $9.75(1.05)$ & $25.00(15.48)$ & this work \\
\hline \multicolumn{4}{|l|}{ Axial dimension $(\mathrm{mm})^{*}$} \\
\hline Major diameter, a & $15.10(1.32)$ & $12.26(1.82)$ & \\
\hline Interim. Diameter, b & $14.77(1.32)$ & $10.54(1.83)$ & \\
\hline Minor diameter, c & $10.83(0.85)$ & $6.29(1.26)$ & \\
\hline Effective diameter, $D_{e}$ & $13.41(1.04)$ & $9.28(1.38)$ & 10.40-17(Kaleta 2011) \\
\hline Sphericity, $\phi$ & $0.89(0.03)$ & $0.76(0.06)$ & 0.90-0.99(Kaleta 2011) \\
\hline Aspect ratio, $\mathrm{R}_{\mathrm{a}}$ & $0.98(0.03)$ & $0.92(0.37)$ & \\
\hline Surface area $\left(\mathrm{mm}^{2}\right)$ & $519.19(80.52)$ & $235.63(81.64)$ & \\
\hline \multicolumn{4}{|l|}{ Densities $\left(\mathrm{g} / \mathrm{cm}^{3}\right)$} \\
\hline True density & $1.18(0.00)$ & $1.16(0.01)$ & 0.70-1.20(Kaleta 2011) \\
\hline Bulk density & $0.35(0.01)$ & $0.39(0.01)$ & 0.22-0.83(Kaleta 2011) \\
\hline True density (dried) & $1.72(0.15)$ & $0.96(0.81)$ & this work \\
\hline Bulk density (dried) & $0.20(0.00)$ & $0.19(0.00)$ & this work \\
\hline
\end{tabular}

$*$ Values are averages of determinations for 100 blueberrie

\subsubsection{Moisture Desorption (Drying) Characteristics and Overall Liquid Diffusion Coefficient}

Drying characteristics of fresh and thawed IQF blueberries were determined in TGA equipment under isothermal drying at $105{ }^{\circ} \mathrm{C}$ under a dry nitrogen atmosphere. To understand how the moisture ratio changes over the drying time, Fig. 10 was plotted for the two samples. The IQF thawed blueberries showed a rapid decline in moisture ratio throughout the drying period when compared to the fresh ones. The fresh blueberries took about 260 min to completely dry whereas the IQF blueberries took only 170 min, about $53 \%$ less time. The rapid moisture loss in the IQF could be attributed to its ruptured surface and internal cell structure. 


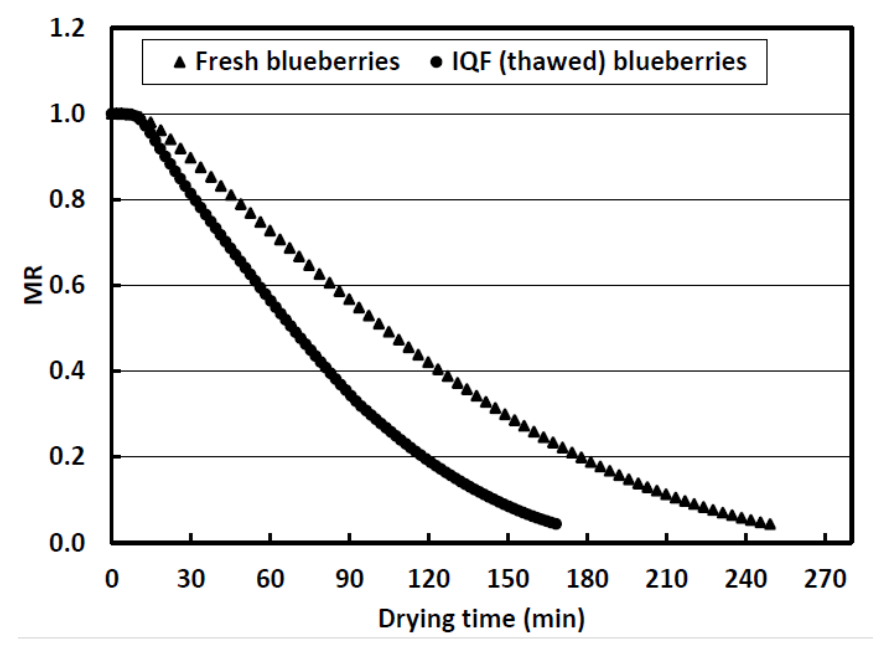

Figure 10. Relative moisture (moisture ratio) over the drying period performed at isothermal temperature of $105{ }^{\circ} \mathrm{C}$ in a thermogravimetric analyzer in dry nitrogen for fresh and IQF (thawed) blueberries.

IQF blueberries were observed to have fractures on their surface and internal tissues, which could possibly have enhanced the rapid escape of moisture during drying (Zielinska et al., 2015). Shi et al. reported a similar trend with the use of $\mathrm{NaOH}$ as a pretreatment prior to drying of blueberries (Shi et al., 2008b). They reported that water loss was increased by the pretreatment at temperature above $80{ }^{\circ} \mathrm{C}$ compared to the samples without pretreatment, which occurred as a result of cracks and deformations made to the fruit tissues clearly visible under the scanning electron microscope (SEM). Zielinska et al., reiterated that freezing/thawing reduces drying time of blueberries (by up to 29\%) compared to fresh ones (Zielinska et al., 2015). To better understand how the drying rate changes with moisture content of blueberries, drying characteristics curves were prepared (Fig. 11). Generally, drying of agriculture products has three different drying periods: 1. initial heating period, 2. constant rate period, and 3. falling rate period (Geankoplis, 2003). The falling rate period progressed in two distinct visible segments (slopes) along with an intermediate transition segment. The first falling rate segment is mainly due to moisture movement controlled by convective flow, which has gentler slope than the latter diffusion flow controlled drying segment (Geankoplis, 2003). In current experiments, there was no observation of a 
constant rate drying period, and the drying proceeded in only heating and falling rate periods. It took about $17 \mathrm{~min}$ to reach isothermal conditions of $105^{\circ} \mathrm{C}$. Fig. 3 also clearly shows that the drying rate was higher for IQF blueberries than the fresh blueberries throughout the moisture range.

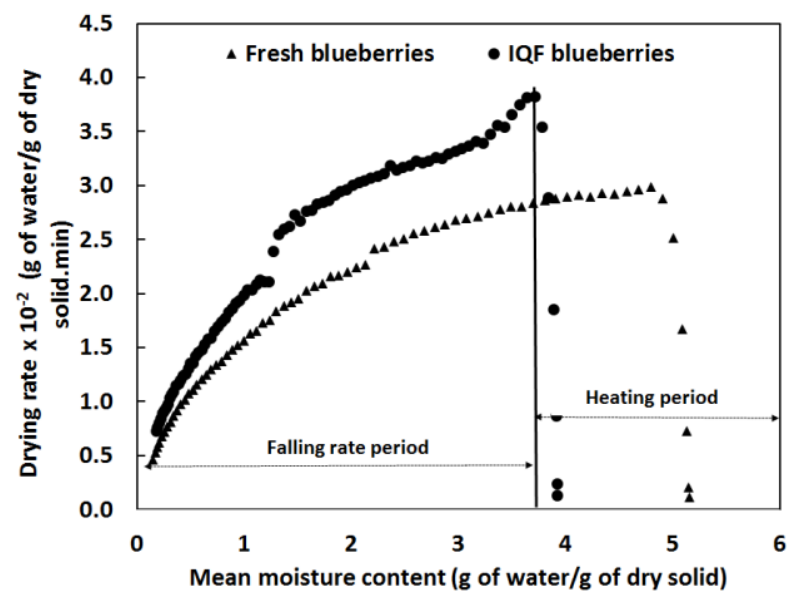

Figure 11. Relationship between drying rate (g of water evaporated per gr of drying fruit per minute) and mean moisture content of fresh and IQF (thawed) blueberries during drying under isothermal temperature of $105^{\circ} \mathrm{C}$ in the thermogravimetric analyzer under dry nitrogen

However, the drying rate declined for both samples as the drying progressed. At the start of drying, moisture present closer to the fruit surface quickly evaporated forming a dry shell encasing a moist core. In this situation, the blueberry took on a core-shell structure. The dried shell continuously grew over time compressing the moist core, which means moisture now had to travel through the dried shell via a “diffusion-in-solid"-dominated process; therefore, the slope of drying curve became less steep. Overall, liquid diffusion coefficients were also calculated for the moisture range of green (fresh) to the moisture content of $15 \%$ (w.b), which is the typical moisture content of commercially dried blueberries. The liquid diffusion coefficients for the IQF (thawed) and fresh blueberries were found to be $8.72 \times 10^{-10} \mathrm{~m}^{2} / \mathrm{s}$ and $9.11 \times 10^{-10} \mathrm{~m}^{2} / \mathrm{s}$, respectively, at the temperature of $105{ }^{\circ} \mathrm{C}$. To our knowledge, there is little information in literature on liquid diffusion coefficients for the drying of blueberries calculated from TGA measurements. The reported values of overall liquid diffusion coefficients are $0.24 \times 10^{-10}, 1.44 \times 10^{-10}$ and $12.11 \times 10^{-10} \mathrm{~m}^{2} / \mathrm{s}$ at temperatures of 40,60 , and $80{ }^{\circ} \mathrm{C}$, respectively for fresh blueberries using a 
laboratory oven dryer. Additionally, liquid diffusion coefficients for steam-blanched blueberries were reported to be $0.49 \times 10^{-10}, 1.93 \times 10^{-10} \mathrm{~m}^{2} / \mathrm{s}$ and $12.80 \times 10^{-10} \mathrm{~m}^{2} / \mathrm{s}$ at temperatures of 40,60 , and $80{ }^{\circ} \mathrm{C}$, respectively. There appears to be little difference in the values of liquid diffusion coefficients due to blanching; however, an increase in temperature does have a significant positive effect. (Liping, 1998).

\subsubsection{Comparing Fresh and IQF Blueberries during Osmotic Dehydration and Subsequent Air Drying}

The initial sugar concentration of blueberries was about $10.20{ }^{\circ}$ Brix for fresh and $12.50{ }^{\circ}$ Brix for IQF blueberries. Fresh and IQF blueberries were subjected to osmotic dehydration in a $42 \pm 2{ }^{\circ}$ Brix sugar solution at $50{ }^{\circ} \mathrm{C}$. During osmotic dehydration, the sugar concentration was continuously measured both for the blueberries and osmotic solution to determine when it becomes constant, which was an indication of completion of the osmotic process. As osmotic dehydration proceeds, the sugar concentration of blueberries tends to increase while the sugar concentration of the osmotic solution tends to decrease until an equilibrium is reached between sugar and water concentrations inside blueberries with that in the osmotic solution. Changes in sugar concentration of fresh blueberries and IQF blueberries and their respective osmotic solutions are presented in Fig. 12a and Fig. 12b.

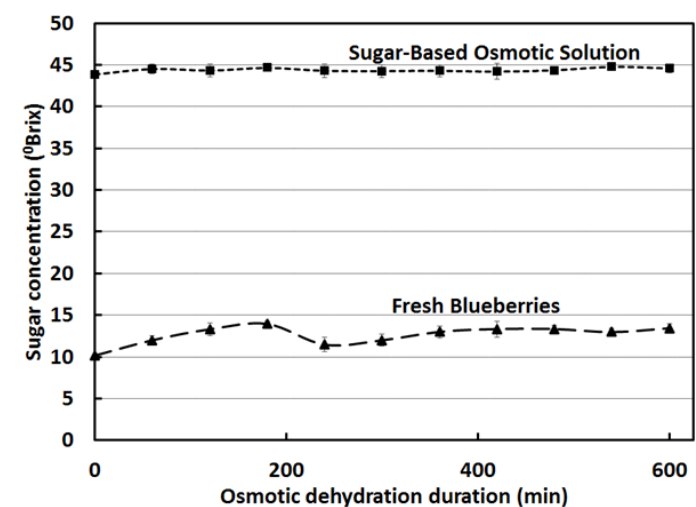

(a)

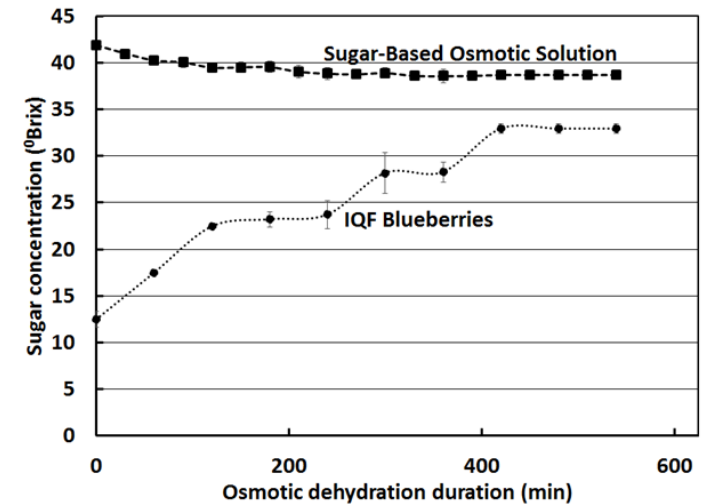

(b)

Figure 12. Variation of sugar concentrations over time for (a) fresh blueberries and its sugar-based osmotic solution and (b) IQF blueberries and its osmotic solution during osmotic dehydration performed at $50^{\circ} \mathrm{C}$ 
A quick observation of these figures indicates that it took an immersion time of about 420 mins for the sugar concentration to stabilize in the blueberries and the osmotic solution. In addition, there was barely any change in the sugar concentration of the osmotic solution for the fresh blueberries (Fig. 12a). However, the sugar concentration of the osmotic solution of IQF blueberries dropped quickly while the sugar concentration of the IQF blueberries increased significantly (Fig. 12b).

The IQF blueberries showed a steady increase in the sugar concentration from $12.50{ }^{\circ}$ Brix to $32.90{ }^{\circ}$ Brix in $420 \mathrm{~min}$ (Fig. 13). In contrast, the fresh blueberries showed an incremental increase from $10.20{ }^{\circ}$ Brix to $13.40{ }^{\circ}$ Brix in $200 \mathrm{~min}$ and remained so even after long hours of immersion (about $10 \mathrm{~h}$ ). The difference in the increase of sugar concentrations between the fresh and IQF blueberries may be explained by the fractured fruit skin and inner cell membranes of the IQF, caused as a result of freezing (Zielinska et al., 2015). Fractured IQF fruit skin and internal cells facilitate two-way diffusion and convective flow (facilitated by mechanical shaking). In the IQF blueberries, ruptured fruit skin does not put an osmotic barrier for sugar flow from the solution to inside the fruit.

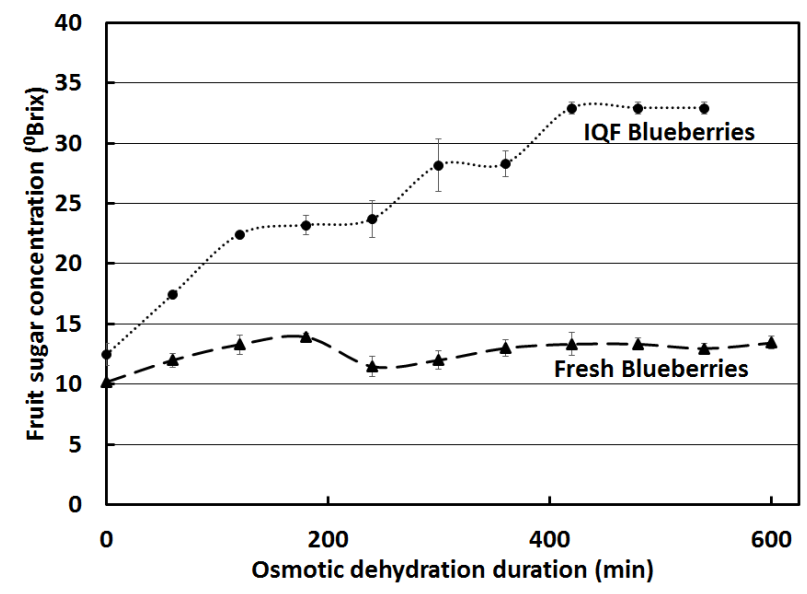

Figure 13. Increase in sugar concentrations for fresh and IQF blueberries during their osmotic dehydration with an osmotic solution at $50^{\circ} \mathrm{C}$. 
On the other hand, the fresh blueberries have a strong osmotic barrier due to their continuous skin, which does not permit sugar to flow easily inside of the fruit. Additionally, total solid gain and water loss of blueberries after osmotic dehydration were also calculated using fruit weight and moisture content before and after the osmotic process (Table 2). It is shown that, thrice as much solid was infused in frozen blueberries $(23 \%)$ compared to the fresh fruit at the end of the osmotic process, while simultaneously 3.9 times water was lost from the IQF berries $(181 \%)$. (Kucner et al., 2013) reported a water loss of $0.66 \mathrm{~g}$ of water per $\mathrm{g}$ of initial dry solid and a solid gain of $0.14 \mathrm{~g}$ dry solid per $\mathrm{g}$ of initial dry solid for osmotic dehydration of frozen blueberries without pretreatment (at $50{ }^{\circ} \mathrm{C}, 65^{\circ}$ Brix sucrose solution, fruit to syrup ratio of 1 to 4 for $240 \mathrm{~min}$ ) (Kucner et al. 2013). It has been generally reported that more water is lost than solid gained during the osmotic dehydration of fruits and vegetables (Azarpazhooh \& Ramaswamy, 2010). Fruit skin acts as an impediment to the infusion of a larger molecular weight sugar like sucrose. Moreover, the simultaneous leaching of the fruit acid into the osmotic solution causes accelerated hydrolysis of sucrose to glucose and fructose and leads to high water loss (Azarpazhooh \& Ramaswamy, 2010). Another observation from Table 2 is that IQF berries show a higher yield than fresh ones. A higher sugar gained is a proof of higher yield (Shi et al., 2009). Osmotically dehydrated fresh and IQF blueberries were further air dried in a fruit dehydrator. The fruit dehydrator was set for an air temperature of $74{ }^{\circ} \mathrm{C}$, the highest rating of the dehydrator model. During the air-drying, the ambient conditions were $21.10 \pm 2.00{ }^{\circ} \mathrm{C}$ and relative humidity of $44.00 \pm 5.00 \%$. Moisture content and water activity $\left(\mathrm{a}_{\mathrm{w}}\right)$ of the samples being dried were consistently monitored at preset intervals of $2 \mathrm{~h}$. Changes in water activity and moisture content during air-drying are shown in Fig. 6. Both the IQF and fresh blueberries showed a steady decline in water activity with drying time. However, for the first $600 \mathrm{~min}$, the $\mathrm{a}_{\mathrm{w}}$ and moisture content of the osmotically dried IQF blueberries showed more rapid decline than the osmotically dried fresh blueberries. Another observation from Fig. 6 is that the osmotically dried IQF blueberries reached an $a_{w}$ value of 0.4 in 420 min, which occurred at the moisture content of $0.05 \mathrm{~g}$ of water per $\mathrm{g}$ of dry solid. 


\section{Table 2}

Average moisture content, initial and final sugar concentration of fresh and IQF blueberries and solutions, solid gain and water loss from fruit, osmotic duration and yields during osmotic dehydration at $50^{\circ} \mathrm{C}$.

\begin{tabular}{|c|c|c|c|c|c|c|c|c|c|c|}
\hline \multirow[t]{2}{*}{ Fruit Type } & \multicolumn{2}{|c|}{$\begin{array}{l}\text { Moisture Content } \\
\text { (g/g of dry solid) }\end{array}$} & \multicolumn{2}{|c|}{$\begin{array}{l}\text { Solution Sugar } \\
\text { Concentration } \\
\left({ }^{\circ} \text { Brix }\right)\end{array}$} & \multicolumn{2}{|c|}{$\begin{array}{c}\text { Fruit Sugar } \\
\text { Concentration } \\
\left({ }^{\circ} \text { Brix }\right)\end{array}$} & \multirow[t]{2}{*}{$\begin{array}{c}\text { Solid Gain } \\
\text { (g/g of dry solid) }\end{array}$} & \multirow[t]{2}{*}{$\begin{array}{c}\text { Water Loss } \\
\text { (g/g of dry solid) }\end{array}$} & \multirow[t]{2}{*}{$\begin{array}{l}\text { OD duration } \\
\text { (min) }\end{array}$} & \multirow[t]{2}{*}{$\begin{array}{c}\text { Yield of OD } \\
\text { Fruit (\%) }\end{array}$} \\
\hline & Initial & $\overline{\text { Final }}$ & Initial & $\overline{\text { Final }}$ & Initial & $\overline{\text { Final }}$ & & & & \\
\hline Fresh & 5.16 & 4.39 & 43.80 & 44.60 & 10.20 & 13.40 & 0.07 & 0.47 & 600 & 93.51 \\
\hline Blueberries & $(0.20)$ & $(0.69)$ & & & & & $(0.02)$ & $(0.08)$ & & $(1.51)$ \\
\hline IQF & 5.70 & 3.97 & 41.80 & 38.60 & 12.50 & 32.90 & 0.23 & 1.81 & 420 & 76.33 \\
\hline Blueberries & (0.57) & $(0.14)$ & & & & & $(0.02)$ & $(0.04)$ & & $(0.77)$ \\
\hline
\end{tabular}

Standard deviation in parentheses. Replicate of two results 
On the other hand, osmotically dried fresh blueberries took $600 \mathrm{~min}$ to attain the same water activity at the same moisture content of $0.05 \mathrm{~g}$ of water per $\mathrm{g}$ of dry solid. A closer look at the chart shows that relative to the initial moisture content, osmotically dried IQF berries showed a higher moisture loss to reach the target water activity than the osmotically dried fresh blueberries. This was corroborated by the work of Shi et al. (2008a), as they observed that reduced drying times of sugar-infused blueberries compared to fresh ones can be attributed to two possible reasons: (1) low initial moisture content of the sugar infused blueberries (2) impediments posed by the infused sugar. Both effects result in lowering the drying rate and thus allowing osmotically dried blueberries to be dried at higher moisture to achieve the same water activity as dried fresh ones.

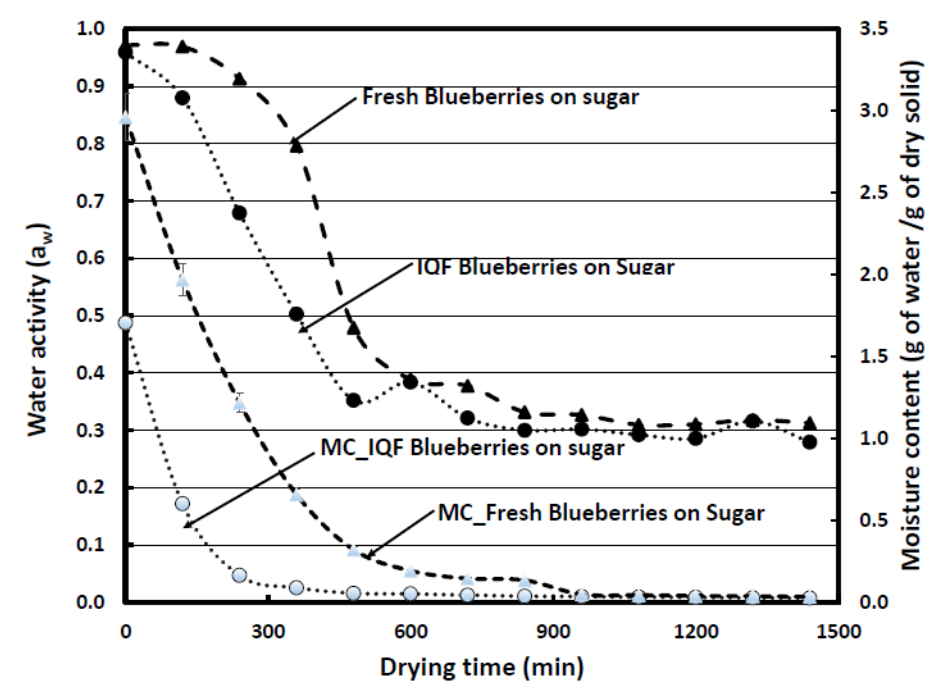

Figure 14. Decrease in water activity and moisture content (MC) during air-drying of osmotically dehydrated fresh and IQF blueberries in a fruit dehydrator at $74{ }^{\circ} \mathrm{C}$

\subsubsection{Comparing Sugar and Apple Juice-Based Osmotic Solutions during Osmotic Dehydration of IQF} Blueberries and Subsequent Air Drying

The IQF blueberries were subjected to osmotic dehydration in an apple juice-based osmotic solution $\left(42.00 \pm 2.00{ }^{\circ}\right.$ Brix) and in a sugar-based osmotic solution $\left(42.00 \pm 2.00{ }^{\circ}\right.$ Brix) at $50{ }^{\circ} \mathrm{C}$. Fig. 15 (a and b) shows changes in the blueberry and osmotic solution sugar concentrations as the osmotic dehydration 
progressed in two situations. In both situations, the sugar concentration in the fruit as well as in the solutions stabilized before 400 min incubation period. In fact, the osmotic process was completed in just 300 min when the apple juice-based solution was used.

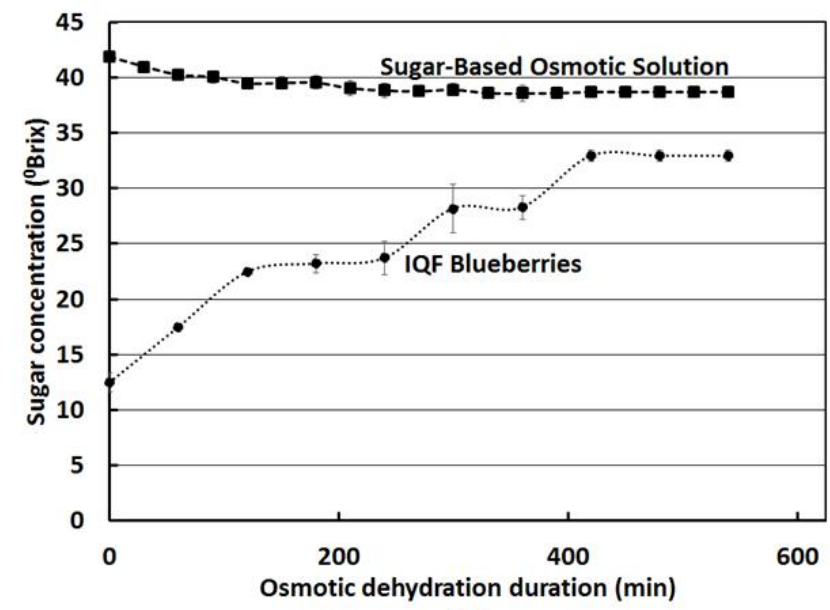

(a)

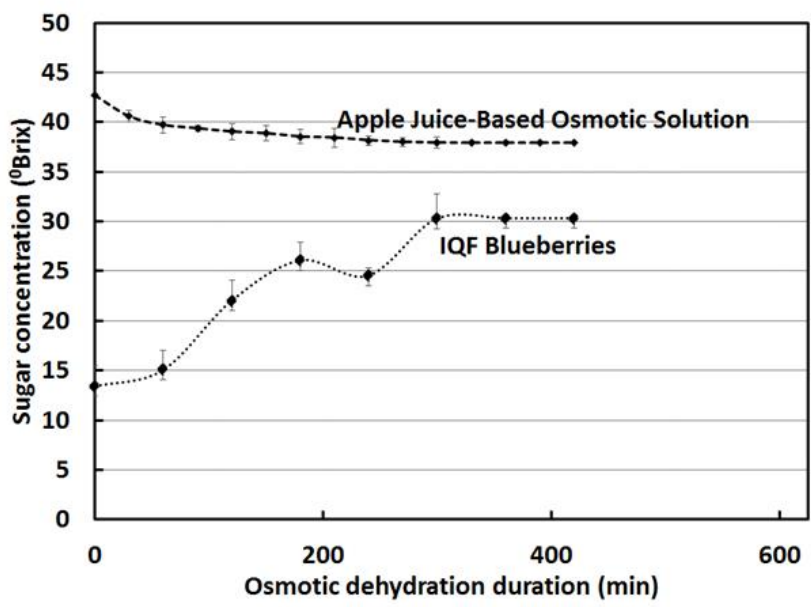

(b)

Figure 15. Variation of sugar concentrations over time for (a) IQF blueberries and its sugar-based osmotic solution and (b) IQF blueberries and its apple juice-based osmotic solution during osmotic dehydration performed at $50^{\circ} \mathrm{C}$.

Therefore, $400 \mathrm{~min}$ are sufficient to complete osmotic process for IQF blueberries in a $42.00 \pm 2.00{ }^{\circ} \mathrm{Brix}$ osmotic solution at $50{ }^{\circ} \mathrm{C}$, irrespective of solution type. The results of the osmotic dehydration studies indicate that the IQF blueberry sugar concentration increased from $12.50{ }^{\circ} \mathrm{Brix}$ to $30.30{ }^{\circ} \mathrm{Brix}$ when the apple juice-based osmotic solution was used and to $32.90{ }^{\circ}$ Brix when the sugar-based osmotic solution was used. There was no statistical difference in the final sugar concentration of the blueberry samples in the two situations (p-value>0.05) (Fig. 16). While the sugar concentration of the fruit increased, the concentration of sugar in both solutions decreased from an average value of $42.26^{\circ}$ Brix to $38.25^{\circ}$ Brix. 


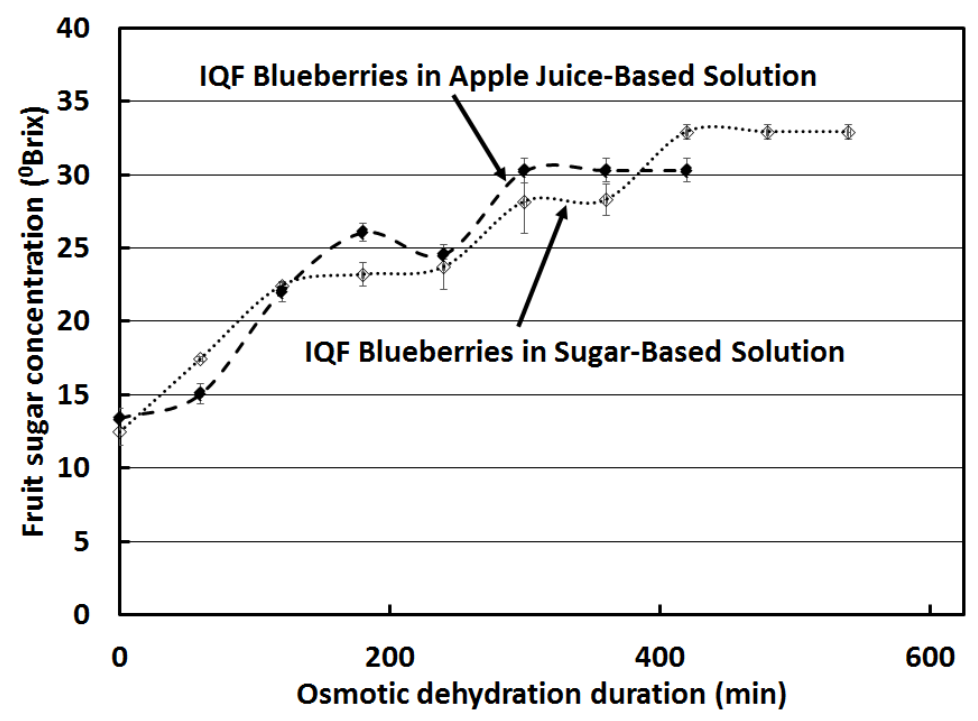

Figure 16. Sugar gained over immersion time for IQF blueberries in (1) sugar and (2) apple juice concentrate osmotic solution

It is observed in Fig. 16 that the sugar concentration of IQF blueberries increased in a nonlinear manner with time. The IQF berries pretreated with apple-based osmotic solution, initially showed a lower sugar gain (first $120 \mathrm{~min}$ ), followed by a higher sugar gain over the next $240 \mathrm{~min}$ than that for the fruit pretreated with sugar-based osmotic solution. It has been reported that most water loss and sugar gain are achieved at the first 1hour of the osmotic process (Azarpazhooh \& Ramaswamy, 2010). In another study, the highest water loss and solid gain were achieved at a contact time after $180 \mathrm{~min}$ (Kucner et al., 2013). Additionally, solid gain and water loss during osmotic dehydration were also calculated; these results are presented in Table 3. The type of osmotic solution did not show any significant difference in water loss. The water loses were 1.91 and $1.81 \mathrm{~g}$ of water per g of dry solids for apple juice-based and sugar-based solutions, respectively. However, types of osmotic solutions had significant effect of solid gains. The use of apple juice-based sugar solution showed solid gains of $0.53 \mathrm{~g}$ dry solid per $\mathrm{g}$ of initial dry solid, which was higher than that shown by the sugar-based solution ( $0.23 \mathrm{~g}$ dry solid per $\mathrm{g}$ of initial dry solid). Another observation from the table is that IQF immersed in apple juice solution shows a higher yield (79.31\%) than in sugar-based solution $(76.33 \%)$. 


\section{Table 3}

Average moisture content, initial and final sugar concentration of IQF blueberries and osmotic solutions (apple juice-based and sugar based), and solid gain in fruit and water loss during osmotic dehydration at $50^{\circ} \mathrm{C}$.

\begin{tabular}{|c|c|c|c|c|c|c|c|c|c|}
\hline \multirow[t]{2}{*}{$\begin{array}{c}\text { Osmotic solution } \\
\text { Type }\end{array}$} & \multicolumn{2}{|c|}{$\begin{array}{l}\text { Moisture Content } \\
\text { (g/g of dry solid) }\end{array}$} & \multicolumn{2}{|c|}{$\begin{array}{l}\text { Osmotic Solution } \\
\text { Concertation } \\
\left({ }^{\circ} \text { Brix }\right)\end{array}$} & \multicolumn{2}{|c|}{$\begin{array}{c}\text { IQF Blueberry } \\
\text { Sugar Concertation } \\
\left({ }^{\circ} \text { Brix }\right)\end{array}$} & \multirow[t]{2}{*}{$\begin{array}{c}\text { Solid Gain } \\
\text { (g/g of dry solid) }\end{array}$} & \multirow[t]{2}{*}{$\begin{array}{c}\text { Water Loss } \\
\text { (g/g of dry solid) }\end{array}$} & \multirow[t]{2}{*}{$\begin{array}{l}\text { Yield of OD Fruit } \\
\qquad(\%)\end{array}$} \\
\hline & Initial & Final & Initial & Final & Initial & Final & & & \\
\hline Apple-Juice-Based & $5.70(0.57)$ & $2.99(0.44)$ & 42.70 & 37.90 & 13.40 & 30.30 & $0.53(0.01)$ & $1.91(0.01)$ & $79.31(0.21)$ \\
\hline \multicolumn{10}{|l|}{ Solution } \\
\hline Sugar-based & $5.70(0.57)$ & $3.97(0.14)$ & 41.80 & 38.60 & 12.50 & 32.90 & $0.23(0.02)$ & $1.81(0.04)$ & $76.33(0.77)$ \\
\hline Osmotic Solution & & & & & & & & & \\
\hline
\end{tabular}

Standard deviation in parentheses. Replicate of two results 
The changes in water activity of osmotically dried IQF blueberries using apple juice and sugar-based osmotic solution, during air-drying in a fruit dehydrator set at $74{ }^{\circ} \mathrm{C}$, are presented in Fig. 17. The data shows that both samples demonstrated a steady decline in water activity with drying time. However, IQF fruit immersed with the sugar-based osmotic solution showed a much more rapid decline for the first 600 min. Moreover, it took a drying time of $420 \mathrm{~min}$ to reach a water activity of 0.4 at a moisture content of $0.05 \mathrm{~g}$ of water per $\mathrm{g}$ of dry solids for the IQF berries immersed in the sugar-based osmotic solution. For the same water activity, it took $480 \mathrm{~min}$ at a moisture content of $0.09 \mathrm{~g}$ of water per $\mathrm{g}$ of dry solids for the IQF berries immersed in the apple juice osmotic solution. The difference in drying time could be attributed to a higher solid gain by the latter sample which slows down the drying rate (Shi et al., 2008).

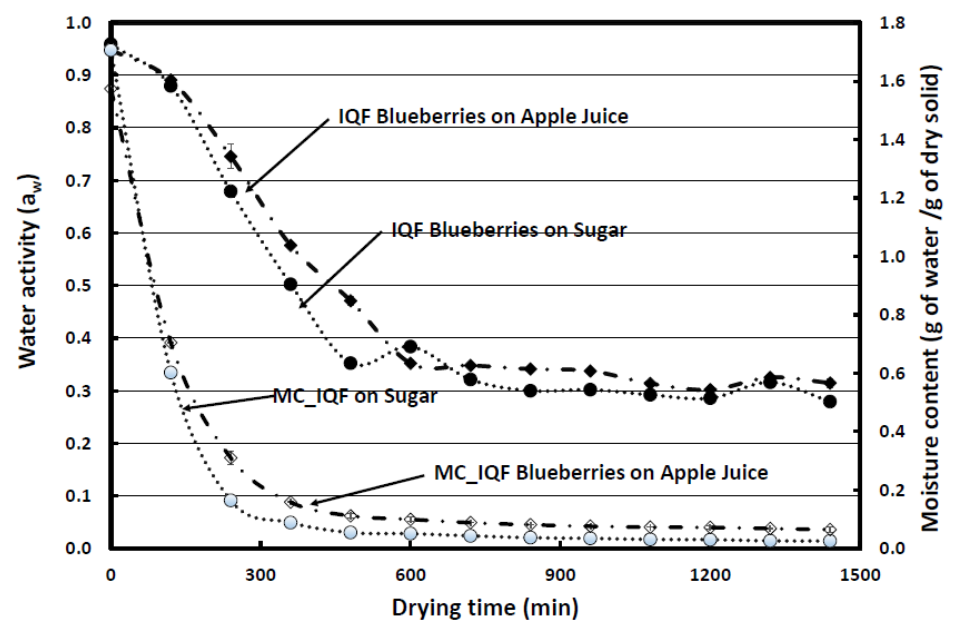

Figure 17. Decrease in water activity of osmotically dehydrated IQF blueberries using sugar-based and apple juice-based osmotic solutions in a fruit dehydrator at $74^{\circ} \mathrm{C}$

\subsection{Conclusion}

It was established from this research that the effect of freezing the fruit prior to hot air drying showed a significant reduction in drying time (53\% reduction) to reach $0.18 \mathrm{~g}$ water $/ \mathrm{g}$ of dry solid compared with the fresh blueberries. IQF and fresh berries followed the convectional drying characteristic curves typical 
of fruits, where only falling rate period but no constant rate regime exists. The drying behavior and higher drying rate of the IQF berries were facilitated by the ruptured nature of the berries' waxy skin caused by freezing.

Moreover, the use of osmotic dehydration prior to drying significantly reduces the moisture content of the IQF fruit by about $30 \%$ (from $5.70-3.97 \mathrm{~g}$ of water/g of dry solid) and fresh blueberries by $15 \%$ (5.16$4.3997 \mathrm{~g}$ of water/g of dry solid). Additionally, an apple juice-based osmotic solution led to higher solid gains in the IQF blueberries than that from a sugar-based osmotic solution. On the subsequent hot air drying, the IQF berries treated with sugar-based solution showed a shorter drying time of 420 min than that treated with apple juice-based solution $(480 \mathrm{~min})$ to achieve a water activity of 0.4 . Therefore, fruit juice concentrates (for example, apple juice) may be used as an osmotic solution substitute forgranular sugar without compromising final yield of the dried blueberries.

Acknowledgements- This work is partially supported by the USDA National Institute of Food and Agriculture, McIntire Stennis project 0222863 and 1007044. In addition, support was also provided by West Virginia University (WVU) Public Service Grant Award\# P-14-006, WVU ADVANCE/Sponsorship Program, and WVU Extension Service- Families and Health Programs.

Authors also acknowledge Dr. John W. Zondlo, Professor, Department of Chemical Engineering, West Virginia University for providing technical review and proofreading of this manuscript. 


\section{References}

American Association of Cereal Chemists. (2000). Approved Methods of the AACC (10th ed.) (Method 44-15A). St. Paul, Minn: The Association

American Society for Testing Materials. (2012). Standard Test Method for Ash in the Analysis Sample of Coal and Coke from Coal; ASTM D3174-12. West Conshohocken, Pa.

American Society for Testing Materials. (2009). Standard Test Method for Ash in the Analysis Sample of Coal and Coke from Coal; ASTM C29/C29M -09. West Conshohocken, Pa.

Azarpazhooh, E. \& Ramaswamy, H. S. (2010). Osmotic dehydration. In S. V. Jangam, C.L. Law \& A.S. Mujumdar, A.S. (Eds.), Drying of Foods, Vegetables and Fruits. (Vol. 1, pp. 83-110). Singapore. Retrived from

http://www.arunmujumdar.com/file/Publications/books/Drying\%20of\%20Foods\%20Vegetables\%20and \%20Fruits\%20Volume\%201.pdf.

Chen, D., Zheng, Y., \& Zhu, X. (2012). Determination of effective moisture diffusivity and drying kinetics for poplar sawdust by thermogravimetric analysis under isothermal condition. Bioresource technology, 107, 451-455.

Feng, H. A. O., Tang, J., Mattinson, D. S., \& Fellman, J. K. (1999). Microwave and spouted bed drying of frozen blueberries: the effect of dryingand pretreatment methods on physical properties and retention of flavor volatiles. Journal of Food Processing and Preservation, 23(6), 463-479. doi: 10.1111/j.1745-4549.1999.tb00398.x

Geankoplis, C. (2003). Transport processes and separation process principles (includes unit operations): Prentice Hall Press.

Giovanelli, G., Brambilla, A., \& Sinelli, N. (2013). Effects of osmo-air dehydration treatments on chemical, antioxidant and morphological characteristics of blueberries. LWT - Food Science and Technology, 54(2), 577-584. doi:http://dx.doi.org/10.1016/j.lwt.2013.06.008

Jain, R. K. \& Bal, S. (1997). Physical properties of pearl millet. Journal of Agricultural Engineering Research (66). 
Jimenez-Garcia, S. N., Guevara-Gonzalez, R. G., Miranda-Lopez, R., Feregrino-Perez, A. A., TorresPacheco, I., \& Vazquez-Cruz, M. A. (2013). Functional properties and quality characteristics of bioactive compounds in berries: Biochemistry, biotechnology, and genomics. Food Research International, 54(1), 1195-1207. doi: http://dx.doi.org/10.1016/j.foodres.2012.11.004

Kaleta, A. \& Górnicki, K. (2011). Databases on physical properties of plants and agricultural products. In J. Gliński, J. Horabik \& J. Lipiec (Eds.), Encyclopedia of Agrophysics (pp. 189-194). Dordrecht: Springer Netherlands

Ketata, M., Desjardins, Y., \& Ratti, C. (2013). Effect of liquid nitrogen pretreatments on osmotic dehydration of blueberries. Journal of Food Engineering, 116(1), 202-212. doi: http://dx.doi.org/10.1016/j.jfoodeng.2012.10.035

Kucner, A., Klewicki, R., \& Sójka, M. (2013). The influence of selected osmotic dehydration and pretreatment parameters on dry matter and polyphenol content in highbush blueberry (vaccinium corymbosum 1.) fruits. Food and Bioprocess Technology, 6(8), 2031-2047. doi: 10.1007/s11947012-0997-0

Liping, Y. (1998). Osmotic-Air Dehydration of Cherries and Blueberries. Msc Thesis. Department of Biosystem Engineering,. University of Manitoba, Winnipeg, Manitoba. Retrived from http://www.collectionscanada.gc.ca/obj/s4/f2/dsk2/tape17/PQDD_0003/MQ32286.pdf

Martineau, L. C., Couture, A., Spoor, D., Benhaddou-Andaloussi, A., Harris, C., Meddah, B., .. Haddad, P. S. (2006). Anti-diabetic properties of the Canadian lowbush blueberry Vaccinium angustifolium Ait. $\quad$ Phytomedicine, 13(9-10), 612-623. doi: http://dx.doi.org/10.1016/j.phymed.2006.08.005

Mohsenin, N. N. (1986). Physical properties of plant and animal materials : Structure, physical, characteristics and mechanical properties. Amsterdam: Gordon and Breach Science Publishers.

Nile, S. H., \& Park, S. W. (2014). Edible berries: Bioactive components and their effect on human health. Nutrition, 30(2), 134-144. doi: http://dx.doi.org/10.1016/j.nut.2013.04.007 
Nsonzi, F., \& Ramaswamy, H. S. (1998). Osmotic dehydration kinetics of blueberries. Drying Technology, 16(3-5), 725-741. doi:10.1080/07373939808917432

Omobuwajo, T. O., Akande, E. A. \& Sanni, L. A. (1999). Selected physical, mechanical and aerodynamic properties of african breadfruit (treculia africana) seeds. Journal of Food Engineering, 40(4), 241-244.

Ramaswamy, H., \& Nsonzi, F. (1998). Convective-air drying kinetics of osmotically pre-treated blueberries. Drying technology, 16(3-5), 743-759.

Shi, J., Pan, Z., McHugh, T. H., \& Hirschberg, E. (2009). Effect of infusion method and parameters on solid gain in blueberries. Food and Bioprocess Technology, 2(3), 271-278. doi: 10.1007/s11947008-0116-4

Shi, J., Pan, Z., McHugh, T. H., Wood, D., Hirschberg, E., \& Olson, D. (2008a). Drying and quality characteristics of fresh and sugar-infused blueberries dried with infrared radiation heating. $L W T$ Food Science and Technology, 41(10), 1962-1972.

doi: $\underline{\text { http://dx.doi.org/10.1016/j.1wt.2008.01.003 }}$

Shi, J., Pan, Z., McHugh, T. H., Wood, D., Zhu, Y., Avena-Bustillos, R. J., \& Hirschberg, E. (2008b). Effect of berry size and sodium hydroxide pretreatment on the drying characteristics of blueberries under infrared radiation heating. Journal of Food Science, 73(6), E259-E265. doi: $10.1111 / \mathrm{j} .1750-3841.2008 .00816 . x$

United States Department of Agriculture (USDA). (2015). National Statistics for blueberries. Retrived from: http://www.nass.usda.gov/Statistics_by_Subject/index.php

Vega-Gálvez, A., Lara, E., Flores, V., Di Scala, K., \& Lemus-Mondaca, R. (2012). Effect of selected pretreatments on convective drying process of blueberries (var. o'neil). Food and Bioprocess Technology, 5(7), 2797-2804. doi: 10.1007/s11947-011-0656-x

Zielinska, M., Sadowski, P., \& Błaszczak, W. (2015). Freezing/thawing and microwave-assisted drying of blueberries (Vaccinium corymbosum L.). LWT - Food Science and Technology, 62(1, Part 2), 555-563. doi: http://dx.doi.org/10.1016/j.lwt.2014.08.002 
Chapter 3: Effects of Liquid Smoke on the Osmotic Dehydration Kinetics of Fresh Apple Cubes.

\begin{abstract}
In this research, influence of addition of Refined Liquid Smoke (RLS) (1\% w/w) to sugar-based Osmotic Solution (OS) (42 ${ }^{\circ}$ Brix) was evaluated during osmotic dehydration (OD) of apples. Cubes of $10 \mathrm{~mm}$ each side were cut from peeled apples and subjected to OD at the incubation temperature of $50{ }^{\circ} \mathrm{C}$ and over a range of OD duration (5 - $240 \mathrm{~min}$.). Influence of addition of RLS was evaluated for selected kinetic variables: solid gain, water loss, dry matter content, soluble solid content, and moisture content. Results showed that addition of RLS during OD significantly increased solid gained, dry matter content, and solid soluble content in apple cubes compared to control OD. In fact, solid gain, dry matter content and solid soluble content were 1.43 g/g.d.s., 3.16 g/g.d.s., and $34.79 \%$ w/w, respectively after a $240 \mathrm{~min}$ for the RLS addition. As result of RLS addition, the sugar concentration in apple cubes increased from $9.90{ }^{\circ}$ Brix to $33.8{ }^{\circ}$ Brix whereas it was $31.02{ }^{\circ}$ Brix for control treatment. Effective diffusion coefficients for solid gain $(2.94 \times 10-10 \mathrm{~m} 2 / \mathrm{s})$ were the same for both control and RLS added OD; however, effective diffusion coefficients for water loss were $7.34 \times 10-10 \mathrm{~m} 2 / \mathrm{s}$ and $4.40 \times 10-10 \mathrm{~m} 2 / \mathrm{s}$, respectively for control and RLS added OD.
\end{abstract}

Keywords: Osmotic dehydration (OD), Liquid smoke, Kinetics, Diffusion coefficient, Apples. ${ }^{2}$

\footnotetext{
${ }^{2}$ Prepared manuscript for submission to LWT
} 


\subsection{Introduction}

Apples are among the predominant fruit crops in the United States market. In the United States, the total apple production in the year 2014 was reported to be 5.2 million tons (11,431.2 million pounds), which was $10 \%$ higher than the year 2013 and 13\% higher than the five-year average (2010-2014) (USApples Association, 2015). West Virginia ranked ninth amongst apple producing states in the United States, with Washington State remaining in the first spot having a total production above half of the US total production for each year (USDA_NASS, 2015). Apple production in the West Virginia is concentrated primarily in four counties (Berkeley, Hampshire, Jefferson, and Morgan County). In the state of West Virginia apple production acreage has been declining over the years although production remain relatively stable. For example, bearing acreage decreased from 4300 acres to 4100 acres in 2014; similarly, total apple production in the state was 37.2 kilotons (82 million pounds) in the year 2014, a $14 \%$ decrease from the previous year. The major reason for the decline may be attributed partly to the fall out of less efficient and small farmers from the industry, due to competition from high production farmers with integrated production and supply-chain; and partly due to the decline in the consumer taste for red delicious apple, which is a predominant variety in the US (Brendan, 2010). The sales contracts between high production farmers and packers threw small farmers out of business. The small farmer do not have direct sales at fresh produce consumer market because large retail outlets prefer to do business with consolidated packers to ensure all year round supplies. Therefore, small farmers must process their apples into value-added food products.

According to the United States Department of Agriculture report, the total utilized production was 37.2 kilotons (82 million pounds) with no quantity recorded for un-harvested or not sold for the state of West Virginia (USDA_NASS_WV, 2015). The report further states that the value of utilized production was $\$ 12.4$ million, a 4\% less than 2013 and $10 \%$ less than five-year average. Of the total utilized production in 2014, fresh fruits accounted for $21 \%$ and whereas processed fruits accounted for $79 \%$, which remained 
consistent over past five-year period. The report states that only $2 \%$ of the processed apples goes into processing other than canning and juice making, possibly dried, frozen and others.

Dried apples represent about $1.6 \%$ of US total utilized apple production for $2014,0.06 \%$ higher than the previous years and $0.1 \%$ less that 5- year average (USApples Association, 2015). The total value from US dried apples for 2014 was $\$ 11,946,000$ down by $\$ 3,430,000$ in 2013 and by $\$ 3,391,200$ less than fiveyear average. While market for dried apples had decreased, small farmers have an economic opportunity to harvest and dry their apples and compete for the dried apple market and not for the fresh apple market.

Apples have been reported to be rich in fiber, protein, sugars, $\beta$-carotene, vitamins, $\mathrm{Ca}, \mathrm{Mg}$, $\mathrm{K}$, phenolic compounds and other trace minerals (Feliciano et al., 2010). Daily consumption of apples has been linked with reduced risk of some types of cancers, cardiovascular disease, asthma, and diabetes (Boyer \& Liu, 2004). However, perishability due to high moisture content, (<84\% w.b.) (Feliciano et al., 2010) is a major barrier to small-scale storage at small farms. Therefore, an option for small farmers would be to transform their harvested apples into dried product through a combination of osmotic dehydration (OD) and air-drying to make it energy efficient and cost effective.

Osmotic dehydration (OD) is a method that has been widely used to produce minimally processed fruits that are used in cereals, jams, ice-cream or bakery products and to produce functional fruits, and fruits fortified minerals or additives (Santacruz-Vazquez et al., 2008). OD process is often times in combination with freeze-drying (Tregunno \& Goff, 1996), convective hot air-drying (Akharume et al., 2016), and microwave drying (Askari et al., 2006) to produce dried fruit snacks. The OD mechanism involves a twoway process of water loss and solid gain without a phase change of liquid water to vapor. Fruit is placed in a hypertonic solution of edible solute, usually an aqueous solution of sucrose, glucose, maltodextrin etc. Consequently, osmotic pressure is initiated due to the concentration gradient between the fruit's cell microstructure and ambient osmotic solution. Thus, a simultaneous moisture removal from the fruit matrix into the solution and solid infusion from the solution into the fruit matrix occurs. In addition, 
leaching of polyphenols, vitamins, and other minerals from fruit to the solution are observed in negligible magnitude. Osmotic dehydration is a partial water removal process and it has been reported to reduce fruit's moisture to about $50 \%$ and to a water activity $\left(\mathrm{a}_{\mathrm{w}}\right)$ in the range of $0.94-0.97$ (Yadav \& Singh, 2014). Therefore, OD is often followed up with other energy intensive drying techniques to reduce the moisture content as well as the water activity beyond the growth of most bacteria, mold and yeast (Beuchat, 1981).

Although a high-water loss is desired during OD, dehydration leads to reduced weight, a concern for some intermediate and dried fruit processors desiring a good return on investment. For example, in OD application for jam production, a 60\% dry matter in the solid /liquid mixture is needed (Allali et al., 2010) and (Albagnac et al., 2002). The amounts of solute infused into the fruit during OD not only compensate for the loss of moisture, but also increase fruit stability and volatile retention. An increase of up to $25 \%$ soluble solids content greatly improves volatile retention and final products exhibit good flavor, texture, sweetness, and long shelf stability (Torreggiani, 1993). The type and concentration of OS solution used affects greatly the ratio of solid gain to water loss index. Various research has used different osmotic solutions or combination of solutions and additives to evaluate the kinetics of osmotic dehydration and improve the functional and sensory quality of the resultant products. Notable among them is the use of sugar and apple juice (Akharume et al., 2016); 0.5\% NaOH, Pectinase and lipase with sucrose (Kucner et al., 2013); fructose, dextrose, polydextrose, sucrose, maltodextrin and corn syrup (Shi et al., 2009).

Liquid smoke, a recent substitute of the age long smoking process, is an aqueous condensate of wood smoke produced by smoldering wood chips or sawdust under limited oxygen and controlled conditions (Saloko et al., 2014). Food-grade liquid smoke is fractionated and refined to remove undesirable polycyclic aromatic hydrocarbon (PAH). Liquid smoke used by the food industry has adjusted intensity of the flavor and color and it is available in commercial market in the form of refined liquid smoke oil or dry powder. Use of food-grade liquid smoke minimizes pollution problems often associated with traditional smoking (Saloko et al., 2014; Sofos et al., 1988). 
Several researchers have explored the potency of commercial liquid smoke as antioxidant and antimicrobial agent in food preservation (Montazeri, Himelbloom, et al., 2013; Van Loo et al., 2012). Additionally, concomitant organoleptic potential (in terms of flavor and color) in food has been explored, especially for consumers desiring smoky flavor, taste, and color (Gonulalan et al., 2004). Van loo et al. investigated the antimicrobial effects of eight commercial liquid smoke products by comparing their minimum inhibitory concentration (MIC) against Salmonella enteritidis, Staphylococcus aureus, and Escherichia coli. They report that liquid smoke has an inhibitory effect on the growth of the bacteria with MIC from 0.5 to $6.0 \%$ for E. coli, 0.5 to $8.0 \%$ for Salmonella, and 0.38 to $6 \%$ for S. aureus (Van Loo et al., 2012). Additionally, liquid smoke has also been applied to texture profiling of meat. Martinez et al. investigated the effects of two different liquid smoke types (coded F1and F2) on the textural analysis of meat products (salted pork loin and salted bacon). The smoke flavoring F1, which is low in carbonyl compounds, modified the cohesiveness, springiness, and gumminess of the loin; and the hardness, fracturability, and springiness of the bacon. Smoke flavoring F2, rich in carbonyl compounds, caused changes in the springiness and gumminess of the loin, and all the texture parameters of the bacon (Martinez et al., 2004). While liquid smoke solution has been extensively used in fish, meat, and other related products, to our knowledge there has been no known application of refined liquid smoke (RLS) to fruit and vegetable products; a possibility in this area for preservation and quality improvement is not implausible.

Therefore, objective of research was to evaluate the influence of addition of refined liquid smoke (RLS) during osmotic dehydration of apples using sugar-based osmotic solution on selected characteristics and properties of osmotically dehydrated apples. The selected properties were the following: solid gain (SG), water loss (WL), dry matter (DM), soluble solid content (SSC), effective diffusion coefficient $\left(\mathrm{D}_{\mathrm{e}}\right)$ and cell structure matrix. 


\subsection{Materials and Method}

\subsubsection{Materials Preparation}

Fresh apples (Variety: Golden Delicious) were purchased from a local grocery (Kroger) store and kept inside refrigerator at $4^{\circ} \mathrm{C}$. The apples were used within 4 days of purchase. The apples were cored, peeled, and cut into cubes of $10 \mathrm{~mm}$ thickness for osmotic dehydration kinetic assay and microstructure evaluation. Full strength refined liquid smoke (RLS) (code 10 poly) was supplied by Kerry Ingredients and Flavors (Monterey TN). It was immediately stored at $4{ }^{\circ} \mathrm{C}$ until use. The characterization of the RLS has been presented by Montazeri et al., which also agreed with the supplier's material safety data sheet SDS (table 4).

Table 4. Characteristics of Refined Liquid Smoke (RLS) used in this research (Montazeri, Oliveira, et al., 2013).

\begin{tabular}{ll}
\hline Characteristic & Code 10-Poly \\
\hline Total phenol content $(\mathrm{mg} / \mathrm{mL})$ & 3.22 \\
$\mathrm{pH}$ & 2.3 \\
Titratable acidity $(\%$ acetic acid, wt/wt.) & 10.3 \\
Gardner color value & 16 \\
\hline
\end{tabular}

\subsubsection{Osmotic Dehydration (OD) Experiments}

To investigate influence of addition of liquid smoke in OS during OD of apples on its osmotic dehydration kinetics, following two different solutions (OS) were prepared: (1) $42{ }^{\circ}$ Brix sugar solution (2) $42{ }^{\circ}$ Brix sugar solution plus $1 \%$ w/w RLS solution. In each OS solution, about $15 \mathrm{~g}$ of apple cubes were added to perform OD experiments. During the OD, the weight ratio of fruit to solution was 1:4. The OD experiments were performed for the durations of $5,15,30,60,90,120,180$, and 240 minutes at isothermal incubation temperature of $50^{\circ} \mathrm{C}$ under atmospheric pressure. Details of experimental set up are presented elsewhere (Akharume et al., 2016). Therefore, total 54 (9 durations $\times 2$ OS solutions $\times 3$ replications) osmotic dehydration experiments were performed. 


\subsubsection{Analytical Measurements for Moisture Content, Soluble Solid, Water Activity and pH.}

Moisture content and dry matter content (DM) determinations were carried out by oven-drying samples to constant weight for $24 \mathrm{~h}$ at temperature of $103 \pm 2{ }^{\circ} \mathrm{C}$. Soluble solid content of samples, previously homogenized, were measured with a hand held Digital hand-held Refractometer (Model: AR200, Reichert, NY USA) according to the AOAC 932.12 standard (AOAC, 1990). Water activity of previously homogenized samples was measured with Aqua Lab water activity meter (Model: 4TE, Decagon Devices, Inc. Pullman WA USA). Finally, $\mathrm{pH}$ of samples was measured using a $\mathrm{pH}$ meter (Model: 350, CORNING, Woburn, MA USA).

\subsubsection{Calculation for Solid Gained, and Water Loss}

Equations 17 and 18 were used to calculate water loss (WL g water/initial dry matter) and solid gain (SG g dry matter/g initial dry solid), respectively (Kucner et al., 2013).

$$
\begin{aligned}
\mathrm{WL} & =\frac{\left[M_{o}\left(1-S_{o}\right)-M_{k}\left(1-S_{k}\right)\right]}{M_{o} S_{o}} \\
\mathrm{SG} & =\frac{\left[M_{k} S_{k}-M_{o} S_{o}\right]}{M_{o} S_{o}}
\end{aligned}
$$

Where:

$M_{o}=$ weight of sample before $\mathrm{OD}(\mathrm{g})$

$M_{k}=$ weight of sample after $\mathrm{OD}(\mathrm{g})$

$S_{o}=$ solid content before OD ( $\mathrm{g}$ dry matter/ $\mathrm{g}$ of initial dry solid).

$S_{k}=$ solid content after OD (g of dry matter/g of initial dry solid).

\subsubsection{Estimation of Effective Diffusion Coefficient Determination}

Empirical and semi-empirical models (Cranks's and Azaura's) (Azuara et al., 1992; Crank, 1975) were used to fit the experimental data and to calculate effective diffusion coefficients $\left(D_{e}\right)$ for solute and water diffusions during OD. The Fick's second law for unsteady state diffusion has been widely applied in literature (Assis et al., 2016; Azuara et al., 1992; Crank, 1975; Rastogi \& Raghavarao, 2004). The 
solution to Fick's second law in a rectangular parallelepiped (dimensions 2a, 2b, 2c) results in the following equation (eqn. 19) for WL or SG (Crank, 1975; Rastogi \& Raghavarao, 1997, 2004) with assumption of negligible shrinkage, uniform initial concentration, uniform moisture distribution and constant diffusivity:

$$
\frac{W L}{W L_{\infty}} \quad \frac{S G}{S G_{\infty}}=1-\sum_{n=1}^{\infty} k_{n}^{3} \cdot \exp \left[-D_{e} \cdot q_{n}^{2} \cdot\left(\frac{1}{a^{2}}+\frac{1}{b^{2}}+\frac{1}{c^{2}}\right) \cdot t\right]
$$

Where: $W L_{\infty}$ and $S G_{\infty}$ are water loss and solid gain, respectively at infinity or equilibrium; $k_{n}=\frac{2 \alpha(1+\alpha)}{1+\alpha+\alpha^{2} q_{n}^{2}}, q_{n}$ is the non-zero positive roots of $\tan ^{q_{n}=-} \alpha q_{n}, \alpha$ is the ratio of volume (mass)

of the solution to volume (mass) of the parallelepiped, and $D_{e}$ is the effective diffusivity of water or solute diffusion. For a cube of equal sides $(a=b=c)$, further compression of eqn. (19) gives equation 20 (Assis et al., 2016), as given below:

$$
\frac{W L}{W L_{\infty}} \quad \frac{S G}{S G_{\infty}}=1-\sum_{n=1}^{\infty} k_{n}^{3} \cdot \exp \left[-D_{e} \cdot q_{n}^{2} \cdot \frac{3}{\left(a^{2}\right)} \cdot t\right]
$$

For diffusion to or from a cube, Fourier number is defined as $D_{e} \cdot \frac{3}{a^{2}} \cdot t$. When the value of the Fourier number is greater than 0.1 , only the first term in the equation 20 is significant and other terms can be neglected. Therefore, it transforms into the equation 21 below:

$$
-\ln \left[\frac{\left(1-\left(\frac{W L}{W L_{\infty}} \text { or } \frac{S G}{S G_{\infty}}\right)\right)}{k_{n}^{3}}\right]=D_{e} \cdot q_{1}^{2} \cdot \frac{3}{a^{2}} \cdot t
$$


The value of effective diffusivity for water transport may be calculated from the slope of the linear regression of the plot of $\left(\frac{1-\frac{W L}{W L_{\infty}}}{k_{n}^{3}}\right)_{\text {versus t. Likewise, effective diffusivity for solute transport may be }}$ calculated from the slope of linear regression of the plot of the $\ln \left(\frac{1-\frac{S G}{S G_{\infty}}}{k_{n}^{3}}\right)$ versus t. However, equation 21 requires experimental values of $W L_{\infty}$ and $S G_{\infty}$, which are calculated using the linear form of the Azuara's model (Azuara et al., 1992) presented in the equations 22 for WL and equation 23 for SG.

$$
\begin{aligned}
\frac{t}{W L} & =\frac{1}{s_{1} * W L_{\infty}}+\frac{t}{W L_{\infty}} \\
\frac{t}{S G} & =\frac{1}{s_{2} * S G_{\infty}}+\frac{t}{S G_{\infty}}
\end{aligned}
$$

Where $s_{1}$ is the parameter related to the rate of water diffusion out of the fruit and $s_{2}$ is the solute diffusion into the fruit. The $W L_{\infty}$ and $S G_{\infty}$ are determined from the slope and intercept of the plot of $\left(\frac{t}{W L}\right)$ and $\left(\frac{t}{S G}\right)_{\text {against time }} t$.

\subsubsection{Scanning Electron Microscopy}

To determine the effect of RLS on the cell microstructure of the OD treated apples, a scanning electron microscope (SEM) (Model: S-4700, Hitachi High Technologies, USA) was used to visualize the dried forms of fresh, sugar infused and liquid smoke infused apples. The samples were oven dried for $24 \mathrm{~h}$ at temperature of $103 \pm 2^{\circ} \mathrm{C}$. Then a cross-sectional cut was made close and parallel to the sample surface. 
Samples were sputted with a thin layer of gold under vacuum with (Denton Desk V Sputter) before visualization.

\subsubsection{Experimental Design and Statistical Analysis}

Data on response variables (water loss, solid gain, and solid soluble content) was analyzed to compare two treatments $\left(42^{\circ}\right.$ Brix sugar solution and $42{ }^{\circ}$ Brix sugar solution plus $1 \%$ w/w RLS) in a completely randomized design. Triplicates of each treatment were performed and results were expressed as mean \pm standard deviation. One-way ANOVA was performed for test of significant with significant level set at $P$ $<0.05$. Tukey's test was used for multiple comparison. All analysis was carried out using SAS Statistical Software (University Edition).

\subsection{Result and Discussion}

\subsubsection{Characteristics of Apples and OD solution}

Prior to OD treatment, cut apple cubes assayed had initial MC of $88.5 \mathrm{~g} / 100 \mathrm{~g}$ of fresh fruit, $\mathrm{pH}$ of $3.78 \pm$ 0.03, dry matter (DM) content of $11.46 \%$, and soluble solid content (SSC) $9.90 \pm 0.54{ }^{\circ}$ Brix as presented in table 5. The cut apple samples were prevented from enzymatic browning by placing them immediately in refrigerator after cutting for a short duration before use. No observable shrinkage was observed (Fig. 18) when apples were cut and stored in the refrigerator for a short time. The $\mathrm{pH}$ of the RLS added solution was $2.78 \pm 0.03$, whereas, it was $5.69 \pm 0.11$ for the control solution (sugar only). The acidic nature of the liquid smoke is generally a result of partial pyrolysis of the cellulose and hemicellulose content of the wood (Saloko et al., 2014). Most liquid smokes are made up of organic acids: acetic acid (majorly), formic acid, propionic, butyric acids, and others (Montazeri, Himelbloom, et al., 2013; Saloko et al., 2014). The characteristic addition of the gardner colored RFS, rapidly made clear sugar-based OS into a brown colored solution. 


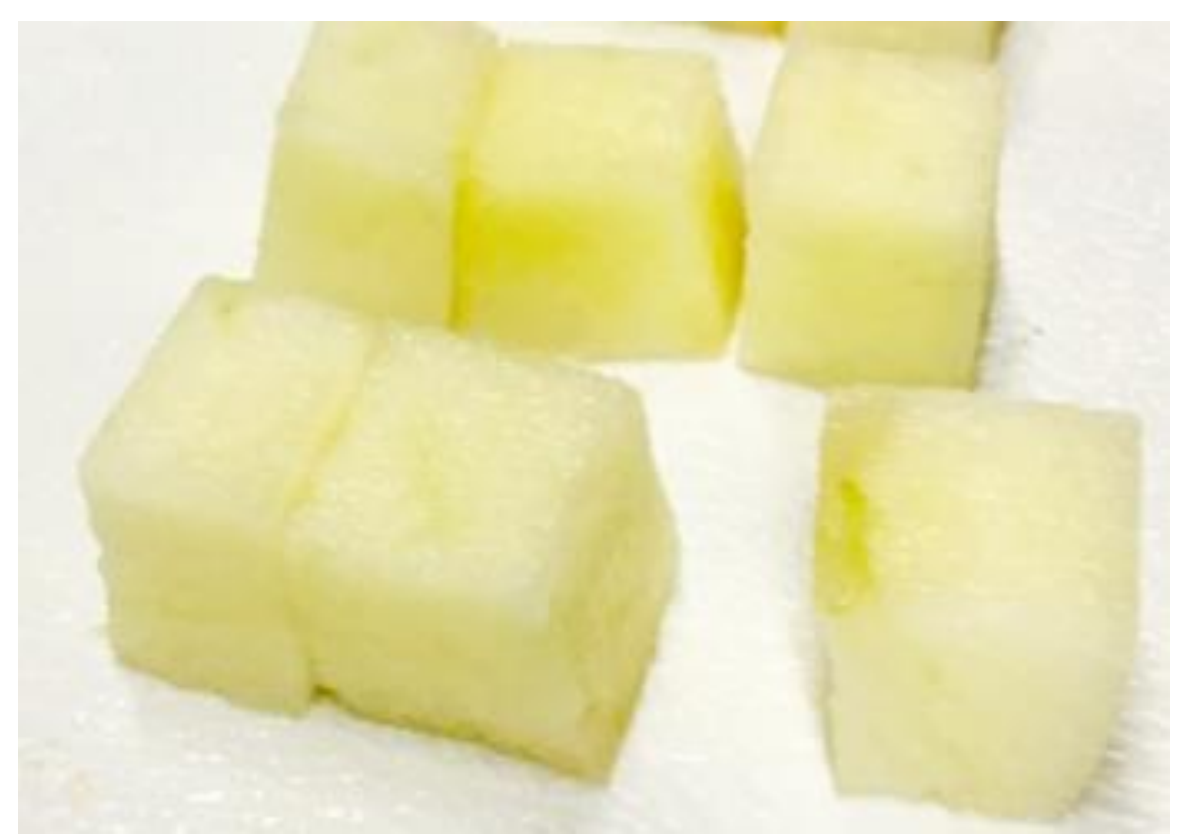

Figure 18. Samples of cut apple cubes before Osmotic Dehydration (OD).

Table 5. Physical characteristic of treated and untreated (control) apple samples before and after 240 min. OD duration. The values in parenthesis are standard deviations from mean values.

\begin{tabular}{|c|c|c|c|c|c|c|c|c|}
\hline \multirow{3}{*}{$\begin{array}{c}\text { Apple } \\
\text { Samples }\end{array}$} & \multicolumn{8}{|c|}{ Physical Characteristic } \\
\hline & \multicolumn{2}{|c|}{$\begin{array}{c}\text { MC } \\
(\mathrm{g} / \mathbf{1 0 0 g})\end{array}$} & \multicolumn{2}{|c|}{ pH } & \multicolumn{2}{|c|}{$\begin{array}{c}\text { SSC } \\
\left({ }^{\circ} \text { Brix) }\right.\end{array}$} & \multicolumn{2}{|c|}{$\begin{array}{c}\text { DMI } \\
(\% \mathbf{\%} / \mathbf{w})\end{array}$} \\
\hline & Initial & Final & Fruit & Solution & Initial & Final & Initial & Final \\
\hline Control & $\begin{array}{l}88.50 \\
(0.17)\end{array}$ & $\begin{array}{l}49.39 \\
(0.70)\end{array}$ & $\begin{array}{c}3.78 \\
(0.02)\end{array}$ & $\begin{array}{c}5.69 \\
(0.11)\end{array}$ & $\begin{array}{c}9.90 \\
(0.31)\end{array}$ & $\begin{array}{l}31.02 \\
(0.10)\end{array}$ & $\begin{array}{l}11.46 \\
(0.16)\end{array}$ & $\begin{array}{l}31.98 \\
(1.80)\end{array}$ \\
\hline Treatment & $\begin{array}{l}88.50 \\
(0.17)\end{array}$ & $\begin{array}{l}47.55 \\
(2.70)\end{array}$ & $\begin{array}{c}3.78 \\
(0.02)\end{array}$ & $\begin{array}{c}2.78 \\
(0.03)\end{array}$ & $\begin{array}{c}9.90 \\
(0.31)\end{array}$ & $\begin{array}{c}33.8 \\
(0.10)\end{array}$ & $\begin{array}{l}11.46 \\
(0.16)\end{array}$ & $\begin{array}{l}34.79 \\
(1.10)\end{array}$ \\
\hline
\end{tabular}

- Moisture content (MC), solid soluble content (SSC), and Dry matter (DM)

\subsubsection{Changes in Moisture Content of Apples at Different OD durations}

Changes in moisture content with OD time were recorded by calculating the moisture content of the batch of apple cubes sample after the OD duration. As shown in figure 19, the desorption of moisture for both samples follow the characteristic exponential function as reported and modelled by several authors (Peleg, 1988; Rastogi \& Raghavarao, 1997; Rastogi et al., 1997; Tsamo et al., 2005). Both control and treated apple samples recorded a sharp decline in $\mathrm{MC}$ with time at least for the first $2 \mathrm{~h}$ before reaching an 
asymptote in the next 1- $2 \mathrm{~h}$. The final moisture contents after $240 \mathrm{~min}$ OD time were $49.39 \%$ and $47.55 \%$ for control and RLS treated OD, respectively (Table 2), which were significantly different (pvalue $=0.0001)$. Similar results were presented by Tsamo and coworkers: moisture removed was 10-20\% of onion slice weight after $120 \mathrm{~min}$ of OD treatment and 45-90\% for tomatoes weight after $100 \mathrm{~h}$ of OD duration (Tsamo et al., 2005).

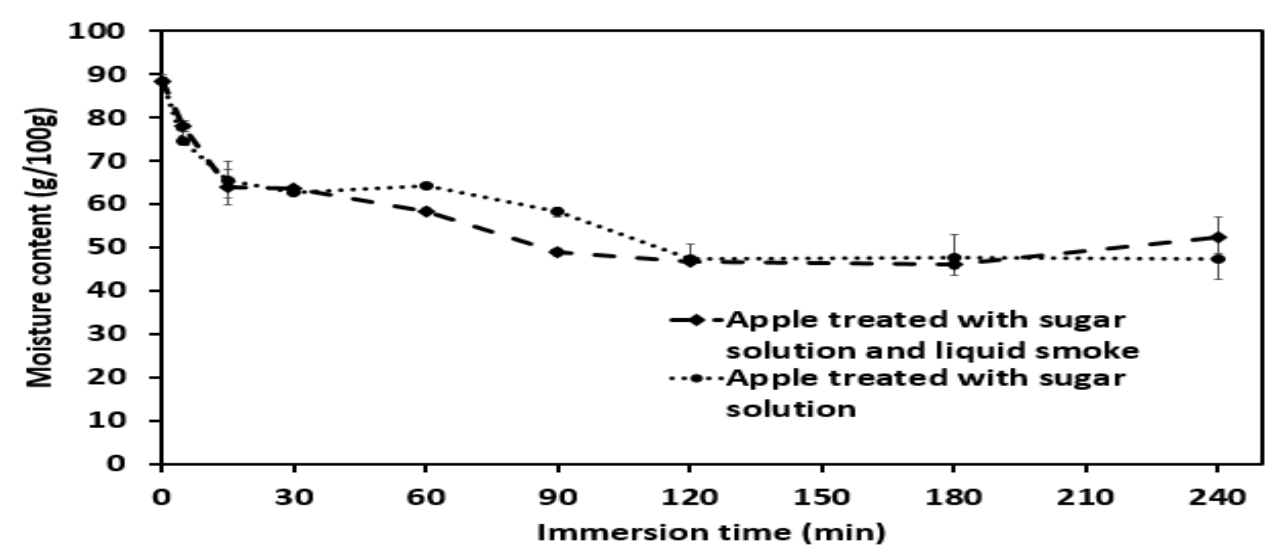

Figure 19. Variation of moisture content apple cubes during osmotic dehydration for different durations from 5- $240 \mathrm{~min}$ at $50^{\circ} \mathrm{C}$ isothermal temperature.

\subsubsection{Changes in Soluble Solid Content (SSC) and Dry Matter Content (DM) with OD Time}

The soluble solid and dry matter content was observed to increase steadily with increasing OD time (Fig. 20a\&b). At the beginning of OD, SSC and DM for both the treatment sample and control sample were 9.9 $\pm 0.31{ }^{\circ}$ Brix and $11.46 \pm 0.16 \% \mathrm{w} / \mathrm{w}$, respectively. In literature, the SSC of fresh apples has been reported in the range of 10 to $15^{\circ}$ Brix depending on variety and ripeness (Allali et al., 2010; Castelló et al., 2009; Zúñiga \& Pedreschi, 2012). Likewise, the DM of fresh apples has been reported to be $13.73 \%$ (McGlone et al., 2003). The addition of the refined liquid smoke significantly (p-value <0.05) increased the DM and SSC, when compared to apple samples treated in pure OS. For example, after $240 \mathrm{~min}$. of OD, the SSC for both samples increased by $213.33 \%$, from $9.9^{\circ}$ Brix to $31.02{ }^{\circ}$ Brix for control treatment. However, a higher increase $(241.41 \%)$ in SSC was recorded for RLS-treated OD apples than the control where SSC increased from $9.9^{\circ}$ Brix. to $33.80{ }^{\circ}$ Brix. Similarly, the DM content increased by $179 \%$ (from $11.46 \%$ to $31.98 \%$ ) for the control and by $203 \%$ (from $11.46 \%$ to $34.79 \%$ ) for the RLS treated OD apples. 
Depending on the process condition, OD treated apples can have as much as $92.4 \% \mathrm{DM}$ content (Klewicki et al., 2009). The effect of liquid smoke treatment on increased solute uptake has not been known to be reported for fruit. A possible explanation is that, there occurs a hydrolysis of the sucrose into low molecular weight sugar (glucose and fructose) by the low $\mathrm{pH}$ concentration characteristic of the RFS (table 5) during OD, which enhances solid uptake. The overall low $\mathrm{pH}$ concentration (2.78) of the solution (sugar and 1\%RFS) may have caused the development of micropores on cell-wall without immediate collapse of cell structure matrix leading to a higher influx of solid across the semi-permeable membrane. Allali et al. report that increasing use of citric acid pretreatment correlates with an increase in SG and WL due to the pH effect (Allali et al., 2010). Additionally, the presence of polyphenol and other contents could also have contributed to the osmolarity of the osmotic solution.

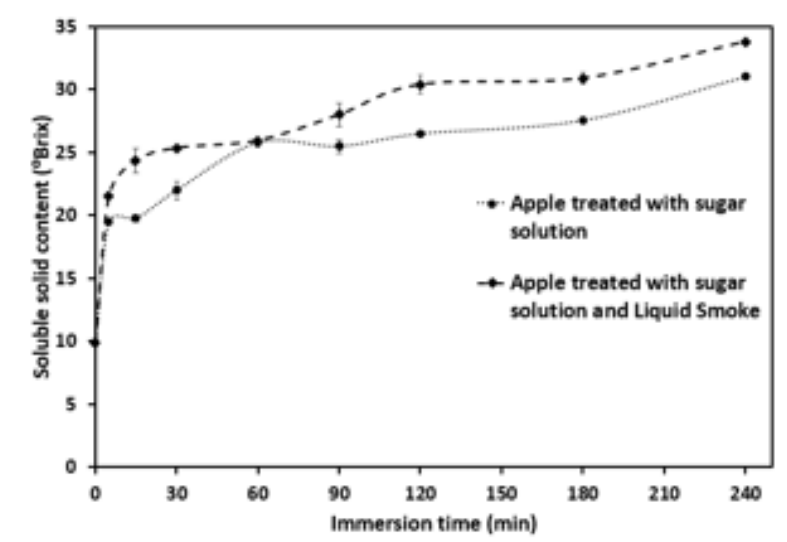

(a)

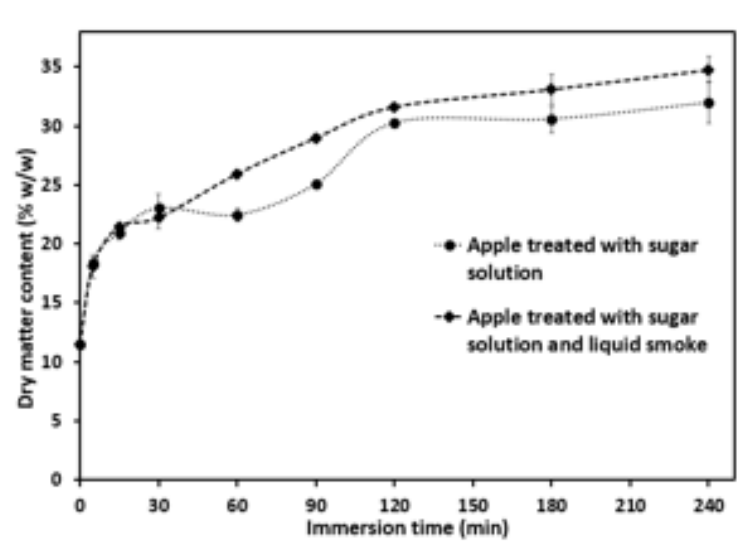

(b)

Figure 20. (a) Soluble solid content and (b) dry matter content in apple cubes during osmotic dehydration for different durations from 5- $240 \mathrm{~min}$ at $50^{\circ} \mathrm{C}$ isothermal temperature.

\subsubsection{Changes in Solid Gain (SG) and Water Loss (WL)}

The evolution of the increase in solid gain (SG) (figure 21a) and water loss (WL) (figure 21b) with time for both RLS treated and controlled samples during OD performed at different durations from 5 min to $240 \mathrm{~min}$ is presented in the figure 21 . It is apparent from the figures (21 a \& b), there was a steady increase in the SG and WL by the fruit in the RLS added and controlled OS due to the osmotic gradient between the fruit samples and its ambient osmotic solutions. The osmotic gradient facilitates mass transfer mechanism. 


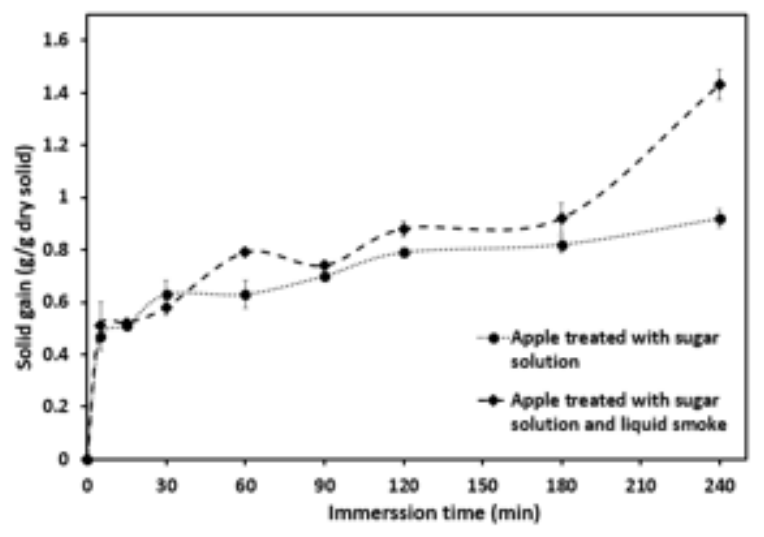

(a)

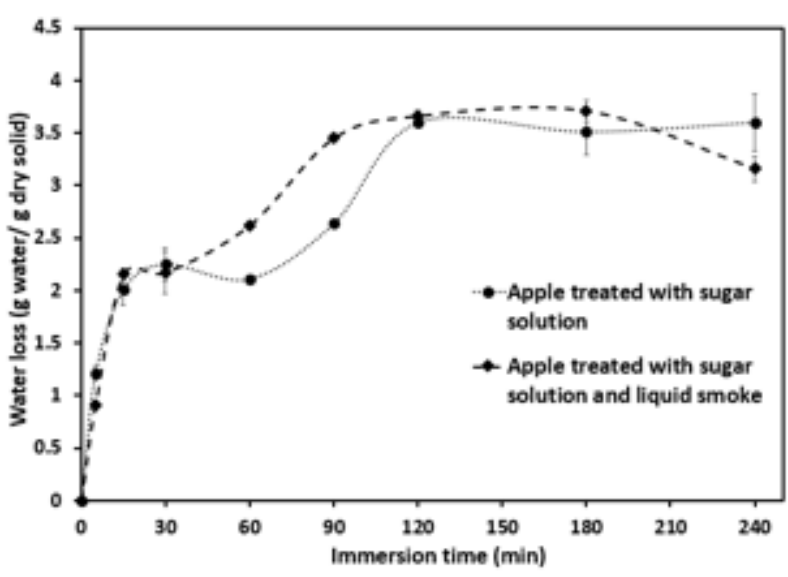

(b)

Figure 21. (a) Soild gain and (b) water loss in apple cubes during osmotic dehydration for different durations from 5- $240 \mathrm{~min}$ at $50^{\circ} \mathrm{C}$ isothermal temperature.

After a duration of 240 min OD, apples treated in osmotic solution with 1\% RLS reached solid gained (SG) of $1.43 \mathrm{~g} / \mathrm{g}$ and WL of $3.16 \mathrm{~g} / \mathrm{g}$. In contrast, apples processed through controlled dehydration reached SG of $0.92 \mathrm{~g} / \mathrm{g}$ and WL of $3.60 \mathrm{~g} / \mathrm{g}$ (Table 6). Statistical analysis reveals that the difference in SG was significant at ( $\mathrm{p}$-value $<0.05)$ while the difference observed in WL was not at the same significant level. Lazarides and coworkers reported similar values for apples treated in OD after $3 \mathrm{~h}: \mathrm{SG}$ was $0.37 \mathrm{~g} / \mathrm{g}$ and WL was $2.30 \mathrm{~g} / \mathrm{g}$ (Lazarides et al., 1995). During the OD process, a higher WL was favored in the first $2 \mathrm{~h}$ of OD for both samples followed by a relatively constant rate of water loss for the next two hours. This behavior has been reported several places in literature (Allali et al., 2010; Atarés et al., 2008; Lazarides et al., 1995; Nieto et al., 2004). For example, Allali and coworkers showed a 25\% WL after $2 \mathrm{~h}$ OD followed by about $32 \%-35 \%$ WL over the next $1-2 \mathrm{~h}$ OD for apple cubes treated with $\quad 70{ }^{\circ}$ Brix sucrose solution (Allali et al., 2010). To better understand how WL and SG progresses over time, rate of WL and SG were calculated and it is presented in the figure 22a and 22b. At the beginning of the OD, the rate of WL was $0.24 \mathrm{~g} / \mathrm{g}$.min for controlled OD, which was slightly higher than the RLS treatment $(0.18$ g/g.min). As OD progressed for an hour, the rate of WL dropped to about $35 \%$ of the initial rate for controlled and about $44 \%$ for the RLS treatment. Likewise, the rate of SG was about $0.09 \mathrm{~g} / \mathrm{g}$.min for 
controlled OD and 0.10 g/g.min for RLS treatment, which decreased by $28 \%$ in an hour. After 4 h of OD, the rate of WL decreased to $20 \%$ and $25 \%$ and the rate of SG decreased $15 \%$ and $16 \%$ for controlled and treated samples respectively.

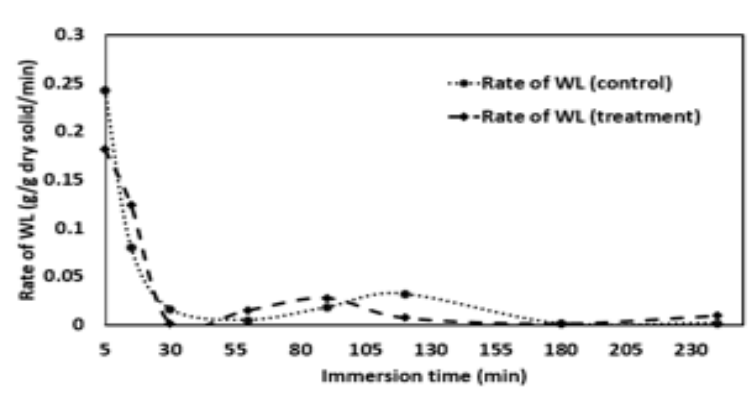

(a)

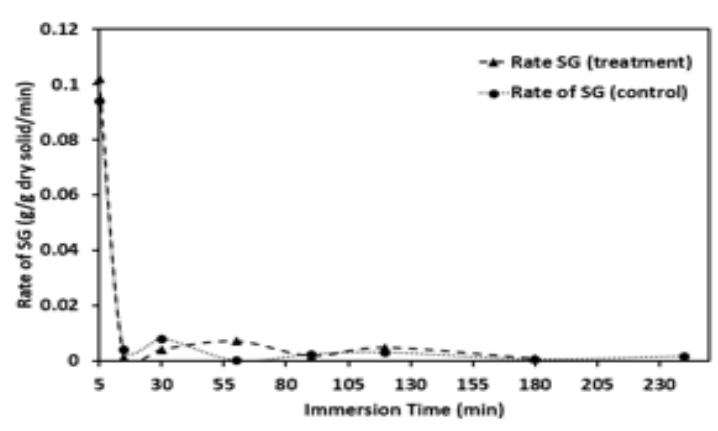

(b)

\section{Figure 22. (a) Rate of water loss (WL), (b) rate of solid gain (SG) in apple cubes during osmotic}

\section{dehydration for different durations from 5- $240 \mathrm{~min}$ at $50^{\circ} \mathrm{C}$ isothermal temperature.}

Lazarides et al., reported a similarly observation for apples treated in sucrose solution and corn syrup. They report $20 \%$ decrease in rate of WL after $1 \mathrm{~h}$ and $25 \%$ decrease in rate of SG to reach after same time (Lazarides et al., 1995). They expressed the opinion that the rapid loss of water in the beginning is obviously due to the large osmotic driving force between the dilute sap of the fresh fruit and the surrounding hypertonic solution. More so, the drop in the mass transfer rate of water and solid have also been well established to be caused by three major phenomena: (1) sharp reduction in the initial concentration of the ambient solution due to large solid uptake in the first hour of OD (2) formation of solute sublayer on the surface of the fruit from the first set of absorbed sugar molecules hinders the mass transfer coefficient of water loss and solid gain at the fruit- osmotic solution interface (3) osmotic shockcollapse of cell of the fruit surface during the first hour of OD causing slow convective mass flow. Additionally, low $\mathrm{pH}$ of the RLS added OS (pH 2-3) might have increased cell porosity and facilitated the diffusion and absorption of solute (Zemke-White et al., 2000). Similarly, the use of ascorbic acid in osmotic solution were reported to increase sharply the WL and SG after $2 \mathrm{~h}$ of OD processing of apples 
(Allali et al., 2010; Mauro et al., 2016; Tappi et al., 2017). They all argue that ascorbic acid caused a modification in the cell wall structure and cellular matrix which consequently imparts diffusion.

\subsubsection{Effects of RLS on Microstructure and Diffusion Kinetics}

The effective diffusion coefficient for water loss was $2.94 \times 10^{-10} \mathrm{~m}^{2} / \mathrm{s}$ for both control as well as RLS treated apples (Table 6). Similar values of effective diffusion coefficient have been reported for apple rings treated in $50 \%$ OS $\left(4.97 \times 10^{-10} \mathrm{~m}^{2} / \mathrm{s}\right)$ (Jalaee et al., 2011), carrot cubes $\left(1.594 \times 10^{-9} \mathrm{~m}^{2} / \mathrm{s}\right)($ Singh et al., 2007), and pineapple cubes $\left(2.40 \times 10^{-9} \mathrm{~m}^{2} / \mathrm{s}\right)($ Rastogi \& Raghavarao, 2004). Similarly, average effective diffusion coefficient for SG was $7.34 \times 10^{-10} \mathrm{~m}^{2} / \mathrm{s}$ for control and $4.40 \times 10^{-10} \mathrm{~m}^{2} / \mathrm{s}$ for the RLS treated apples. These results were within reported values $10^{-10} \mathrm{~m}^{2} / \mathrm{s}$ (Assis et al., 2016; Ochoa-Martinez et al., 2007; Zúñiga \& Pedreschi, 2012).

Table 6. Osmotic dehydration kinetics of treated and untreated (control) apple samples before and after $\mathbf{2 4 0} \mathrm{min}$. OD duration. The values in parenthesis are standard deviations from mean values.

\begin{tabular}{|c|c|c|c|c|c|c|}
\hline \multirow{3}{*}{$\begin{array}{c}\text { Apple } \\
\text { samples }\end{array}$} & \multicolumn{6}{|c|}{ OD kinetics } \\
\hline & \multicolumn{2}{|c|}{$\begin{array}{l}\text { WL } \\
(g / g)\end{array}$} & \multicolumn{2}{|c|}{$\begin{array}{c}\text { SG } \\
(g / g)\end{array}$} & \multicolumn{2}{|c|}{$\begin{array}{c}\mathbf{D}_{\mathrm{e}} \times 10^{-10} \\
\left(\mathrm{~ms}^{-2}\right)\end{array}$} \\
\hline & Initial & Final & Initial & Final & Deuxt. & Desce \\
\hline Control & 0.00 & $\begin{array}{c}3.60 \\
(0.30)\end{array}$ & 0.00 & $\begin{array}{c}0.92 \\
(0.06)\end{array}$ & 2.94 & 7.34 \\
\hline Treatment & 0.00 & $\begin{array}{c}3.16 \\
(0.10)\end{array}$ & 0.00 & $\begin{array}{c}1.43 \\
(0.10)\end{array}$ & 2.94 & 4.40 \\
\hline
\end{tabular}

- Water loss (WL), solid gain (SG), and effective diffusion coefficient (De)

To appreciate the effect of the different osmotic treatments on mass transfer at cell level, SEM micrographs of oven-dried apple from controlled OS and treatment osmotic solution were taken as shown in figure 23a-f. Micrographs of the surface in contact with the solution were photographed at high magnification. Osmotic dehydration was observed to cause collapse of cell wall and cellular structure for both samples. No difference was noticed in the cell matrix for both samples after $2 \mathrm{~h}$ and $4 \mathrm{~h}$ treatment 
and it is difficult to distinguish between the cell wall and the cellular spaces because the surfaces are all covered with sugar, similar to an observation reported by (Sosa et al., 2012). Collapse of the cell walls takes place when water is rapidly drawn out of call cavities, like sucking water from thin walled drinking straw. Hydrostatic tension forces develop during the flow of capillary water. As water is removed from cell cavities near the surface, it exerts a pull-on water deeper in the cell cavity. This tension pull is inward on the walls of cells whose cavities are full of water, and the result is an inward collapse of the cell walls. The danger of collapse is greatest early in osmotic dehydration when many cell cavities are full of water, and if the beginning osmotic gradient is very high . Cell wall collapse was not present in the RLS-treated apples after the first hour. There was a noticeable difference in the micrograph taken after $1 \mathrm{~h}$. Larger intercellular spaces and well-defined cell wall can be seen. This may be attributed partly to partial solubilization of pectin in the middle lamella of cells (Tortoe \& Orchard, 2006) and partly to the increase in cell porosity as a result of low acid solution after $1 \mathrm{~h}$ (Zemke-White et al., 2000). As the OD progress the cells closer to the fruit surface collapse in response to the osmotic stress as shown in the micrograph after $2 \mathrm{~h}$ and 4 h.,neighboring cells shrink (Lewicki \& Porzecka-Pawlak, 2005).
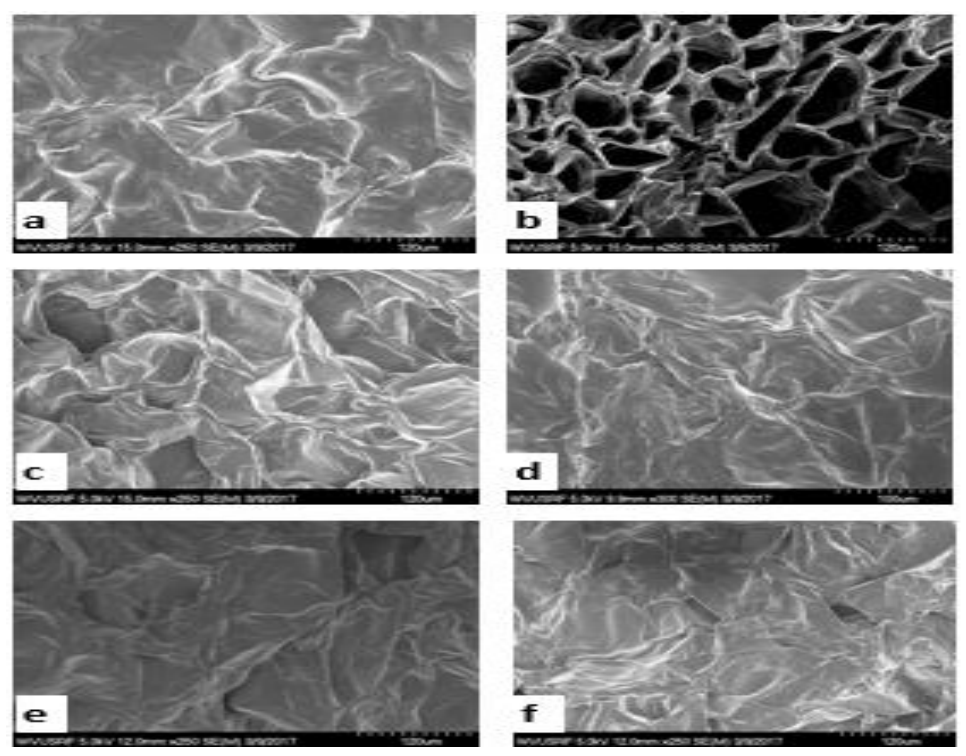

Figure 23. Scanning electron microscopy (SEM) micrographs of treated and untreated (control) apple samples. (a) control after $1 \mathrm{~h}$; (b)treatment after $1 \mathrm{~h}$; (c) control after $2 \mathrm{~h}$; (d) treatment after $2 \mathrm{~h}$; (e) control after $4 \mathrm{~h}$; and (f) treatment after $4 \mathrm{~h}$ of osmotic dehydration. 


\subsection{Conclusion}

In this experiment, influence of the addition of RLS during OD of apples cubes was investigated. The OD process reduced moisture content of fruit to about $53 \%$ of the initial moisture content. The final WL was $247 \%$ and $197 \%$ of the initial observed WL (5 min. OD time) and the final SG was $180 \%$ and $96 \%$ of the initial observed SG (5 min. OD time) for RLS-treated and control OD, respectively. Addition of 1\% RLS to the OS significantly increases SSC, DM, and SG but not WL. Finally, addition of RLS during OD prevented collapse of the surface cells of the apple cubes during the first hour of OD, thereby facilitating higher water loss and solid gained than the control. Overall, microstructural images showed that osmotic dehydration causes plasmolysis of the cell wall and modified the cellular structure of apple cell at the surface in contact with osmotic solution for both treated and controlled sample.

\section{Acknowledgements}

The research work is available for commercialization through WVU Intellectual Property Disclosure\# 2017-039. This work is partially supported by the USDA National Institute of Food and Agriculture, McIntire Stennis project. In addition, support was also provided by West Virginia University (WVU) Extension Service-Families and Health Programs and also by Northeast Center to Advance Food SafetySpecial Projects Grant Program. Project dissemination support was provided by USDA/NIFA under Award Number 2015-49200-24225.

Additionally, authors thank West Virginia University Shared Research Facilities for access and utilization of their scanning electron microscope (SEM). 


\section{References}

Akharume, F. U., Singh, K., \& Sivanandan, L. (2016). Characteristics of apple juice and sugar infused fresh and frozen blueberries. LWT - Food Science and Technology, 73, 448-457. doi:http://dx.doi.org/10.1016/j.lwt.2016.06.041

Albagnac, G., Varoquaux, P., \& Montigaud, J.-C. (2002). Technologies de transformation des fruits: Tec \& doc.

Allali, H., Marchal, L., \& Vorobiev, E. (2010). Effects of vacuum impregnation and ohmic heating with citric acid on the behaviour of osmotic dehydration and structural changes of apple fruit. Biosystems Engineering, 6-13. doi:http://dx.doi.org/10.1016/j.biosystemseng.2009.08.005

AOAC. (1990). Official Methods of Analysis (15 ${ }^{\text {th }}$ ed.). Food Composition; Additives; Natural Contaminants. Arlington, Virginia USA: Association of Official Analytical Chemist (AOAC), Inc.

Askari, G., Emam-Djomeh, Z., \& Mousavi, S. (2006). Effects of combined coating and microwave assisted hot-air drying on the texture, microstructure and rehydration characteristics of apple slices. Food Science and Technology International, 12(1), 39-46.

Assis, F. R., Morais, R., \& Morais, A. M. (2016). Mathematical modelling of osmotic dehydration kinetics of apple cubes. Journal of Food Processing and Preservation.

Atarés, L., Chiralt, A., \& González-Martínez, C. (2008). Effect of solute on osmotic dehydration and rehydration of vacuum impregnated apple cylinders (cv. Granny Smith). Journal of Food Engineering, 89(1), 49-56. doi:http://dx.doi.org/10.1016/j.jfoodeng.2008.04.002

Azuara, E., Cortés, R., Garcia, H. s., \& Beristain, C. i. (1992). Kinetic model for osmotic dehydration and its relationship with Fick's second law. International Journal of Food Science \& Technology, 27(4), 409-418.

Beuchat, L. R. (1981). Microbial stability as affected by water activity. Cereal Foods World, 26(7), 345-349.

Boyer, J., \& Liu, R. H. (2004). Apple phytochemicals and their health benefits. Nutrition Journal, 3(1), 5. doi:10.1186/1475-2891-3-5

Castelló, M., Igual, M., Fito, P., \& Chiralt, A. (2009). Influence of osmotic dehydration on texture, respiration and microbial stability of apple slices (Var. Granny Smith). Journal of Food Engineering, 91(1), 1-9.

Crank, J. (1975). The mathematics of diffusion: Oxford: Clarendon Press.

Feliciano, R. P., Antunes, C., Ramos, A., Serra, A. T., Figueira, M. E., Duarte, C. M. M., .. . Bronze, M. R. (2010). Characterization of traditional and exotic apple varieties from Portugal. Part 1 - Nutritional, phytochemical and sensory evaluation. Journal of Functional Foods, 2(1), 35-45. doi:http://dx.doi.org/10.1016/j.jff.2009.12.004

Gonulalan, Z., Kose, A., \& Yetim, H. (2004). Effects of liquid smoke on quality characteristics of Turkish standard smoked beef tongue. Meat Science, 66(1), 165-170.

Jalaee, F., Fazeli, A., Fatemian, H., \& Tavakolipour, H. (2011). Mass transfer coefficient and the characteristics of coated apples in osmotic dehydrating. Food and Bioproducts Processing, 89(4), 367-374.

Klewicki, R., Konopacka, D., Uczciwek, M., Irzyniec, Z., Piasecka, E., \& Bonazzi, C. (2009). Sorption isotherms for osmo-convectively-dried and osmo-freeze-dried apple, sour cherry, and blackcurrant. The Journal of Horticultural Science and Biotechnology, 84(6), 75-79. 
Kucner, A., Klewicki, R., \& Sójka, M. (2013). The Influence of selected osmotic dehydration and pretreatment parameters on dry matter and polyphenol content in highbush blueberry (vaccinium corymbosum 1.) fruits. Food and Bioprocess Technology, 6(8), 2031-2047. doi:10.1007/s11947-012-0997-0

Lazarides, H. N., Katsanidis, E., \& Nickolaidis, A. (1995). Mass transfer kinetics during osmotic preconcentration aiming at minimal solid uptake. Journal of Food Engineering, 25(2), 151-166.

Lewicki, P. P., \& Porzecka-Pawlak, R. (2005). Effect of osmotic dewatering on apple tissue structure. Journal of Food Engineering, 66(1), 43-50. doi:http://dx.doi.org/10.1016/j.jfoodeng.2004.02.032

Martinez, O., Salmerón, J., Guillén, M. D., \& Casas, C. (2004). Texture profile analysis of meat products treated with commercial liquid smoke flavourings. Food Control, 15(6), 457461. doi:http://dx.doi.org/10.1016/S0956-7135(03)00130-0

Mauro, M. A., Dellarosa, N., Tylewicz, U., Tappi, S., Laghi, L., Rocculi, P., \& Rosa, M. D. (2016). Calcium and ascorbic acid affect cellular structure and water mobility in apple tissue during osmotic dehydration in sucrose solutions. Food Chemistry, 195, 19-28. doi:http://dx.doi.org/10.1016/j.foodchem.2015.04.096

McGlone, V. A., Jordan, R. B., Seelye, R., \& Clark, C. J. (2003). Dry-matter - a better predictor of the post-storage soluble solids in apples? Postharvest Biology and Technology, 28(3), 431-435. doi:http://dx.doi.org/10.1016/S0925-5214(02)00207-7

Montazeri, N., Himelbloom, B. H., Oliveira, A., Leigh, M. B., \& Crapo, C. A. (2013). Refined liquid smoke: a potential antilisterial additive to cold-smoked sockeye salmon (Oncorhynchus nerka). Journal of Food Protection ${ }^{\circledR}, 76(5), 812-819$.

Montazeri, N., Oliveira, A., Himelbloom, B. H., Leigh, M. B., \& Crapo, C. A. (2013). Chemical characterization of commercial liquid smoke products. Food science \& nutrition, 1(1), 102-115.

Nieto, A. B., Salvatori, D. M., Castro, M. A., \& Alzamora, S. M. (2004). Structural changes in apple tissue during glucose and sucrose osmotic dehydration: shrinkage, porosity, density and microscopic features. Journal of Food Engineering, 61(2), 269-278. doi:http://dx.doi.org/10.1016/S0260-8774(03)00108-0

Ochoa-Martinez, C. I., Ramaswamy, H. S., \& Ayala-Aponte, A. A. (2007). A comparison of some mathematical models used for the prediction of mass transfer kinetics in osmotic dehydration of fruits. Drying Technology, 25(10), 1613-1620. doi:10.1080/07373930701590665

Peleg, M. (1988). An empirical model for the description of moisture sorption curves. Journal of Food Science, 53(4), 1216-1217.

Rastogi, N. K., \& Raghavarao, K. S. M. S. (1997). Water and solute diffusion coefficients of carrot as a function of temperature and concentration during osmotic dehydration. Journal of Food Engineering, 34(4), 429-440. doi:http://dx.doi.org/10.1016/S02608774(98)80034-4

Rastogi, N. K., \& Raghavarao, K. S. M. S. (2004). Mass transfer during osmotic dehydration of pineapple: considering Fickian diffusion in cubical configuration. LWT - Food Science and Technology, 37(1), 43-47. doi:http://dx.doi.org/10.1016/S0023-6438(03)00131-2

Rastogi, N. K., Raghavarao, K. S. M. S., \& Niranjan, K. (1997). Mass transfer during osmotic dehydration of banana: Fickian diffusion in cylindrical configuration. Journal of Food Engineering, 31(4), 423-432. doi:http://dx.doi.org/10.1016/S0260-8774(96)00086-6 
Saloko, S., Darmadji, P., Setiaji, B., \& Pranoto, Y. (2014). Antioxidative and antimicrobial activities of liquid smoke nanocapsules using chitosan and maltodextrin and its application on tuna fish preservation. Food Bioscience, 7, 71-79.

Santacruz-Vazquez, C., Santacruz-Vazquez, V., Jaramillo-Flores, M. E., Chanona-Perez, J., Welti-Chanes, J., \& Gutiérrez-López, G. F. (2008). Application of osmotic dehydration processes to produce apple slices enriched with $\beta$-carotene. Drying Technology, 26(10), 1265-1271.

Shi, J., Pan, Z., McHugh, T. H., \& Hirschberg, E. (2009). Effect of Infusion Method and Parameters on Solid Gain in Blueberries. Food and Bioprocess Technology, 2(3), 271278. doi:10.1007/s11947-008-0116-4

Singh, B., Kumar, A., \& Gupta, A. K. (2007). Study of mass transfer kinetics and effective diffusivity during osmotic dehydration of carrot cubes. Journal of Food Engineering, 79(2), 471-480. doi:http://dx.doi.org/10.1016/j.jfoodeng.2006.01.074

Sofos, J., Maga, J., \& Boyle, D. (1988). Effect of ether extracts from condensed wood smokes on the growth of Aeromonas hydrophila and Staphylococcus aureus. Journal of Food Science, 53(6), 1840-1843.

Sosa, N., Salvatori, D. M., \& Schebor, C. (2012). Physico-chemical and mechanical properties of apple disks subjected to osmotic dehydration and different drying methods. Food and Bioprocess Technology, 5(5), 1790-1802.

Tappi, S., Mauro, M. A., Tylewicz, U., Dellarosa, N., Dalla Rosa, M., \& Rocculi, P. (2017). Effects of calcium lactate and ascorbic acid on osmotic dehydration kinetics and metabolic profile of apples. Food and Bioproducts Processing, 103, 1-9.

Torreggiani, D. (1993). Osmotic dehydration in fruit and vegetable processing. Food Research International, 26(1), 59-68. doi:http://dx.doi.org/10.1016/0963-9969(93)90106-S

Tortoe, C., \& Orchard, J. (2006). Microstructural changes of osmotically dehydrated tissues of apple, banana, and potato. Scanning, 28(3), 172-178.

Tregunno, N., \& Goff, H. (1996). Osmodehydrofreezing of apples: structural and textural effects. Food Research International, 29(5), 471-479.

Tsamo, C. V. P., Bilame, A.-F., Ndjouenkeu, R., \& Jiokap Nono, Y. (2005). Study of material transfer during osmotic dehydration of onion slices (Allium cepa) and tomato fruits (Lycopersicon esculentum). LWT - Food Science and Technology, 38(5), 495-500. doi:http://dx.doi.org/10.1016/j.lwt.2004.07.015

USApples Association. (2015). The Production and Utilization Analysis for the 2015 U.S. Apple Association Apple Crop Outlook and Marketing Conference Retrieved from, Vienna, Virginia:

USDA_NASS. (2015). National Statistic for Apples. Retrieved from: https://www.nass.usda.gov/Statistics_by_Subject/result.php?92ED1E2C-CFEA-3FAD$865 \mathrm{~A}-$ DC7FEE024C42\&sector=CROPS\&group=FRUIT\%20\%26\%20TREE\%20NUTS\&com m=APPLES

USDA_NASS_WV. (2015). West Virginia Annual Bulletin. Retrieved from Charleston, West Virginia:

Van Loo, E. J., Babu, D., Crandall, P. G., \& Ricke, S. C. (2012). Screening of commercial and pecan shell-extracted liquid smoke agents as natural antimicrobials against foodborne pathogens. Journal of Food Protection®, 75(6), 1148-1152. 
Yadav, A. K., \& Singh, S. V. (2014). Osmotic dehydration of fruits and vegetables: a review. Journal of Food Science and Technology, 51(9), 1654-1673. doi:10.1007/s13197-0120659-2

Zemke-White, W. L., Clements, K. D., \& Harris, P. J. (2000). Acid lysis of macroalgae by marine herbivorous fishes: effects of acid $\mathrm{pH}$ on cell wall porosity. Journal of Experimental Marine Biology and Ecology, 245(1), 57-68. doi:http://dx.doi.org/10.1016/S0022-0981(99)00151-3

Zúñiga, R. N., \& Pedreschi, F. (2012). Study of the pseudo-equilibrium during osmotic dehydration of apples and its effect on the estimation of water and sucrose effective diffusivity coefficients. Food and Bioprocess Technology, 5(7), 2717-2727. doi:10.1007/s11947-011-0621-8 
Chapter 4: Influence of Liquid Smoke on Quality and Microbial Shelf Life of Convectively and Osmoconvectively Dried Apples Slices

\begin{abstract}
The infusion of Refined Liquid Smoke (RLS) during osmotic dehydration in apples slices was performed and its effect on some selected quality attributes (color, texture, and microbial load) of resulting apples was evaluated over storage period under vacuum and non-vacuum packaging. Prior to hot air drying at 74 ${ }^{\circ} \mathrm{C}$, fresh apple slices were pretreated in osmotic dehydration using either $42 \%$ w/w sugar solution or $42 \%$ w/w sugar solution with $1 \%$ food grade refined liquid smoke (RLS). The quality attributes were measured at room temperature during a 5-month storage period. For control, quality attributes of convectively dried apples with no osmotic dehydration pretreatment were used. The result showed that dried apple slices pretreated in pure sugar solution retain the color of fruit better than untreated dried samples, while samples infused with RLS showed a characteristic brown coloration. Additionally, RLS infused dried apples showed the highest textural properties and control showed the lowest. In all samples, significant microbial reduction (below $5 \log \mathrm{CFU} / \mathrm{g}$ ) was recorded throughout storage period. However, RLS infused dried apples showed the highest microbial growth reduction and the control showed the lowest microbial growth reduction in a non-vacuum package.
\end{abstract}

Key words; osmo-convective dehydration, smoky apples, liquid smoke, quality, and microbial growth ${ }^{\mathbf{3}}$.

\footnotetext{
${ }^{3}$ Manuscript under preparation
} 


\subsection{Introduction}

Fruit preservation is key to minimizing fruit deterioration, eradicating waste, loss of farm revenue, ensuring availability all year around, and providing safe, nutritive, and qualitative fruit to the consumers. Conventional air drying, amidst others (freezing, canning, modified packaging, juice making, etc.) is a common technique used to process, preserve, and extend shelf life of fruits. Dried fruits have many advantages, such as convenience in transport and storage, reduction in deterioration caused by microbial and chemical reactions, widening and diversifying available market products as well as directly or indirectly providing a good return of investment from long-term sales (Chun, et al., 2012; Mišljenović, et al., 2011). In the US, the value of exported fruits and vegetables, including juices was about 7.4 billion dollars in 2016 (USDA, 2017). Dried apples represented about 1.6\% of US total utilized apple production for 2014, valued at about \$11.9 million (USApples Association, 2015).

Fruit dried through convectional method, using equipment such as a commercial food dehydrator, fluidized bed dryer, drum dryer, rotary dryer, cabinet, convective oven, etc. especially at high temperature (beyond $80{ }^{\circ} \mathrm{C}$ ), results in dried product with poor product quality (low nutrient value, discoloration, less flavor), excessive shrinkage, low rehydration ratio, and is prone to maillard and caramelization reactions at lower moisture content (Koyuncu, et al., 2007; Pallas, 2011). Owning to its low water activity $(<0.6)$, low $\mathrm{pH}$ and thermal treatment, dried fruits are presumed to be shelf stable and are generally stored and distributed at room temperature. However, fungal spore and fungal producing Ochratoxin-A can be present on dried fruits (Bayman, et al., 2002; Bayman \& Mahoney, 2002; Iamanaka, et al., 2005; Ic, et al., 2007; Trucksess \& Scott, 2008). For example, Chun et al., detected $1.36 \log$ CFU/g and $1.20 \log$ CFU/g indigenous total bacterial count in freeze-dried and hot-air dried blueberries, respectively (Chun, et al., 2012). Similarly, Ic et. al., reported a range of $2 \log$ to $3 \log$ CFU/g indigenous yeast and mold bioburden on selected retailed dried fruits (Ic, et al., 2007). Dried fruits are ready to eat meal and are often added to cereal or rehydrated without no further microbial decontamination step. The European union maximum permitted levels are $4 \mu \mathrm{g} \mathrm{kg}-1$ for total aflatoxins in dried fruit intended for direct consumption and $10 \mu \mathrm{g}$ 
kg-1 for Aflatoxins or ochratoxin A (OTA) in dried vine fruit. Additionally, the United States Food and Drug Administration (FDA) proposes a maximum allowable level of bacteria reduction in food including dried fruits to be $5 \log$ CFU/g (Chun, et al., 2012; Derrickson-Tharrington, et al., 2005).

Osmotic dehydration (OD) as pretreatment and a synergistic approach to drying has been widely applied and reported to effectively manage the inherent challenges of hot-air drying (Mandala, et al., 2005; Nsonzi \& Ramaswamy, 1998; Pan, et al., 2003; Rudy, et al., 2013; Torreggiani \& Bertolo, 2001). Because OD removes the initial moisture content of fruit by $30-70 \%$ without changing it to vapor phase, the time and energy required for drying is considerably reduced. Several reports have also shown that infusion of humectants into fruit during OD reduces the water activity of the fruit to the range of 0.94 0.97 (Yadav \& Singh, 2014), by binding the available water molecules and as such increasing shelf life. The infused solutes equally maintain the fruit pigment, retain flavor, reduce volatile compound loss, and improve texture and consumer acceptability (Aktas, et al., 2013; Castelló, et al., 2009; Chardonnet, et al., 2001; Chauhan, et al., 2011; Falade \& Shogaolu, 2010; Dorota Konopacka, et al., 2008; Moreno, et al., 2000). Generally, the quality of osmo-convective dried products depends largely on the osmotic pretreatment steps: the choice of osmotic agent and concentration, temperature of osmotic solution, fruit to solution ratio and all other process conditions associated with osmotic dehydration (Pan et al., 2003). One important advantage of OD step in effective osmo-convective dehydration "hurdle technology", is the ability to control the osmotic solution (OS) to impart the desired organoleptic, nutritive and nutraceutical properties, including anti-microbial quality in the resultant food formulation. Many researchers have taken the advantage of OD to infuse different nutrients and edible compounds into food (dried or intermediate) (Barrera, et al., 2004; Betoret, et al., 2003; Erihemu, et al., 2015; Haizhen, et al., 2006; Santacruz-Vázquez, et al., 2008). In this vein, we explored the use of food grade refined liquid smoke (RLS), as an anti-microbial agent and flavor additive in osmo-convective dehydration to produce “dried smoky apple snacks". Liquid smoke production and utilization have been a subject of continuous research for the past three decades. Liquid smoke is the water condensate of the pyrolysis or smoldering 
of wood chip or wood dust. It is further fractionated and refined by the removal of harmful poly aromatic hydrocarbon (PAH) to produce food grade refined liquid smoke, available in market as liquid smoke oil or powder.

Hitherto, food products have been infused with smoke flavor and taste by bringing the food in contact with the smoke from wood burning. Natural smoke has been widely reported to preserve the nutritional components and wholesomeness of food (meats, fish, cheese etc.) as well as improve their quality, and extend shelf life (Ablett \& Gallant, 2014; Gonulalan, Kose, \& Yetim, 2004; Martinez, Salmerón, Guillén, \& Casas, 2007; Van Loo, Babu, Crandall, \& Ricke, 2012). Tensile strength and water-resistant properties of gelatin film used in food packaging were increased with the addition of desirable amount of liquid smoke (Wang, et al., 2016).

Therefore, the objective of this research was to evaluate infusion of refined liquid smoke (RLS) during osmotic dehydration on selected quality attributes (color, texture, and microbial activity) of osmoconvectively dried apples under vacuum and non- vacuum packaging during a storage period of five months at room temperature.

\subsection{Materials and Method}

\subsubsection{Materials preparation}

Fresh apples (Var. Golden Delicious), obtained from the grocery (Kroger, USA) were stored at $4^{\circ} \mathrm{C}$. The apples were used within 4 days of purchase. The apples were cored, peeled, and cut mechanically using a kitchen slicer into slices $6 \mathrm{~mm}$ thickness for osmotic dehydration kinetic assay. Full strength refined liquid smoke (RLS) (code 10 poly) was supplied by Kerry Ingredients and Flavors (Monterey TN). It was immediately stored at $4^{\circ} \mathrm{C}$ until use. The characterization of the RLS has been presented by Montazeri et al., (Montazeri, et al., 2013), which also agreed with the supplier's material safety data sheet SDS (table 4). 


\section{2.2 Osmotic dehydration experiment and follow-up convection drying}

The apple slices were pretreated with osmotic dehydration in either of the following two different osmotic solutions: (1) $42{ }^{\circ}$ Brix sugar solution and (2) $42{ }^{\circ}$ Brix sugar solution plus $1 \%$ w/w RLS. Some untreated apple slices were used as control. OD experiment was carried out for $3 \mathrm{~h}$, fruit to solution ratio of 1:4 at incubation temperature of $50^{\circ} \mathrm{C}$. Details of experimental set-up are presented elsewhere (Akharume et al., 2016). Follow up hot-air drying was carried out in a food dehydrator (Model: 3900T, Excalibur Products, CA. USA) set at temperature of $74^{\circ} \mathrm{C}$ operating under atmospheric pressure. All samples were dried in for $8 \mathrm{~h}$ until water activity of $0.3-0.35$.

\subsubsection{Storage conditions for dried samples}

For the microbial shelf study and quality attribute analysis, dried apple slices (a control sample and two samples pre-treated in two different OD solution) were packaged under two packaging conditions (Vacuum and Non-vacuum). After packaging, the samples were stored at room temperature to simulate the common shelf storage temperature used in retail grocery stores for $0,3,6,9,12,15,30,60,90,120$, and 150 days. Triplicate samples were taken out at each storage period for analysis.

\subsubsection{Analytical Measurements}

\subsubsection{Moisture content, water activity and $\mathrm{pH}$.}

Moisture content was determined by drying samples to constant weight in an oven for $24 \mathrm{~h}$ at temperature of $103 \pm 2^{\circ}$. Soluble solid content of samples, previously homogenized, were measured with a Reichert Digital Refractometer per the method of Association of Official Analytics Chemist (AOAC) 932.12 (AOAC 1990). Also, water activity of previously homogenized samples was measured using Aqua Lab water activity meter (Model: series 3TE, Decagon Devices, Inc. WA. USA). Finally, pH of samples was measured using a pH meter (Model: 350, CORNING, Woburn, MA USA). 


\subsubsection{Color measurement}

Change in the color of the dried samples was measured several times over storage duration using a colorimeter (Model:CR-300, Chroma Meter, Minolta, Japan). For a given storage duration triplicate samples were pulled. Color measurements were made on five samples from each experimental run and at three different locations on each sample. The standard measurement was taken on a white paper, for which the Hunter values were following: $\mathrm{L}^{*}($ degree of lightness $)=97.70, \mathrm{a}^{*}($ green - to red +$)=-0.07$, and $\mathrm{b}^{*}($ blue - to yellow +$)=1.86$. Additionally, total color difference $\Delta E$, Chroma and Hue angle were calculated according to equations 23,24 , and 25 , respectively.

$\Delta E=\sqrt{\left(L_{0}^{*}-L^{*}\right)^{2}+\left(a_{0}^{*}-a^{*}\right)^{2}+\left(b_{0}^{*}-b^{*}\right)^{2}}$

Chroma $=\sqrt{\left(a^{* 2}+b^{* 2}\right)}$

Hue angle $=\tan ^{-1}\left(\frac{b^{*}}{a^{*}}\right)$

\subsubsection{Measurement of mechanical properties}

The change in the texture of samples with storage duration and non-vacuum packaging was measured with a texture analyzer (TA-HDi, stable micro systems, Ltd., Godalming, UK) equipped with a flat platetype probe of $250 \mathrm{~kg}$ weight. The texture profile analysis was measured at room temperature, setting

parameters as follows: pre-test speed of $2.0 \mathrm{~mm} . \mathrm{s}^{-1}$, post-test speed of $5.0 \mathrm{~mm} \cdot \mathrm{s}^{-1}$ and a relative deformation of $50 \%$. Textural analysis was performed on three replicates (3 bags) from each storage condition and five samples for each sample bag (experimental runs). Textural attributes of force, hardness, springiness, gumminess, and chewiness were calculated from the force-deformation data captured by a computer software program.

\subsubsection{Microbial analysis}

To determine microbial spoilage during storage, $10 \mathrm{~g}$ of dried apple was homogenized with $90 \mathrm{ml}$ of $0.1 \%$ Buffered Peptone water in a filter bag using a stomacher at maximum speed for $2 \mathrm{~min}$. A $1 \mathrm{ml}$ aliquot of 
filtered sample was further diluted with sterile Butterfield's Phosphate-Buffered Water (Weber Scientific, NJ. USA) using a 10-fold serial dilution protocol. $0.1 \mathrm{ml}$ aliquot of the properly diluted sample was plated onto sterile tryptic soy agar (TSA: DifcoTM, MD, USA) plates and evenly spread on the surface with a sterile cell spreader. Plates were incubated at $37^{\circ} \mathrm{C}$ for $48 \mathrm{~h}$ in order to determine total aerobic plate count (APC). In addition, $1 \mathrm{ml}$ aliquot of the properly diluted sample was separately spread plated onto Yeast/Mold Petri film (3MTM PetrifilmTM, MN, USA) and incubated for 3-5 days at $28^{\circ} \mathrm{C}$. Microbial counts are reported as mean values of three determinations and are expressed as log colony forming units per gram (CFU/g). Counts between 25-250 for APC and 3-150 for Mold/Yeast were considered according to FDA's Bacteriological Analytical Manual (BAM) (Maturin \& Peeler, 1998; Tournas, 2000).

\subsubsection{Experimental design and statistical analysis}

A three-way factorial design with three treatment factor levels (sugar infused dried apples, sugar + RLS infused dried apples, untreated dried apples), two packaging factor levels (vacuum and non-vacuum). and eleven-time factor levels $(0,3,6,9,12,15,30,60,90,120$, and 150 days $)$ was adopted to measure various response variables (color, texture parameters, and microbial assay). Response variables measured include: color analysis $\left(\mathrm{L}^{*}, \mathrm{a}^{*}, \mathrm{~b}^{*}, \Delta E\right.$, chroma, and hue angle), texture analysis (force, hardness, springiness, gumminess, and chewiness), and microbial load (total plate count ((APC)), total yeast count, and total mold count). Analysis of covariance (ANCOVA) was used to establish a test of significance between treatments, with significance level set at $p<0.05$, and a multiple comparison was performed using the tukey test of SAS program (University edition).

\subsection{Results and Discussion}

\subsubsection{Characteristics of apples before and after osmo-convective dehydration.}

Prior to OD treatment, apples used in osmo-convective experiment had initial moisture content (MC) of $88.5 \mathrm{~g} / 100 \mathrm{~g}$ of fruit, and color attributes of fresh apples were $80 \pm 0.3,-4.5 \pm 0.1$, and $24 \pm 0.6$ for $\mathrm{L}^{*}, \mathrm{a}^{*}$, and $b^{*}$, respectively and a $\mathrm{pH}$ of $3.78 \pm 0.03$. The $\mathrm{pH}$ of the RLS added solution was $2.78 \pm 0.03$, whereas it was $5.69 \pm 0.11$ for the control solution (sugar only). The acidic nature of liquid smoke is generally a 
result of products of partial pyrolysis of the cellulose and hemicellulose polymers present in wood (Saloko, et al., 2014). Liquid smoke is made up of organic acids: acetic acid (majorly), formic acid, propionic, butyric acids, and others (Montazeri, et al., 2013; Saloko, et al., 2014).

After convective drying, the moisture content of untreated, sugar-infused and RLS-infused samples was 5 $\mathrm{g} / 100 \mathrm{~g}$ fruit, $6 \mathrm{~g} / 100 \mathrm{~g}$ fruit, and $6.2 \mathrm{~g} / 100 \mathrm{~g}$ fruit, respectively. The $\mathrm{pH}$ of the dried fruit was 3.64, 3.69 and 3.61 for untreated, sugar -infused and RLS-infused samples, respectively. No shrinkage was observed physically in the dried fruit osmosed in a combination of sugar solution and liquid smoke, minimal shrinkage was observed with dried samples osmosed in pure sugar solution and considerable shrinkage was observed in the untreated samples (Fig.24a-c).
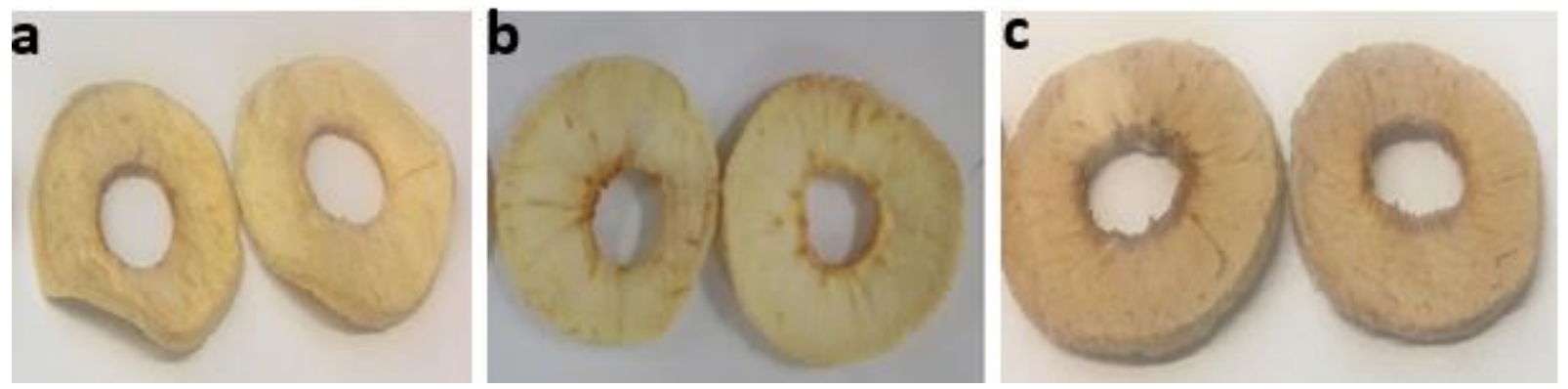

Figure 24. Samples of (a) untreated (b) sugar-infused (c) smoke-infused dried apple slices

\subsubsection{Changes in color parameters during storage duration}

Dried fruit's color is a function of the chemical, biological and physical reactions that occur during thermal processing. Color correlates well with other physiochemical properties and as such have been used as the fastest and simplest indirect measurement other quality attributes like flavor and other pigments (Pathare, et al., 2013). The primary pigments imparting color quality are the fat-soluble chlorophylls (green) and carotenoids (yellow, orange, and red) and the water-soluble anthocyanins (red, blue), flavonoids (yellow), and betalains (red). In addition, enzymatic and non-enzymatic browning reactions may result in the formation of water soluble brown, gray, and black colored pigments. The enzymes involved in browning reactions include polyphenol oxidase, which catalyzes the oxidation of 
polyphenolic compounds, and phenylalanine ammonia lyase, which catalyzes the synthesis of precursors to phenolic substrates (Barrett, et al., 2010). Regarding Fig 1, it is obvious that the RLS infused dried product had a uniform brown coloration while the sugar infused and untreated dried apples maintained the degree of white coloration of the initial fresh fruits with few dashes of brown color. The characteristic color of the RLS-infused sample may be due primarily to a combination of cold staining by brown coloration pigment (phenolics acid) on the fruit matrix present in the RLS-based osmotic solution (OS), which itself had rapidly turned brown after addition of the RLS into the solution and heat induced maillard reaction. The carbonyl compounds present in liquid smoke reacts with the protein compound forming maillard reaction products, which contributes to the golden-brown color (Montazeri et al., 2013; Varlet et al., 2007). Maillard reaction and ascorbic acid oxidation occur when apples are exposed to hot air at temperatures above $70^{\circ} \mathrm{C}$ for eight hours (Chong et al., 2013; Clegg \& Morton, 1965). Additionally, the oxidation of ascorbic acid produces reactive carbonyl compounds such as $\alpha$ - and $\beta$ - unsaturated carbonyl, which are browning agents (Chong et al., 2013). Secondarily, the brown coloration may be due to oxidation of polyphenols to o- quines catalyzed by polyphenol oxidase (PPO) as was seen in the untreated and sugar-infused samples (Beveridge \& Harrison, 1984; Chong et al., 2013). Since the brown coloration in both untreated and sugar-infused samples are considerably small and non-uniform, it could be primarily attributed to cold staining and maillard reaction (Toledo, 2007).

Table 2. Presents the color intensity indicators $\left(\mathrm{L}^{*}, \mathrm{a}^{*}, \mathrm{~b}^{*}\right)$, total color change, chroma and hue angle of untreated, sugar-infused and RLS-infused dried apple slices. It can be observed that there was a high deviation from control in $\mathrm{L}^{*}$ values for all samples, irrespective of the storage time and packaging condition, an indication browning occurred during the thermal treatment. For example, after air drying, the degree of lightness $L^{*}$ for untreated, sugar-infused and RLS-infused samples was $78 \pm 0.4,76.4 \pm 0.4$, and $67.8 \pm$ 0.3 , respectively; degree of redness was $1.0 \pm 0.2,1.0 \pm 0.2$, and $6.0 \pm 0.2$, respectively; degree of yellowness was $29.0 \pm 0.2,29.0 \pm 0.2$, and $22.8 \pm 0.6$, respectively. Overall, the RLS treated apples showed the highest change in color $(\Delta \mathrm{E})(17.7 \pm 0.3)$ whereas the sugar-infused and untreated samples showed similar color change $(7.9 \pm 0.3)$. Statistical analysis of the data reveals that the difference in 
degree of lightness was significantly $(\mathrm{P}<0.05)$ influenced by the main effects of pretreatments and time, but not type of packaging. However, the least deviation was recorded in the sugar-infused sample, and the largest deviation occurred in RLS-infused samples. The reason for minimal deviation of sugar-infused dried apples could be due to loss of ascorbic acid, vitamin $\mathrm{C}$ polyphenols (anthocyanin and phenolic) by the fruit usually during the OD pretreatment step. With these losses, there is not much polyphenols or ascorbic acid for Polyphenol oxidase (PPO) catalyzed oxidation. Giovanelli et al. reported a significant degradation of polyphenols in osmo-air dried blueberries in which the blueberries were osmosed in (1) sucrose solution and (2) glucose/fructose. 
Table 7. Changes in color parameters of convectively dried apple slices: untreated, treated in pure sugar OS, and treated in sugar OS with $1 \%$ RLS

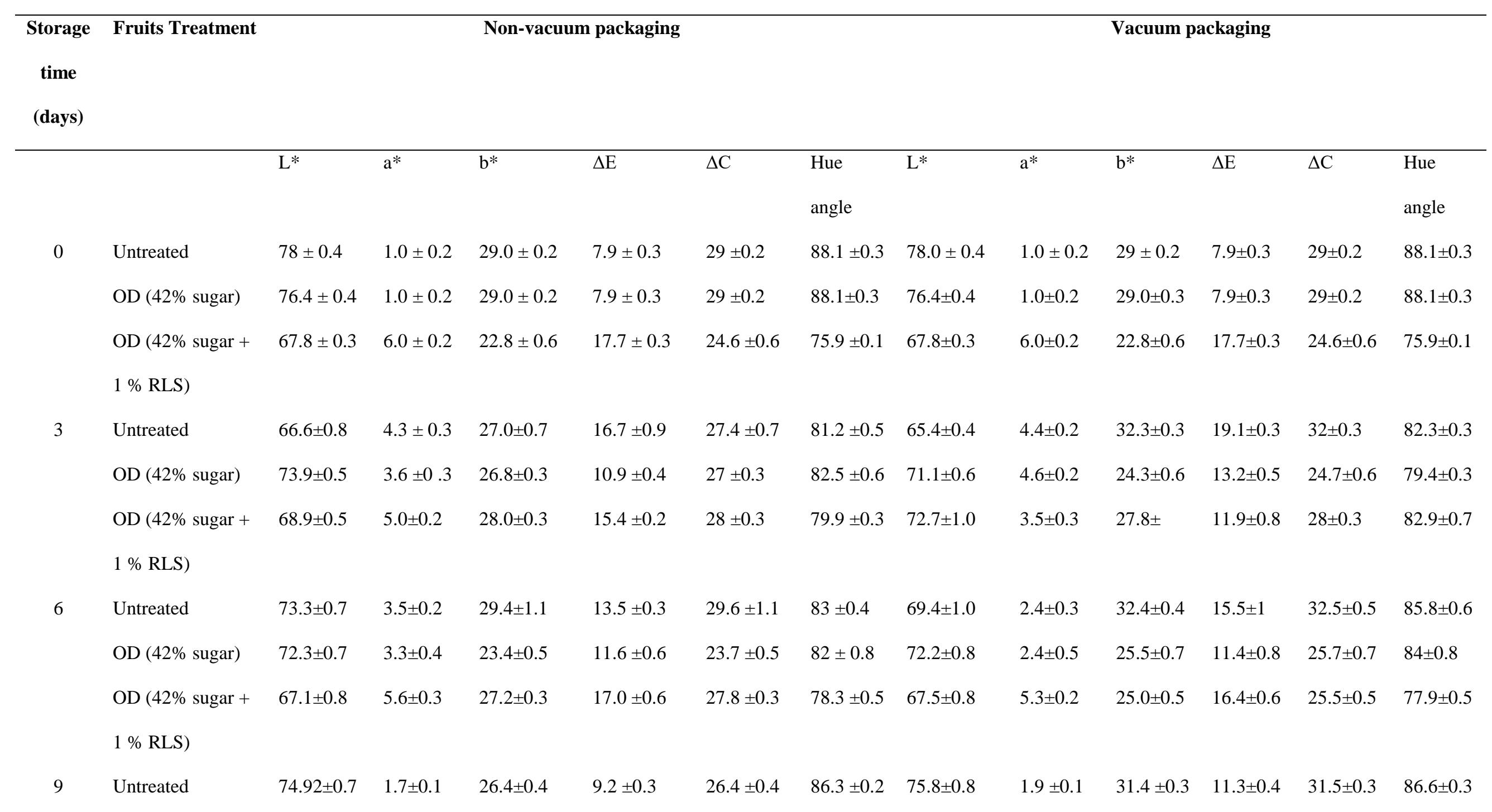




\begin{tabular}{|c|c|c|c|c|c|c|c|c|c|c|c|c|}
\hline DD (42\% sugar) & $73.9 \pm 0.9$ & $2.7 \pm 0.3$ & $25.3 \pm 0.5$ & $10.1 \pm 0.6$ & $25.5 \pm 0.5$ & $83.9 \pm 0.7$ & $74.0 \pm 0.5$ & $1.2 \pm 0.1$ & $22.9 \pm 0.7$ & $9.3 \pm 0.3$ & $23 \pm 0.6$ & $86.8 \pm 0.4$ \\
\hline D (42\% sugar + & $67.8 \pm 1.0$ & $4.4 \pm 0.2$ & $25.4 \pm 0.5$ & $15.7 \pm 0.8$ & $25.7 \pm 0.5$ & $80.2 \pm 0.3$ & $70.6 \pm 0.9$ & $3.8 \pm 0.3$ & $25.3 \pm 0.1$ & $12.9 \pm 0.8$ & $25.7 \pm 0.1$ & $81 \pm 0.7$ \\
\hline
\end{tabular}

$1 \%$ RLS)

12 Untreated

\begin{tabular}{|c|c|c|c|c|c|c|c|c|c|c|c|c|}
\hline Untreated & $74.1 \pm 0.6$ & $1.7 \pm 0.1$ & $28.3 \pm 0.3$ & $10.1 \pm 0.4$ & $28.4 \pm 0.3$ & $86.4 \pm 0.3$ & $70.9 \pm 1.5$ & $3.4 \pm 0.4$ & $29 \pm 0.2$ & $14.3 \pm 1.1$ & $29.3 \pm 0.1$ & $83.0 \pm 0.8$ \\
\hline (42\% sugar) & $78.1 \pm 0.5$ & $0.5 \pm 0.2$ & $20.4 \pm 0.8$ & $7.7 \pm 0.5$ & $20.5 \pm 0.8$ & $87.8 \pm 0.5$ & $75.1 \pm 1.1$ & $0.5 \pm 0.2$ & $22.9 \pm 0.7$ & $9.0 \pm 0.6$ & $22.9 \pm 0.6$ & $87.3 \pm 0.4$ \\
\hline$)(4$ & $65.4 \pm 0.7$ & $3.3 \pm 0.4$ & $21.7 \pm 1.1$ & $17.8 \pm 0.7$ & $22 \pm 1.1$ & $82 \pm 0.7$ & $65.9 \pm 0.7$ & $3.9 \pm 0.1$ & $23.9 \pm 0.6$ & $16.8 \pm 0.5$ & $24.2 \pm 0.6$ & $0.6 \pm 0$ \\
\hline
\end{tabular}
$1 \%$ RLS)

15 Untreated

$82.7 \pm 0.5 \quad 0.3 \pm 0.1 \quad 29.1 \pm 0.2 \quad 7.9 \pm 0.2$

$29.1+0.2$

$89.4 \pm 0.3 \quad 71.5 \pm 1.1$

$2.3 \pm 0.2$

$28.6 \pm 0.5 \quad 13.0 \pm 0.6$

$28.7 \pm 0.5 \quad 85.4 \pm 0.4$

OD (42\% sugar)

$74.5 \pm 0.3$

$0.3 \pm 0.2 \quad 23.6 \pm 0.5 \quad 7.4 \pm 0.4$

$23.7 \pm 0.5$

$87 \pm 0.1 \quad 73.7 \pm 0.8$

$1.2 \pm 0.3$

$25 \pm 0.7$

$86.4 \pm 0.5$

OD $(42 \%$ sugar +

$1 \%$ RLS)

Untreated

$69.3 \pm 0.8 \quad 4.6 \pm 0.4$

$23.5 \pm 1.5 \quad 16 \pm 0.7$

$24 \pm 1.6$

$79.2 \pm$

$71.5 \pm 0.9$

$3.4 \pm 0.2$

$28.7 \pm 0.8$

$13.6 \pm 0.7$

$28.9 \pm 0.9$

$83.3 \pm 0.3$

OD (42\% sugar)

$73.4 \pm 0.8 \quad 3.6 \pm 0.5$

$25.5 \pm 0.4 \quad 11 \pm 0.9$

$25.9 \pm 0.5 \quad 0.5$

$66.7 \pm 0.9$

$3.2 \pm 0.4$

$23.2 \pm 1$

$0 \quad 16.2 \pm 0.9$

$23.5 \pm 1$

$82.1 \pm 0.9$

OD $(42 \%$ sugar +

$63.1 \pm 0.9 \quad 3.5 \pm 0.1 \quad 20.5 \pm 0.3$

$19.2 \pm 0.9$

$20.7 \pm 0$

$81.6 \pm 0.8$

$61.1 \pm 0.5$

$8.6 \pm 0$

$30.1 \pm 0$

$23.9 \pm 0$

$31.3 \pm 0.2 \quad 74.10 .2$

$1 \%$ RLS)

60

Untreated

$72.2 \pm 0.6-4.2 \pm 0.1$

$23.5 \pm 0.4$

$80.3 \pm 0.3$

OD (42\% sugar)

$72.2 \pm 0.8 \quad 3.0 \pm 0.3 \quad 24.3 \pm 0.3 \quad 11.3 \pm 0.7$

$82.1 \pm 0.2$

OD $(42 \%$ sugar +

$65.7 \pm 0.8 \quad 5.6 \pm 0.2$

$28.5 \pm 0.5 \quad 18.5 \pm 0.6$

$24.6 \pm 0.3 \quad 83.1 \pm 0.6 \quad 70.2 \pm 0.3$

$4.9 \pm 0.1$

$27.6 \pm 0.2 \quad 26.8 \pm 0.5 \quad 28.0 \pm 0.2 \quad 80 \pm 0.3$ $1 \%$ RLS) 


\begin{tabular}{|c|c|c|c|c|c|c|c|c|c|c|c|c|c|}
\hline \multirow{4}{*}{90} & Untreated & $72.7 \pm 0.5$ & $4.6 \pm 0.3$ & $31.7 \pm 0.2$ & $14.1 \pm 0.5$ & $32 \pm 0.2$ & $81.7 \pm 0.4$ & $57.2 \pm 0.9$ & $7.0 \pm 0.4$ & $29.8 \pm 0.5$ & $26.5 \pm 0.8$ & $30.7 \pm 0.5$ & $77 \pm 0.7$ \\
\hline & OD (42\% sugar) & $74.8 \pm 1.0$ & $2.8 \pm 0.4$ & $27.2 \pm 0.3$ & $10.3 \pm 0.8$ & $27.4 \pm 0.4$ & $84.3 \pm 0.8$ & $65.2 \pm 0.5$ & $4.6 \pm 0.2$ & $25.5 \pm 0.6$ & $17.8 \pm 0.4$ & $25.9 \pm 0.6$ & $79.7 \pm 0.4$ \\
\hline & OD (42\% sugar + & $68.8 \pm 1.1$ & $11.9 \pm 1.8$ & $28.5 \pm 0.4$ & $18.5 \pm 1.5$ & $31.8 \pm 1.2$ & $69.3 \pm 2.5$ & $68.8 \pm 0.5$ & $5.3 \pm 0.2$ & $23.7 \pm 0.6$ & $15.3 \pm 0.4$ & $24.3 \pm 0.6$ & $77.5 \pm 0.2$ \\
\hline & $1 \%$ RLS) & & & & & & & & & & & & \\
\hline \multirow[t]{4}{*}{120} & Untreated & $68.9 \pm 0.8$ & $6.2 \pm 0.4$ & $31.6 \pm 0.4$ & $17.4 \pm 0.8$ & $32.2 \pm 0.4$ & $79 \pm 0.7$ & $67.4 \pm 0.4$ & $3.7 \pm 0.1$ & $25.9 \pm 0.2$ & $15.3 \pm 0.3$ & $26.2 \pm 0.2$ & $82 \pm 0.2$ \\
\hline & OD (42\% sugar) & $72.3 \pm 0.5$ & $3.9 \pm 0.3$ & $26.4 \pm 0.5$ & $11.8 \pm 0.6$ & $26.7 \pm 0.5$ & $81.9 \pm 0.6$ & $59.3 \pm 0.9$ & $4.3 \pm 0.3$ & $25.9 \pm 0.4$ & $22.7 \pm 0.9$ & $26.3 \pm 0.4$ & $80.5 \pm 0.7$ \\
\hline & OD (42\% sugar + & $65.6 \pm 0.4$ & $6.0 \pm 0.2$ & $25.0 \pm 0.5$ & $18.1 \pm 0.4$ & $25.7 \pm 0.5$ & $76.5 \pm 0.3$ & $54.7 \pm 0.4$ & $7.5 \pm 0.1$ & $28.4 \pm 0.3$ & $28.4 \pm 0.2$ & $29.4 \pm 0.3$ & $75.2 \pm 0.2$ \\
\hline & $1 \%$ RLS) & & & & & & & & & & & & \\
\hline \multirow[t]{4}{*}{150} & Untreated & $75.7 \pm 0.5$ & $4.8 \pm 0.1$ & $29.5 \pm 0.4$ & $12 \pm 0.4$ & $29.9 \pm 0.4$ & $80.7 \pm 0.1$ & $65.0 \pm 1.3$ & $4.3 \pm 0.2$ & $26.5 \pm 0.6$ & $18.4 \pm 0.9$ & $26.8 \pm 0.6$ & $80.8 \pm 0.1$ \\
\hline & OD (42\% sugar) & $71.7 \pm 0.9$ & $3.5 \pm 0.3$ & $25.4 \pm 0.8$ & $12.9 \pm 0.6$ & $25.7 \pm 0.9$ & $82 \pm 0.6$ & $71.2 \pm 1.1$ & $3.7 \pm 0.2$ & $29.6 \pm 0.6$ & $14.3 \pm 0.6$ & $29.8 \pm 0.6$ & $82.7 \pm 0.4$ \\
\hline & OD (42\% sugar + & $60.6 \pm 0.8$ & $6.9 \pm 0.2$ & $27.3 \pm 0.3$ & $22.9 \pm 0.7$ & $28.2 \pm 0.3$ & $75.9 \pm 0.3$ & $55.3 \pm 0.2$ & $8.8 \pm 0.3$ & $29.4 \pm 0.2$ & $28.6 \pm 0.6$ & $30.7 \pm 0.2$ & $73.5 \pm 0.4$ \\
\hline & $1 \%$ RLS) & & & & & & & & & & & & \\
\hline
\end{tabular}


Polyphenol degradation was lowest in untreated samples, having total losses of phenolics and anthocyanins of 11 and 26\%, respectively. A combined loss of 21-25\% total phenolic was recorded for osmosed samples in sucrose and glucose/fructose osmotic solution, while $43 \%$ and $30 \%$ losses of total anthocyanins were reported for sucrose and glucose/fructose osmosed blueberries (Giovanelli, et al., 2013). Unlike sugar-infused samples, the samples osmosed in a solution of both sugar and RLS (though they may have lost polyphenols from fruit during OD) should have gained abundance of polyphenols and carbonyl compound from the infused RLS to complement. These compounds as explained above are responsible for the brown coloration of the RLS-infuse dried sample. Total color change $\left(\Delta \mathrm{E}^{*}\right)$ was not often observed during the first two weeks of storage irrespective of the package condition except for the RLS-infused dried apples, which have a characteristic brown color due to their peculiar pretreatment. This remains so for the entire storage time and dried fruit packaged in a non-vacuum-packed bag, with $\Delta \mathrm{E}^{*}$ range of $7.9-17.4$ for untreated sample at all time high after 4 months of storage; $\Delta \mathrm{E}^{*}$ range of 7.9 12.9 for sugar infused dried apple, reaching its highest after 5 months of storage; while $\Delta \mathrm{E}^{*}$ range for RLS-infused, dried apples ranged between $15.4-22.9$ reaching its highest after 5 months of storage. The effects of vacuum package were observed to have no effect on the total change in color for the first 15 30 days of storage. However, considerable total color change $\left(\Delta \mathrm{E}^{*}\right)$ was noticed in the untreated dried apples reaching an all-time high after 60 days (26.8); sugar-infused apples reach their highest after 120 days (22.7) and RLS-infused after 60 days (28.7). Similar results were reported in literature, where sucrose and trehalose osmosed samples were found within the range of 14.24 -17.14 (Aktas, et al., 2013). They also reported that $\Delta \mathrm{E} *$ was rather high in untreated samples, compared with osmosed samples.

\subsubsection{Mechanical Properties}

Textural parameters of fruits are perceived with the sense of touch, either when the product is picked up by hand or placed in the mouth and chewed (Barrett et al., 2010). Textural properties of fracture force hardness, springiness, gumminess, and chewiness were measured for all samples except the ones vacuum packed. Samples stored in vacuum packaging glued together and were difficult to separate without 
inducing some form of pre-stress. Even after 1 day of storage, attempts to separate the apples slices caused fractures, which impaired textural measurements. Result of textural analysis of samples packed in non-vacuum polyethylene bags are presented in table 8 . It is observed that dried apple slices pretreated in sugar with RLS showed a considerably higher fracture force, hardness, springiness, gumminess, and chewiness compared to dried apples pretreated in pure sugar solution and untreated dried apples, immediately after drying and throughout the storage period. Untreated apples showed the least textural properties. However, the amount of springiness varied among different dried apple samples assayed possible due to the maturity, ripeness and tissue structure of the fruit used (D. Konopacka \& Plocharski, 2001). Additionally, the texture properties measure did not show a linear correlation with time similar to the moisture content of the samples at each storage period. However, the moisture content was observed to be relative stable and within the range of $5-8 \mathrm{~g} / 100 \mathrm{~g}$ fresh fruit. Lewicki and Lukaszuk reported that dewatering caused substantial changes in mechanical properties of apple tissue for osmo-convective dehydration of apple cubes. Shrinkage due to osmotic pre-treatment was small but stiffness was half the value obtained by convective drying of apple cubes to the same final water content (Lewicki \& Lukaszuk, 2000). It is reported that osmotic dehydration increases the hardness of fruits and improves it plasticity and chew-ability by lowering its glass transition temperature (Tg), even at low moisture content. The lowering of Tg is possible since OD infuses the product with low molecular weight humectants (glucose, fructose, invert sugar, etc.) (Aktas, et al., 2013; Bhandari \& Howes, 1999; Chauhan, et al., 2011; Lewicki \& Lukaszuk, 2000). The effects of liquid smoke on the hardness and textural properties of food are due to the presence of abundant carbonyl compound, which reacts with the protein compound in the food. The addition of liquid smoke increased the tensile strength of gelatin film, depending on the liquid smoke concentration. A $3 \mathrm{wt} \%$ of liquid smoke gave about $50 \%$ improvement in tensile strength of gelatin film (Wang, et al., 2016). 
Table 8. Texture properties of convectively dried apple slices: untreated, treated in pure sugar OS, and treated in sugar OS with $1 \%$ RLS

\begin{tabular}{|c|c|c|c|c|c|c|}
\hline \multirow{2}{*}{$\begin{array}{l}\text { Storage time } \\
\quad \text { (days) }\end{array}$} & \multirow[t]{2}{*}{ Treatment } & \multicolumn{4}{|c|}{ Non-vacuum packaging } & \multirow[b]{2}{*}{ Chewiness } \\
\hline & & Force (gf) & Hardness (g) & Springiness & Gumminess & \\
\hline \multirow[t]{3}{*}{0} & Untreated & $14724.3 \pm 747.1$ & $12173.7 \pm 630.2$ & $0.6 \pm 0.1$ & $2052.9 \pm 179$ & $1887.4 \pm 544$ \\
\hline & OD (42\% sugar) & $46053.8 \pm 4736.7$ & $38376.7 \pm 4003.9$ & $0.9 \pm 0.1$ & $10643.3 \pm 1139.1$ & $12350.6 \pm 2309.1$ \\
\hline & $\begin{array}{l}\text { OD }(42 \% \text { sugar }+ \\
1 \% \text { RLS })\end{array}$ & $68057.7 \pm 7687.3$ & $62642.7 \pm 6721.2$ & $1.5 \pm 0.1$ & $16961.4 \pm 1910.8$ & $31121.0 \pm 5073.4$ \\
\hline \multirow[t]{3}{*}{3} & Untreated & $11914.6 \pm 916.3$ & $10068.5 \pm 669.8$ & $0.8 \pm 0.1$ & $2460.4 \pm 278.7$ & $2697.8 \pm 646.9$ \\
\hline & OD (42\% sugar) & $71318.1 \pm 6389.4$ & $63202.2 \pm 5789.4$ & $1.3 \pm 0.1$ & $20255.3 \pm 1848.6$ & $20016.5 \pm 1696.7$ \\
\hline & $\begin{array}{l}\text { OD }(42 \% \text { sugar }+ \\
1 \% \text { RLS })\end{array}$ & $123955.8 \pm 10602.5$ & $110787.4 \pm 8944.6$ & $0.6 \pm 0.1$ & $32168.2 \pm 2010.2$ & $17746.2 \pm 2265.1$ \\
\hline \multirow[t]{3}{*}{6} & Untreated & $39943.5 \pm 3178.3$ & $2043.2 \pm 786.4$ & $0.2 \pm 0.1$ & $405.2 \pm 162.1$ & $341.8 \pm 136.7$ \\
\hline & OD (42\% sugar) & $56089.4 \pm 4437.7$ & $49427.7 \pm 4006.2$ & $1.4 \pm 0.1$ & $15254.0 \pm 1251.3$ & $23023.1 \pm 2756.6$ \\
\hline & $\begin{array}{l}\text { OD }(42 \% \text { sugar }+ \\
1 \% \text { RLS })\end{array}$ & $64166.2 \pm 1895.1$ & $58311.3 \pm 1398.1$ & $1.8 \pm 0.0$ & $22910.5 \pm 863.1$ & $42053.7 \pm 1583.2$ \\
\hline \multirow[t]{3}{*}{9} & Untreated & $40668.6 \pm 1850.5$ & $35864.5 \pm 1569.7$ & $1.2 \pm 0.1$ & $12845.3 \pm 514.2$ & $16242.1 \pm 2119.7$ \\
\hline & OD (42\% sugar) & $52979.1 \pm 1948.2$ & $47406.4 \pm 1692.2$ & $1.5 \pm 0.1$ & $17388.7 \pm 693.8$ & $26190.9 \pm 2260.8$ \\
\hline & $\begin{array}{l}\text { OD }(42 \% \text { sugar }+ \\
1 \% \text { RLS })\end{array}$ & $80824.9 \pm 1910.3$ & $72180.0 \pm 1849.6$ & $1.0 \pm 0.1$ & $25197.4 \pm 1154.7$ & $28253.2 \pm 4735.0$ \\
\hline \multirow[t]{3}{*}{12} & Untreated & $20983.6 \pm 1833.9$ & $19118.6 \pm 1424.3$ & $1.1 \pm 0.1$ & $15146.9 \pm 1628.7$ & $21112.4 \pm 3973.9$ \\
\hline & OD (42\% sugar) & $69834.7 \pm 4003.7$ & $61727.0 \pm 3617.2$ & $1.3 \pm 0.1$ & $19408.8 \pm 962.1$ & $24670.8 \pm 2204.2$ \\
\hline & $\begin{array}{l}\text { OD }(42 \% \text { sugar }+ \\
1 \% \text { RLS })\end{array}$ & $63763.0 \pm 1323.6$ & $56439.8 \pm 1073.5$ & $1.5 \pm 0.1$ & $22233.2 \pm 427.8$ & $32724.1 \pm 2510.7$ \\
\hline \multirow[t]{3}{*}{15} & Untreated & $91958.2 \pm 6439.7$ & $80930.6 \pm 5552.2$ & $1.2 \pm 0.2$ & $21417.3 \pm 1071.8$ & $23193.7 \pm 2635.9$ \\
\hline & OD (42\% sugar) & $58586.5 \pm 4624.1$ & $51896.9 \pm 3729.8$ & $1.9 \pm 0.0$ & $21145.2 \pm 1355.6$ & $40318.5 \pm 28152.2$ \\
\hline & $\begin{array}{l}\text { OD }(42 \% \text { sugar }+ \\
1 \% \text { RLS })\end{array}$ & $75057.9 \pm 5208.2$ & $66574.7 \pm 4606.2$ & $1.8 \pm 0.0$ & $25963.1 \pm 1635.6$ & $47650.2 \pm 3003.7$ \\
\hline
\end{tabular}


30

60

90

120

150

$\begin{array}{llll}\text { Untreated } & 38334.1 \pm 1020.4 & 35364.6 \pm 876.0 & 1.8 \pm 0.0 \\ \text { OD (42\% sugar) } & 47405.2 \pm 6018.0 & 43318.2 \pm 5456.1 & 1.3 \pm 0.1 \\ \text { OD (42\% sugar }+ & 95828.5 \pm 2772 & 81545.7 \pm 2865.9 & 1.5 \pm 0.1 \\ 1 \% \text { RLS) } & & & \\ \text { Untreated } & 49993.2 \pm 4281.6 & 45851.3 \pm 3683.7 & 1.5 \pm 0.1 \\ \text { OD (42\% sugar) } & 62269.1 \pm 4450.1 & 53327.9 \pm 3208.1 & 0.8 \pm 0.1 \\ \text { OD (42\% sugar }+ & 63619.8 \pm 5220.2 & 51166.5 \pm 4858.8 & 1.3 \pm 0.1 \\ 1 \% \text { RLS } & & & \\ \text { Untreated } & 37254.5 \pm 4111.8 & 33900.4 \pm 5616.9 & 1.6 \pm 0.0 \\ \text { OD (42\% sugar) } & 59135.8 \pm 3851.9 & 50838.8 \pm 3481.3 & 1.1 \pm 0.1 \\ \text { OD (42\% sugar + } & 117758.8 \pm 5589.1 & 104034.0 \pm 4845.1 & 1.0 \pm 0.1\end{array}$
$1 \%$ RLS)

Untreated
OD (42\% sugar)
OD (42\% sugar +
$1 \%$ RLS)

$22012.5 \pm 458.7$

$17196.5 \pm 2247.1$

$30290.0 \pm 1173.6$

$20845.2 \pm 4907.6$

$13682.9 \pm 1111.4$

$30213.7 \pm 2888.7$

$39146.2 \pm 2710.6$ $13044.9 \pm 642.0$

$31918.4 \pm 1562.5$

$43518.9 \pm 1081.3$ $32103.1 \pm 2187.9$ $28059.6 \pm 1283.6$

$22299.8 \pm 1686.7$ $29787.9 \pm 1473.5$ $28514.9 \pm 2324.5$
$40402.3 \pm 839.7$ $26111.5 \pm 4849.4$ $46827.7 \pm 4209$

$29533.7 \pm 9420.3$ $13256.9 \pm 2422.8$ $49832.7 \pm 7428.3$

$70418.3 \pm 4969.9$ $15415.7 \pm 2067.2$ $29919.1 \pm 5545.2$

$79852.5 \pm 2505$ $45785.9 \pm 4412.8$ $17638.2 \pm 2223.6$

$31565.1 \pm 4907.7$ $41640.1 \pm 5313$ $27841.9 \pm 4005$
$74356.1 \pm 2549.4 \quad 1.3 \pm 0.1$

$108608.4 \pm 7034.4 \quad 0.9 \pm 0.1$ 


\subsubsection{Microbial analysis}

Concurrent use of multiple factors affecting microbial growth in order to extend shelf-life of food products is commonly referred to as "hurdle technology". These factors include $\mathrm{pH}$, water activity, temperature, redox potential, competitive microflora, and preservatives (Leistner, 2000). In the present study, the effect of RLS addition to osmotic dehydration of apples on total aerobic plate count and yeast/mold count under different storage and packaging conditions was evaluated (Figure 25a and 25b). Figure 25a reveals that on day 0, the microbial counts of untreated, sugar-infused, and RLS-infused dried apples were $4.3 \mathrm{log}$ CFU/g, not detectable (ND), and $4.2 \log$ CFU/g respectively. After three days under non-vacuum packaging, the untreated sample showed slight microbial growth at $5.3 \log$ CFU/g; while the sugar-infused sample reached $5.4 \log$ CFU/g. No growth was detected in RLS-infused samples until day 12 and 15 . This indicates that addition of liquid smoke extended the lag phase for about 11 days before any detectable growth.

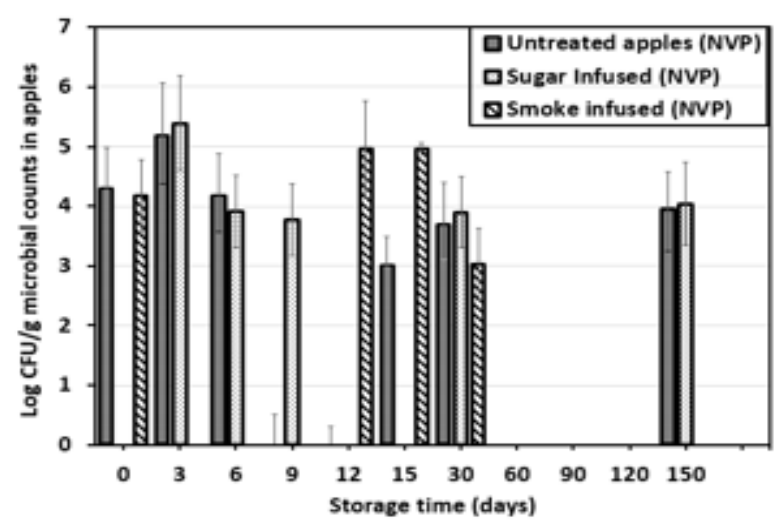

(a)

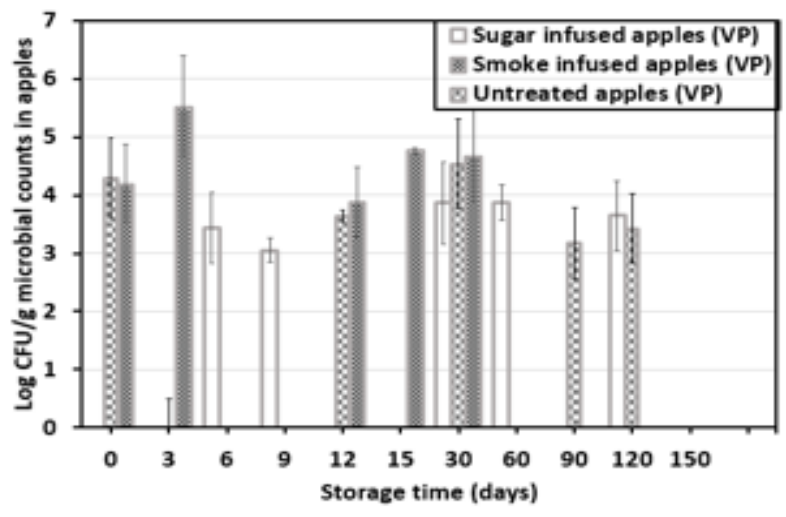

(b)

Figure 25. Aerobic plate count (APC) in apple slices that were untreated, sugar-infused, or RLSinfused and stored at room temperature in (a) non-vacuum pack (NVP) or (b) vacuum pack (VP). Blank space shows below detection level.

The results of vacuum package on total microbial growth are presented in figure $25 \mathrm{~b}$. The RLS-infused apple samples showed the least lag time, followed by sugar-infused sample. However, microbial growth was no longer detected in RLS-infused sample after 30 days of storage, unlike untreated and sugar-infused 
dried apple samples that still recorded a detectable growth after 150 days. It may be evident that the vacuum packaging has a negative effect on the RLS-infused apples and a positive effect on the untreated sample and sugar-infused dried apple sample, overall statistical analysis showed that package type insignificantly $(\mathrm{p}>0.05)$ influenced the observed differences, but pretreatment and storage time did have a significant effect $(\mathrm{p}<0.05)$ on microbial growth and reduction. Microbial counts were less than $5 \log$ CFU/g, which is the maximum permissible level in food (Chun, et al., 2012).

Total yeast and mold counts for vacuum and non-vacuum package are presented in Figure 26a and $26 \mathrm{~b}$. Yeast growth was detected after drying of untreated and RLS-infused dried apples, while as much as $1 \log$ CFU/g was found in the sugar-infused sample. Samples of untreated and RLS-infused dried apples showed a lag time of 9 and 12 days, respectively while growth was immediately detected in the sugar-infused samples after 3 days of storage in a non-vacuum condition.

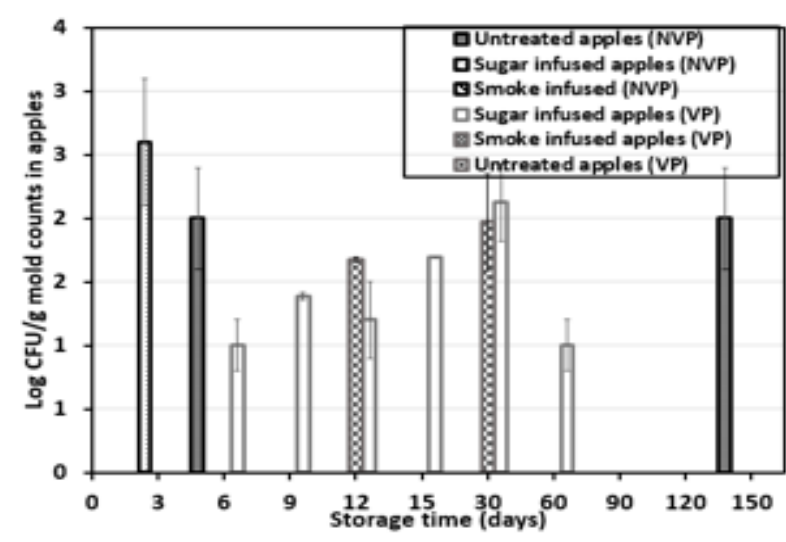

(a)

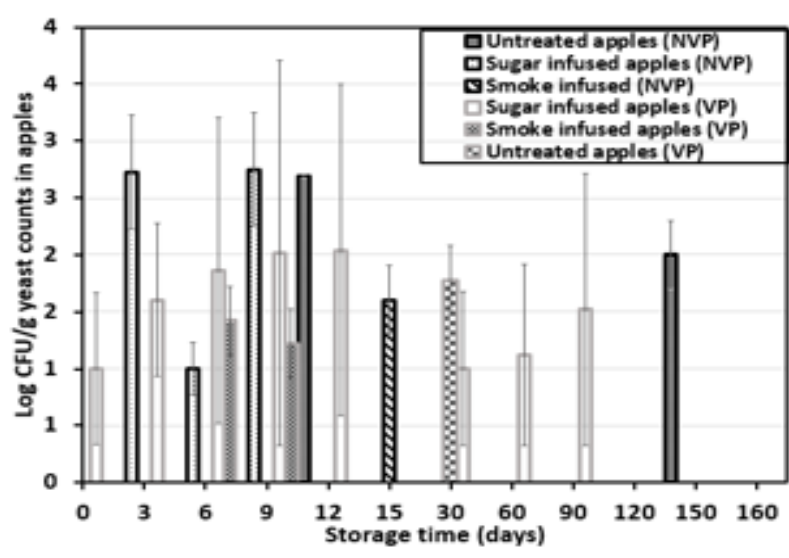

(b)

Figure 26. (a) Total yeast count and (b) total mold count in apple slices untreated, sugar- infused, RLS-infused and stored at room temperature in non-vacuum pack (NVP) and vacuum pack (VP). Blank space show below detection level.

Again, vacuum impacted negatively on the yeast growth in sugar-infused and RLS-infused dried apples, except the untreated dried apples. Overall statistical analysis reveals that storage time and package type insignificantly $(\mathrm{p}>0.05)$ influenced the observed differences, but pretreatment have a significant effect on 
yeast growth and reduction. Mold growth was not detected in non-vacuum packed RLS-infused apples. It was only detected after 3 days and 6 days of storage in sugar-infused and untreated dried apples, respectively. Molds seemed to grow better under vacuum than non-vacuum packaging for all samples. However, overall statistical analysis revealed that storage time and packaging type insignificantly $(\mathrm{p}>$ $0.05)$ influenced observed differences, but pretreatment had a significant $(\mathrm{p}<0.05)$ effect on mold growth and reduction.

\subsection{Conclusion}

From this study exploring the use of liquid smoke as a food additive and antimicrobial agent, we concluded that osmo-convective dehydration using sugar as an osmotic agent retains the freshness color of dried apples better than untreated dried apples. Adding liquid smoke to sugar based osmotic solution causes a uniform brown coloration in the resultant dried fruit, due to an abundance of browning agents (carbonyls and polyphenols) present in the liquid smoke. The uniformity of the brown coloration does not suggest an off-color as is seen with untreated or sugar-infused dried apples, but a peculiar color of the dried fruit itself. Addition of liquid smoke was responsible for higher values of fracture force, hardness, gumminess, and chewiness recorded in RLS-infused dried apples compared to other samples. Finally, liquid smoke increased lag phase of microbial growth in dried apples during storage to a greater extent than untreated dried apples or sugar-infused dried apples. More so, effect of packaging type did not significantly affect the growth or death of the indigenous bacteria in the stored apple snacks. In the 5month shelf study, none of the treated samples showed microbial growth above 5- log CFU/g.

\section{Acknowledgements}

The research work is available for commercialization through WVU Intellectual Property Disclosure\# 2017-039. This work is partially supported by the USDA National Institute of Food and Agriculture, McIntire Stennis project. In addition, support was also provided by West Virginia University (WVU) Extension Service-Families and Health Programs and also by Northeast Center to Advance Food Safety- 
Special Projects Grant Program. Project dissemination support was provided by USDA/NIFA under Award Number 2015-49200-24225. 
References

Akharume, F. U., Singh, K., \& Sivanandan, L. (2016). Characteristics of apple juice and sugar infused fresh and frozen blueberries. LWT - Food Science and Technology, 73, 448-457. doi:http://dx.doi.org/10.1016/j.lwt.2016.06.041

Aktas, T., Ulger, P., Daglioglu, F., \& Hasturk, F. (2013). Changes of nutritional and physical quality characteristics during storage of osmotic pretreated apple before hot air drying and sensory evaluation. Journal of Food Quality, 36(6), 411-425.

Barrera, C., Betoret, N., \& Fito, P. (2004). Ca2+ and Fe2+ influence on the osmotic dehydration kinetics of apple slices (var. Granny Smith). Journal of Food Engineering, 65(1), 9-14. doi:http://dx.doi.org/10.1016/j.jfoodeng.2003.10.016

Barrett, D. M., Beaulieu, J. C., \& Shewfelt, R. (2010). Color, flavor, texture, and nutritional quality of fresh-cut fruits and vegetables: desirable levels, instrumental and sensory measurement, and the effects of processing. Critical Reviews in Food Science and Nutrition, 50(5), 369-389.

Bayman, P., Baker, J. L., Doster, M. A., Michailides, T. J., \& Mahoney, N. E. (2002). Ochratoxin production by the Aspergillus ochraceus group and Aspergillus alliaceus. Applied and Environmental Microbiology, 68(5), 2326-2329.

Bayman, P., Baker, J. L., \& Mahoney, N. E. (2002). Aspergillus on tree nuts: incidence and associations. Mycopathologia, 155(3), 161-169.

Betoret, N., Puente, L., Díaz, M. J., Pagán, M. J., García, M. J., Gras, M. L., . . Fito, P. (2003). Development of probiotic-enriched dried fruits by vacuum impregnation. Journal of Food Engineering, 56(2-3), 273-277. doi:http://dx.doi.org/10.1016/S0260-8774(02)00268-6

Bhandari, B., \& Howes, T. (1999). Implication of glass transition for the drying and stability of dried foods. Journal of Food Engineering, 40(1), 71-79.

Castelló, M., Igual, M., Fito, P., \& Chiralt, A. (2009). Influence of osmotic dehydration on texture, respiration and microbial stability of apple slices (Var. Granny Smith). Journal of Food Engineering, 91(1), 1-9.

Chardonnet, C. O., Sams, C. E., Conway, W. S., Mount, J. R., \& Draughon, F. A. (2001). Osmotic dehydration of apple slices using a sucrose $/ \mathrm{CaCl} 2$ combination to control spoilage caused by Botrytis cinerea, Colletotrichum acutatum, and Penicillium expansum. Journal of Food Protection ${ }^{\circledR}, 64(9), 1425-1429$.

Chauhan, O. P., Singh, A., Singh, A., Raju, P. S., \& Bawa, A. S. (2011). Effects of Osmotic Agents on Colour, Textural, Structural, Thermal, and Sensory Properties of Apple Slices. International Journal of Food Properties, 14(5), 1037-1048. doi:10.1080/10942910903580884

Chun, H. H., Kim, M. S., Chung, K. S., Won, M., \& Song, K. B. (2012). Dehydration of blueberries using maltodextrin and the physicochemical properties of dried blueberries. Horticulture, Environment, and Biotechnology, 53(6), 565-570.

Derrickson-Tharrington, E., Kendall, P. A., \& Sofos, J. N. (2005). Inactivation of Escherichia coli O157:H7 during storage or drying of apple slices pretreated with acidic solutions.

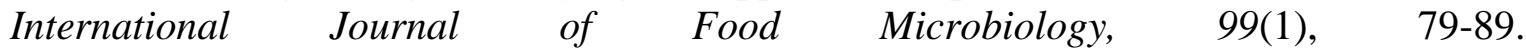
doi:http://dx.doi.org/10.1016/j.ijfoodmicro.2004.07.015

Erihemu, Hironaka, K., Koaze, H., Oda, Y., \& Shimada, K. (2015). Zinc enrichment of whole potato tuber by vacuum impregnation. Journal of Food Science and Technology, 52(4), 2352-2358. doi:10.1007/s13197-013-1194-5 
Falade, K. O., \& Shogaolu, O. T. (2010). Effect of pretreatments on air-drying pattern and color of dried pumpkin (cucurbita maxima) slices. Journal of Food Process Engineering, 33(6), 1129-1147.

Giovanelli, G., Brambilla, A., \& Sinelli, N. (2013). Effects of osmo-air dehydration treatments on chemical, antioxidant and morphological characteristics of blueberries. LWT-Food Science and Technology, 54(2), 577-584.

Haizhen, M., Min, Z., \& Jincai, S. (2006). Effect of drying process parameters on dehydrated cabbage enriched with selenium. Drying Technology, 24(12), 1657-1663. doi:10.1080/07373930601031497

Iamanaka, B. T., Taniwaki, M. H., Menezes, H. C., Vicente, E., \& Fungaro, M. H. P. (2005). Incidence of toxigenic fungi and ochratoxin $\mathrm{A}$ in dried fruits sold in Brazil. Food Additives \& Contaminants, 22(12), 1258-1263. doi:10.1080/02652030500260447

Ic, E., Kottapalli, B., Maxim, J., \& Pillai, S. D. (2007). Electron beam radiation of dried fruits and nuts to reduce yeast and mold bioburden. Journal of Food Protection $®, ~ 70(4), 981-985$.

Konopacka, D., Jesionkowska, K., Mieszczakowska, M., \& Płocharski, W. (2008). The usefulness of natural concentrated fruit juice as osmotic agent for osmo-dehydrated dried fruit production. Journal of Fruit and Ornamental Plant Research, 16, 275-284.

Konopacka, D., \& Plocharski, W. (2001). Effect of raw material storage time on the quality of apple chips. Drying Technology, 19(3/4), 559.

Koyuncu, T., Tosun, İ., \& Pinar, Y. (2007). Drying characteristics and heat energy requirement of cornelian cherry fruits (Cornus mas L.). Journal of Food Engineering, 78(2), 735-739. doi:http://doi.org/10.1016/j.jfoodeng.2005.09.035

Leistner, L. (2000). Basic aspects of food preservation by hurdle technology. International Journal of Food Microbiology, 55(1-3), 181-186. doi:http://dx.doi.org/10.1016/S01681605(00)00161-6

Lewicki, P. P., \& Lukaszuk, A. (2000). Effect of osmotic dewatering on rheological properties of apple subjected to convective drying. Journal of Food Engineering, 45(3), 119-126.

Mandala, I. G., Anagnostaras, E. F., \& Oikonomou, C. K. (2005). Influence of osmotic dehydration conditions on apple air-drying kinetics and their quality characteristics. Journal of Food Engineering, 69(3), 307-316. doi:http://dx.doi.org/10.1016/j.jfoodeng.2004.08.021

Maturin, L. J. r., \& Peeler, J. T. r. (1998). Aerobic Plate Count. In R. I. Merker (Ed.), Bacteriological Analytical Manual (BAM) (8, Revision A ed.). Center for Food Safety and Applied Nutrition, FDA: FDA.

Mišljenović, N. M., Koprivica, G. B., Pezo, L. L., Kuljanin, T. A., Bodroža-Solarov, M. I., \& Filipčev, B. V. (2011). Application of Peleg model to study mass transfer during osmotic dehydration of apple in sugar beet molasses. Acta Periodica Technologica(42), 91-100.

Montazeri, N., Oliveira, A., Himelbloom, B. H., Leigh, M. B., \& Crapo, C. A. (2013). Chemical characterization of commercial liquid smoke products. Food science \& nutrition, 1(1), 102-115.

Moreno, J., Chiralt, A., Escriche, I., \& Serra, J. A. (2000). Effect of blanching/osmotic dehydration combined methods on quality and stability of minimally processed strawberries. Food Research International, 33(7), 609-616. doi:http://doi.org/10.1016/S0963-9969(00)00097-1

Nsonzi, F., \& Ramaswamy, H. (1998). Osmotic dehydration kinetics of blueberries. Drying Technology, 16(3-5), 725-741. 
Pallas, L. (2011). Drying methods and their effects on bioactive compounds and quality of Georgia blueberries. Unpublished doctoral dissertation]. Athens, GA: University of Georgia.

Pan, Y., Zhao, L., Zhang, Y., Chen, G., \& Mujumdar, A. S. (2003). Osmotic dehydration pretreatment in drying of fruits and vegetables. Drying Technology, 21(6), 1101-1114.

Pathare, P. B., Opara, U. L., \& Al-Said, F. A.-J. (2013). Colour measurement and analysis in fresh and processed foods: a review. Food and Bioprocess Technology, 6(1), 36-60.

Rudy, S., Dziki, D., Krzykowski, A., Polak, R., Biernacka, B., \& Kulig, R. (2013). Influence of osmotic dehydration on convective drying process of cherries. Teka Komisji Motoryzacji $i$ Energetyki Rolnictwa, 13(1).

Saloko, S., Darmadji, P., Setiaji, B., \& Pranoto, Y. (2014). Antioxidative and antimicrobial activities of liquid smoke nanocapsules using chitosan and maltodextrin and its application on tuna fish preservation. Food Bioscience, 7, 71-79.

Santacruz-Vázquez, C., Santacruz-Vázquez, V., Jaramillo-Flores, M. E., Chanona-Pérez, J., Welti-Chanes, J., \& Gutiérrez-López, G. F. (2008). Application of osmotic dehydration processes to produce apple slices enriched with $\beta$-carotene. Drying Technology, 26(10), 1265-1271. doi:10.1080/07373930802307266

Torreggiani, D., \& Bertolo, G. (2001). Osmotic pre-treatments in fruit processing: chemical, physical and structural effects. Journal of Food Engineering, 49(2), 247-253.

Tournas, V. Stack., M.E. (ret.); Mislivec, P. B. (dec.); Koch, H. A.; Bandler, R. (2000). Yeasts, Molds, and Mycotoxins. In R. I. Merker (Ed.), Bacteriological Analytical Manual (BAM) (8, Revision A ed.). Center for Food Safety and Applied Nutrition (CSFAN), FDA.

Trucksess, M., \& Scott, P. (2008). Mycotoxins in botanicals and dried fruits: a review. Food Additives and Contaminants, 25(2), 181-192.

USApples Association. (2015). The Production and Utilization Analysis for the 2015 U.S. Apple Association Apple Crop Outlook and Marketing Conference Retrieved from, Vienna, Virginia:

USDA. (2017). Outlook for US Agricultural Trade. Retrieved from USDA

Wang, W., Li, C., Zhang, H., \& Ni, Y. (2016). Using liquid smoke to improve mechanical and water resistance properties of gelatin films. Journal of Food Science, 81(5), E1151-E1157.

Yadav, A. K., \& Singh, S. V. (2014). Osmotic dehydration of fruits and vegetables: a review. Journal of Food Science and Technology, 51(9), 1654-1673. doi:10.1007/s13197-0120659-2

Chapter 5: Summary

5.1 Summary 
Osmotic dehydration as a pretreatment step to convective drying is such an important unit process, without which the convective drying of fruit would become inefficient and energy intensive. However, the infusion of sugar (especially for dietary concern customers) is a challenge that is yet to be fully solved.

In this research, use of apple juice during osmotic dehydration of fresh and frozen blueberries was compared with traditional sucrose solution. Additionally, use of liquid smoke during traditional sucrosebased osmotic dehydration of apples was evaluated for process kinetics,textural characteristics, and shelflife of the product.

The results of using apple juice during osmotic dehydration have been presented in the chapter 2. Our research established that the effect of freezing the fruit prior to hot air drying showed a significant reduction in drying time (53\% reduction) to reach $0.18 \mathrm{~g}$ water /g of dry solid compared with the fresh blueberries. Individually Quickly Frozen (IQF) and fresh berries followed the convectional drying characteristic curves typical of fruit, where only falling rate period but no constant rate regime exists. The drying behavior and higher drying rate of the IQF berries were facilitated by the ruptured nature of the berries' waxy skin caused by freezing. The use of osmotic dehydration prior to drying significantly reduced the moisture content of the IQF fruit by about $30 \%$ (from $5.70-3.97 \mathrm{~g}$ of water/g of dry solid) and fresh blueberries by $15 \%(5.16-4.3997 \mathrm{~g}$ of water/g of dry solid). Additionally, an apple juice-based osmotic solution led to higher solid gains in the IQF blueberries than that achieved from a sugar-based osmotic solution. On the subsequent hot air drying, the IQF berries treated with sugar-based solution showed a shorter drying time of 420 min than that treated with apple juice-based solution (480 min) to achieve a water activity of 0.4 . Therefore, fruit juice concentrates (for example, apple juice) may be used as an osmotic solution as a substitute for granulated sugar without compromising final yield of the dried blueberries.

The results of using refined liquid smoke (RLS) during osmotic dehydration (OD) have been presented in the chapter 3. The OD process reduced moisture content of fruit to about $53 \%$ of the initial moisture 
content. The final WL was $247 \%$ and $197 \%$ of the initial observed WL (5 min. OD time) and the final SG was $180 \%$ and $96 \%$ of the initial observed SG (5 min. OD time) for RLS-treated and control OD, respectively. Addition of $1 \%$ RLS to the OS significantly increased WL and SG. Finally, addition of RLS during OD prevented collapse of the surface cell of the apple cubes during the first hour of OD, thereby facilitating higher water loss and solid gained than the control. Overall, microstructural images showed that osmotic dehydration causes plasmolysis of the cell wall and modified the cellular structure of apple cell at the surface in contact with osmotic solution for both treated and controlled samples.

Finally, influence of RLS on textural characteristics and shelf life of dried apples have been presented in the chapter 4 . The results showed that osmo-convective dehydration using sugar as an osmotic agent retains the freshness color of dried apples better than untreated dried apples. Addition of liquid smoke to sugar based osmotic solution causes a uniform brown coloration in the resultant dried fruit due to abundance of browning agents (carbonyls and polyphenols) present in the liquid smoke. The uniformity of the brown coloration does not suggest an off-color as is seen with untreated or sugar-infused dried apples, but a peculiar color of the dried fruit itself. Addition of liquid smoke was responsible for higher value of fracture force, hardness, gumminess, and chewiness recorded in smoke-infused dried apples compared to other samples. Finally, the antimicrobial effect of liquid smoke increased the lag time of dried apples in storage better than pure sugar infusion or non-treatment. More so, non-vacuum packed osmosed dried apples showed a lower microbial growth compared to vacuum packed ones, although there is no significant difference due to the type of package. In this study, all samples showed a microbial shelf life of 5 months. 


\subsection{Recommendation for future research}

In this study, a lot of attention has been focused on the kinetics and microbiology of osmotic dehydration and convective drying. The possibility of using apple juice as an alternative to the conventional use of sugar syrup has been explored. Additionally, the possibility of infusing smoke into dried apples as both a flavor and antimicrobial agent has been undertaken as well and results reported. While all these have been accomplished, there is much yet to be done. The qualitative sensorial analysis is an area that needs to be studied for RLS-infused fruits. Research is also needed to understand the nutritional profile of RLS infused fruits. Here intent was to develop technology for producing RLS-infused apple snacks that would be adopted by the small-scale apple farmers who have very hard time selling their products in fresh produce market. Therefore, a detailed economic impact analysis is needed to demonstrate scale of benefits to the state of West Virginia if farmers adopt this practice. The economic impact analysis would provide insight to policy makers to assist small farmers with infrastructure and market opportunities.

Appendix I: Color assay measurement from 0- 150 days of storage 


\begin{tabular}{|c|c|c|}
\hline 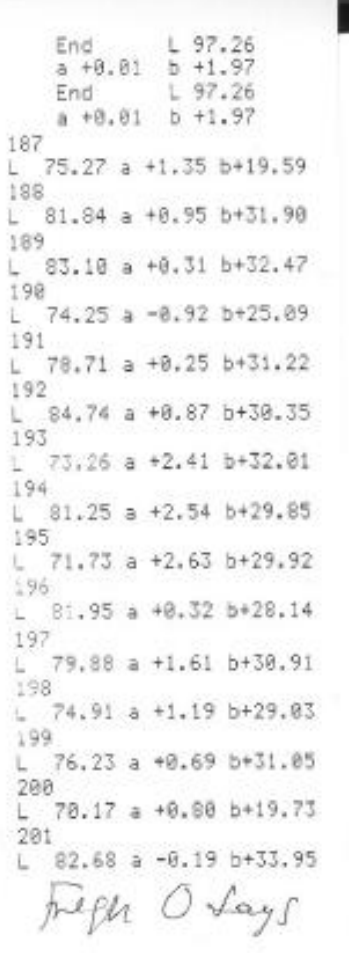 & 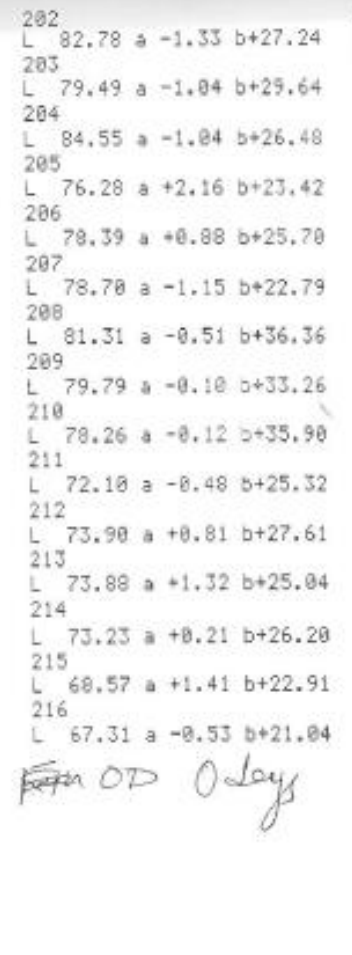 & 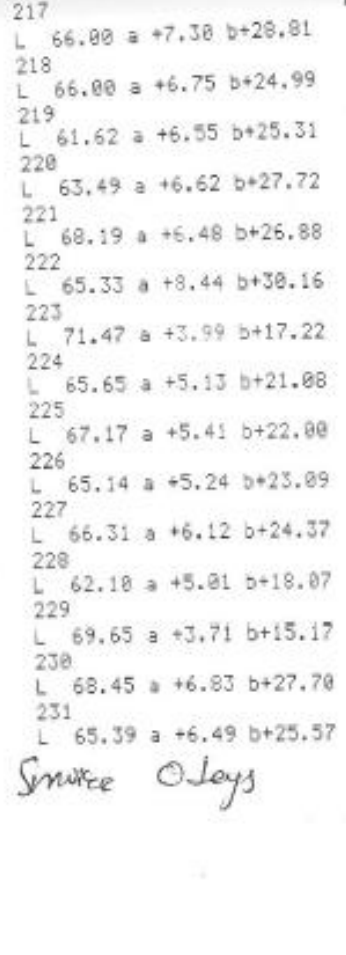 \\
\hline 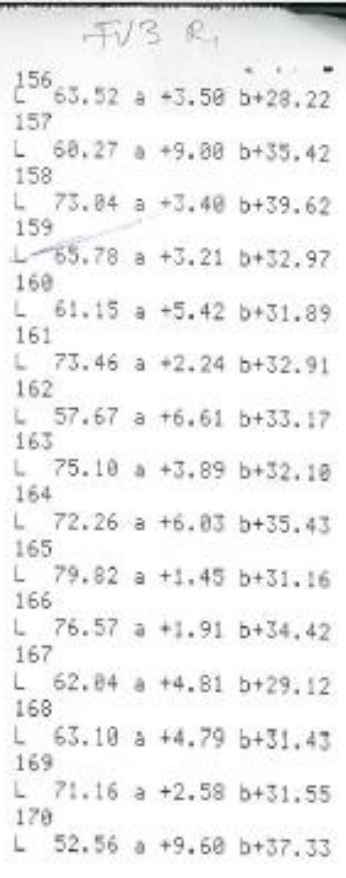 & 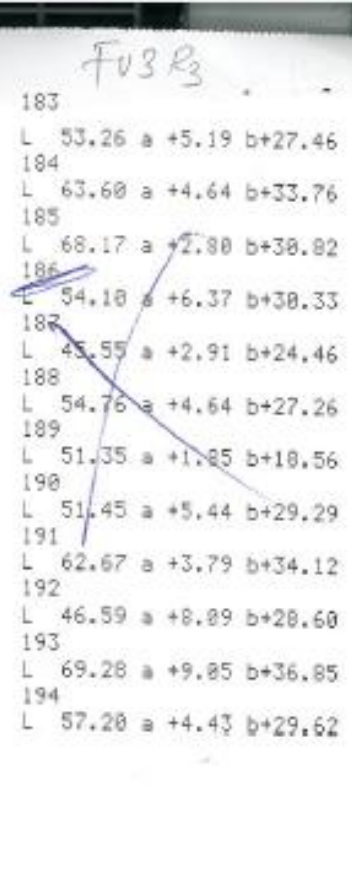 & 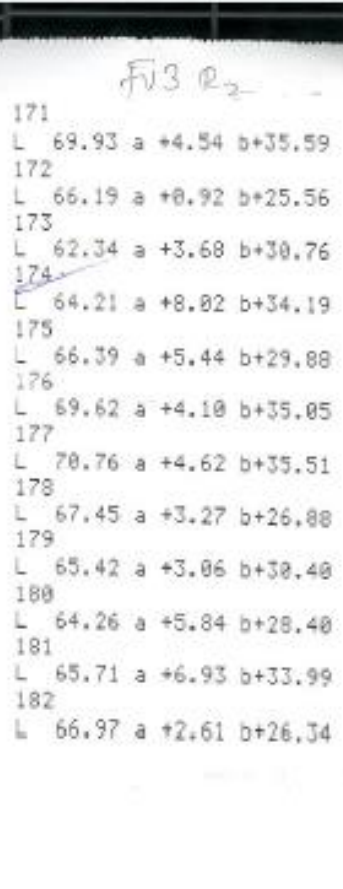 \\
\hline
\end{tabular}

$1.66^{80.82}$ a $-5.79 b+26.55$ 116
$-\quad 89.37$ a $-4.86 b+24.83$ 117

L 79.89 a -3.23 b +23.26

49.55 a -5.85 b+28.24 119

$\downarrow-76.07$ a $-4.83 \mathrm{~b}+26.17$ 120 L. 76.87 a -6.36 b+32.74 12 :

78.86 a $-3.69 b+23.54$ 122

L 78.50 a -4.63 o+22.J9 125 L 81.54 a $-4.95 \quad b+21.67$ 124

L 82.18 a $-3.48 b+21.84$ $L^{125} 8 e .23$ a -3.66 b+21.89 1268.23 a $-3.66 b+21.89$ L 81.71 a $-4.53 b+22.62$ $L^{127} 81.72,-4.43 b+22.76$ 128 (12.72 $-4.43 b+22.76$ L 81.76 a $-4.65 b+21.27$ L $80,98 a-4.20 b+21,14$ $[67.31$ a $-0.53 \mathrm{~b}+21.84$ सxin OD Oloys Smike Oleys Weph $O$ Vays

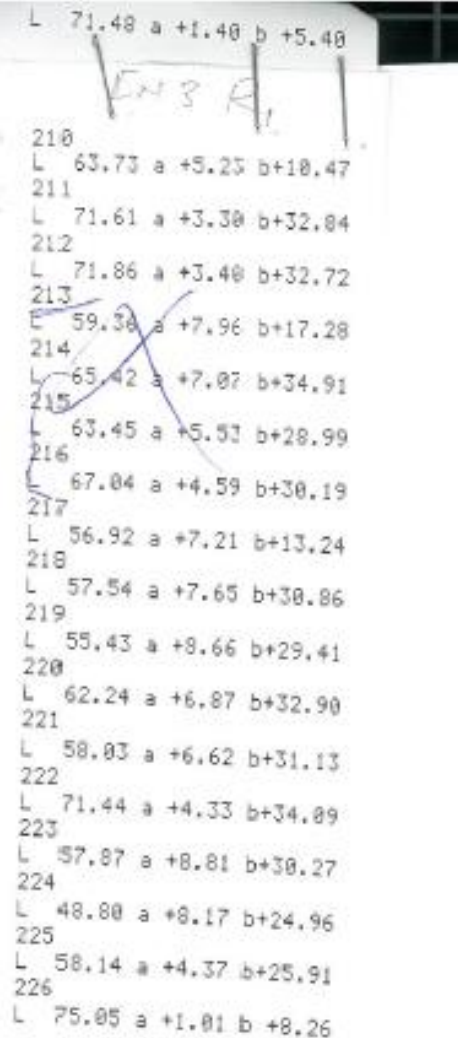




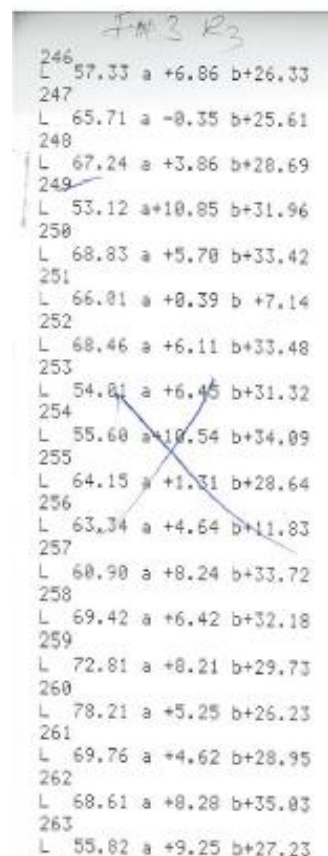

263

L 55.82 a $49.25 b+27.23$

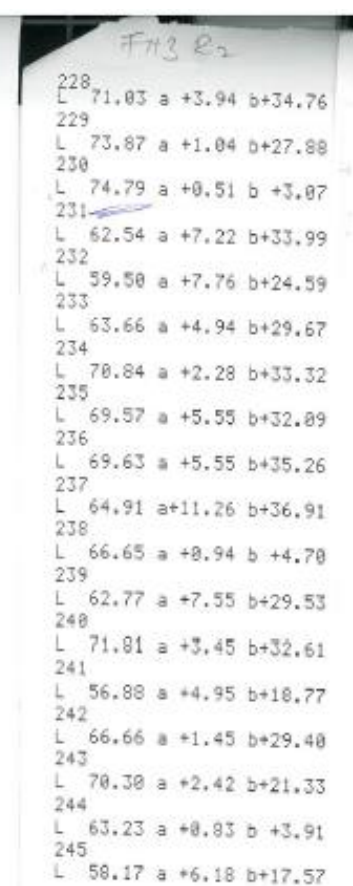

L $58.17 a+6.18 b+17.57$

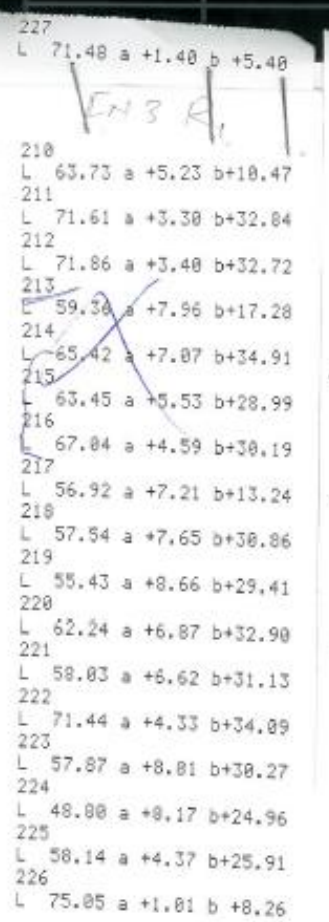

ODV $\& R_{3}$

140

L. $2.15 a-1.16 b+h .8$

14 69.27 a $+3.51 b+23.5$ 142 $L 73.05$ a $+4.71 b+27,4$ 143

162.51 a $-1.39 b+23.40$ $L^{112} 72.66$ a $+5.60 \mathrm{~b}+30.76$ L $6.7 .33 a+5.28 b+24.59$ $114.30 \mathrm{~g}+5.28 \mathrm{~b}+24.59$ L $55.15 a+7.84 b+27.74$

L $66.77 a+5.99 b+27,95$ $76.99 a+1.63 b+26.44$ $L_{118} 78.33 a+1.47 b+23.15$

L $79.52 a+3.10 b+27.93$ L 74.65 a -4.48 a +23.64 126

L 67.44 a $+4.95 t+27.67$ 121

$5 i .79=+5.85+272.4$

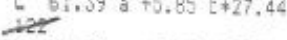
L $74.70 a+6.06 t+39.21$ $L^{123} 62.01+46.84 z+26.34$ $L_{124}^{62.01}+46.84:+26.34$ L 58.61 a $\div 7.31$ o $\div 27,: 8$ L $72.71 a+4.64 b+25.4$ $145^{66.95} a+3.75 b+19.0$ L 64.80 a $+4.28 b+29.5$ 146 a $+4.28 \mathrm{~b}+20.6$ i. 65.92 a $+3.88 \mathrm{~b}+18.9$ L $71.65 a+6.85 b+26.21$ $\mathrm{L}_{149} 74.38 \mathrm{a}+3.68 \mathrm{~b}+21.9 \mathrm{i}$ $\sum_{160}^{149} 77.18$ a +3.34 b+22.1: $L_{15 t^{56.56} a+3.34 b+21.6 c}$ $68.96++3.91 b+24,92$ 152 $L_{158} 78.98 a+3.48 b+28.16$ $72.28=-6.09 b+25.12$ $15467.24 a+8.54 b+31.77$ 155 . 37 a +8.54 b+31.77 $[\quad 77.53 a+5.17 b+28.62$

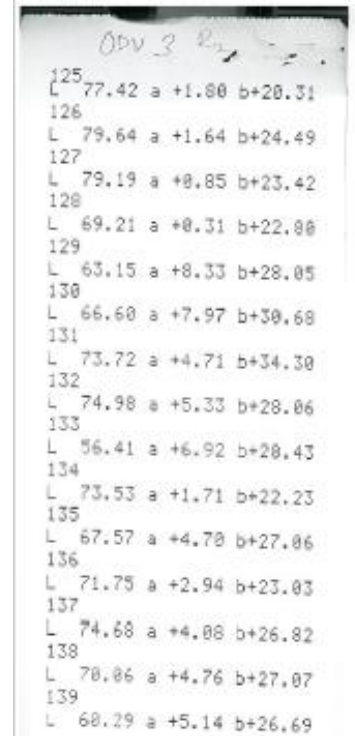

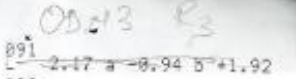

692

$62.45 a+1.23 b+24.79$

$68.92 a+3.51 b+22.96$

$094 \quad 0.920 .5 .510+22.96$

695 75.27 a $+0.42 b+25.25$

095. $a+6.17 b+28.10$

996

$89673.81=+4.5^{3} b+24.56$

69772.37 a +4.50 b+27.39

${ }^{898} 76.06$ of +2.70 b7+19.56

67.87 a $+4.33 b+19.97$

72.30 a $+2.97 b+19.87$

$L_{101} 72.30 a+2.97 b+19.87$

L 76.77 a +2.71 b+23.81

102

$103^{76.62 a+4.43 b+24.05}$

L $76.24 a+4.16 b+24,69$

104

L $68.84 a+5.57 b+29.70$

$\quad 73.77 \mathrm{a}+3.44 \mathrm{~b}+32.29$

$\begin{aligned} & 196 \\ & 207\end{aligned} 76.68+3.28 b+29.40$

$19866.61 \mathrm{a}+5.37 \mathrm{~b}+27.54$

69.03 a +4.87 be36.36

$-73.43 \times+4.93 b+25.26$

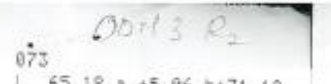

L 65.18 a $+5.96 b+31.12$ $\frac{0.4}{81.35}$ a $+3.84 b+24.78$

$L_{976} 76.31$ a $+1.56 b+39.47$

e76

$L_{077} 73.19$ a $+4.43 b+26.69$

L 72.21 a $+5.42 b+29.78$

az8

e79

$55.87 a+7.38$ b +28.46

$980.85 .87 a+7.380+28.46$

L. $56.78 a+6.78 b+25.66$

L 69.46 a $+7.97 \mathrm{~b}+28.92$

$682^{69.46++7.970+28.92}$

$i \quad 67.65 a+2.96 b+23.22$

L $68.64 a+3.52 b+24.28$

984

$L_{085} 58.97$ a $+4.51 b+24.15$

$L 66.05 a+4.67 b+22.30$

to6 $68.05 a+4.13 b+21.10$

$L^{987} 57.25 a+4.29 b+20.68$

L $79.66 a+1.41 b+35.68$

089

$\frac{1}{899} 72.43 a+3.43 b+26.57$

L $76.60 \mathrm{a}+3.79 \mathrm{~b}+39.64$

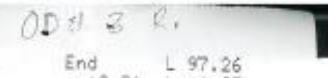
End
$a+0 . e t \quad b+1.97$ $958 \quad 77.92 a+3.84 b+27.16$ $659^{77.92 a+3.84 b+27.16}$ $L_{368} 60.65 \mathrm{a}+8.32 \mathrm{~b}+29.96$

$75.78 a+3.97 b+25.97$ 82.31 a $+1.51 b+28.09$ L $70.58 a+4.16 b+28.31$ 663

L $83.40 a+1.68 b+27.94$ 864 L. $72.24 a+2.27 b+19.50$ 665

L $\quad 65.31$ a +3.93 b+24.74 $666.09 .22 a+3.43 \mathrm{~b}+22.40$ $967 \quad 79.22$ a $+3.43 b+22,4 b$

$-82.80 a+8.22 b+18.85$ L $73.33 a+5.96 b+26.62$ $969+73.35$ a $+5.96 b+26.62$ L $74.93 a+6.75 b+25.19$ L $75.16 a+4.25 b+23.99$ $671{ }^{75.16 \text { a }+4.25 b+23.89}$ L 70.42 a $44.38 b+23.55$ $L \quad 74.86 a+5.55 b+26.53$

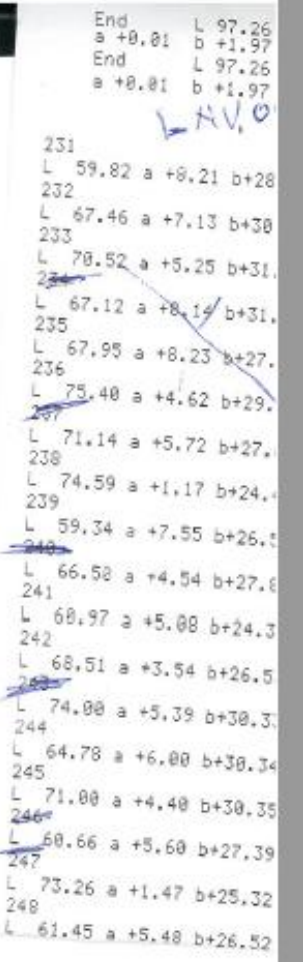



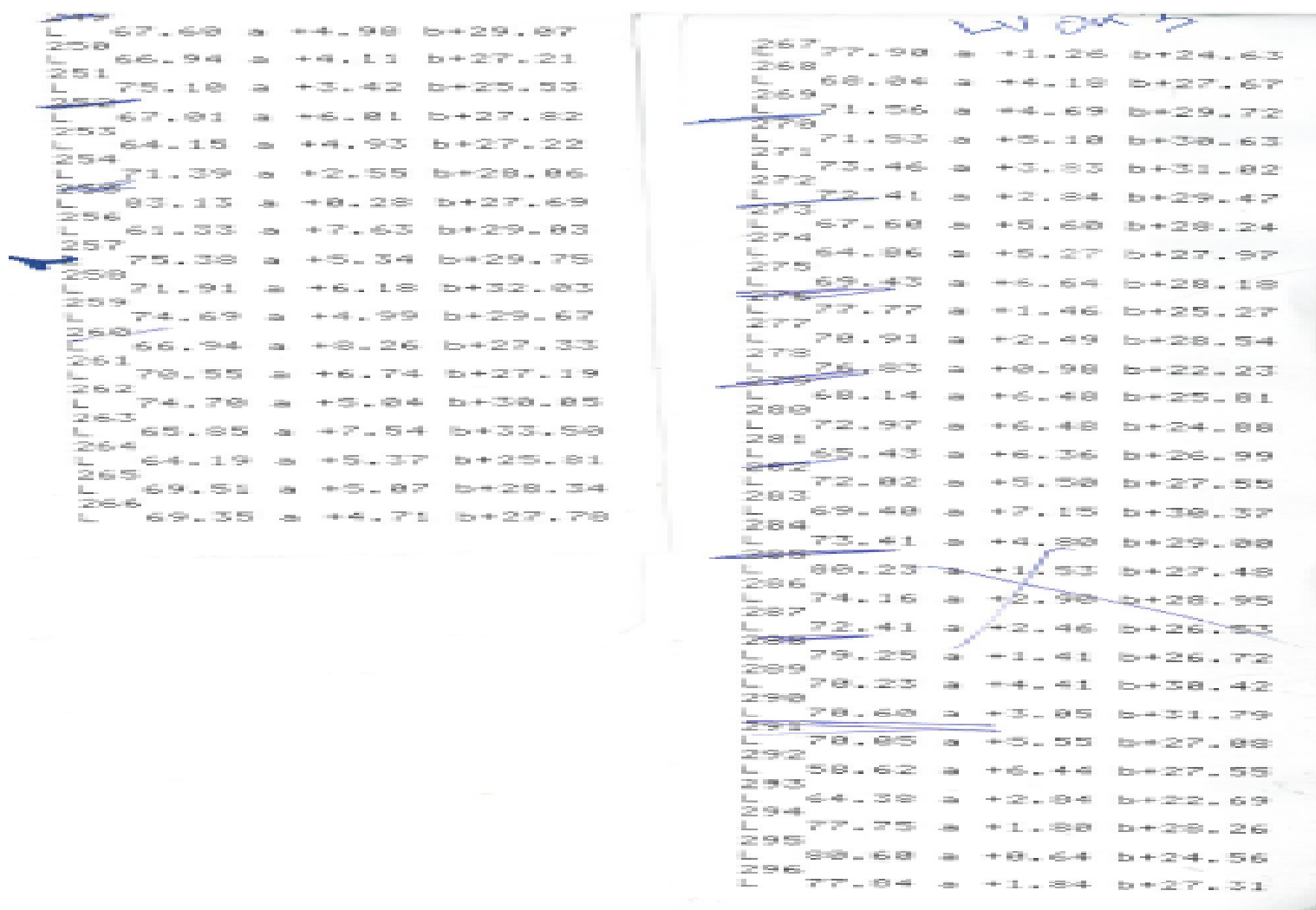

\begin{tabular}{|c|c|}
\hline 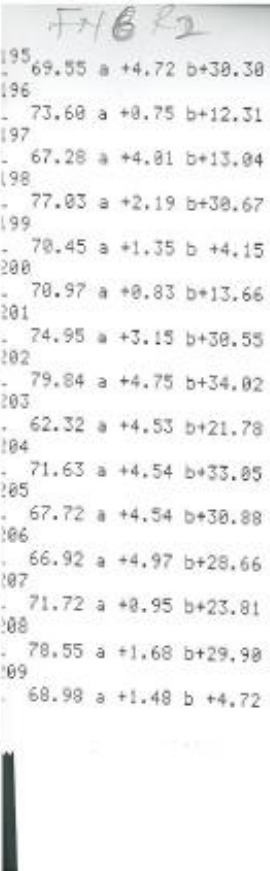 & 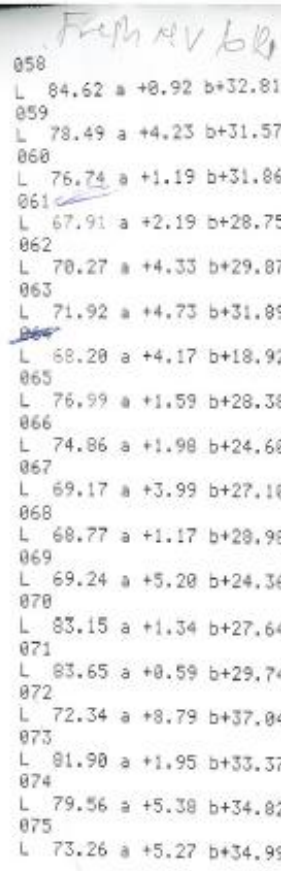 \\
\hline
\end{tabular}

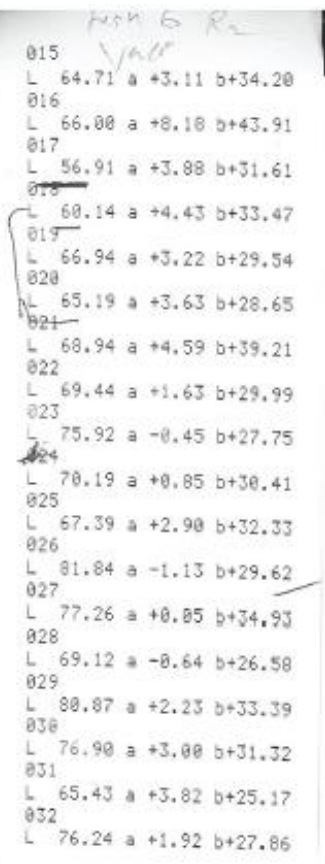

$040 \quad$ Fray ${ }^{2} 6 c_{3}$
$\frac{1}{941} 77.39 a+3.35 b+34.64$

84177.39 a +3.35 b*34.64 $\mathrm{L}_{42} 69.90$ a $+7.46 \mathrm{a}+36.87$ $\frac{1}{843} 76.66 a+3.18 t+33.18$ $\int_{044}^{843} 79.46$ a $+0.86 t+31.73$ ${ }_{645}^{644} 61.60$ a $+7.62 b+28.72$ L $75.63 a+3.12 b+53.98$ 64. $\overrightarrow{76.89} a+5.83 b+33.76$ $64770.29 a+4.71 b+30.19$ $348,90.07=-3.94$ b 352.97 $049.67 a+3.84 b+32.97$ $78.94 a+3.68$ b*33.58

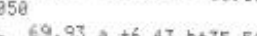
$69.93 a+6.43 b+35.56$ $72.49 a+5.79 b+37.19$ L 52 . $74.15 a+4.98 b-34.65$

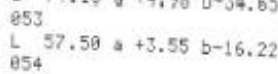
$L 80.81 a+3.61 b+35.26$ $L \quad 85.96 a-9.95 b+28.25$ $\begin{aligned} & 656 \\ & \mathrm{~L}\end{aligned} 77.27 \mathrm{a}+1.30 \mathrm{~b}+35.31$ L $74.16 a+1,96 b+33.51$ 


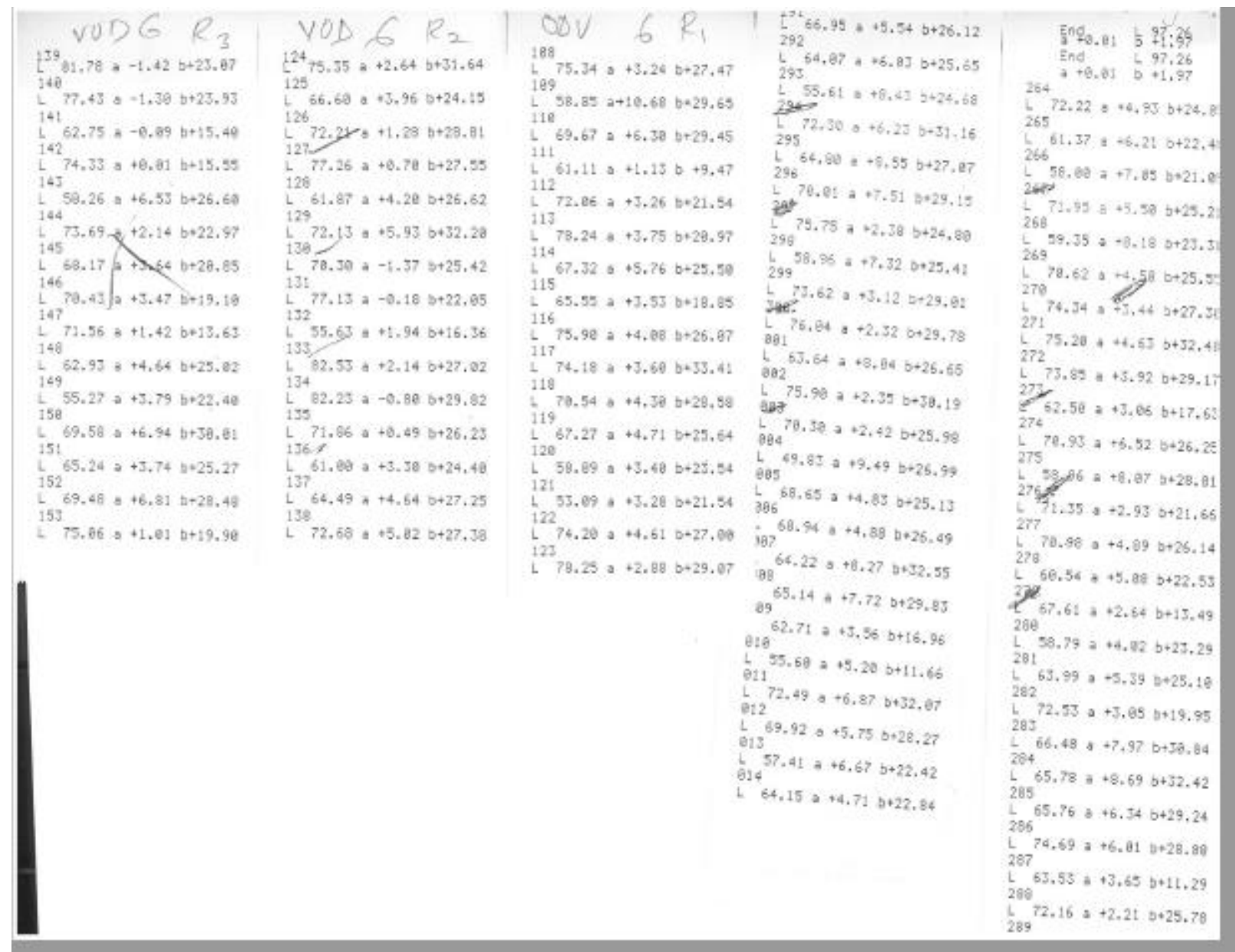

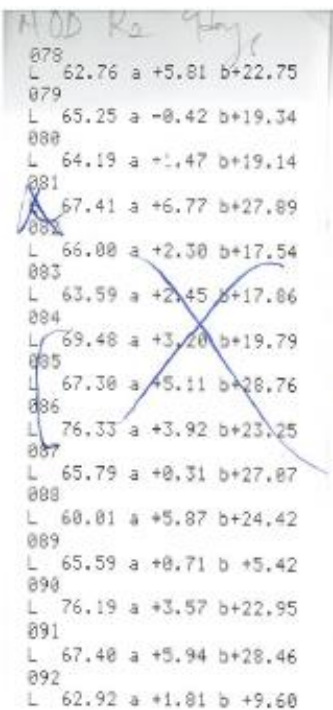

L $62.92 a+1.81$ b +9.60

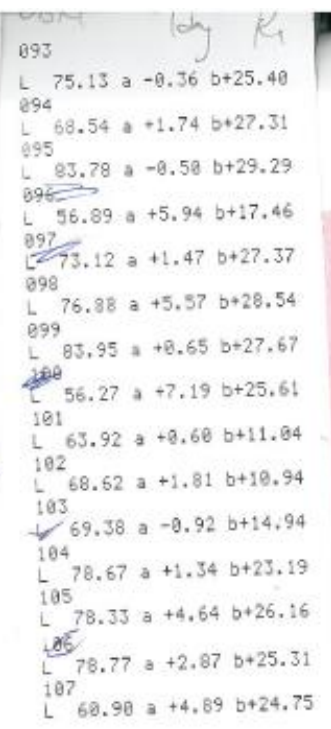

$L^{07} 60.90 a+4.89 b+24.75$

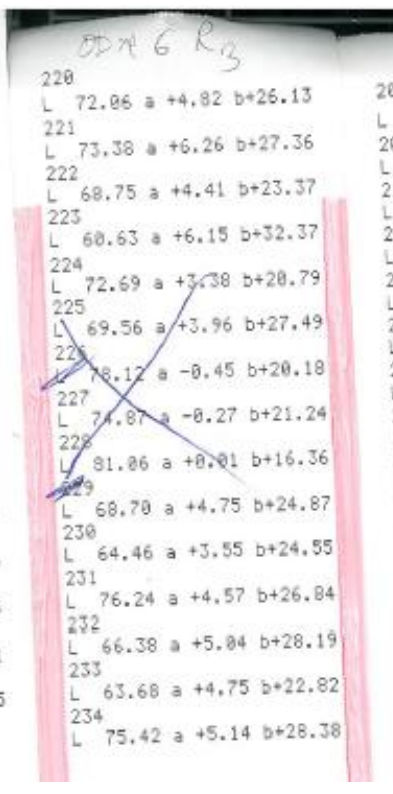

208 $20 \times 5$

$65.91 a+3.93 a+22.14$ 209

L $67.19 a+4.81 b+27.22$

$L_{L}^{210} 75.11$ a +4.36 s+23.93

$L 75.11$ a $+4.36 a+23.93$
$21175.83 a+2.58 b+22.43$

21273.57 a $+3.95 b+27.29$

213

$70.50 a+3.54 b+24.86$

214

$73.30 \approx+4.70 b+25.65$

$21579.40=+3.37 b+23.35$

216 66.59 a $+4.23 b+21.02$

$217{ }_{63.70 a+4.07 b+23.39}$

218 . 63.70 a +4.07 b+25.30

$\left[\begin{array}{l}218 \\ L\end{array} 67.32\right.$ a $+4.59 b+24.43$ 219

$64.65 a+8.12 b+30.65$

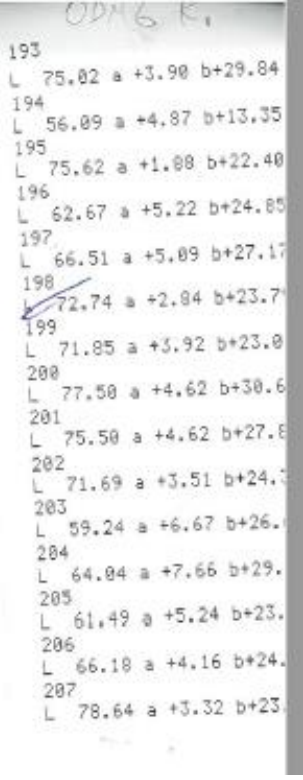




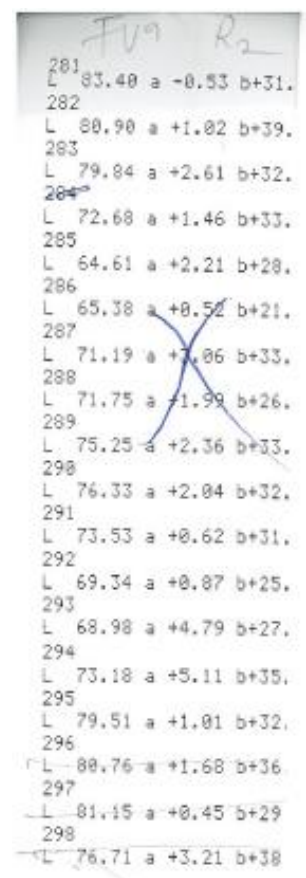

262

$76.68 a+1.28$ b+28.70

263

L $76.29 a+2.27 b+27.68$

L $77.24 a+1.36 b+33.28$

L $65.77 \mathrm{a}+3.38 \mathrm{~b}+29.28$

266

L $78.38 a+3.94 b+29.91$

$74.40 \mathrm{a}+2.80 \mathrm{~b}+34.41$

268

$165.48 a+2.80 b+27.87$

$L_{279}^{2} 79.83 a+1.12 b+27.58$

$t 73.88 a+2.19 b+34.09$

271

L $63.61 \mathrm{a}+2.33 \mathrm{~b}+29.79$

$L_{273}^{272} 60.02 a+5.86 b+17.74$

L $75.97,+1.10 b+32.62$

27489.77 a $-1.19 b+31,82$

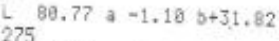

275

L $64.33 \mathrm{a}+1.16 \mathrm{~b}+23.92$

276

$L_{277} 79.86 a+0.12 b+23.16$

$\sum_{278}^{279.32} a+3.77 \mathrm{~b}+34.70$

L $72.85 a+1.69 b+35.04$

$279 \quad 72.85=+1.60$ b435. 84

$L_{289}^{7} 76.95 \mathrm{a}+3.28$ b+31.74

L $80.87 a+0.88 b+31.81$

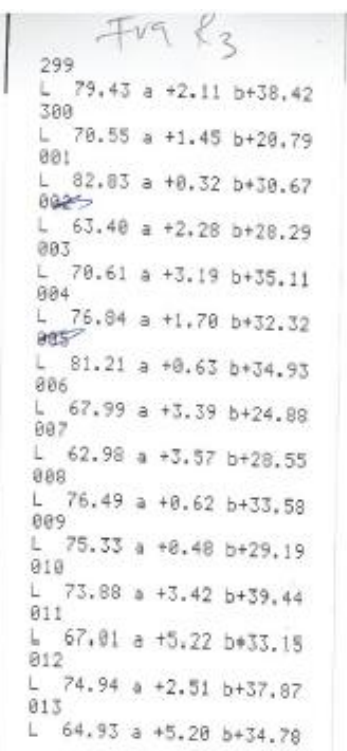

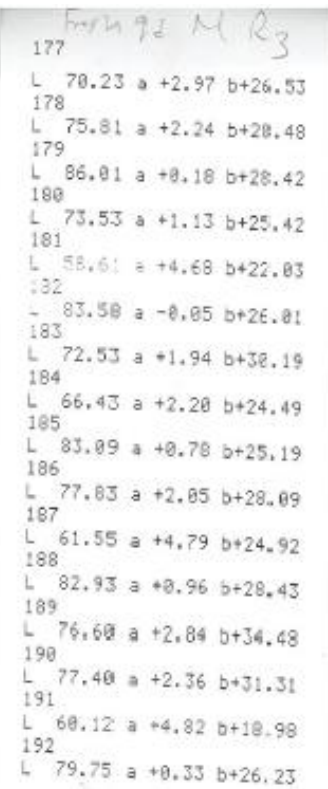

$16275,87 \mathrm{a}+2,66 \mathrm{~b}+29,17$ $163 \quad 0.87$ a +2.66 b 6029.17 L. $78.07 a+2.49 b+26.59$ $16466.96 a+1.15 b+23.84$ $165^{66.96 a+1.15 b+23.84}$ $L^{165} 84.24+48.61 b+31.73$ $L_{167}^{166} 76.31$ a $+2.35 b+28.12$ L $66.72 a+2.87 b+15.86$ 168 " 85.82 a $+8.320+26.48$ 169 l $78.32 a+2.98 b+33.18$ 170 L $79.34 \mathrm{a}+2.97 \mathrm{~b}+28.33$ 28 $71.67=-0.02 \mathrm{~b}+25.17$ L $66.74 a+4.87 b+26.55$ 173 i 78.71 a +2.46 b +36.21 127 $73.72 \mathrm{a}-1.07 \mathrm{a}+13.27$ 175 a 17.72 a -1.07 o+13.27 L $67.61 a+2.90 b+27.99$ L $73.71 a+1.03 b+30.83$

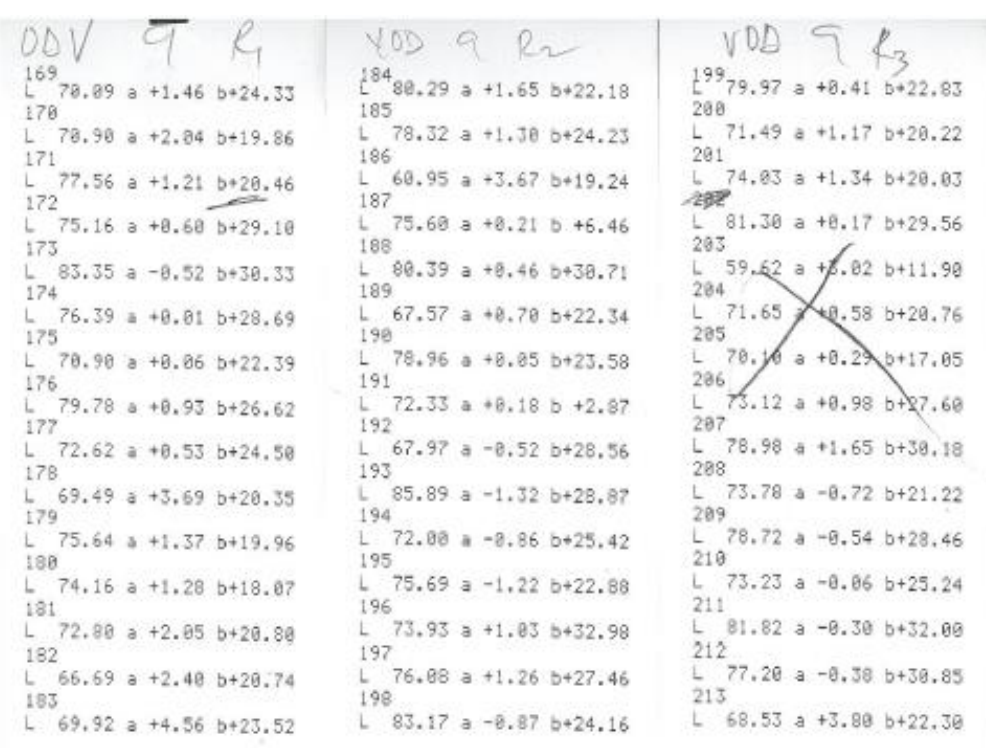

$69.92 a+4.56 b+23.52$
78.32 a +1.36 b+24.2J

$L^{186} 60.95 a+3.67 b+19.24$

$l^{187} 75.60 a+8.21 b+6.46$

188 .

L $80.39 a+8.46$ b+30.?

L $67.57 a+8.78 b+22.34$

L $78.96 a+8.85 \mathrm{~b}+23.58$

$L_{192} 72.33 a+6.18 b+2.87$

$L \quad 67.97$ a $-8.52 b+28.56$

85.89 a -1.32 b+28.87

$L_{195} 72.00$ a $-3.86 b+25.42$

[ 75.69 a $-1.22 b+22.88$

L $73.93 a+1.83 b+32.98$

L $76.88 a+1.26 b+27.46$

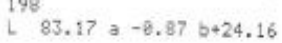

$t^{199} 79.97 \mathrm{a}+8.41 \quad \mathrm{~b}+22.83$ $20001.49 a+1.17 b+20.22$

$201.03 a+1.34 b+20.03$ $29281.30 a+0.17 b+29.56$ ${ }^{203} 59.52 a+\% .02 b+11.90$ 71.65 ag b+20.76 $70.00+0.290+17.05$ $73.12 a+0.98 b+27.66$ 78.98 a $+1.65 b+39.18$ 73.78 a $-0.72 b+21.22$ 78.72 a $-9.54 b+28.46$ 73.23 a $-0.06 b+25.24$ 81.82 a $-8.30 \mathrm{~b}+32.09$ 77.20 a $-0.38 b+30.85$ $68.53 a+3.88 b+22.38$

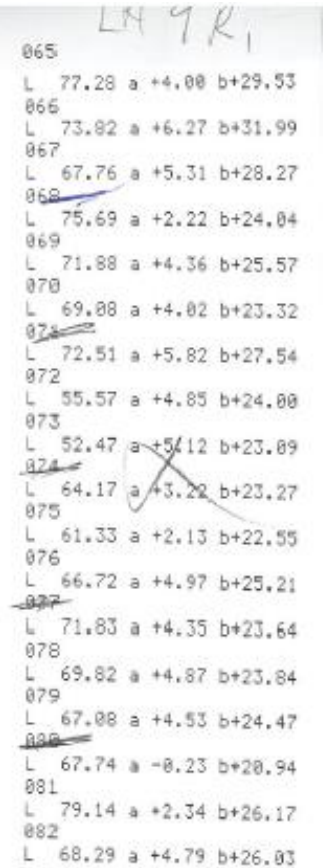

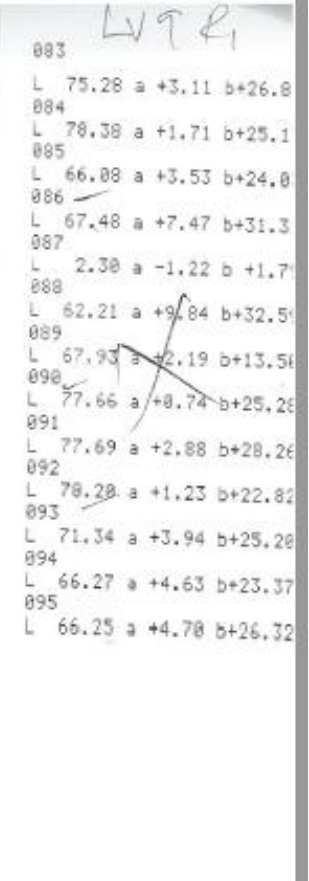




\begin{tabular}{|c|c|c|}
\hline 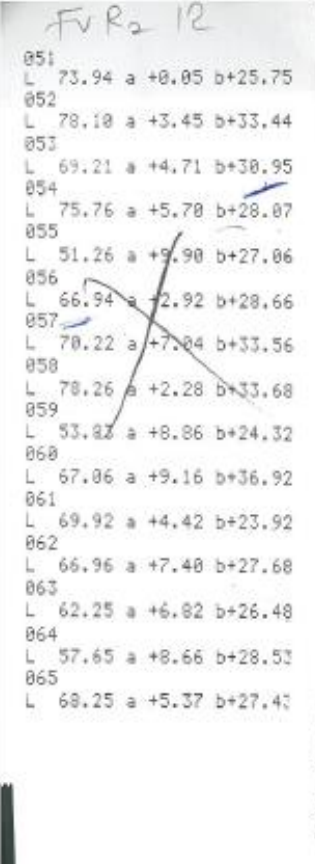 & 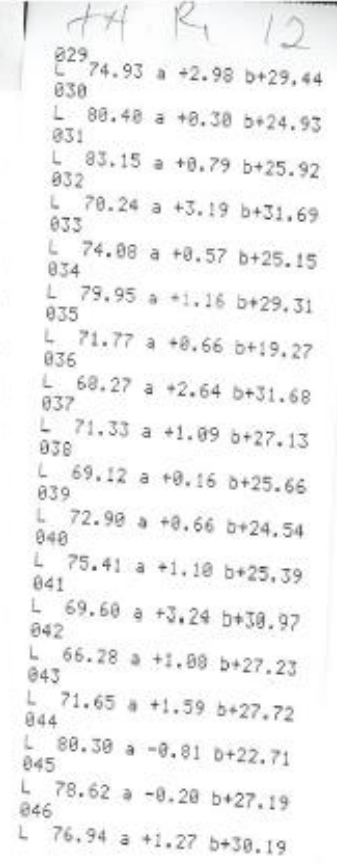 & 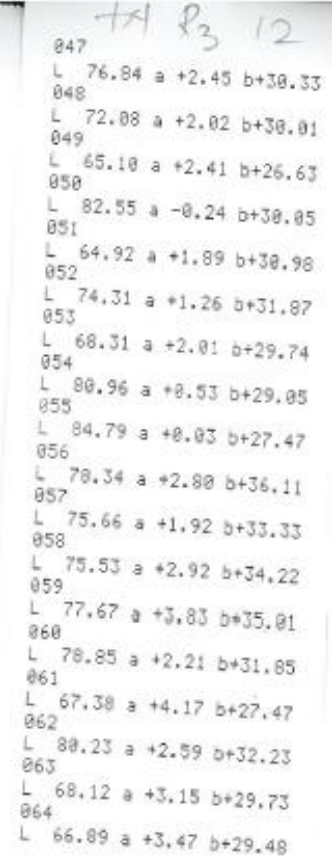 \\
\hline
\end{tabular}

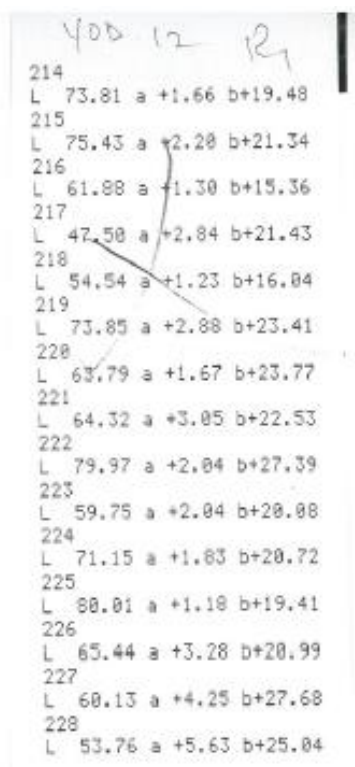

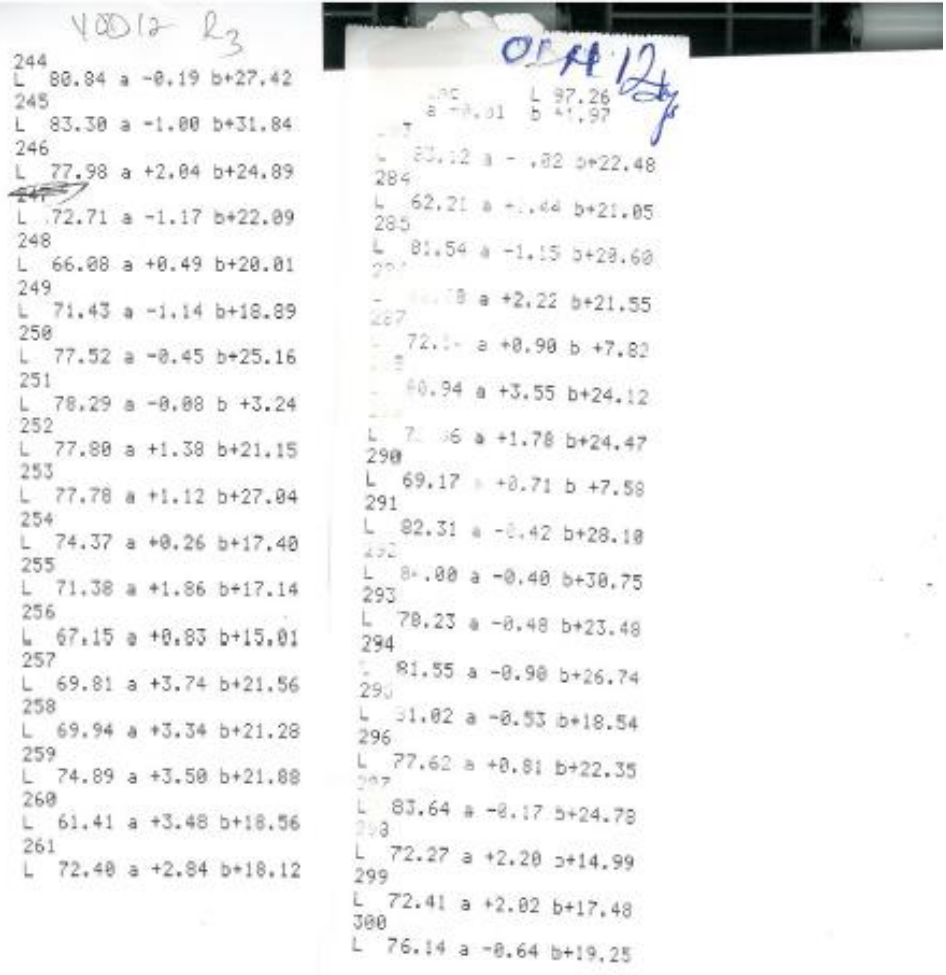

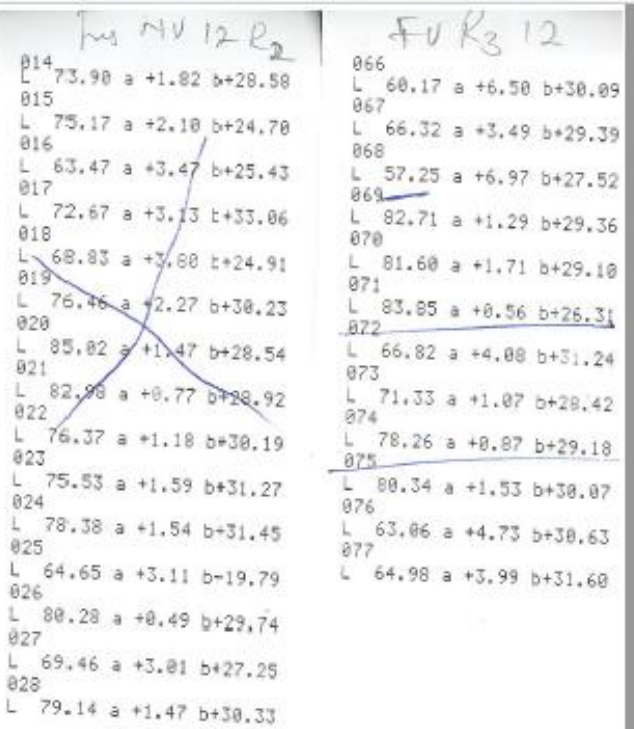



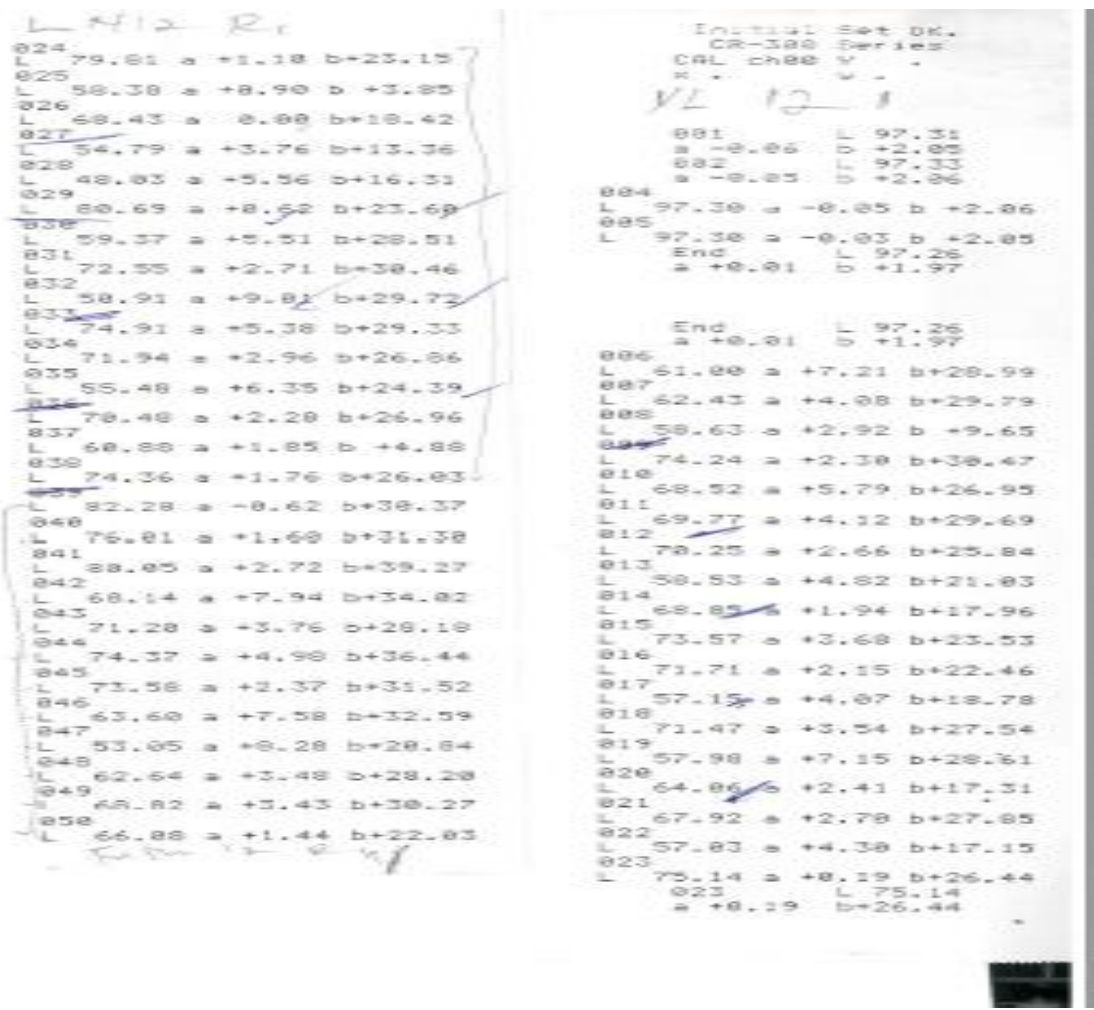

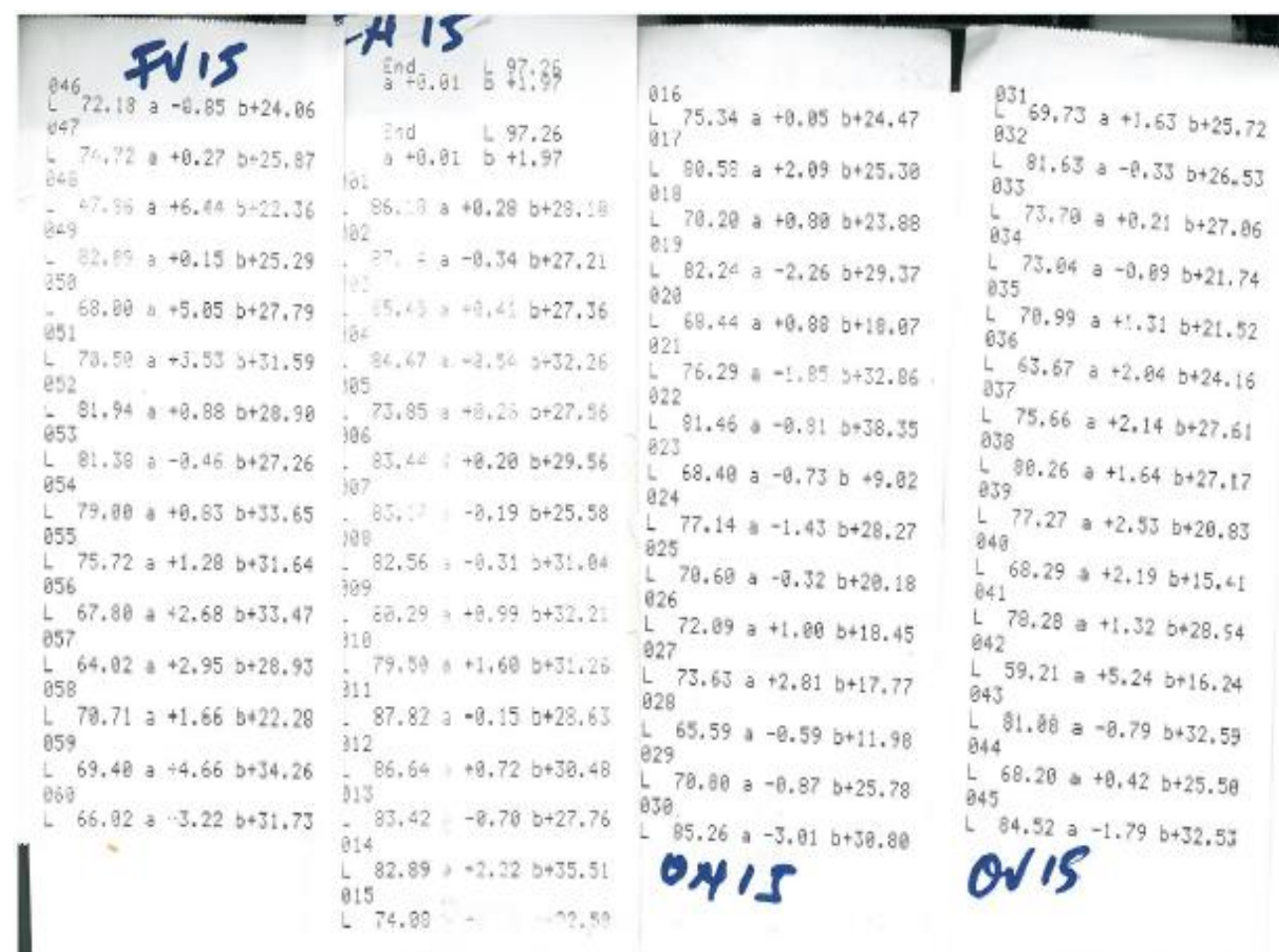

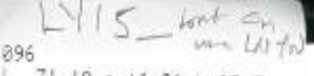

0971.18 a $+6.21 b+27.71$

897

L $26.77++5.10$ b+26.94

- 74.61 a $+4.75 b+25.39$

$999^{74.61 a+4.75 b+25.39}$

108.78 a $+4.67 \mathrm{~b}+24.24$

L. $68.43 a+5.33 b+28.29$

+65.67 a +6.63 b+38.65

$76.80=+3.56 b+24.46$

103

L. $73.64 a+4,93 b+25,48$ 104

-71.81 a $+0.65 \mathrm{~b}+12.84$

$68.41 a+\sqrt{3} 36 b+23.44$ 106

$[65.847 \times 5.93 b+21.26$

$72.17 \mathrm{a}+5.65 \mathrm{~b}+28.55$

Lep

-64.89 a +5.45 b+27.11 109

$69.87 a+5.74 b+27.41$

1178.68 a $+5.32 b+29.57$ 65.81 a $+6.26 b+26.92$ 112

$\leftarrow 68.15$ a $+4.57 b+27.65$ 113

$L 72.47 \mathrm{a} a+5.87$ b+27.75

114

L 68.35 a +5.01 b+27.18

L 56.96 * +6.27 o+23.15

$L^{116} 62.46$ g $>5.65 b+26.13$ 

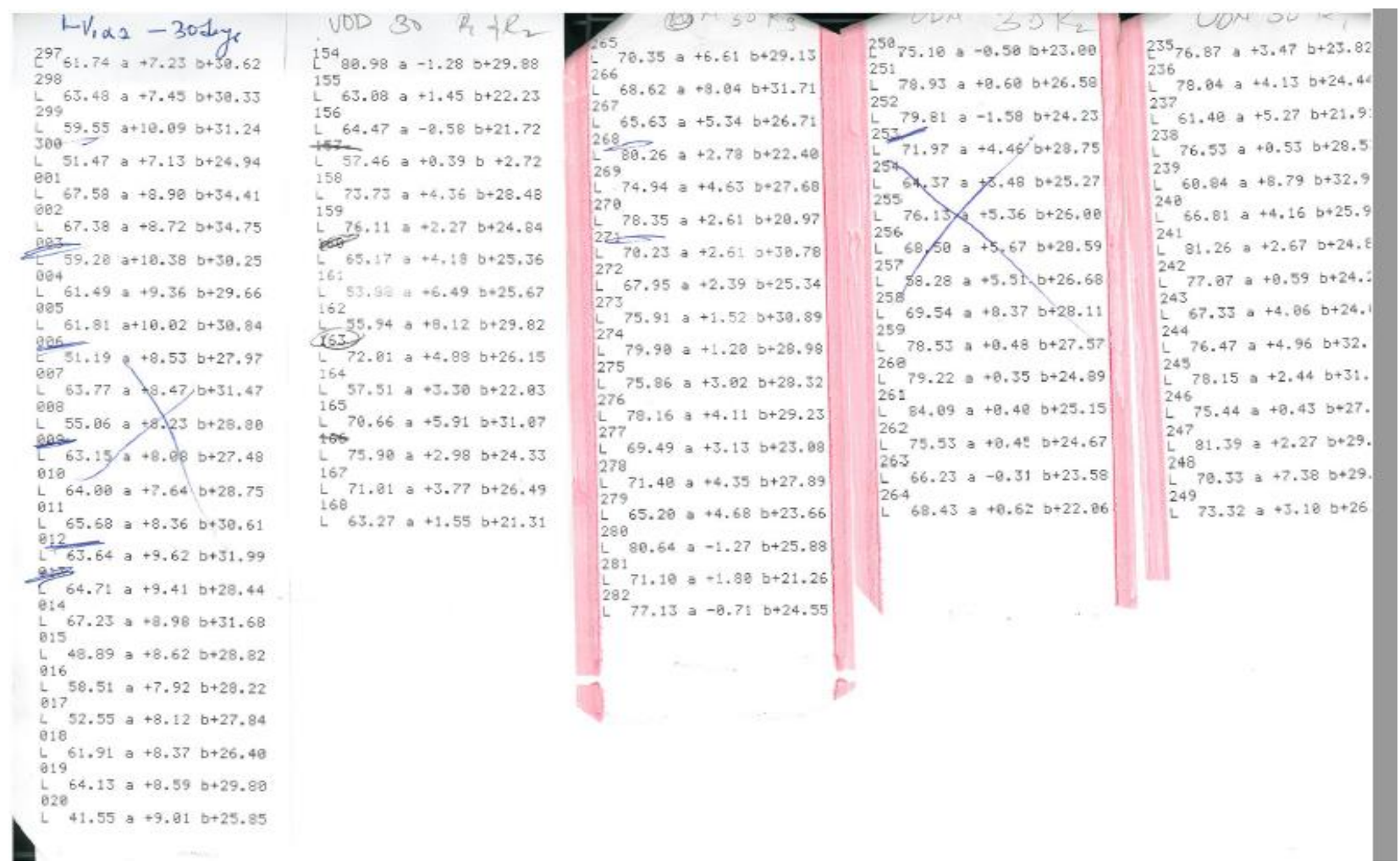

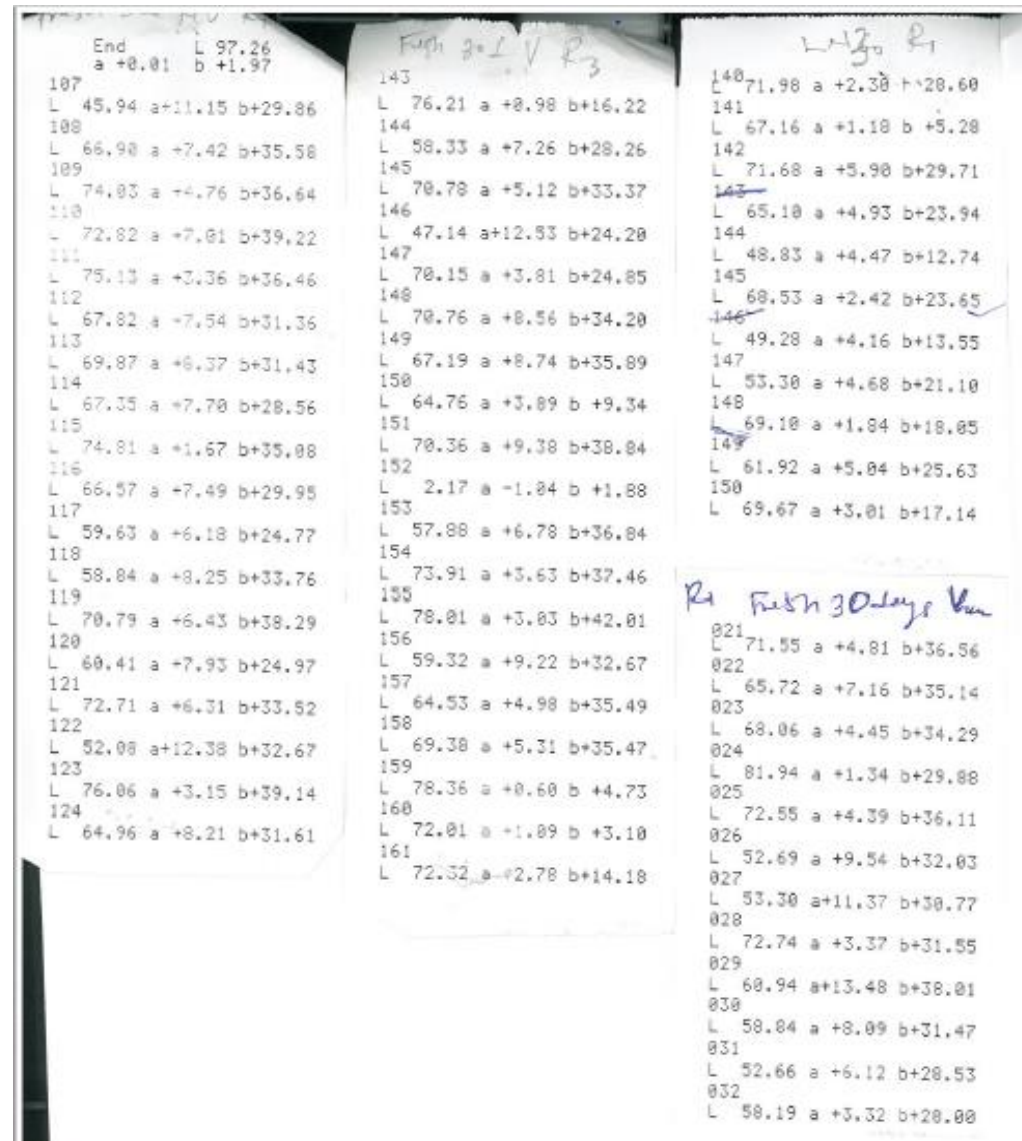

Frish Jortys $R_{3}$ $e^{945} 72.88$ a $+2.53 a+25.21$ $L^{946} 75.45 a+1.69 b+31.43$ $84752.33 a+6.76 b+27.82$ $\begin{aligned} & \mathrm{L} \\ & 848\end{aligned} 52.33 \mathrm{a}+6.76 \mathrm{~b}+27.82$ $L \quad 64.01$ a +8.78 b+37.98 ${ }^{949} 68.79 a+6.58 b+31.81$ L 68.26 a +4.65 b+39.71 $L 58.26 a+4.65 b+30.71$
$5.63 .70 a+8.53 b+25.60$ $65272.70 a+1.62 b+32.31$ $05357.73 a+2.25 b+9.88$ L $55 d .73 a+2.25 b+9.88$ L 59.06 a $+6.91 \quad b+20.57$ $\begin{aligned} & 255 \\ & L\end{aligned} 63.29 a+18.71 b+34.14$ L $63.29 a+10.71 \quad b+34.14$
$L \quad 61.77 a+6.29 b+18.41$ L 61.77 a $+6.29 b+18.41$
$b 7.18$ a $+4.39 b+23.15$

\begin{tabular}{|c|}
\hline 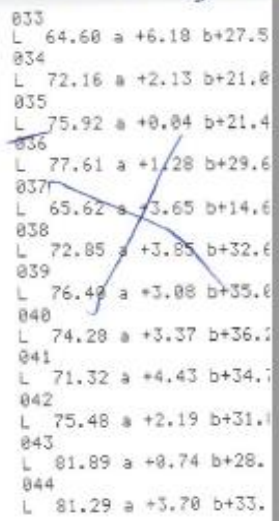 \\
\hline
\end{tabular}




\begin{tabular}{|c|c|}
\hline 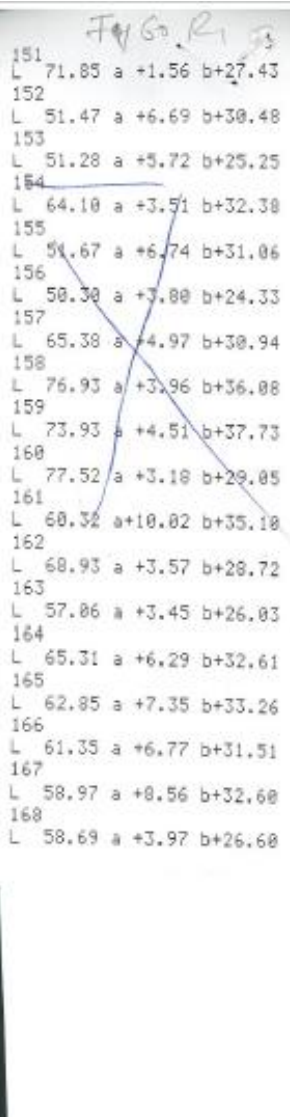 & 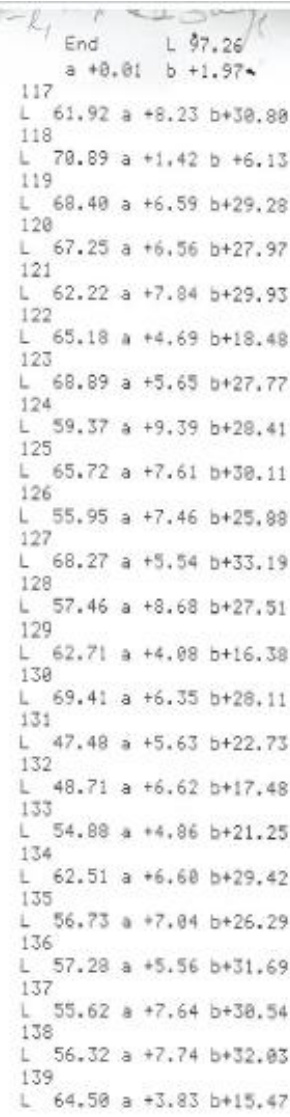 \\
\hline
\end{tabular}

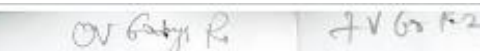

20170.21 a +2.86 b+30.32

$202,25,43 a+9.23 b+15.26$

$\frac{1}{203} 75.43$ a $+0.23 b+15.26$

L. 74.95 a $+1.13 b+18.80$

L 78.91 a $+6.73 b+21.80$

295 .

L. 78.87 a $+1.06 b+34.46$

$77.42 a+2.49 b+35.52$

$20780.28 a+1.85 \mathrm{~b}+31.55$

288 . $80.28 a+1.85 b+31.55$

L $64.85 a+4.32 b+28.98$

299 61.78 a $+8.57 b+21.99$

21061.78 a $+5.57 b+21.90$

210 . 59.94 a +4.97 b*27.53

L 64.70 a +3.91 b+27.54

$212^{64.70 a+3.91 b+27.54}$

L 60.09 a -9.64 b+25.90

${ }^{213} 72.44 \mathrm{a}+1.32 \mathrm{~b}+29.61$

$21472.44 a+1.32 b+29.61$

L $79.90 a+1.72 b+32.99$

215

$21672.44 a+2.46 b+32.26$

$L 63.74 a+0.35 b+24.58$

$21771.72 a+1.75 b+39.86$

218

L. $70.39 \mathrm{a}+8.68 \mathrm{~b}+26.95$

219

+75.74 a $+2.61 b+37.69$

226

${ }^{226} 73.23 a+3.21 b+32.88$

$[68.84++8.88 b+3 e .33$

$6999.68 a+3.07 b+26.18$

$780.68=0.12 b+23.19$

7145.58 a +2.12 b+2.5.10

67267.13 a $+6.45 b+34.63$

67.77 a $+2.89 b+27.27$

$17359.69 a+7.88 b+33.22$

$17445.18 a+4.67 b+25.56$

$17569.35 a+3.98 b+34.67$

176 s3.34, +4.70 b-27.35

$L_{177} 53.34 a+4.70 b-27.35$

17735.91 a $+1.71 b+17.18$

178 53.23 a $+4.78 b+26.58$

179 a

$180^{64.39 a+9.36 b+31.46}$

${ }^{180} 52.74 a+11.61 b+31.53$

181

$18268.51,+4.89$ 5+27.37

$L_{183} 68.51$ a +4.89 $5+27.37$

$L^{183} 56.85 a+4.86 \mathrm{~b}+26.79$

$L^{184} 71.88$ a +1.59 s+24.47

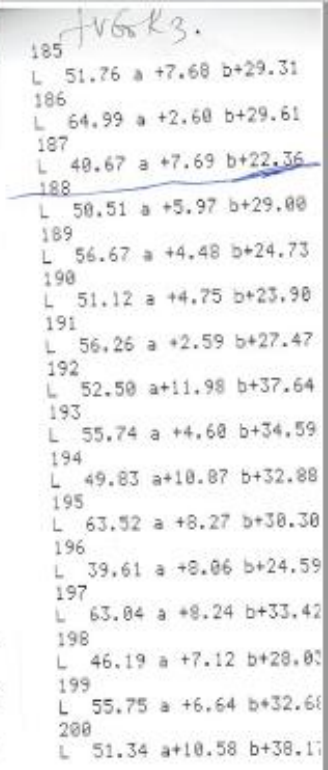

$51.76 \mathrm{a}+7.68 \mathrm{~b}+29.31$ $64.99 a+2.60 b+29.6 !$

58.51 a $+5.97 b+29.98$

$51.12 a+4.75 b+23.96$

19

$192.52 .50 a+11.98 b+37.64$

$\stackrel{193}{L} 55.74 a+4.60 b+34.59$

$19449.83 a+10.87 b+32.88$

L 63.52 a +8.27 b+30.30

196 39.61 a +8.06 b+24.59

$19763.94+8.24 \mathrm{~b}+33.4 \mathrm{z}$

198

199

L $51.34 a+10.58 b+38.1$

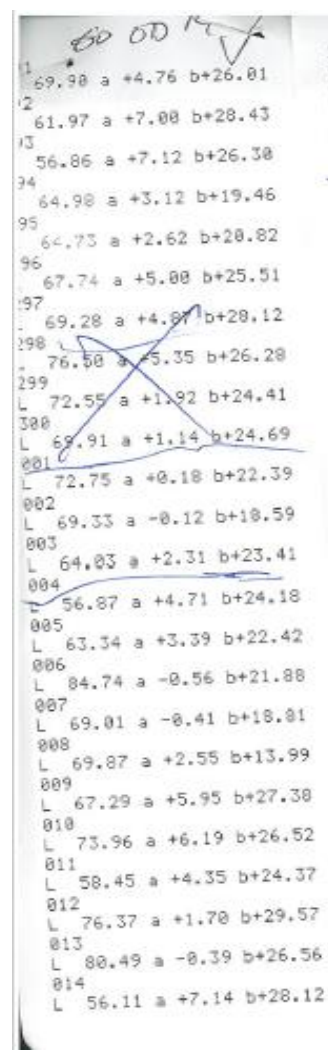

UUOKK W. $27078.45 a+1.38 b+24.68$ $27176.50 \mathrm{a}+1.48 \mathrm{~b}+20.87$ $27263.30 a+2.92 b+20.96$ $273 \quad 63.30$ a $+2.92 b+20.06$ $\frac{273}{274.98 a+5.83 b+19.34}$ $27463.23=+6.19 b+29.36$ 27567.80 a $-9.88 b+26.61$ $27653.42 \mathrm{a}+8.49 \mathrm{D}+22.38$ $27752.06 a+5.30 b+23.59$ 278 . 52.06 a +5.30 b+23.59 27965.17 a $+7.84 \mathrm{o}+26.33$ 27946.58 a $+6.91 \mathrm{~b}+22.30$ 28052.49 a $+8.85 \mathrm{~b}+29.25$ $28166.45 \mathrm{a}+2.32 \mathrm{~b}+24.91$ $282.48 .68 \mathrm{a}+5.97 \mathrm{~b}+24.27$

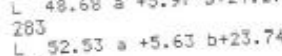
$284{ }_{49.72 a+6.47 b+25.83}^{52.53 a+5.63 b+25.74}$ 285.79 a $+6.47 b+25.83$ $28558.40=+4.48 b+26.98$ $28661.44 a+6.18 b+29.44$ 287 $57.79 a+7.86 b+26.11$ 288 71.66 a $+4.52 b+25.69$ L 71.66 a +4.52 b+26.69 L $67.33 a+5.73 b+26.56$ L $64.22 a+7.86 \mathrm{D}+31.08$

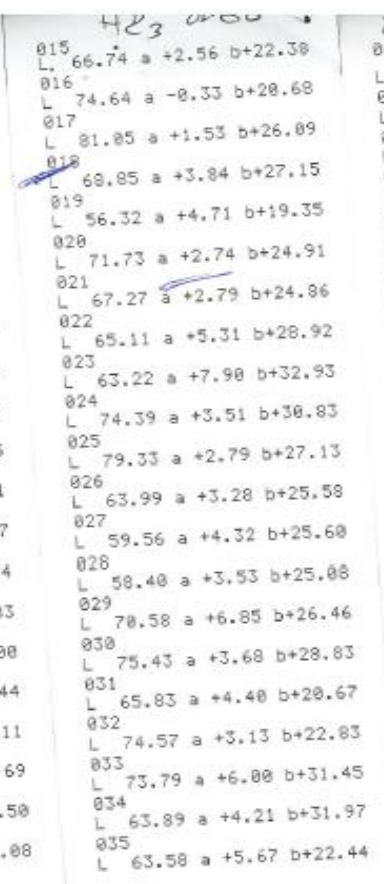
$16.74=+2.56 b+22.38$ $317.05=+1.53 p+26.09$ $56.32 a+4.71 b+19.35$ $92071.73 \mathrm{a}+2.74 \mathrm{~b}+24.91$ $L ^ { 2 1 } 6 7 . 2 7 \longdiv { a + 2 . 7 9 } b + 2 4 . 8 6$ 62265.11 a $+5.31 b+28.92$ $2353.22 \mathrm{a}+7.90 \mathrm{~b}+32.93$ 2474.39 a +3.51 b+30. 83 $025-39 a+2.79 b+27.13$ $92663.99 a+3.28 b+25.58$ $02759.56 \mathrm{a}+4.32 \mathrm{~b}+25.68$ 028 58.48 a $+3.53 b+25.68$ 02978.58 a $+6.85 b+26.46$ 93075.43 a $+3.68 \mathrm{~b}+28.83$ 83165.83 a $+4.48 b+29.67$ 332 . $74.57 a+3.13 b+22.83$ $23373.79 a+6.08 b+31.45$ 23.4 63.89 a +4.21 b+31.97 $l^{335} 63.58 a+5.67 b+22.44$

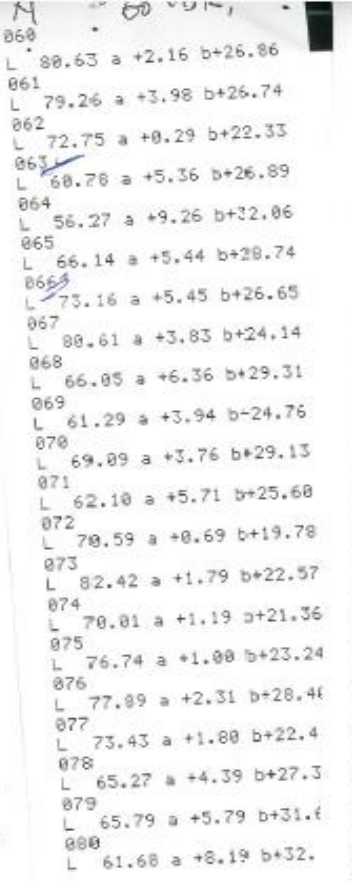
$M \mathrm{~K}_{2}$, $0^{\circ}$ OD $036.54 .5 i^{\circ} a+1.43 b+19.79$ $83764.83 a+4.98 b+23.28$ $0388^{64.03} a+4.98 b+23.28$ L $72.42 a+1.64 b+25.59$ L 63.81 a $+5.63 b+22.23$ $65.33 a+4.95 b+23.92$ $34169.99 a+3.61 b+27.21$ $76.84 a+2.92 b+23.72$ 74.59 a +4.27 b +32.53 $58.98 a+6.03 b+27.98$ 845 646 61.50 a $+6.58 b+26.7$ $70.88 a+1.82 b+17.50$ L $74.73 a+2.21 b+25.68$ L $79.33 a+0.35 b+5.30$ L $79.65 a+3.38 b+26.89$ L $65.36 .31 \mathrm{a}+3.57 \mathrm{~b}+25.46$ L $69.78 a+5.81 b+28.82$ L $67.62 a+4.13 b+27.62$ 95373.16 a $+5.95 b+28.29$ 0540.16 a $+5.950+28.29$ L $59.29 a+7.12 b+29.63$ ${ }^{6} 64.72 a+3.77 b+26.84$ $L_{057}^{056} 73.93 a+5.22 b+27.27$ $958^{74.03 a+5.94 b+28.31}$ $\frac{158}{9} 73.73$ a $+5.86 b+27.44$ L $73.96 a+3.96 b+24.41$ 


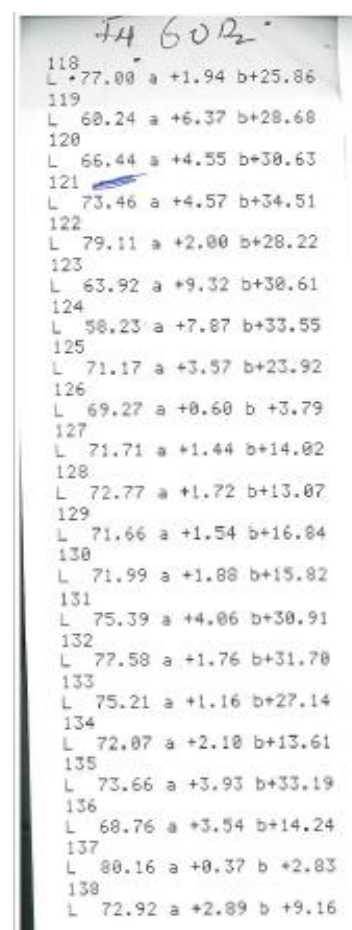
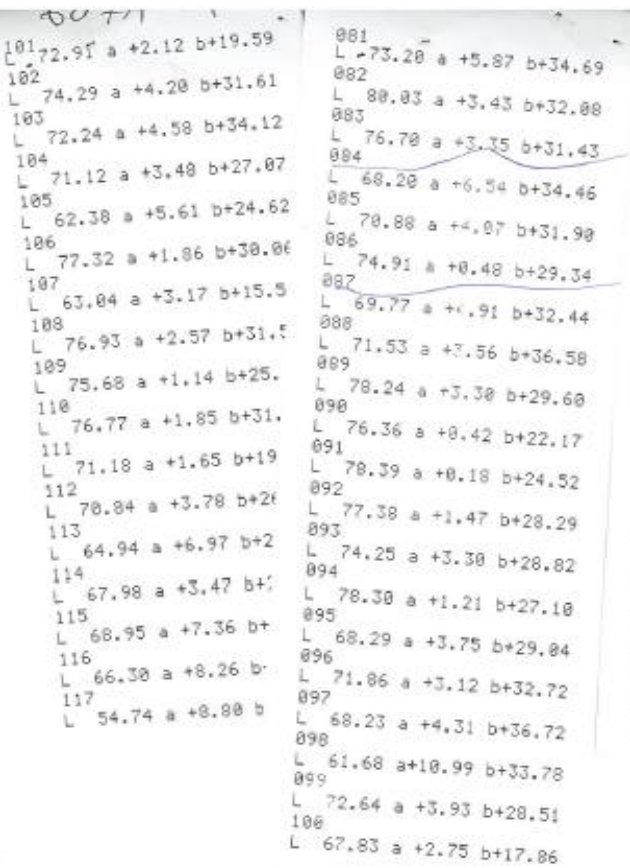

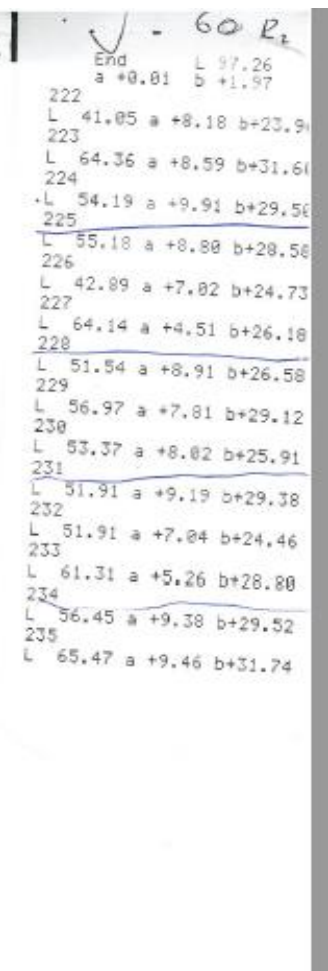

Eacg $\operatorname{sit}$

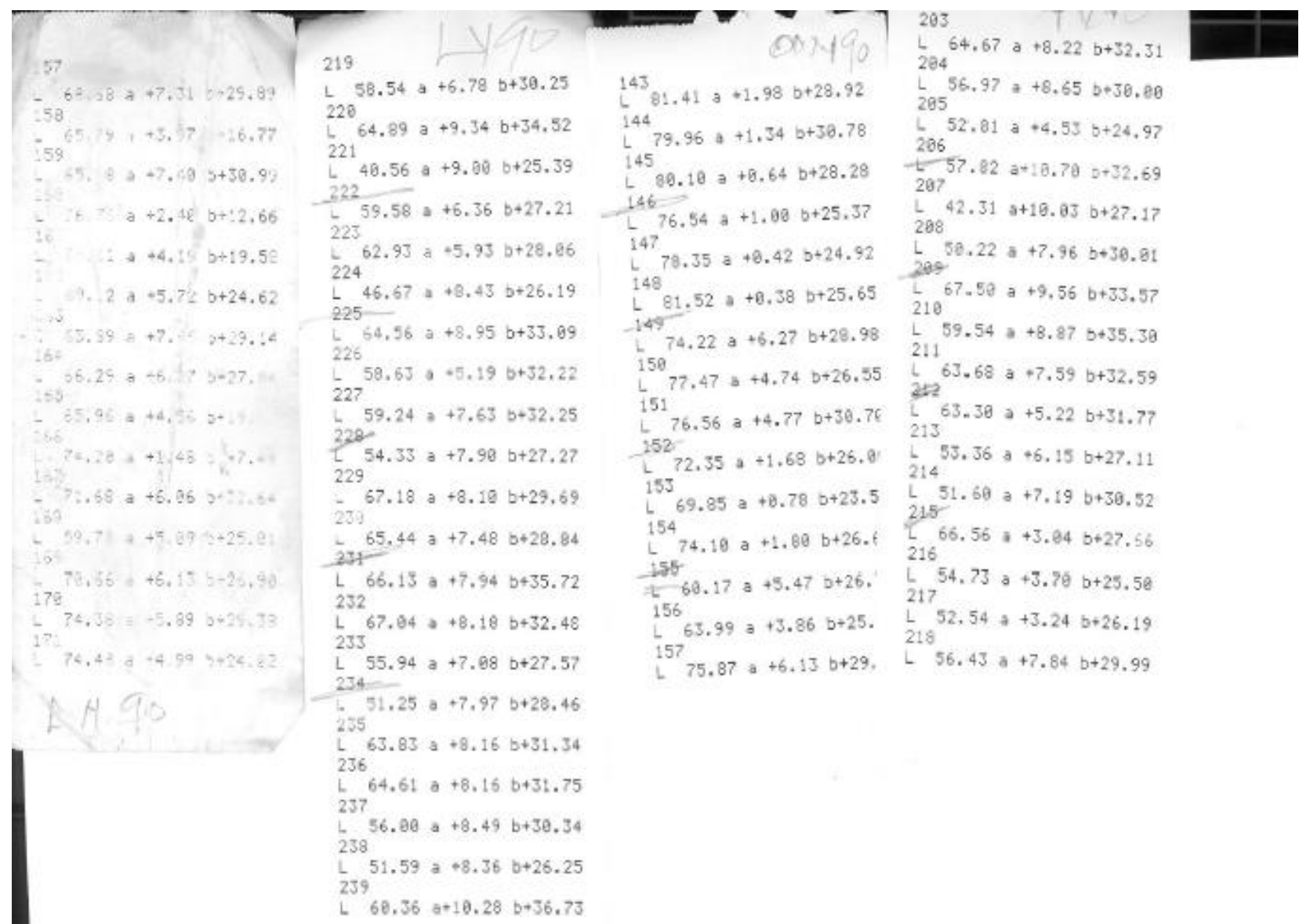



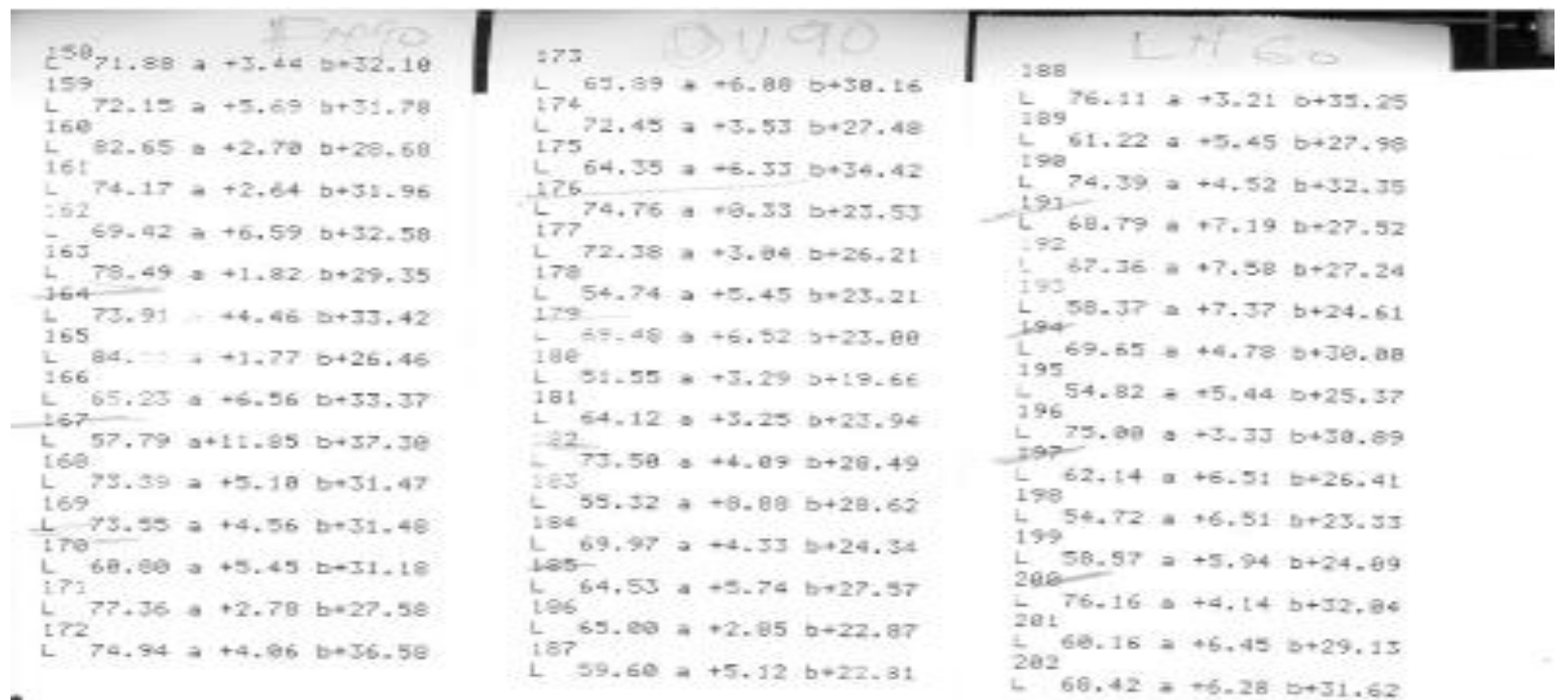

I

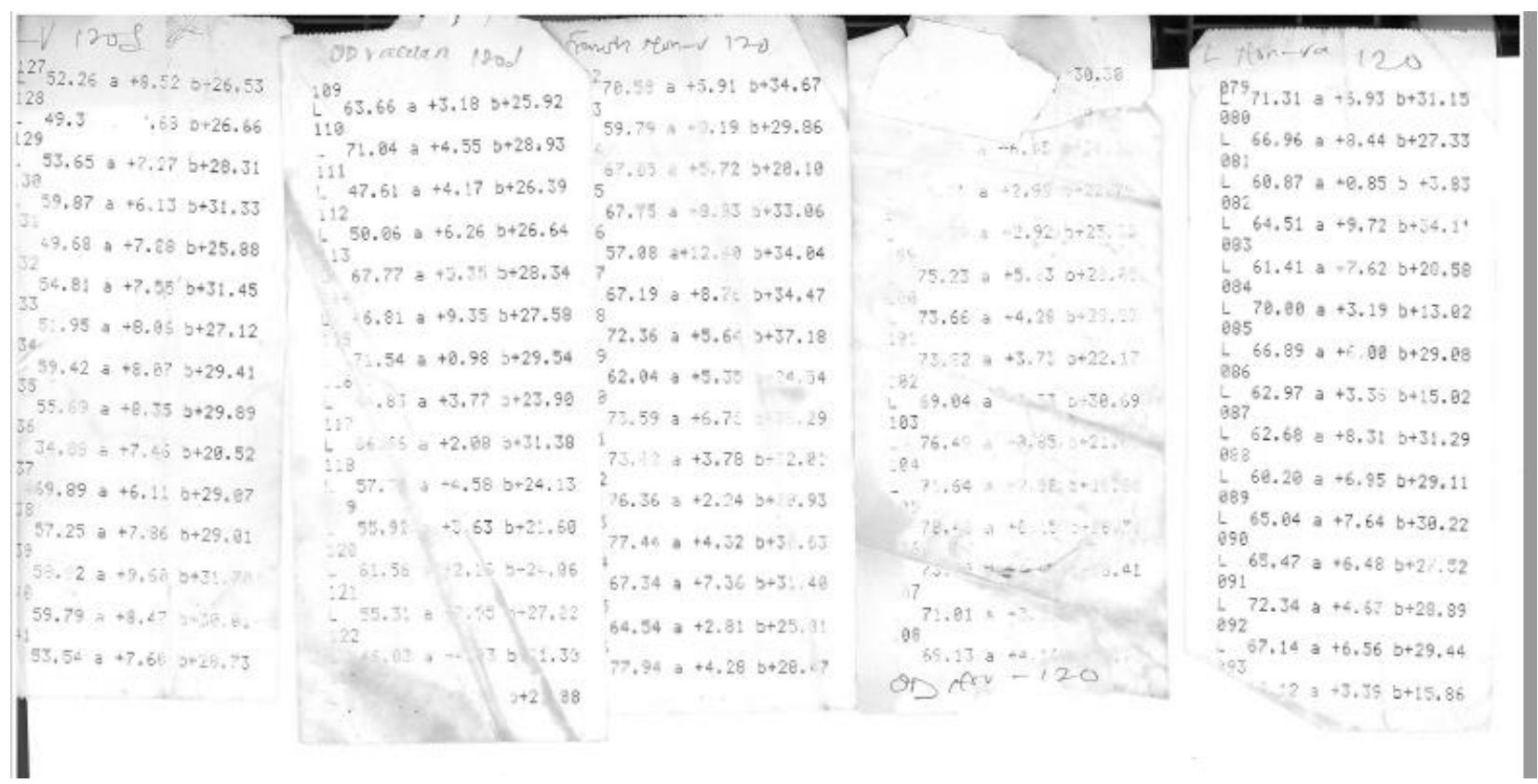




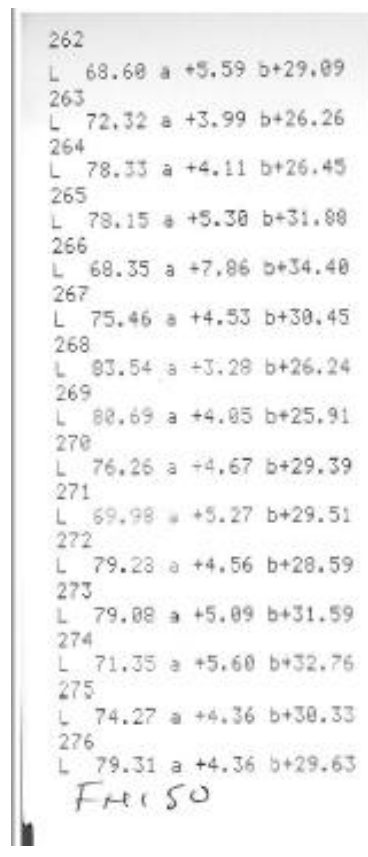

(

L $\quad 76.62 a+2.78 b+27.76$ $L_{012}^{11} 68.87 a+6.12 b+29.28$ $L^{012} 68.01$ a $+4.60 b+29.76$ 013 L $68.89 a+3.80 b+26.23$ a. 1.4 71.97 a $+4,19 b+26.45$ $815+1.97$ a $+4+19 b+26.45$ L $69.53 a+3.31 b+24.86$ $016,72.62 a+4.88 b+36.94$ $L_{17} 72.62 a+4.88 b+36.94$ 017.65 .33 a $+5.40 b+31.35$

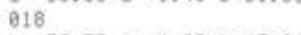
L $52.39 \mathrm{a}+4.02 \mathrm{~b}+13.91$ 819.78 .94 a +3.28 o +33.44 $\frac{1}{829} 78.94 a+3.28 a+33.44$ 820 L $85.99 a+2.31 b+34.88$ L22 L 74.43 a $+3.24 \mathrm{~b}+32.95$ 023 $\operatorname{l}_{24} 74.24 a+3.72 b+32.02$ L $83.17 a+1.95 \mathrm{~b}+30.8 \mathrm{\theta}$ ODV i 50
$2^{247} 55.61=44.42 b+23.67$ 248 2497.13 a $57.17 b+26.38$ L $59.94 a+8.66 b+29.42$ 258

$54.92 a+6.95 b+24,42$

$63.88 a+4.49 b+18.02$ 252 $L_{2=3} 59.58 a+7.94 b+33.23$ $-58.28 a+9.90 b+31.92$ 254 a 25.00 b+31.92 L 46.92 a $+8.12 b+27.49$ 255 $25663.11 \mathrm{a}+8.29 \mathrm{~b}+27.81$ $25766.49 a+6.07 b+24.13$

$658.37 \mathrm{a}+4.73 \mathrm{~b}+33.38$ $57.80 a+6.92 b+26,16$ $25957.80 a+6.92 b+26.16$ L 64.56 a $+6.12 b+26.26$ 260 $63.44 a+7.97 b+28.90$ $26169.59 a+6.83 b+28.75$ LN I 50
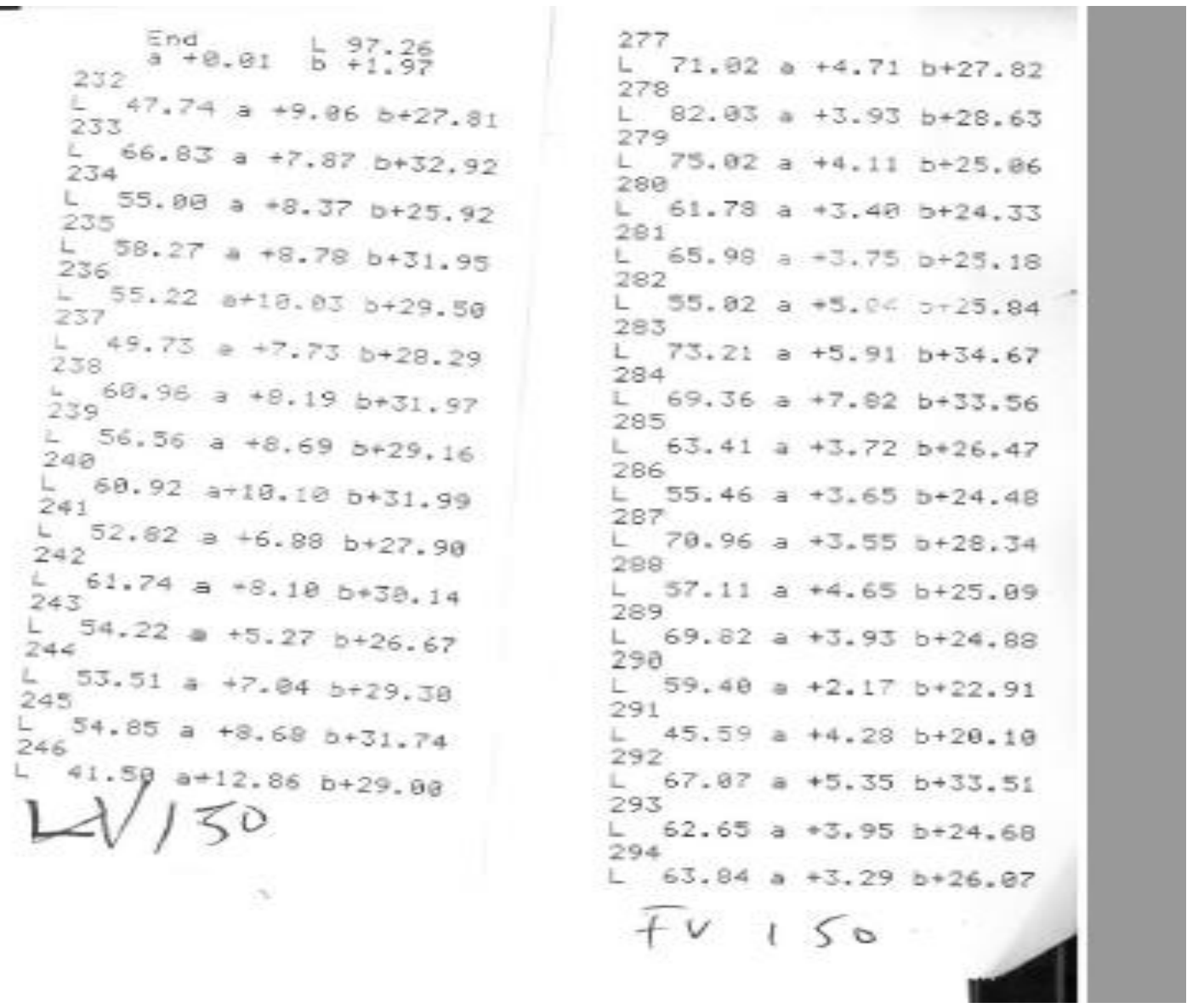
Osmotic Dehydration Kinetics of apple immersed in sucrose solution (42+119Brix), performed at atmospheric condition (t

Control Exper

$\begin{array}{cccccc}\text { Moisture Content (MC' wgt of pan(g) } & \text { Wgt of pantfruit(g) } & \text { Wgt of fruit only (g) } & \text { Wgt of oven-dry fruittpan (g wgt of oven-dry fruit (g) } \\ \text { Replicate } 1 & 2.61 & 17.57 & 14.96 & 4.38 & 1.77 \\ 2 & 2.65 & 17.67 & 15.01 & 4.34 & 1.68 \\ 3 & 2.66 & 17.62 & 14.97 & 4.35 & 1.70 \\ \text { Average moisture cont } & 2.6 & 17.6 & 15.0 & 4.4 & 1.7 \\ \text { STD } & 0.0 & 0.0 & 0.0 & 0.0 & 0.0\end{array}$

Dry matter content Wgt of pan(g) Wgt of pantfruit(g) Wgt of fruit only (g) Wgt of oven-dry fruittpan (g wgt of oven-dry fruit (g)

\begin{tabular}{rrrrrr} 
Replicate 1 & 2.61 & 17.57 & 14.96 & 4.38 & 1.77 \\
2 & 2.65 & 17.67 & 15.01 & 4.34 & 1.68 \\
3 & 2.66 & 17.62 & 14.97 & 4.35 & 1.70 \\
Average DM & 2.64 & 17.62 & 14.98 & 4.36 & 1.72 \\
STD & 0.02 & 0.04 & 0.02 & 0.02 & 0.04 \\
& \multicolumn{2}{c}{ Dry matter at 0D time, Solid gained, Water Loss }
\end{tabular}

\section{Before 0D}

Time of OD/ Replicate Wgt of cyl (g) Wgt of cyl + Soln. (g) Wgt of soln. (g)

$\begin{array}{rrrrr}5 \text { mins } & \text { Replicate } & 240.15 & 300.15 & 60.00 \\ & 2 & 239.43 & 299.43 & 60.00 \\ & 3 & 240.21 & 300.22 & 60.01 \\ & 4 & 306.12 & 366.12 & 60.00 \\ 15 \text { mins| } & 5 & 274.47 & 334.48 & 60.01 \\ & 2 & 239.41 & 299.42 & 59.99 \\ & 3 & 240.21 & 300.20 & 60.01 \\ & 4 & 306.10 & 366.10 & 59.99 \\ 30 \text { mins } \mid & 5 & 274.48 & 334.49 & 60.00 \\ & \text { Replical } & 240.06 & 300.09 & 60.01 \\ & 2 & 239.42 & 299.42 & 60.03 \\ & 3 & 240.18 & 300.18 & 60.00 \\ & 4 & 306.10 & 366.10 & 60.00 \\ & & & 60.00\end{array}$

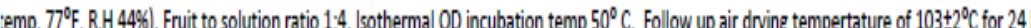
rement

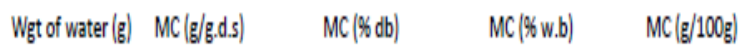

$\begin{array}{rrrrr}13.19 & 7.44 & 744.24 & 88.16 & 0.88 \\ 13.33 & 7.92 & 791.57 & 88.78 & 0.89 \\ 13.27 & 7.83 & 782.95 & 88.67 & 0.89 \\ 13.3 & 7.7 & 772.92 & 88.5 & 0.9 \\ 0.1 & 0.2 & 20.58 & 0.3 & 0.0\end{array}$

Dry matter content DM $(\% w / w) \quad$ Fruit Brix $($ Brix) $\quad$ Fruit pH Solution Brix (OBrix) Solution pH

$\begin{array}{rrrrrr}0.12 & 11.84 & 10.6 & 3.82 & 42.1 & 5.423 \\ 0.11 & 11.22 & 9.3 & 3.762 & 42.2 & 5.837 \\ 0.11 & 11.33 & 9.8 & 3.756 & 41.9 & 5.8 \\ 0.11 & 11.46 & 9.90 & 3.78 & 42.07 & 5.69 \\ 0.00 & 0.27 & 0.54 & 0.03 & 0.12 & 0.19\end{array}$

\section{After 00}

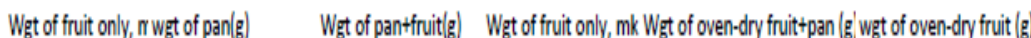

$\begin{array}{lrrrrl}15.07 & 2.65 & 16.14 & 13.50 & 5.16 & 2.51 \\ 15.29 & 2.66 & 16.99 & 14.32 & 5.33 & 2.67 \\ 15.33 & 2.63 & 16.65 & 14.02 & 5.16 & 2.52 \\ 15.4 \text { AVG } & & 16.59 & 13.95 & 5.21 & 2.57 \\ 14.91 \text { STD } & & 0.35 & 0.34 & 0.08 & 0.07 \\ 15.07 & 2.49 & 15.58 & 13.09 & 5.05 & 2.56 \\ 15.00 & 2.65 & 14.76 & 12.11 & 5.25 & 2.60 \\ 14.98 & 2.61 & 14.74 & 12.13 & 5.25 & 2.64 \\ 15.01 \text { AVG } & & 15.03 & 12.44 & 5.18 & 2.60 \\ 15.03 \text { STD } & & 0.39 & 0.46 & 0.09 & 0.03 \\ 15.01 & 2.67 & 15.59 & 12.92 & 5.28 & 2.61 \\ 15.05 & 2.65 & 14.29 & 11.64 & 5.50 & 2.85 \\ 15.05 & 2.65 & 14.85 & 12.20 & 5.63 & 2.98 \\ 14.96 \text { AVG } & & 14.91 & 12.25 & 5.47 & 2.81\end{array}$




\begin{tabular}{|c|c|c|c|c|c|c|c|c|c|c|c|c|}
\hline 14.93 STD & & 0.53 & 0.52 & 0.14 & 0.15 & \multirow{3}{*}{\multicolumn{2}{|c|}{5}} & \multirow[b]{3}{*}{274.46} & \multirow[b]{3}{*}{334.46} & \multirow[b]{3}{*}{60.00} & \multirow[b]{3}{*}{12.64} & \multirow[b]{3}{*}{27.57} \\
\hline 15.00 & 2.69 & 14.94 & 12.26 & 5.32 & 2.63 & & & & & & & \\
\hline 14.88 & 2.65 & 15.15 & 12.50 & 5.61 & 2.97 & \multirow[b]{2}{*}{$60 \mathrm{mins}$} & & & & & & \\
\hline 15.04 & 2.53 & 15.02 & 12.49 & 5.30 & 2.77 & & Replicate & 240.06 & 300.10 & 60.04 & 12.16 & 27.16 \\
\hline 15.08 AVG & & 15.04 & 12,42 & 5.41 & 2.79 & & 2 & 239.42 & 299.41 & 59.99 & 12.17 & 27.05 \\
\hline 15.00 STD & & 0.08 & 0.11 & 0.14 & 0.14 & & 3 & 240.19 & 300.20 & 60.01 & 12.17 & 27.21 \\
\hline 14.95 & 2.64 & 14.28 & 11.64 & 5.50 & 2.86 & & 4 & 306.12 & 366.15 & 60.03 & 12.22 & 27.30 \\
\hline 14.97 & 2.64 & 14.17 & 11.53 & 5.56 & 2.92 & & 5 & 274.42 & 334.43 & 60.01 & 12.21 & 27.21 \\
\hline 14.95 & 2.63 & 14.33 & 11.70 & 5.58 & 2.96 & 90 mins & Replicate & 240.06 & 300.08 & 60.02 & 12.16 & 27.11 \\
\hline 14.94 AVG & & 14.26 & 11.62 & 5.55 & 2.91 & & 2 & 239.42 & 299.42 & 60.00 & 12.16 & 27.14 \\
\hline 14.98 STD & & 0.07 & 0.07 & 0.03 & 0.04 & & 3 & 240.19 & 300.07 & 59.88 & 12.17 & 27.11 \\
\hline 15.07 & 2.62 & 12.59 & 9.98 & 5.63 & 3.01 & & 4 & 306.14 & 366.11 & 59.97 & 12.17 & 27.11 \\
\hline 15.05 & 2.70 & 12.93 & 10.24 & 5.82 & 3.13 & & 5 & 274.45 & 334.44 & 59.99 & 12.16 & 27.14 \\
\hline 15.03 & 2.66 & 13.07 & 1041 & 579 & 3.13 & $120 \mathrm{mins}$ & Replicate & 240.06 & 300.09 & 60.03 & 12.62 & 27.69 \\
\hline 14.95 AVG & & & & 2.17 & 3.13 & & 2 & 239.42 & 299.45 & 60.03 & 12.16 & 27.20 \\
\hline & & 12.87 & 10.21 & 5.75 & 3.09 & & 3 & 240.18 & 300.15 & 59.97 & 12.16 & 27.19 \\
\hline 14.97 STD & & 0.20 & 0.18 & 0.08 & 0.05 & & 4 & 306.12 & 366.14 & 60.02 & 12.15 & 27.10 \\
\hline 15.05 & 2.61 & 12.36 & 9.75 & 5.85 & 3.24 & & 5 & 274.43 & 334.41 & 59.98 & 12.15 & 27.12 \\
\hline 15.01 & 2.65 & 13.58 & 10.93 & 5.79 & 3.14 & 180 mins & Replicate & 240.09 & 300.22 & 60.13 & 12.39 & 27.44 \\
\hline 15.04 & 2.61 & 12.84 & 10.22 & 5.66 & 3.04 & & 2 & 239.43 & 299.88 & 60.45 & 12.28 & 27.29 \\
\hline 15.01 AVG & & 12.93 & 10.30 & 5.77 & 3.14 & & 3 & 240.16 & 300.51 & 60.35 & 12.33 & 27.37 \\
\hline 15.08 STD & & 0.50 & 0.48 & 0.08 & 0.08 & & 4 & 306.15 & 366.26 & 60.11 & 12.28 & 27.29 \\
\hline 15.01 & 2.63 & 12.42 & 9.79 & 6.02 & 3.40 & & 5 & 275.89 & 335.91 & 60.02 & 12.20 & 27.28 \\
\hline 15.04 & 2.51 & 13.93 & 11.41 & 5.68 & 3.16 & 240 mins & Replicate & 240.04 & 300.04 & 60.00 & 12.34 & 27.35 \\
\hline 15.00 & 2.49 & 12.53 & 10.04 & 5.85 & 3.36 & & 2 & 239.47 & 299.47 & 60.00 & 12.71 & 27.75 \\
\hline 14.99 AvG & & 12.96 & 10.41 & 5.85 & 3.31 & & 3 & 306.17 & 366.20 & 60.03 & 12.25 & 27.25 \\
\hline 15.03 STD & & 0.69 & 0.71 & 0.14 & 0.10 & & 4 & 240.21 & 300.23 & 60.02 & 12.31 & 27.30 \\
\hline 15.01 & 2.61 & 13.91 & 11.30 & 6.71 & 4.10 & & 5 & 276.02 & 336.00 & 59.98 & 12.66 & 27.69 \\
\hline 15.02 & 2.57 & 14.01 & 11.44 & 6.63 & 4.06 & 300 mins & Replicate & 306.20 & 366.22 & 60.02 & 12.25 & 27.26 \\
\hline 15.02 & 2.66 & 14.46 & 11.80 & 6.79 & 4.13 & & 2 & 239.47 & 299.47 & 60.00 & 12.64 & 27.66 \\
\hline 15.05 AVG & & 14.13 & 11.51 & 6.71 & 4.10 & & 3 & 240.80 & 300.80 & 60.00 & 12.22 & 27.24 \\
\hline 15.02 & 2.65 & 14.22 & 0.21 & 0.07 & 0.03 & & 4 & 240.07 & 300.07 & 60.00 & 12.23 & 27.28 \\
\hline & & & & & & & 5 & 275.95 & 335.96 & 60.01 & 12.65 & 27.68 \\
\hline
\end{tabular}




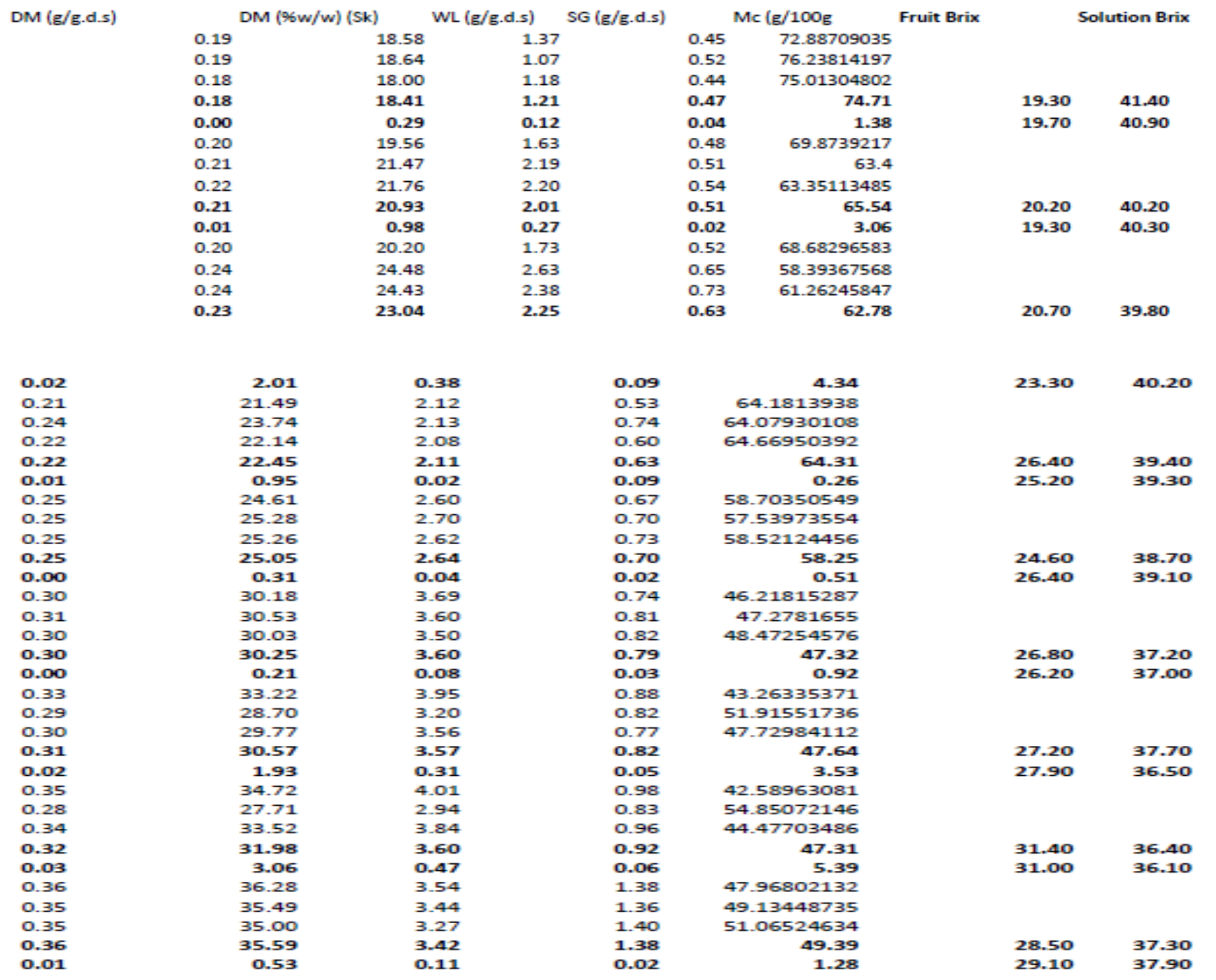


Appendix II: Osmotic dehydration kinetics

Osmotic Dehydration Kinetics of apple immersed in sucrose + $1 \%$ liquid smoke solution (42t19 Brix), performed at atmospheric co

Treatment Exp

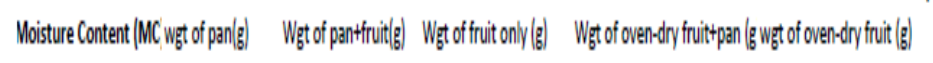

$\begin{array}{llllll}\text { Replicate } 1 & 2.61 & 17.57 & 14.96 & 4.38 & 1.77 \\ 1 & 2.65 & 1767 & 1501 & 434 & 168\end{array}$

$\begin{array}{llllll}2 & 2.65 & 17.67 & 15.01 & 4.34 & 1.68 \\ 3 & 2.66 & 17.62 & 14.97 & 4.35 & 1.70\end{array}$

$\begin{array}{llllll}\text { Average moisture con } & 2.6 & 17.6 & 15.0 & 4.4 & 1.7\end{array}$

STD

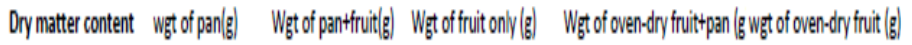

\begin{tabular}{rrrrrr} 
Repicate 1 & 2.61 & 17.57 & 14.96 & 4.38 & 1.77 \\
2 & 2.65 & 17.67 & 15.01 & 4.34 & 1.68 \\
3 & 2.66 & 17.62 & 14.97 & 4.35 & 1.70 \\
Average DM & 2.64 & 17.62 & 14.98 & 4.36 & 1.72 \\
STD & 0.02 & 0.04 & 0.02 & 0.02 & 0.04 \\
& & \multicolumn{4}{c}{ Dry matter at 00 time, Solid gained, Water loss } \\
& Before 0D & &
\end{tabular}

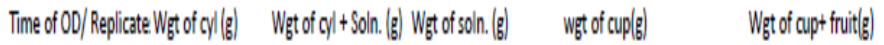

$\begin{array}{rrrrrrr}5 \text { mins } \mid & \text { Repicate } & 240.15 & 300.80 & 60.73 & 12.18 & 27.10 \\ & 2 & 239.43 & 300.03 & 60.60 & 12.64 & 27.60 \\ & 3 & 240.23 & 301.02 & 60.79 & 12.22 & 27.20 \\ & 4 & 306.17 & 366.77 & 60.60 & 12.20 & 27.20 \\ & 5 & 274.50 & 335.10 & 60.60 & 12.67 & 27.60 \\ 15 \text { mins| } & \text { Repicate. } & 240.06 & 300.76 & 60.70 & 12.22 & 27.26 \\ & 2 & 239.47 & 300.07 & 60.60 & 12.19 & 27.25 \\ & 3 & 300.19 & 360.79 & 60.60 & 12.66 & 27.66 \\ 30 \text { mins } & 4 & 306.06 & 366.66 & 60.60 & 12.24 & 27.24 \\ & 5 & 274.44 & 335.10 & 60.66 & 12.21 & 27.30 \\ & \text { Replical } & 240.11 & 300.71 & 60.60 & 12.18 & 27.22 \\ & 2 & 239.43 & 300.03 & 60.60 & 12.66 & 27.65 \\ & 3 & 240.25 & 300.85 & 60.60 & 12.23 & 27.33 \\ 4 & 306.16 & 366.91 & 60.75 & 12.21 & 27.13\end{array}$

Indition (temp. $77^{\circ}$ F, R.H 44\%). Fruit to solution ratio 1:4. Isothermal 00 incubation temp $50^{\circ} \mathrm{C}$. Follow up air drying tempertature of $103 \pm 2^{\circ}$ eriement

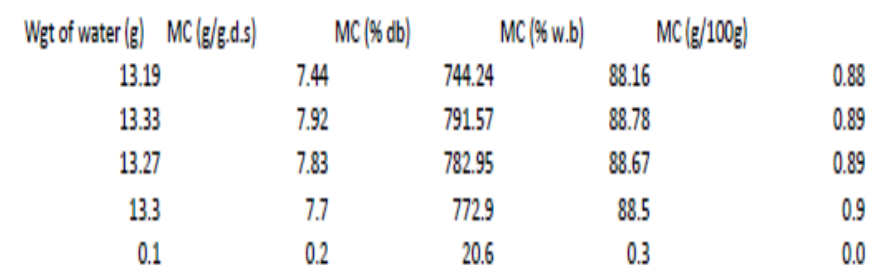

\begin{tabular}{|c|c|c|c|c|c|}
\hline Dry matter content DM $(\% \mathrm{w} / \mathrm{w})$ & & FruitpH & Solution Brix ("Brix) & Solution pH & \\
\hline 0.12 & 11.84 & 10.6 & 3.82 & 42.1 & 2.707 \\
\hline 0.11 & 11.22 & 9.3 & 3.76 & 42.2 & 2.841 \\
\hline 0.11 & 11.33 & 9.8 & 3.76 & 41.9 & 2.8 \\
\hline 0.11 & 11.46 & 9.90 & 3.78 & 42.07 & 2.78 \\
\hline 0.00 & 0.27 & 0.54 & 0.03 & 0.12 & 0.06 \\
\hline
\end{tabular}

After 00

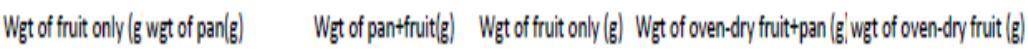

$\begin{array}{llrrrl}14.91 & 2.09 & 16.59 & 14.50 & 5.06 & 2.97 \\ 14.96 & 2.64 & 16.85 & 14.21 & 5.02 & 2.38 \\ 14.98 & 2.64 & 16.69 & 14.05 & 5.04 & 2.41 \\ 15.00 \text { AVG } & & 16.71 & 14.26 & 5.04 & 2.58 \\ 14.93 \text { STD } & & 0.11 & 0.18 & 0.02 & 0.27 \\ 15.04 & 2.64 & 15.13 & 12.49 & 5.28 & 2.64 \\ 15.06 & 2.51 & 14.76 & 12.25 & 5.19 & 2.68 \\ 15.00 & 2.63 & 14.58 & 11.95 & 5.19 & 2.56 \\ 15.00 \text { AVG } & & 14.82 & 12.23 & 5.22 & 2.63 \\ 15.09 \text { STD } & & 0.23 & 0.22 & 0.04 & 0.05 \\ 15.04 & 2.67 & 15.66 & 12.99 & 5.28 & 2.61 \\ 14.99 & 2.61 & 14.32 & 11.71 & 5.42 & 2.81 \\ 15.10 & 2.62 & 14.81 & 12.19 & 5.37 & 2.75 \\ 14.92 \text { AVG } & & 14.93 & 12.30 & 5.36 & 2.72\end{array}$




\begin{tabular}{|c|c|c|c|c|c|c|c|c|c|c|c|c|}
\hline \multirow{6}{*}{60 mins } & 5 & 274.46 & 335.20 & 60.74 & 12.61 & 27.64 & & & & & & \\
\hline & Replicate & 240.11 & 300.71 & 60.60 & 12.66 & 27.70 & 15.02310 & 260 & $\begin{array}{r}0.55 \\
14.54\end{array}$ & $\begin{array}{r}0.53 \\
1186\end{array}$ & $\begin{array}{l}0.06 \\
572\end{array}$ & $\begin{array}{l}0.18 \\
3.04\end{array}$ \\
\hline & 2 & 239.49 & 300.09 & 60.60 & 12.20 & 27.22 & $\begin{array}{l}15.04 \\
15.02\end{array}$ & $\begin{array}{l}.68 \\
2.67\end{array}$ & $\begin{array}{l}17.34 \\
14.48\end{array}$ & 11.80 & $\begin{array}{l}2.12 \\
5.76\end{array}$ & $\begin{array}{l}3.04 \\
3.09\end{array}$ \\
\hline & 3 & 240.22 & 300.92 & 60.70 & 12.17 & 27.22 & $\begin{array}{l}15.02 \\
15.05\end{array}$ & 2.67 & 14.61 & 11.95 & 5.78 & 3.11 \\
\hline & 4 & 306.17 & 366.94 & 60.77 & 12.64 & 27.64 & 15.00 AVG & & 14.54 & 11.87 & 5.75 & 3.08 \\
\hline & 5 & 274.48 & 335.26 & 60.78 & 12.23 & 27.17 & 14.94 STD & & 0.06 & 0.06 & 0.03 & 0.03 \\
\hline \multirow[t]{5}{*}{90 mins } & Replicate & 240.21 & 300.81 & 60.60 & 12.19 & 27.20 & 15.01 & 2.65 & 13.01 & 10.36 & 5.68 & 3.03 \\
\hline & 2 & 306.14 & 366.75 & 60.61 & 12.65 & 27.68 & 15.03 & 2.50 & 12.88 & 10.38 & 5.43 & 2.93 \\
\hline & 3 & 274.45 & 335.09 & 60.64 & 12.17 & 27.18 & 14.99 & 2.62 & 12.92 & 10.30 & 5.66 & 3.04 \\
\hline & 4 & 240.06 & 300.86 & 60.61 & 12.19 & 27.10 & 14.45 AVG & & 12.94 & 10.35 & 5.59 & 3.00 \\
\hline & 5 & 239.43 & 300.19 & 60.64 & 12.20 & 27.22 & 15.05 STD & & 0.05 & 0.03 & 0.11 & 0.05 \\
\hline \multirow[t]{5}{*}{120 mins| } & Replicte & 240.11 & 300.91 & 60.80 & 12.20 & 27.26 & 15.06 & 2.63 & 13.10 & 10.47 & 6.00 & 3.37 \\
\hline & 2 & 239.43 & 300.02 & 60.59 & 12.66 & 27.66 & 15.00 & 2.68 & 12.64 & 9.96 & 5.85 & 3.18 \\
\hline & 3 & 240.20 & 300.85 & 60.65 & 12.21 & 27.26 & 15.05 & 2.68 & 13.04 & 10.36 & 5.88 & 3.19 \\
\hline & 4 & 306.14 & 366.74 & 60.60 & 12.64 & 27,76 & 15.12 AVG & & 12.92 & 10.26 & 5.91 & 3.25 \\
\hline & 5 & 274.46 & 335.17 & 60.71 & 12.20 & 27.19 & 15.00 STD & & 0.21 & 0.22 & 0.07 & 0.09 \\
\hline \multirow[t]{5}{*}{180 mins } & Replicte & 306.19 & 366.82 & 60.63 & 12.68 & 27.73 & 15.06 & 2.65 & 12.65 & 10.01 & 5.83 & 3.18 \\
\hline & 2 & 240.20 & 300.84 & 60.64 & 12.19 & 27.21 & 15.02 & 2.61 & 12.75 & 10.14 & 5.79 & 3.18 \\
\hline & 3 & 239.48 & 300.14 & 60.66 & 12.66 & 27.66 & 15.00 & 2.67 & 12.45 & 9.77 & 5.51 & 2.83 \\
\hline & 4 & 240,06 & 300,64 & 60.58 & 12.21 & 27.21 & 15.00 AVG & & 12.62 & 9.97 & 5.71 & 3.06 \\
\hline & 5 & 276.10 & 335.05 & 58.95 & 12.66 & 27.65 & 14.99 STD & & 0.13 & 0.15 & 0.15 & 0.16 \\
\hline \multirow[t]{5}{*}{240 mins } & Replicte & 306.15 & 366.71 & 60.56 & 12.27 & 27.30 & 15.03 & 2.69 & 15.02 & 12.33 & 6.72 & 4.03 \\
\hline & 2 & 239.46 & 300.12 & 60.66 & 12.18 & 27.19 & 15.02 & 2.61 & 14.58 & 11.96 & 6.72 & 4.11 \\
\hline & 3 & 240.18 & 300.77 & 60.59 & 12.66 & 27.68 & 15.02 & 2.65 & 14.50 & 11.85 & 7.08 & 4.43 \\
\hline & 4 & 275.98 & 335,03 & 59.05 & 12.208 & 27.246 & 15.04 AVG & & 14.70 & 12.05 & 6.84 & 4.19 \\
\hline & 5 & 240.07 & 300.71 & 60.64 & 12.21 & 27.21 & $15.01 \mathrm{STD}$ & & 0.23 & 0.20 & 0.17 & 0.17 \\
\hline \multirow[t]{5}{*}{300 mins } & Replicte & 240.02 & 300.65 & 60.63 & 12.39 & 27.39 & 15.00 & 2.55 & 14.97 & 12.42 & 6.86 & 4.31 \\
\hline & 2 & 239.47 & 300.07 & 60.60 & 12.40 & 27.44 & 15.04 & 2.67 & 12.64 & 9.96 & 6.18 & 3.51 \\
\hline & 3 & 240.18 & 300.80 & 60.62 & 12.37 & 27.44 & 15.07 & 2.62 & 13.14 & 10.52 & 6.26 & 3.65 \\
\hline & 4 & 306.18 & 361.80 & 55.62 & 1232 & 27.31 & 14.99 Average & & 13.58 & 10.97 & 6.43 & 3.82 \\
\hline & 5 & 275.95 & 336.61 & 60.66 & 1232 & 27.29 & 14.97 STD & & 1.00 & 1.05 & 0.30 & 0.35 \\
\hline
\end{tabular}


$\mathrm{DM}$ (g/g.d.s)

$\begin{array}{lrr} & \text { DM (\$w/w) (Sk) } & \text { WL (g/g.d.s) } \\ 0.20 & 20.49 & 0.98 \\ 0.17 & 16.72 & 0.82 \\ 0.17 & 17.13 & 0.94 \\ 0.18 & 18.11 & 0.91 \\ 0.02 & 1.69 & 0.07 \\ 0.21 & 21.14 & 2.01 \\ 0.22 & 21.88 & 2.18 \\ 0.21 & 21.42 & 2.26 \\ 0.21 & 21.48 & 2.15 \\ 0.00 & 0.30 & 0.11 \\ 0.20 & 20.09 & 1.70 \\ 0.24 & 24.00 & 2.55 \\ 0.23 & 22.56 & 2.27 \\ 0.22 & 22.22 & 2.17\end{array}$

SG (g/g.d.s)

$\mathrm{Mc}\left(\mathrm{g} / 100_{E}\right.$ Fruit Brix

$\begin{array}{lr}0.74 & 77.2965 \\ 0.39 & 79.11515 \\ 0.40 & 77.74366\end{array}$

$\begin{array}{lr}0.51 & 78.05 \\ 0.16\end{array}$

$\begin{array}{lr}0.16 & 0.77 \\ 0.53 & 65.49202\end{array}$

$\begin{array}{ll}0.53 & 65.49202 \\ 0.55 & 63.54582\end{array}$

$0.49 \quad 62.6$

$\begin{array}{lr}0.49 & 62.6 \\ 0.52 & 63.88\end{array}$

$0.51 \quad 69.01596$

$0.64 \quad 59.36499$

$0.59 \quad 62.51656$

$0.58 \quad 63.63$

2.27
2.17

Solution Brix

21.60

41.50

$21.50 \quad 40.90$

$\begin{array}{ll}26.10 & 40.60 \\ 22.60 & 39.80\end{array}$

$25.10 \quad 40.20$

$25.60 \quad 39.60$

$0.05 \quad 4.02$

$0.76 \quad 58.68857$

0.7958 .00825

$0.81 \quad 58.68554$

$0.79 \quad 58.46$

$\begin{array}{ll}0.76 & 48.83411\end{array}$

$\begin{array}{ll}0.76 & 48.83411 \\ 0.70 & 49.56753\end{array}$

$0.77 \quad 48.41937$

$\begin{array}{ll}0.74 & 48.94\end{array}$

$0.95 \quad 47.11545$

$\begin{array}{ll}0.95 & 47.11545 \\ 0.85 & 45.20128\end{array}$

$0.85 \quad 47.60734$

$\begin{array}{lr}0.88 & 46.64\end{array}$

$0.84 \quad 45.31385$

$0.85 \quad 46.33367$

$\begin{array}{ll}0.85 & 46.33367 \\ 0.65 & 46.27433\end{array}$

$\begin{array}{lr}0.78 & 45.97 \\ 0.09 & 0.47\end{array}$

$1.34 \quad 55.23391$

$\begin{array}{ll}1.39 & 52.31722\end{array}$

$\begin{array}{ll}1.39 & 52.31722 \\ 1.57 & 49.40072\end{array}$

$\begin{array}{lr}1.43 & 52.32 \\ 0.10 & 2.38\end{array}$

$1.51 \quad 54.09333$

$1.03 \quad 42.92647$

$1.11 \quad 45.63977$

$1.22 \quad 47.55$

$0.21 \quad 4.76$

$25.80 \quad 39.50$

$26.10 \quad 38.90$

$29.60 \quad 37.70$

$26.40 \quad 37.60$

$29.10 \quad 37.50$

$31.70 \quad 37.60$

$\mathbf{3 0 . 1 0} \quad 37.30$

$31.70 \quad 37.10$

33.50 $\quad 36.20$

$34.10 \quad 36.50$

$33.10 \quad 36.50$

$\mathbf{3 2 . 3 0} \quad \mathbf{3 6 . 3 0}$ 
Appendix III: Microbial analysis data

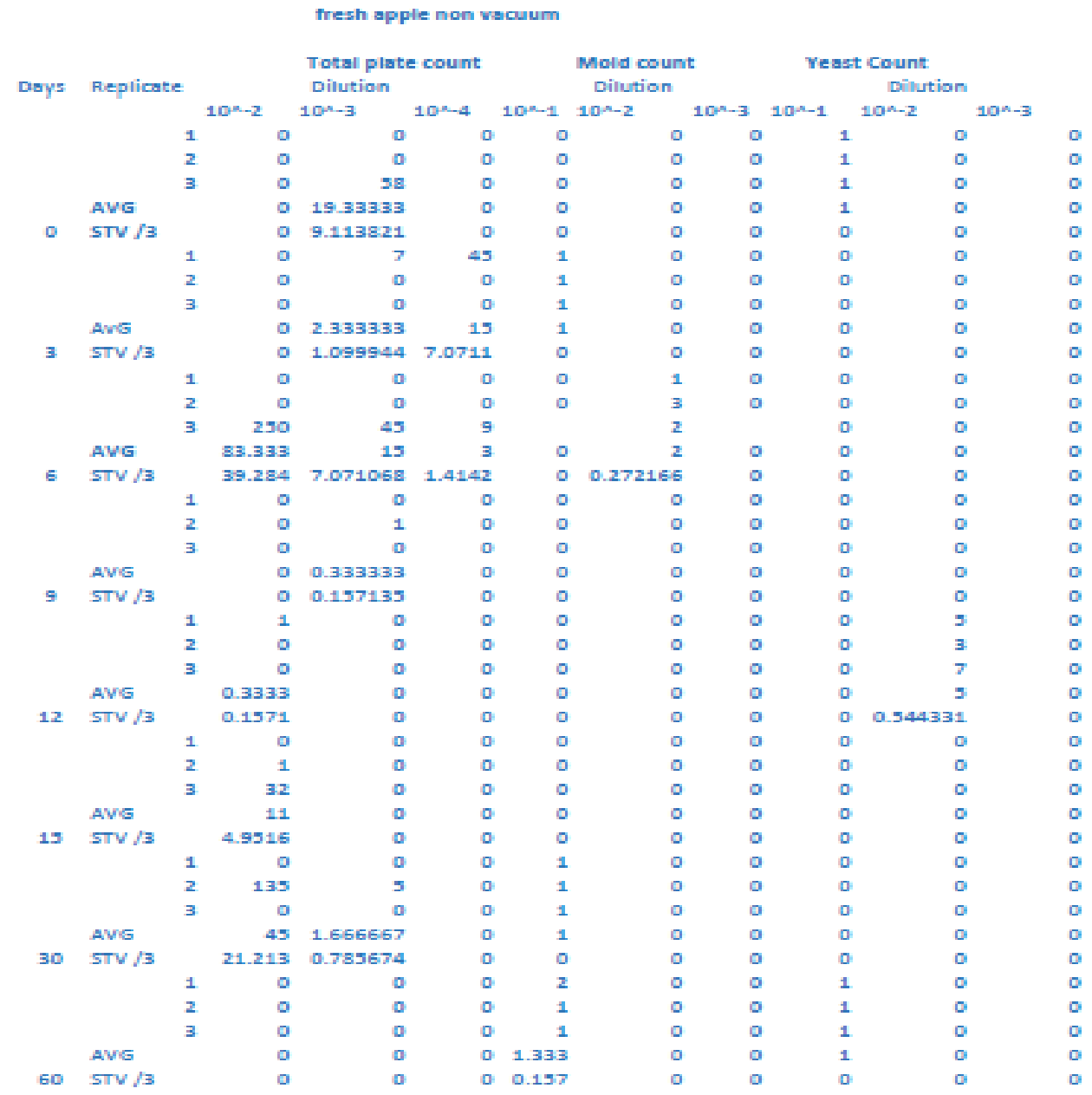

\begin{tabular}{|c|c|c|c|c|c|c|c|c|c|c|c|}
\hline & & 1 & 0 & 0 & 0 & 0 & 0 & 0 & 0 & 0 & 0 \\
\hline & & 2 & 0 & 0 & 0 & 0 & 0 & 0 & 0 & 0 & c \\
\hline & & 3 & 0 & 0 & 0 & 0 & 0 & 0 & 0 & 0 & 0 \\
\hline & AVG & & 0 & 0 & 0 & 0 & 0 & 0 & 0 & 0 & 0 \\
\hline \multirow[t]{5}{*}{90} & $S T V / 3$ & & 0 & 0 & 0 & 0 & 0 & 0 & 0 & 0 & 0 \\
\hline & & 1 & 0 & 0 & 0 & 0 & 0 & 0 & 0 & 0 & o \\
\hline & & 2 & 0 & 0 & 0 & 0 & 0 & 0 & 0 & 0 & c \\
\hline & & 3 & 0 & 0 & 0 & 0 & 0 & 0 & 0 & 0 & 0 \\
\hline & AVG & & 0 & 0 & 0 & 0 & 0 & 0 & 0 & 0 & 0 \\
\hline \multirow[t]{5}{*}{120} & $5 \pi V / 3$ & & 0 & 0 & 0 & 0 & 0 & 0 & 0 & 0 & 0 \\
\hline & & 1 & 201 & 101 tnte & & 3 & 0 & 0 & 2 & 0 & o \\
\hline & & 2 & 63 tnte & & 46 & 0 & 2 & 0 & 0 & 1 & o \\
\hline & & 3 tntec & tnte & tntec & & 1 & 0 & 1 & 0 & 0 & 1 \\
\hline & AVG & & 132 & 101 & 46 & 0 & 0.666667 & 0.333 & 0.6667 & 0.333333 & 0.333333 \\
\hline 130 & $\sin / / 3$ & & 23 & 0 & 0 & 0.416 & 0.31427 & 0.157 & 0.3143 & 0.157135 & 0.157135 \\
\hline
\end{tabular}


fresh apple vacuum

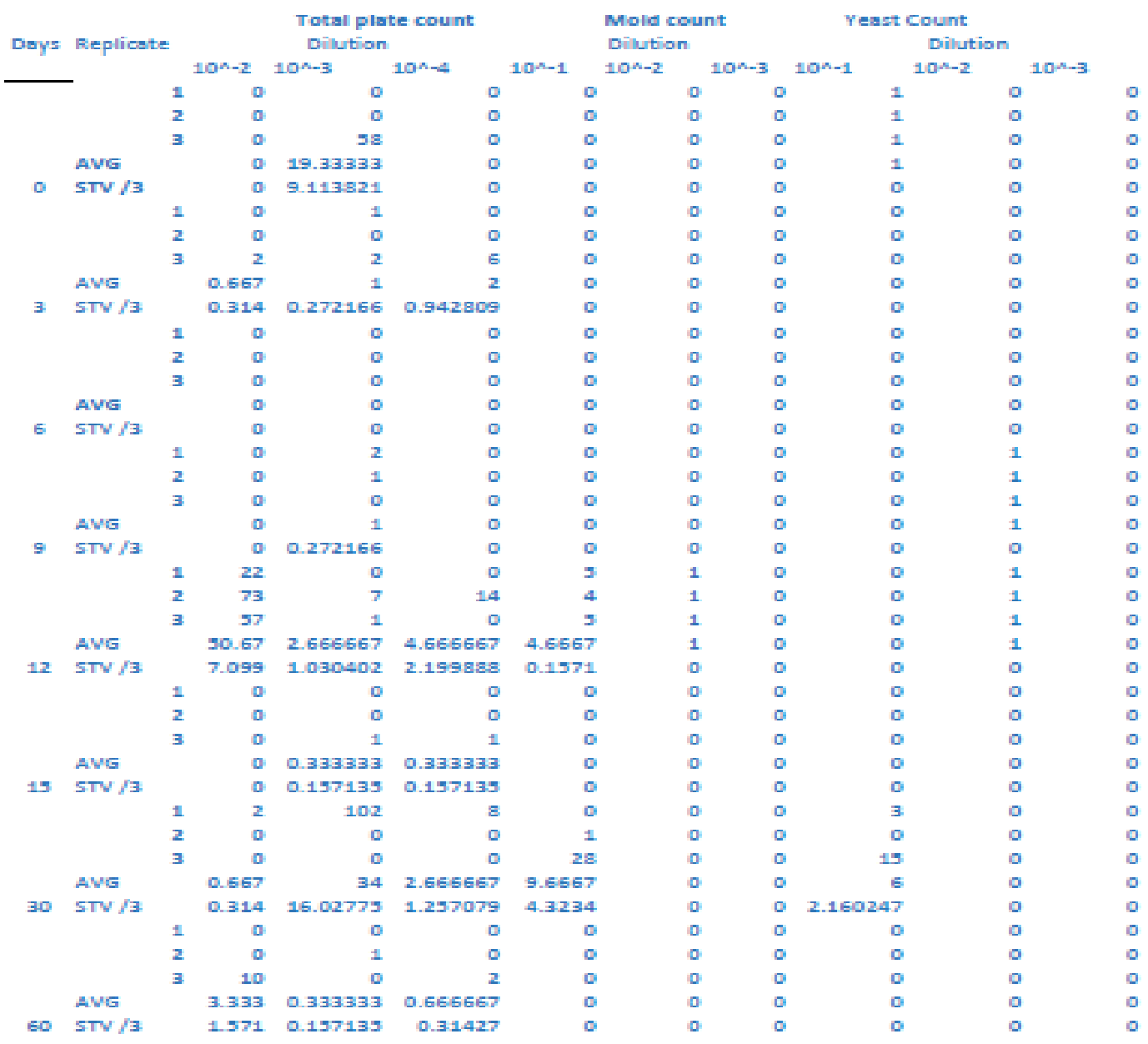

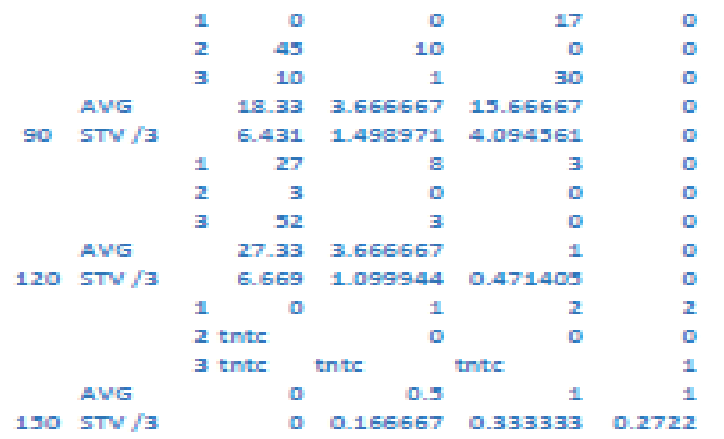

$\begin{array}{rrrrr}0 & 0 & 0 & 0 & 0 \\ 0 & 0 & 0 & 0 & 0 \\ 0 & 0 & 0 & 0 & 0 \\ 0 & 0 & 0 & 0 & 0 \\ 0 & 0 & 0 & 0 & 0 \\ 0 & 0 & 0 & 0 & 0 \\ 0 & 0 & 0 & 0 & 0 \\ 0 & 0 & 0 & 0 & 0 \\ 0 & 0 & 0 & 0 & 0 \\ 0 & 0 & 0 & 0 & 0 \\ 0 & 1 & 1 & 0 & 0 \\ 0 & 0 & 0 & 2 & 0 \\ 0 & 0 & 0 & 0 & 0 \\ 0 & 0.333 & 0.333333 & 0.666667 & 0 \\ 0 & 0.157 & 0.157135 & 0.31427 & 0\end{array}$


OD apple mon vacuum

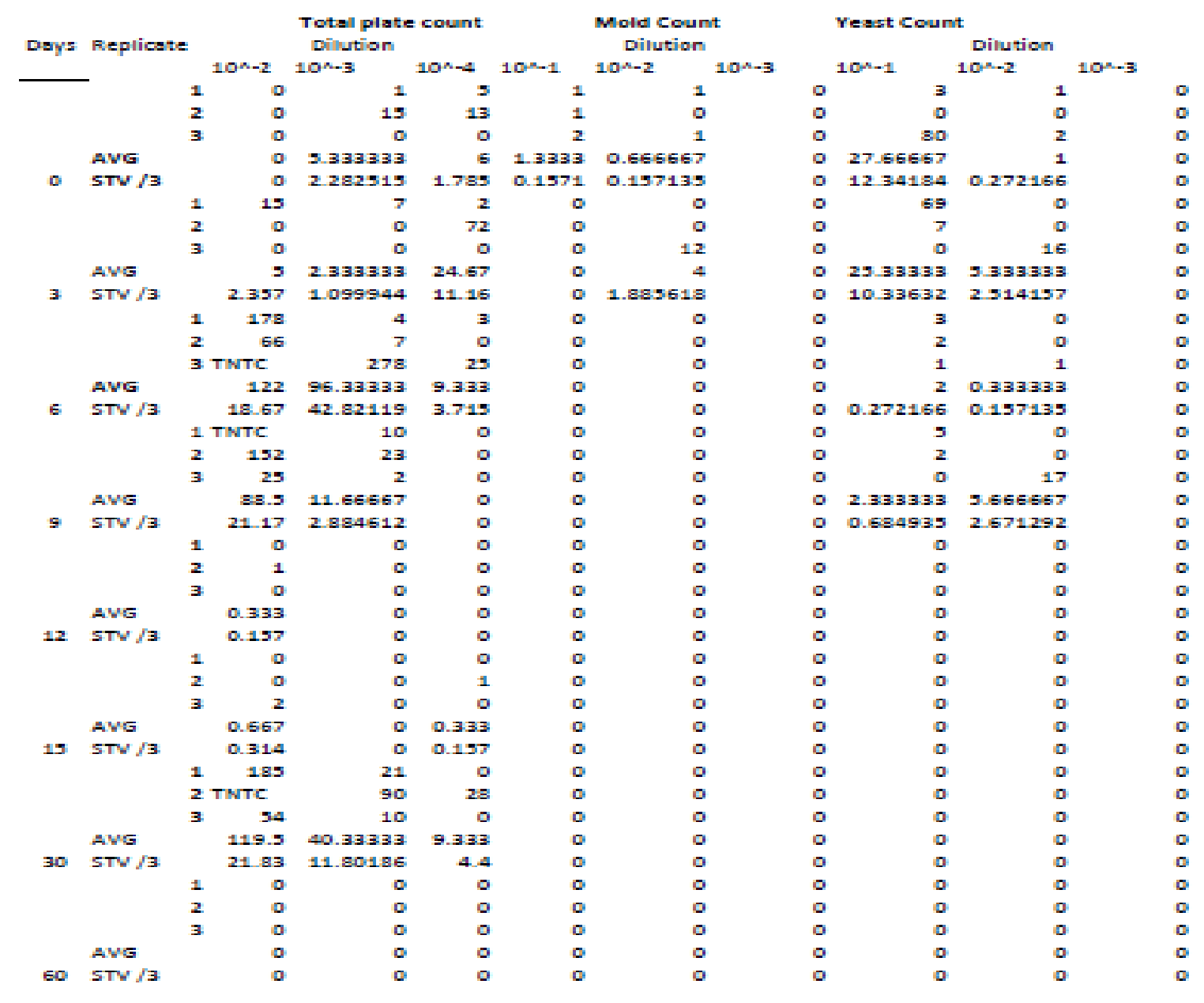

\begin{tabular}{|c|c|c|c|c|c|c|c|c|c|c|}
\hline & & 4 & 0 & 0 & 0 & 1 & 0 & 0 & 0 & 0 \\
\hline & & 0 & 0 & 0 & 0 & 1 & 0 & 0 & 0 & 0 \\
\hline & & 0 & 0 & 0 & 0 & 1 & 0 & 0 & 0 & 0 \\
\hline & Avg & 1.333 & 0 & 0 & 0 & 1 & 0 & 0 & 0 & 0 \\
\hline \multirow[t]{5}{*}{90} & $\operatorname{sTn} / 3$ & 0.629 & 0 & 0 & 0 & 0 & 0 & 0 & 0 & 0 \\
\hline & & 12 & 0 & 0 & 0 & 0 & 0 & 0 & 0 & 0 \\
\hline & & 3 & 0 & 0 & 0 & 0 & 0 & 0 & 0 & 0 \\
\hline & & 0 & 0 & 0 & 0 & 0 & 0 & 0 & 0 & 0 \\
\hline & Awg & 5 & 0 & 0 & 0 & 0 & 0 & 0 & 0 & 0 \\
\hline \multirow[t]{5}{*}{120} & $\operatorname{sTV} / 3$ & 1.7 & 0 & 0 & 0 & 0 & 0 & 0 & 0 & 0 \\
\hline & & 12 & 19 & 1 & 2 & 0 & 0 & 0 & 0 & 0 \\
\hline & & 2 tnite & 3 & nte & 2 & 1 & 0 & 0 & 1 & 0 \\
\hline & & 3 & 33 & 18 & 0 & 0 & 0 & 0 & 1 & o \\
\hline & Avg & 6 & 18.33333 & 95 & 1. 3333 & 0.333333 & 0 & 0 & 0.566657 & 0 \\
\hline 190 & $\operatorname{sTV} / 3$ & 2 & 4093506 & 2.833 & 0.3143 & 0.197135 & 0 & 0 & 0.157135 & 0 \\
\hline
\end{tabular}




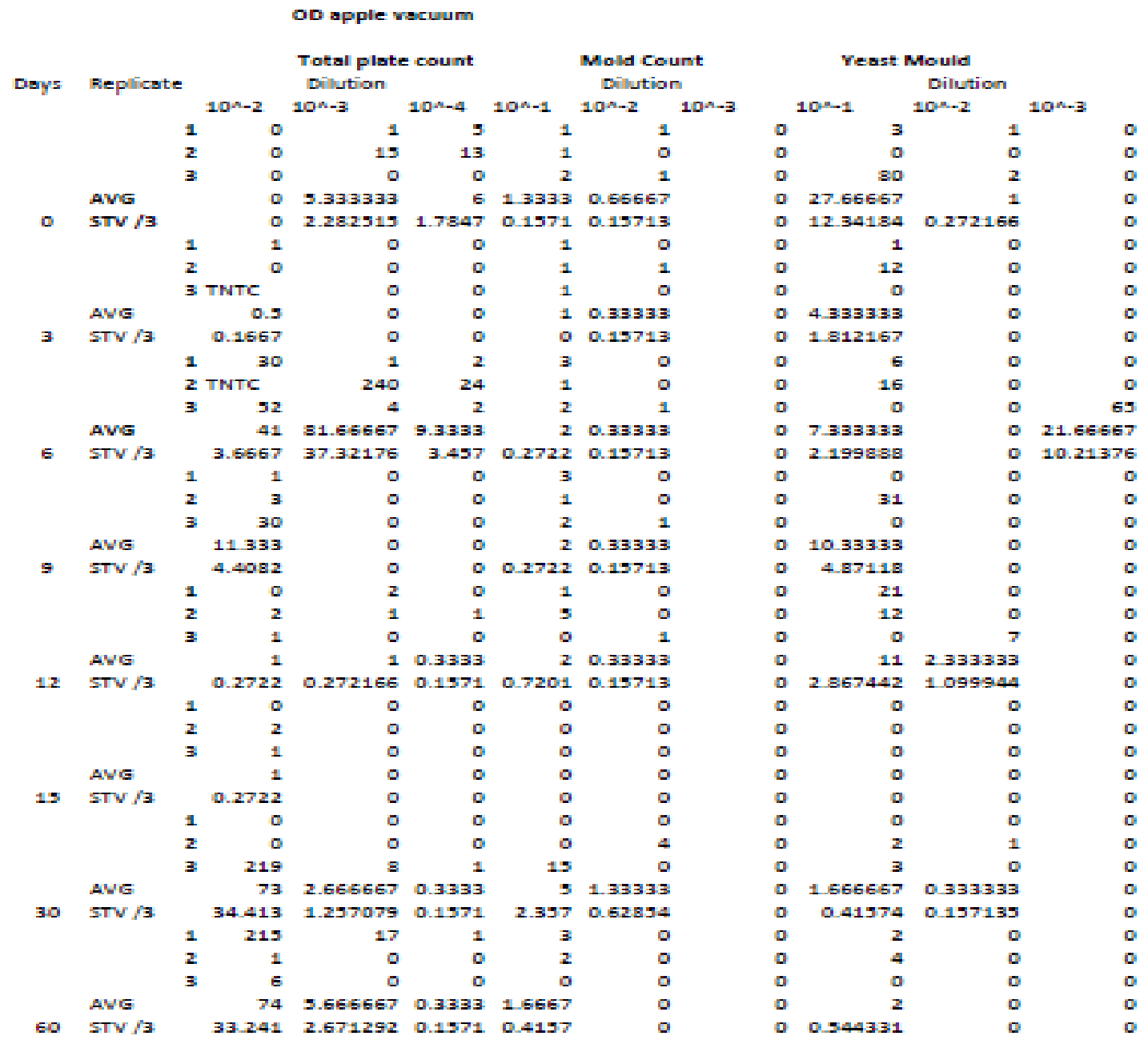

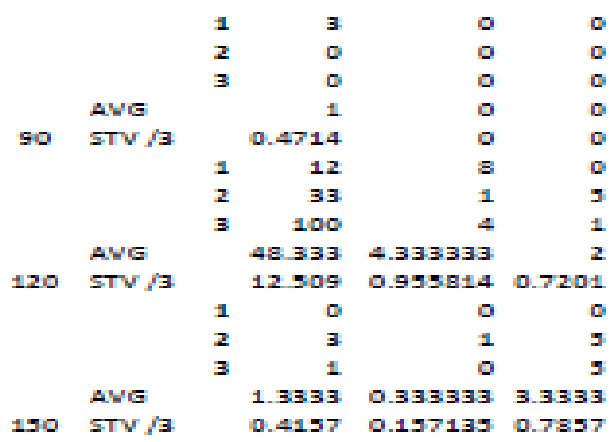


Liquid smoked spple non vacuum

\begin{tabular}{|c|c|c|c|c|c|c|c|c|c|c|c|c|c|}
\hline Deryz & \multicolumn{2}{|c|}{ Replicate } & \multicolumn{3}{|c|}{$\begin{array}{l}\text { Total plate count } \\
\text { Dilution }\end{array}$} & \multicolumn{3}{|c|}{$\begin{array}{l}\text { Mold Count } \\
\text { Dilution }\end{array}$} & \multicolumn{5}{|c|}{$\begin{array}{l}\text { yeast Count } \\
\text { Dillution }\end{array}$} \\
\hline \multirow{6}{*}{0} & & 1 & 0 & 45 & 0 & 0 & 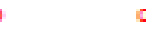 & 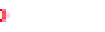 & 0 & 0 & & 0 & o \\
\hline & & 3 & tnte & tnite & 0 & o & d & o & 0 & 0 & & 0 & o \\
\hline & AVG & & 0 & 45 & 0 & 0 & d & o & 0 & 0 & & 0 & c \\
\hline & $\operatorname{str} / 3$ & & 0 & 0 & 0 & 0 & d & o & 0 & 0 & & 0 & c \\
\hline & & 3 & 0 & 6 & tinte & 0 & d & s & 0 & 0 & & 0 & o \\
\hline & AVG & & 0 & 2 & 1 & 0 & d & o & 0 & 0 & & 0 & o \\
\hline \multirow[t]{4}{*}{3} & $\operatorname{STV} / 3$ & & 0 & 0.942309 & 0.333 & 0 & d & b & 0 & 0 & & 0 & c \\
\hline & & 1 & 0 & 0 & 0 & 0 & d & o & 0 & 0 & & 0 & o \\
\hline & & 2 & 1 & 0 & 0 & 0 & d & o & 0 & 0 & & 0 & c \\
\hline & & 3 & 0 & 0 & 0 & 0 & d & o & 0 & 0 & & 0 & c \\
\hline \multirow[t]{5}{*}{6} & $S T V / 3$ & & 0.1571 & 0 & 0 & 0 & d & b & 0 & 0 & & 0 & c \\
\hline & & 1 & 1 & 0 & 0 & 0 & d & 0 & 0 & 0 & & 0 & o \\
\hline & & 2 & 0 & 0 & 0 & 0 & d & o & 0 & 0 & & 0 & c \\
\hline & & 3 & 0 & 0 & 0 & o & o & o & 0 & 0 & & 0 & c \\
\hline & AVG & & 0.3333 & 0 & 0 & 0 & d & 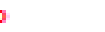 & 0 & 0 & & 0 & c \\
\hline \multirow[t]{5}{*}{9} & $\operatorname{STV} / 3$ & & 0.1971 & 0 & 0 & 0 & d & o & 0 & 0 & & 0 & c \\
\hline & & & ente & 19 & 3 & 1 & o & b & 0 & 64 & & 0 & c \\
\hline & & & ente & 79 & 0 & 1 & 1 & 1 & 0 & 44 & & 0 & c \\
\hline & & & ente & 196 & 0 & 1 & d & o & 0 & 0 & & 1 & c \\
\hline & AVG & & 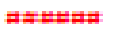 & 93 & 1 & 1 & 0.333333 & & 0 & 36 & 0.33333 & & 0 \\
\hline \multirow[t]{5}{*}{12} & $\operatorname{STV} / 3$ & & 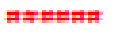 & 24.49943 & 0.471 & 0 & $0.15713=$ & & 0 & 8.911083 & 0.15713 & & 0 \\
\hline & & & tinte & 62 & 3 & 1 & d & o & 0 & 12 & & 0 & c \\
\hline & & & ente & 183 & 0 & 0 & d & 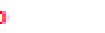 & 0 & 0 & & 0 & c \\
\hline & & 3 & tinte & 31 & 2 & 1 & 1 & 1 & 0 & 0 & & 0 & 6 \\
\hline & AVG & & 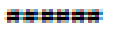 & 92 & 1. 667 & 0.6667 & 0.333333 & & 0 & 4 & & 0 & 2 \\
\hline \multirow[t]{5}{*}{15} & $S T V / 3$ & & 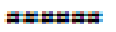 & 21.85982 & 0.416 & 0.1571 & 0.157135 & & 0 & 1.895618 & & 0 & 0.94281 \\
\hline & & 1 & 15 & 0 & 0 & 0 & d & b & 0 & 0 & & 0 & o \\
\hline & & 2 & 32 & 0 & 22 & 0 & d & o & 0 & 0 & & 0 & c \\
\hline & & 3 & 12 & 18 & 2 & 0 & d & o & 0 & 0 & & 0 & c \\
\hline & AVG & & 19.667 & 6 & $\mathrm{a}$ & 0 & d & b & 0 & 0 & & 0 & o \\
\hline \multirow[t]{5}{*}{30} & $S T V / 3$ & & 2.9355 & 2.828427 & 3.311 & 0 & d & b & 0 & 0 & & 0 & c \\
\hline & & 1 & 2 & 0 & 0 & 1 & . & b & 0 & 0 & & 0 & o \\
\hline & & 2 & 0 & 0 & 0 & 0 & d & b & 0 & 0 & & 0 & c \\
\hline & & 3 & & 0 & 0 & 0 & d & 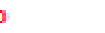 & 0 & 0 & & 0 & 0 \\
\hline & AVG & & 1 & 0 & 0 & 0.3333 & d & b & 0 & 0 & & 0 & c \\
\hline 60 & $S T V / 3$ & & 0.3333 & 0 & 0 & 0.1571 & d & b & 0 & 0 & & 0 & 0 \\
\hline
\end{tabular}

\begin{tabular}{|c|c|c|c|c|c|c|c|c|c|c|c|}
\hline & & 1 & 1 & 0 & 4 & 0 & 0 & 0 & 0 & 0 & 0 \\
\hline & & 2 & 2 & 0 & 1 & 0 & 0 & 0 & 0 & 0 & 0 \\
\hline & & 3 & 0 & 3 & 0 & 0 & 0 & 0 & 0 & 0 & 0 \\
\hline & AVG & & 1 & 1.666667 & 1.667 & 0 & 0 & 0 & 0 & 0 & 0 \\
\hline \multirow[t]{5}{*}{90} & $S T V / 3$ & & 0.2722 & 0.785674 & 0.567 & 0 & 0 & 0 & 0 & 0 & 0 \\
\hline & & 1 & 6 & 1 & 0 & 0 & 0 & 0 & 0 & 0 & 0 \\
\hline & & 2 & 0 & 3 & 0 & 0 & 0 & 0 & 0 & 0 & 0 \\
\hline & & 3 & 4 & 3 & 0 & 0 & 0 & 0 & 0 & 0 & 0 \\
\hline & AVG & & 3.3333 & 2.333333 & 0 & 0 & 0 & 0 & 0 & 0 & 0 \\
\hline \multirow[t]{5}{*}{120} & $5 T V / 3$ & & 0.8315 & 0.31 .427 & 0 & 0 & 0 & 0 & 0 & 0 & 0 \\
\hline & & 1 & 3 & 0 & 0 & 0 & 0 & 0 & 0 & 0 & 0 \\
\hline & & 2 & 1 & 0 & 7 & 0 & 0 & 0 & 0 & 0 & 0 \\
\hline & & 3 & 0 & 0 & 0 & 0 & 0 & 0 & 0 & 0 & 0 \\
\hline & AVG & & 2 & 0 & 2333 & 0 & 0 & 0 & 0 & 0 & 0 \\
\hline 150 & $5 \mathrm{TV} / 3$ & & 0.7201 & 0 & 1.1 & 0 & 0 & 0 & 0 & 0 & 0 \\
\hline
\end{tabular}


Liquid smoked apple vacuum

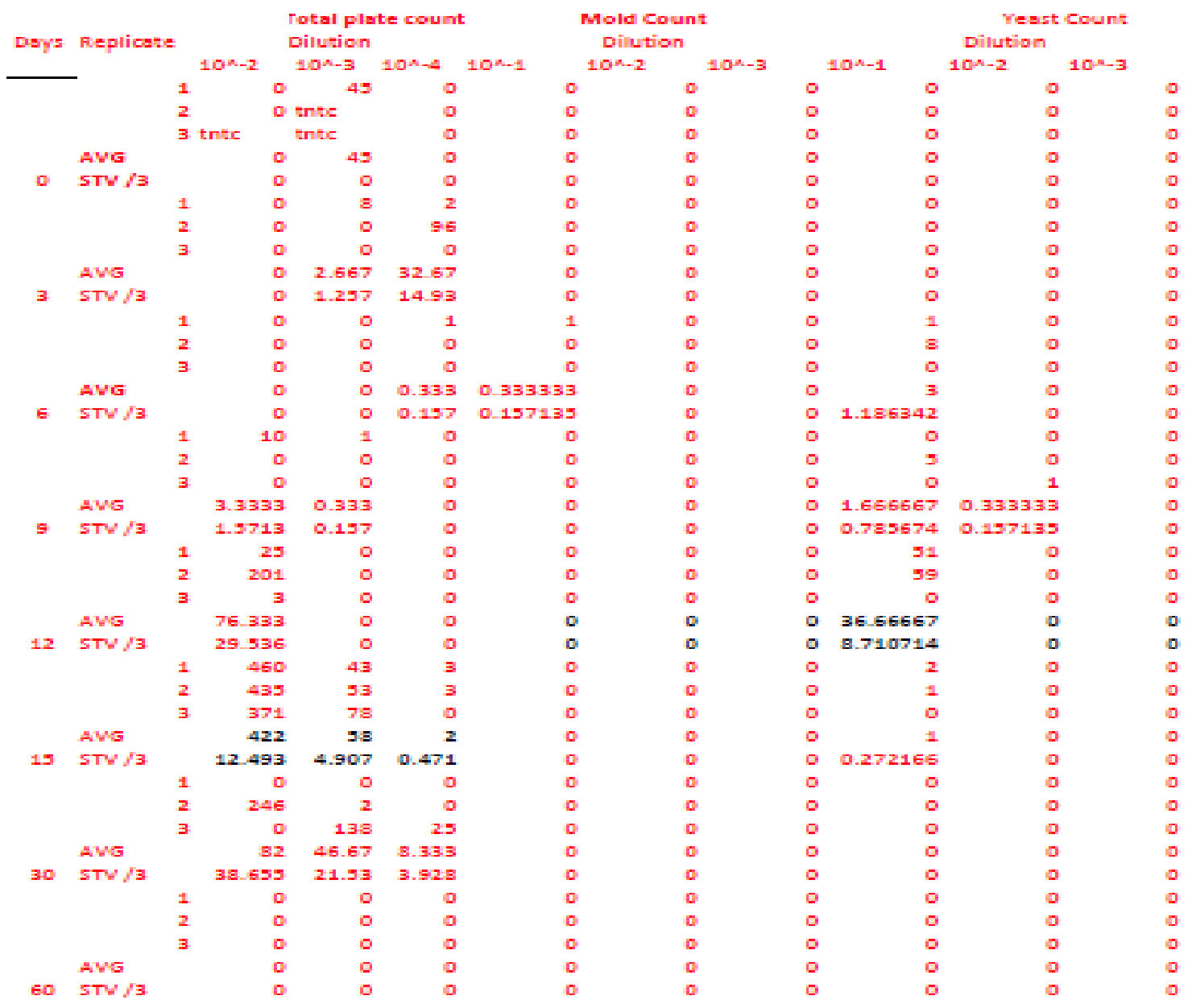

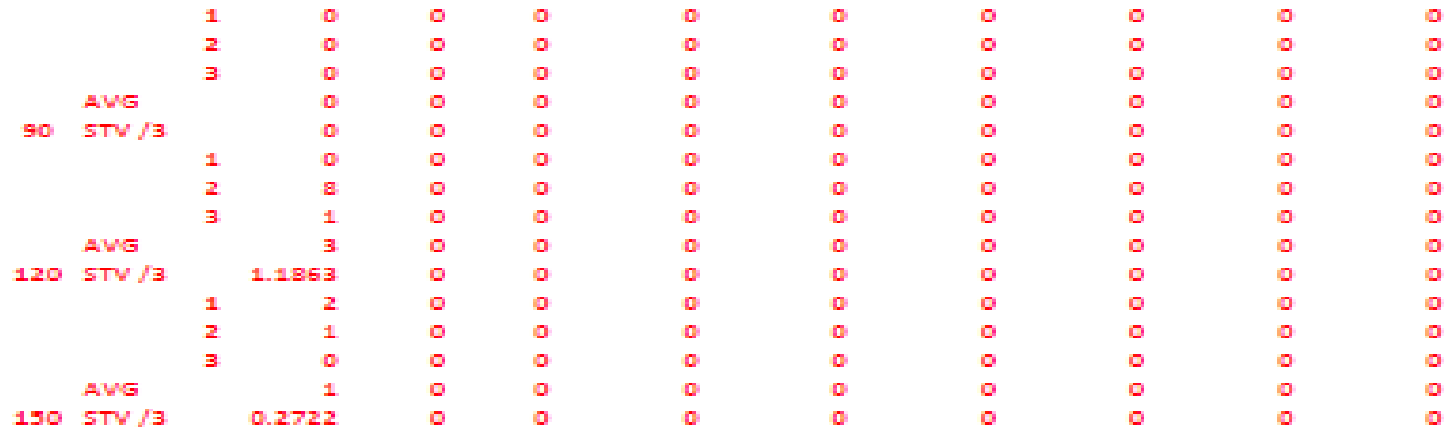


Appendix IV: Textural analysis

Texture Analysis of Dried Fruits

\begin{tabular}{|c|c|c|c|c|c|}
\hline $\begin{array}{l}\text { Package } \\
\text { Days }\end{array}$ & $\begin{array}{l}\text { Fresh Dried } \\
\text { Force }\end{array}$ & Hardness & Cohesiveness & Gumminess & Chevwiness \\
\hline \multirow[t]{4}{*}{0.0} & 16496.1 & 12492.4 & 0.1 & 1418.J & 180.9 \\
\hline & 19325.3 & 16869.4 & 0.2 & 3597.5 & 6998.5 \\
\hline & 9235.4 & 8086.9 & 0.2 & 1587.7 & 437.9 \\
\hline & 13890.2 & 11246.1 & 0.1 & 1607.9 & 332.3 \\
\hline AVG & 14724.3 & 12173.7 & 0.2 & 2052.9 & 1887.4 \\
\hline $5 T D / 5$ & 741.7 & 630.2 & 0.0 & 179.0 & 544.3 \\
\hline \multirow[t]{4}{*}{3.0} & 16739.3 & 13479.7 & 0.3 & 4487.2 & 8234.0 \\
\hline & 6810.7 & $5 \approx 78.4$ & 0.2 & 1000.5 & EOG.1 \\
\hline & 16212.7 & 13229.7 & 0.2 & 3004.2 & 1642.3 \\
\hline & 7895.6 & 7686.1 & 0.2 & 1349.6 & 308.7 \\
\hline AVG & 11914.6 & 10068.5 & 0.2 & 2460.4 & $2697 . a$ \\
\hline $5 T D / 5$ & $916 \ldots 3$ & $669 . a$ & 0.0 & 278.7 & 646.9 \\
\hline \multirow[t]{5}{*}{6.0} & 10578.0 & 9901.3 & 0.2 & 2026.3 & 1709.0 \\
\hline & 58214.4 & 33.8 & 0.0 & 0.0 & 0.0 \\
\hline & 40275.9 & -109.0 & 0.0 & 0.1 & 0.0 \\
\hline & 43262.1 & 3.45 .2 & 0.0 & -0.2 & 0.0 \\
\hline & 47387.1 & 44.5 & 0.0 & 0.0 & 0.0 \\
\hline AVG & 39943.5 & 20.43 .2 & 0.0 & 405.2 & 34.8 \\
\hline $5 T D / 5$ & 3178.3 & 786.4 & 0.0 & 162.1 & 136.7 \\
\hline \multirow[t]{5}{*}{90} & 51508.9 & 44154.4 & 0.4 & 17927.0 & 32174.2 \\
\hline & 31925.7 & 46497.4 & 0.3 & 13668.9 & 4567.7 \\
\hline & 31107.2 & 28453.7 & 0.4 & 10534.4 & 19321.8 \\
\hline & 31771.7 & 28923.1 & 0.4 & 11331.1 & 20792.9 \\
\hline & 37029.8 & 31693.7 & 0.4 & 11165.1 & 435.4 .4 \\
\hline AVG & 40668.6 & 35964.5 & 0.4 & 12845.3 & 16242.1 \\
\hline$S T D / 5$ & 1850.5 & 1569.7 & 0.0 & 514.2 & 2119.7 \\
\hline \multirow[t]{5}{*}{12.0} & 14608.7 & 14201.2 & 0.5 & 6631.3 & 4387.7 \\
\hline & 11396.2 & 10971.6 & 1.2 & 12869.6 & 10199.2 \\
\hline & 17870.1 & 16964.1 & 1.2 & 20303.7 & 37274.2 \\
\hline & 37421.1 & 31341.3 & 0.2 & $7683 . a$ & 1869.7 \\
\hline & 23661.8 & 22114.5 & 1.3 & 28245.8 & 51831.1 \\
\hline AVG & 20983.6 & 19118.6 & 0.9 & 15146.9 & 21112.4 \\
\hline $5 T D / 5$ & 1833.9 & 1424.3 & 0.1 & 1628.7 & 3973.9 \\
\hline \multirow[t]{5}{*}{150} & 99127.2 & 53159.9 & 0.3 & 15148.2 & 27809.5 \\
\hline & 143698.3 & 125471. & 0.2 & $30179 . a$ & 9456.3 \\
\hline & 114464.4 & 100955.7 & 0.2 & 22653.1 & 6773.2 \\
\hline & 65502.5 & 59918.3 & 0.3 & 16467.4 & 30369.6 \\
\hline & 77008.7 & 65917.4 & 0.3 & 22638.1 & 41559.9 \\
\hline AVG & 91958.2 & 80930.6 & 0.3 & 21417.3 & 23193.7 \\
\hline $5 T D / 5$ & 6439.7 & 5552.2 & 0.0 & $1071 . a$ & 2635.9 \\
\hline
\end{tabular}

\begin{tabular}{|c|c|c|}
\hline$\exists 0$ a & $2 \equiv 190.3$ & ZEEAT.0 \\
\hline & 409429 & $\exists 7 E-61.4$ \\
\hline & $40 \in 00.1$ & Eacosola \\
\hline & $419 \pm \equiv=$ & $\exists>1 E \equiv 4.9$ \\
\hline & $404-4=.6$ & $\exists \in \rightarrow \in 4$ \\
\hline Avg & $\exists \equiv \equiv \equiv \pm 4$ & $\equiv 5 \equiv E-6$ \\
\hline STDu/s & $10 z 04$ & ene. \\
\hline EOD & $\exists \equiv \in M \equiv$. & 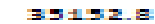 \\
\hline & 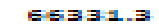 & $\leq 1 \exists \equiv 14$ \\
\hline & $7=0022=$ & $\operatorname{mos}>11$ \\
\hline & Hesed? & $16427=1$ \\
\hline & $90 \geq 7=0$ & $4 \tan 44$ \\
\hline Aug & $4=9032$ & $45 \operatorname{asc} 3$ \\
\hline$S T D / S$ & $=20116$ & Ja11_a \\
\hline solo & $9=49 \pm 4$ & $5=0-3.2$ \\
\hline & $\pm \geq 13=4$ & 11000.2 \\
\hline & $4 \geq \geq 7=0$ & $\exists 90045$ \\
\hline & $9 \equiv 13=0$ & $922 \equiv 15$ \\
\hline & $\pm=2 E \theta .9$ & $1342 \geq 15$ \\
\hline Aug & $97 \geq 545$ & $\exists \equiv 900.4$ \\
\hline STD/s & $=1110$ & $\equiv 609.7$ \\
\hline $1 \geq 0.0$ & $5 \equiv-7 \equiv 2 \geq$ & :3577.7 \\
\hline & 50707.0 & \$1476.1 \\
\hline & HE195x-4 & 1-age6.9 \\
\hline & 79 acesis & s? \\
\hline & $5 \equiv 9 \pm>.6$ & $\Rightarrow 20=1.4$ \\
\hline Aug & $10=1960$ & $5516=0$ \\
\hline STDJs & 5979 & 56I1 \\
\hline 190.0 & $\operatorname{Es} 430.1$ & 60423.1 \\
\hline & $9=200.6$ & $\operatorname{sor}=4 E$ \\
\hline & $4 \geq z \geq=3$ & $\equiv \sin =7.4$ \\
\hline & 907454 & $\angle \nabla e=5 . e$ \\
\hline AU⿴ & SIETE? & 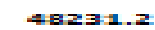 \\
\hline $5 T 0 / 5$ & HTHEI & 1757 \\
\hline
\end{tabular}

4907.7 


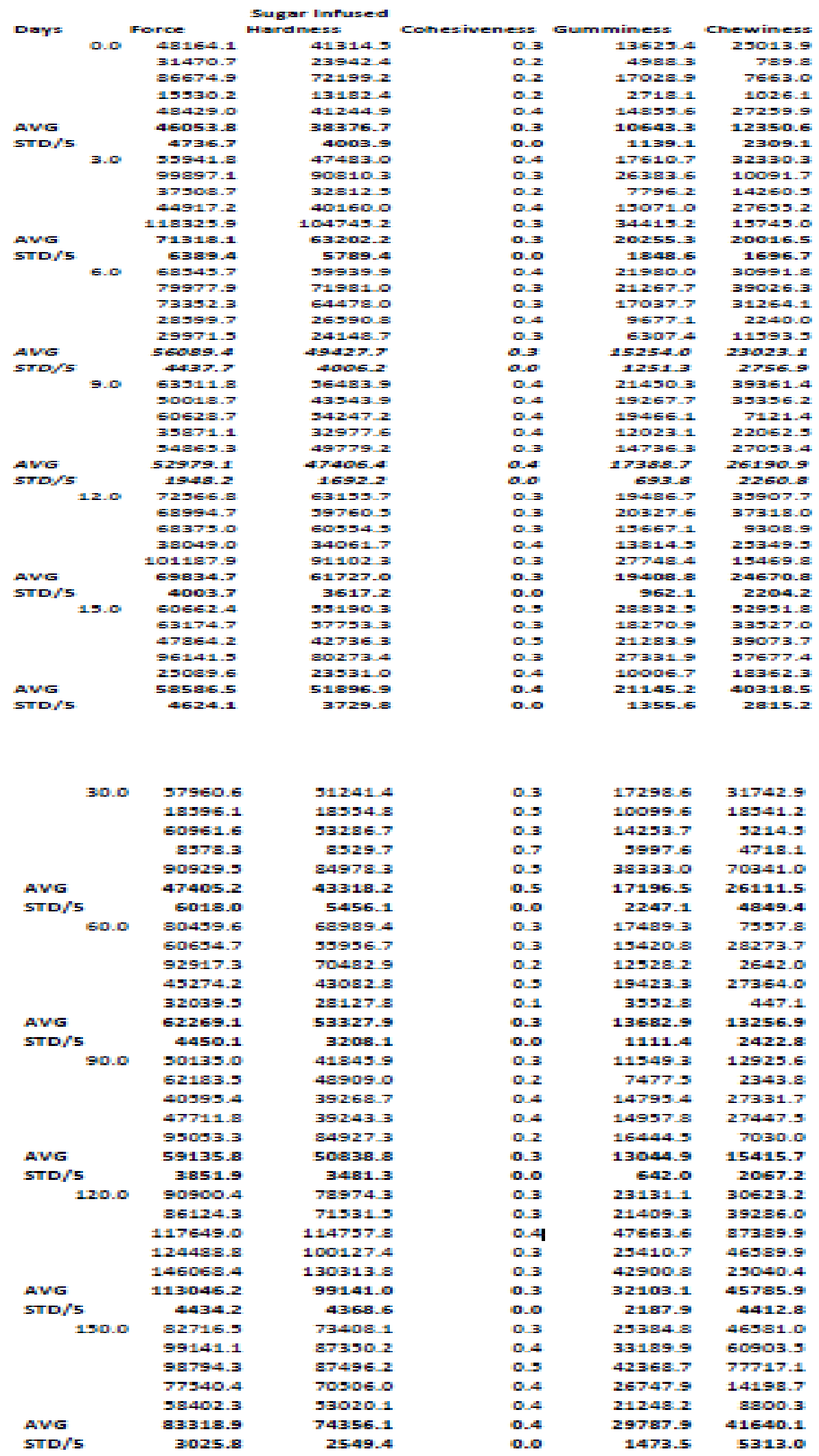




\begin{tabular}{|c|c|c|c|c|c|c|}
\hline \multirow{2}{*}{ Dayz } & \multicolumn{2}{|c|}{ Smake imrused } & Hardinese & comeriventes & \multirow{2}{*}{ 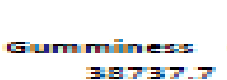 } & \multirow{2}{*}{$\begin{array}{r}\text { Cherwines: } \\
\text { T10aj }\end{array}$} \\
\hline & a.p & $142 E \equiv 0 . \mathrm{E}$ & 112030: & $0 . \equiv$ & & \\
\hline & & $19 \pm 19 \Xi \pm$ & $1 \equiv 7311.6$ & $a_{-}=$ & Axs & $\pm \equiv 163 \equiv$ \\
\hline & & SeEsate & 907454 & 0. & $102 \equiv 0.3$ & Đ155e \\
\hline & & 149000.3 & I1⿴囗十日:1 1 & $a .3$ & $\equiv \pm 42 x_{-4}$ & IIPEa \\
\hline & & alazs.s & rosora & 0.4 & 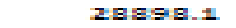 & 900079 \\
\hline & & $\sec 3.7$ & 62642.3 & 0.3 & 16961.4 & $\equiv \pm 1 \geq 1.0$ \\
\hline \multirow{6}{*}{ STDVs } & & $P \in \equiv \Omega . \exists$ & sr21. & D.o & 1910.9 & $5073-$ \\
\hline & $\exists-10$ & 130029.6 & 100200.9 & 0.2 & $2=E=942$ & 94425 \\
\hline & & $11 \equiv \equiv \equiv 4 \Omega$ & 100790 & a.झ & I92:E0.11. & $\equiv 519$ \\
\hline & & 492265 & $4 a \pm 27$ & 0.4 & $200 \equiv 3$ & $\exists>7>9$ \\
\hline & & $2140=0.7$ & $1 \pm \log 20$ & 0.3 & $\angle 97 \sin$ & $2 z=020$ \\
\hline & & $107 \pm=7$ & 101345.7 & 0.4 & 30917.7 & $10063=$ \\
\hline AvG & & $1 \geq 3955 . a$ & $1109 \mathrm{ar} .4$ & $a$ & $\exists \geq 1 \in=\geq .2$ & $17740 z$ \\
\hline \multirow[t]{5}{*}{ smbjs } & & 10E0z.5 & $\equiv 94-6$ & D. & 20010 & 2xest 1 \\
\hline & E.o & $4 a 000$ & $\angle 69 \in=9$ & 0.4 & 170042 & 31905. \\
\hline & & Eeses.s & $994 \in 2 a$ & 0.4 & $2 \operatorname{sen} 1$ & 470103 \\
\hline & & $7401 \geqslant E$ & $5 \equiv 7 a z . a$ & $0 . \exists$ & 20719.6 & $\exists \equiv 0 \geq 0=$ \\
\hline & & E71-9.9 & 59439.6 & 0.4 & 20229 & $91 \equiv 24 \leq$ \\
\hline A vg & & Endere? & $\operatorname{seg} 1 \times 1 . \equiv$ & $a=$ & $270 \times 0=$ & 120509 \\
\hline \multirow[t]{6}{*}{ sidous } & & $\operatorname{tas} x$ & I & a.o & s63.1 & $15 a=2$ \\
\hline & 9.0 & agESE.E & $7 \geq 373.9$ & 0.4 & 34911.1 & $E \equiv \equiv 07 \equiv$ \\
\hline & & $70-111.0$ & 59004.9 & $0 . \exists$ & $196=0.2$ & F⿻a日n $x$ \\
\hline & & $E a 7=19$ & 994009 & a & IEา & $4916 E T$ \\
\hline & & $90 \log 2$ & 39290.9 & $0 . \pm$ & 20300.7 & 1311027 \\
\hline & & $9 \pm 1=a z$ & $x= \pm 112$ & $a_{-2}$ & Ha: $11 \mathrm{I}$ & $\operatorname{sen} 0 z$ \\
\hline A vG & & solaty 9 & 7xHed.a & a. $=$ & 25195 & 200532 \\
\hline \multirow[t]{5}{*}{ stops } & & $19 \pm 0 \exists$ & $18-9.5$ & a.a & 1154.7 & 77350 \\
\hline & $1 \geq 0$ & Sande & $47-4 \equiv 2 \equiv$ & 0.4 & 20seds & $\exists \equiv-0 \equiv z$ \\
\hline & & GaE $=2 \mathrm{a}$ & $97 \pm 939$ & 0.4 & 249745 & 49007 \\
\hline & & $6:-4=1.4$ & $\sin \cos 2$ & 0.4 & 240113.3 & $\mathbb{1}=0 \in \mathrm{E}$ \\
\hline & & $\operatorname{tgs} 112$ & sodul 7 & 0.3 & 194197 & $\exists=\operatorname{sen} 2$ \\
\hline AUE & & EsTes.o & $564 \pi 9.8$ & a.4 & 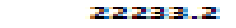 & $\equiv 27 \geq 41$ \\
\hline STL $0 . \mathrm{s}$ & & $1 \exists I \equiv$. & 1003.5 & a.a & $4 x>a$ & 2510.7 \\
\hline & $1=0$ & \#17T:3.E & Mossed.9 & 0.4 & $\exists a \pm z=2$ & $\cos \theta \theta_{1}=$ \\
\hline & & seanga & $517 \pm 0.9$ & 0.9 & $164: 3=9$ & $\exists 00545$ \\
\hline & & $45 \mathrm{sen} .2$ & 44009.0 & $0 .=$ & 21000.1 & $\exists \equiv=93 x$ \\
\hline & & IロIョa & $5640=a$ & 0.4 & zange-9 & $91 \equiv 15=$ \\
\hline $\begin{array}{l}\text { Awg } \\
\text { STD/s }\end{array}$ & & $\begin{array}{l}75059.9 \\
5200.2\end{array}$ & $\begin{array}{r}\operatorname{cs57}=7 \\
460=2\end{array}$ & $\begin{array}{l}0.4 \\
0.0\end{array}$ & $\begin{array}{l}25963.11 \\
1605.6\end{array}$ & $\begin{array}{r}476502 \\
30037\end{array}$ \\
\hline
\end{tabular}

\begin{tabular}{|c|c|c|c|c|c|}
\hline$\equiv 0.0$ & 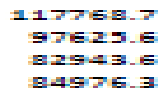 & 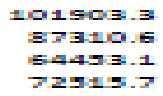 & $\begin{array}{l}0.4 \\
0 .= \\
0.4 \\
0.4\end{array}$ & $\begin{array}{l}\equiv 97 \equiv=.9 \\
\geq 70=0.9 \\
\geq 4219.3 \\
\geq 97=1.2\end{array}$ & 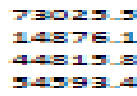 \\
\hline Ang & gsaze.s & $\operatorname{a15}=4 \leq-3$ & $a-4$ & $\equiv 0 \geq 1 \equiv .7$ & $4 \in \equiv \equiv \geq 7.7$ \\
\hline STris & $\geq>>\geq .0$ & zeeses & a.a & $1 \pm 7 \geqslant$ & 42090 \\
\hline salo & $=97 \div \mathrm{a}=$ & $-3 \pm 41.9$ & $1 . z$ & $\Rightarrow 9507 \mathrm{~g}$ & susas: \\
\hline & $95 \pm \leq 7-4$ & $=0200.1$ & 0.2 & $10212=5$ & $=\operatorname{san} \equiv$ \\
\hline & $44204=$ & $\equiv \geq 7=0$ & $1 .=$ & $\angle P E=E-10$ & $\sin 00=$ \\
\hline & $\exists \log =0-4$ & 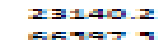 & 1.2 & Iax 149 & $\begin{array}{r}91797=1 \\
7091\end{array}$ \\
\hline Ang & ese & 51100 & 0.9 & $\equiv 191 \equiv-4$ & $490 \equiv 2$ \\
\hline STDOAs & 5220.2 & 4ns $\equiv . \mathrm{E}$ & a.1 & $2 a=a \equiv .7$ & $7 \neq \geq a$ \\
\hline$=0.0$ & 142979.2 & $\pm \geq a \geq 3=10$ & $a .2$ & zasena & $\pm \equiv 74-4=$ \\
\hline & $9 \in 0 \equiv \equiv \equiv .7$ & $\equiv=\exists \pm \geq$ & $a . \equiv$ & $x-7>-3$ & Toena \\
\hline & $1 \geq 00=0$ & $10 \cos =1$ & $a .2$ & $200=\equiv .2$ & $576 \pm \equiv$ \\
\hline & $779=4$ & Taz4s.7 & $a . \equiv$ & $x \equiv \equiv \equiv=7$ & $4 \equiv \equiv \pm \equiv \equiv$ \\
\hline & $1922 \equiv 10$ & $\pm \equiv a \exists \geq \equiv$ & $a= \pm$ & $=\geq E-D_{-} \equiv$ & $7=1100=$ \\
\hline Ang & $1 \pm=7$ In_a & $10=03=-0$ & $a \equiv$ & zecose & $29019-1$ \\
\hline 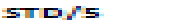 & $55 \equiv 0$ & $40-4=1$ & a.a & 15ED-S & seas 2 \\
\hline 1200 & $1193=9.4$ & $110 \geq 14=6$ & $0 .=$ & 267269 & $\pm 00=a \geq 1$ \\
\hline & $17+12 \geq 9.7$ & $\pm=30000$ & $a . \equiv$ & $=0 \leq-6.7$ & $\pm=63=$ \\
\hline & 102009.9 & 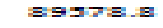 & $a .2$ & $\geq 14 \geq=-3$ & $\exists=297=$ \\
\hline & 102001212 & $\equiv \Xi \exists-4 \equiv$ & $a . \equiv$ & $270001 \mathrm{E}$ & $=2 a 0=$ \\
\hline & $1 \geq 4-4=9-4$ & 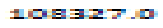 & 0.2 & $\geq E>>-1$ & $1=267=$ \\
\hline Ang & $1 \geq \equiv a 1 \equiv$ & $=00=6-11.1$ & $a=$ & zestan-9 & 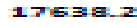 \\
\hline STDrs & 5309.2 & 4747.1 & D.a & $1 \geq a \equiv . E$ & $2 \geq 23=$ \\
\hline $1=0.0$ & 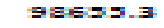 & $\equiv=3 \pm=2$ & $a . \equiv$ & $24006-4$ & $4=10=\equiv$ \\
\hline & ETs:00.4 & $515-4 \geq z$ & $0 . \equiv$ & 1EE1日. & $\equiv=0:=$ \\
\hline & $1400=0$ & $\pm 17 \in E=1$ & $a . \equiv$ & $\equiv 0 \equiv \equiv=7$ & $90590=$ \\
\hline & 130019 & 111400.2 & D. $\equiv$ & Iag-4.7 & $\operatorname{ton} 97 z$ \\
\hline & $197 \mathrm{ag}=$ & Hes & $0 . \equiv$ & $=14100$ & $2=04 \equiv=1$ \\
\hline AMG & $1 \geq 3216.3$ & 100060014 & $a \equiv$ & $\exists 0290.10$ & $\geq 7 \equiv 41=$ \\
\hline STDrs & Ea $7 \geq=7$ & $70 a=-4$ & D.a & $2= \pm 2=-5$ & 400sin \\
\hline
\end{tabular}

